\title{
DOE/PC/92534--11
}

\section{Selective Catalytic Reduction of Sulfur Dioxide to Elemental Sulfur}

\author{
Final Report \\ June 1995 \\ by \\ Wei Liu \\ Maria Flytzani-Stephanopoulos \\ Adel F. Sarofim \\ Department of Chemical Engineering \\ Massachusetts Institute of Technology \\ Cambridge, MA 02139
}

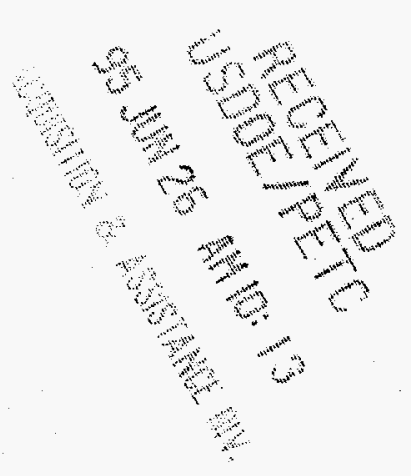

Prepared for

The U.S. Department of Energy

The Pittsburgh Energy Technology Center

Pittsburgh, Pennsylvania

DOE/Project Manager: Dr. Michael Baird (PETC)

Grant No.: DE-FG22-92PC92534 


\section{Executive Summary}

Elemental sulfur recovery from $\mathrm{SO}_{2}$-containing gas stream is highly attractive as it produces a salable product and no waste to dispose of. However, commercially available schemes are complex and involve multi-stage reactors, such as Claus plant. This project has investigated new metal oxide catalysts for the single stage selective reduction of $\mathrm{SO}_{2}$ to elemental sulfur by a reductant, such as $\mathrm{CO}$. Significant progress in catalyst development has been made during the course of the project. We have found that fluorite oxides, $\mathrm{CeO}_{2}$ and $\mathrm{ZrO}_{2}$, and rare earth zirconates such as $\mathrm{Gd}_{2} \mathrm{Zr}_{2} \mathrm{O}_{7}$ are active and stable catalysts for reduction of $\mathrm{SO}_{2}$ by $\mathrm{CO}$. More than $95 \%$ sulfur yield was achieved at reaction temperatures about $450^{\circ} \mathrm{C}$ or higher with the feed gas of stoichiometric composition. Reaction of $\mathrm{SO}_{2}$ and $\mathrm{CO}$ over these catalysts demonstrated a strong correlation of catalytic activity with the catalyst oxygen mobility. Furthermore, the catalytic activity and resistance to $\mathrm{H}_{2} \mathrm{O}$ and $\mathrm{CO}_{2}$ poisoning of these catalysts were significantly enhanced by adding small amounts of transition metals, such as $\mathrm{Co}, \mathrm{Ni}, \mathrm{Co}$, etc. The resulting transition metal-fluorite oxide composite catalyst has superior activity and stability, and shows promise in long use for the development of a greatly simplified single-step sulfur recovery process to treat variable and dilute $\mathrm{SO}_{2}$ concentration gas streams. Such a simple catalytic converter may offer the long-sought "Claus-alternative" for coal-fired power plant applications.

Among various active composite catalyst systems the $\mathrm{Cu}-\mathrm{CeO}_{2}$ system has been extensively studied. XRD, XPS, and STEM analyses of the used $\mathrm{Cu}-\mathrm{CeO}_{2}$ catalyst found that the fluorite crystal structure of ceria was stable at the present reaction conditions, small amounts of copper was dispersed and stabilized on the ceria matrix, and excess copper oxide particles formed copper sulfide crystals of little contribution to catalytic activity. A working catalyst consisted of partially sulfated cerium oxide surface and partially sulfided copper clusters. The overall reaction kinetics were approximately represented by a first order equation. The reaction mechanism was discussed within the Redox framework. The copper and cerium oxide in the composite catalyst play different roles: copper provides $\mathrm{CO}$ adsorption sites and cerium oxide provides oxygen vacancy sites. Thus, a synergism is realized.

The project objectives were extended to other oxidation reactions, $\mathrm{CO}$ oxidation and methane oxidation, to generalize the complete oxidation activity of the new catalysts. The catalytic properties for oxidation of $\mathrm{CO}$ and hydrocarbon are useful information to singlestep sulfur recover process development, because practical reaction streams for $\mathrm{SO}_{2}$ reduction by $\mathrm{CO}$ may contain certain amounts of oxygen and/or hydrocarbons. In addition, new complete oxidation catalysts would benefit technologies in (a) gas turbine exhaust cleanup and (b) vehicle exhaust emission control.

The $\mathrm{Cu}-\mathrm{CeO}_{2}$ and $\mathrm{Cu}-\mathrm{ZrO}_{2}$ composites were found to be active catalysts for complete oxidation of $\mathrm{CO}$ and methane. The $\mathrm{Cu}-\mathrm{CeO}_{2}$ catalyst showed a $\mathrm{CO}$ oxidation activity higher than any other base metal oxide catalysts reported in the literature, demonstrating a 
strong synergism. The $\mathrm{Au}-\mathrm{CeO}_{2}$ was identified as an active and stable catalyst for low temperature $\mathrm{CO}$ oxidation. STEM microstructure analyses revealed that copper in the $\mathrm{Cu}-$ $\mathrm{CeO}_{2}$ composite existed in the forms of isolated ions, clusters, and bulk $\mathrm{CuO}$ particles. Isolated ions and clusters were strongly bonded to the cerium oxide matrix. $\mathrm{Cu}^{+1}$ species was observed with all the $\mathrm{Cu}-\mathrm{CeO}_{2}$ catalysts by XPS. The oxidation rates of $\mathrm{CO}$ and methane over the $\mathrm{Cu}-\mathrm{CeO}_{2}$ catalysts were expressed by the following equation:

$$
\frac{d P_{\mathrm{CO} 2}}{d t}=\frac{k K_{R} P_{R} P_{O}^{n}}{1+K_{R} P_{R}}
$$

where $P_{R}$ denotes the partial pressure of $C O$ or methane and $P_{O}$ is the partial pressure of oxygen, and $n$ is a small number close to zero. The activation energies of the surface reactions are $78-94 \mathrm{~kJ} / \mathrm{mol}$ for $\mathrm{CO}$ oxidation and $79 \mathrm{~kJ} / \mathrm{mol}$ for methane oxidation, respectively. The heat of adsorption derived from the kinetics is in the range of 28 to $62 \mathrm{~kJ} / \mathrm{mol}$ for $\mathrm{CO}$ and $14 \mathrm{~kJ} / \mathrm{mol}$ for methane, respectively. The Langmuir-Hinshelwood mechanism and synergistic reaction model were proposed for $\mathrm{CO}$ oxidation over the $\mathrm{Cu}-$ $\mathrm{CeO}_{2}$ and $\mathrm{Au}-\mathrm{CeO}_{2}$ catalysts. In this model, copper clusters of $\mathrm{Cu}^{+1}$ species or gold particles provide sites for $\mathrm{CO}$ adsorption, cerium oxide provides the oxygen source, and the reaction proceeds at the interface of the two kinds of materials. 


\section{Acknowledgments}

We would like to acknowledge our collaborators: Dr. Andreas Tschope, a BASF Postdoctoral Fellow, and Prof. Jackie Y. Ying at MIT Department of Chemical Engineering for preparation of nanocrystalline cerium oxide catalysts and chemisorption measurements; Mr. Robert Williams, B.S. '93, Ms. Farnaz Haghseta, B.S. '96, Mr. Cyrus Wadia, B.S. '96, undergraduate students at MIT, and Mr. Eric Mullins, a visiting student from Cumberland College under DOE/ORISE Program, for their assistance in catalyst preparation and activity tests.

We also wish to thank several staff members at MIT Materials Science and Engineering Center: Dr. Anthony Garratt-Reed for STEM analyses, Mr. Michael Frongillo

for HRTEM analyses, Mr. Leonard Sudenfield for SEM analyses, Mr. John Martin and Ms. Elizabeth L. Shaw for their assistance in XPS analyses, and Dr. Joseph Adario for his assistance in XRD analyses. This work made use of the MRSEC Shared Facilities supported by the National Science Foundation under Award Number DMR-9400334. 


\section{Contents}

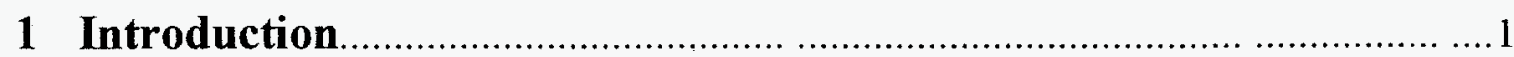

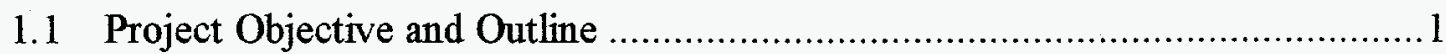

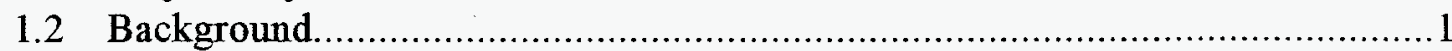

1.2.1 Old Problems and New Challenges-Flue Gas Desulfurization (FGD)....1

1.2.2 Previous and Ongoing Studies of Catalytic Reduction of Sulfur Dioxide to Elemental Sulfur...................................................3

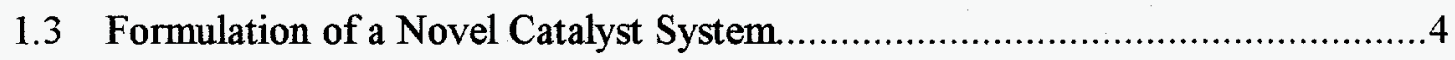

1.3.1 Catalyst Formula ............................................................................

1.3.2 Main Reactions Studied in This Project...............................................

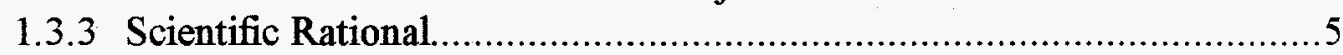

1.4 Outline of Present Research Approach ......................................................

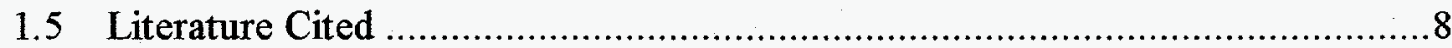

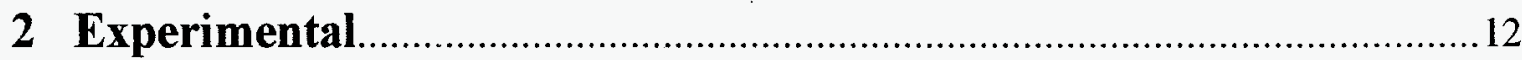

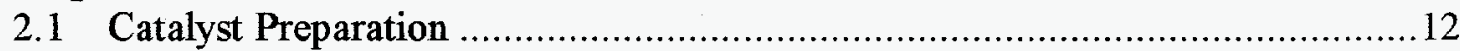

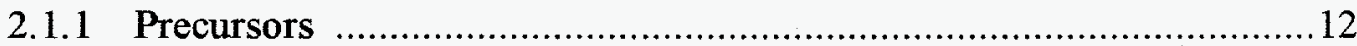

2.1.2 Complexation Method with Citric Acid ………….........................12

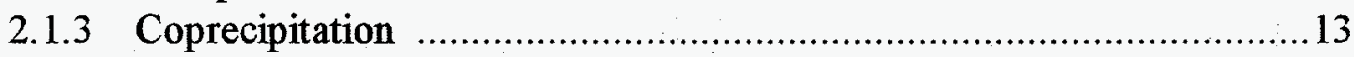

2.1.4 Catalyst Support and Impregnation ..............................................14

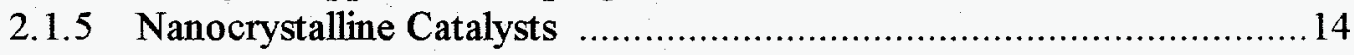

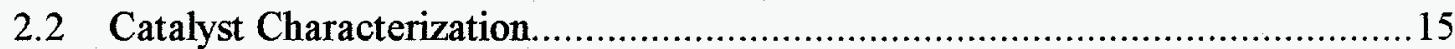

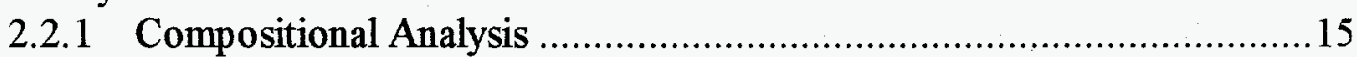

2.2.2 Surface Area, Pore Size, and Metal Dispersion .................................15

2.2.3 X-ray Powder Diffraction (XRD) …………….............................. 17

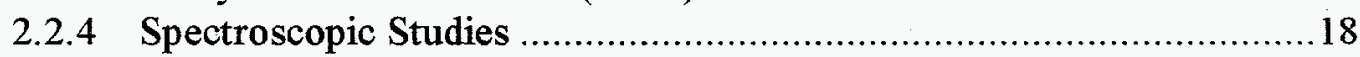

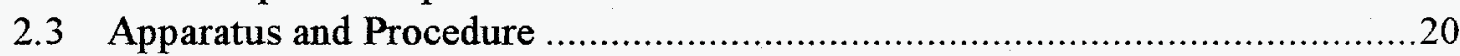

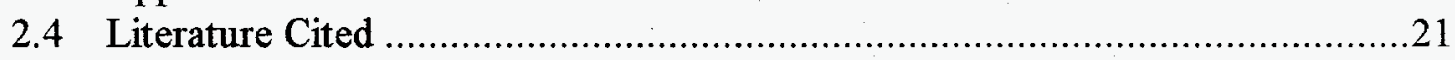

3 Reduction of $\mathrm{SO}_{2}$ by $\mathrm{CO}$ to Elemental Sulfur over Ceria Catalysts ...30

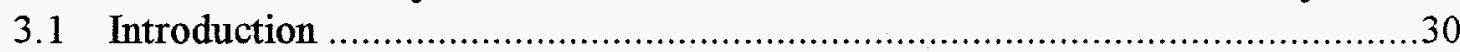

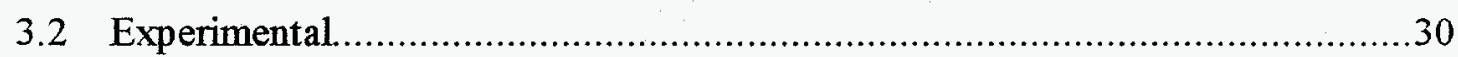

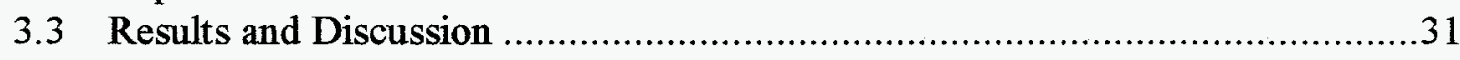

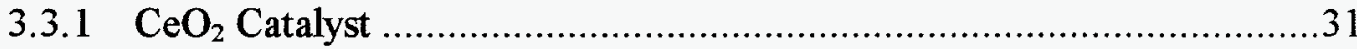

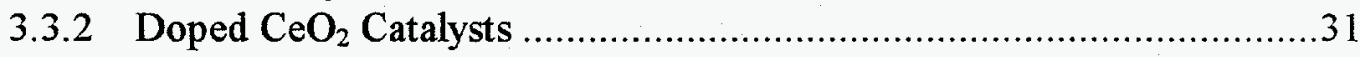

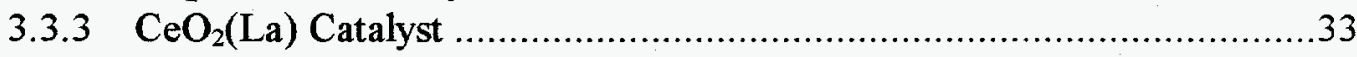

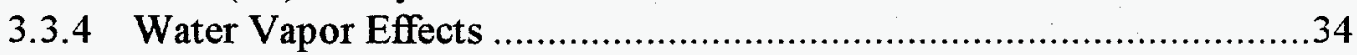

3.3.5 $\mathrm{CeO}_{2}(\mathrm{La})$ Is an Active Catalyst for Claus Reaction

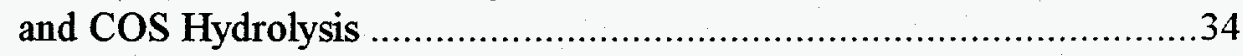

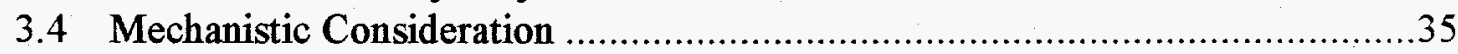

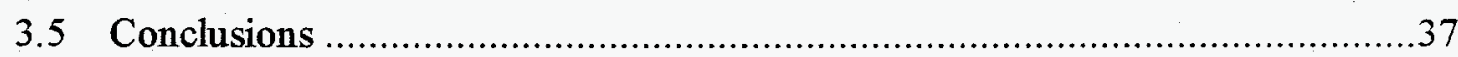




\section{Reduction of $\mathrm{SO}_{2}$ by $\mathrm{CO}$ to Elemental Sulfur}

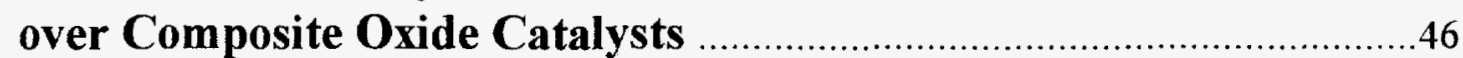

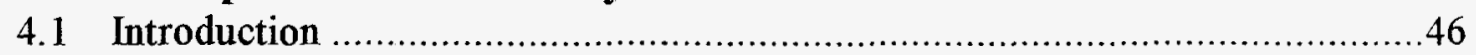

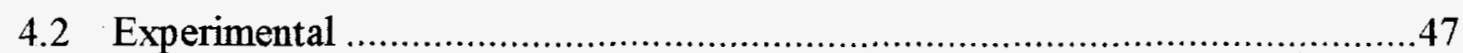

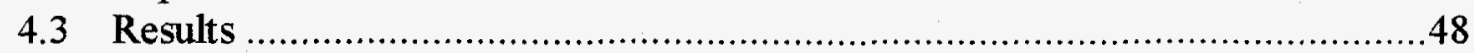

4.3.1 Transition Metal-Impregnated Ceria Catalysts ...................................48

4.3.2 Effect of Copper Content on the Catalyst Activity and Selectivity of the Cu-Ce-O System ............................................49

4.3.3 Zirconate and Zirconia Catalysts....................................................49

4.3.4 Effect of Carbon Dioxide on Catalyst Activity and Selectivity ..............50

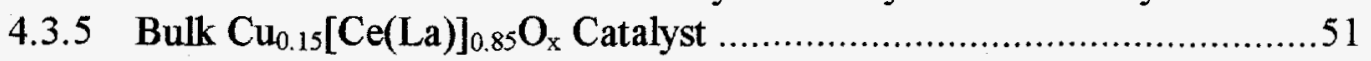

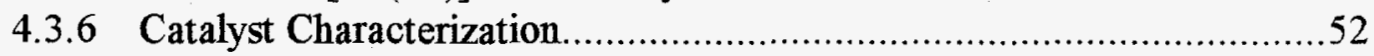

4.3.7 Reducibility of the $\mathrm{Cu}_{0.15}[\mathrm{Ce}(\mathrm{La})]_{0.85} \mathrm{O}_{\mathrm{x}}$ Catalyst..............................54

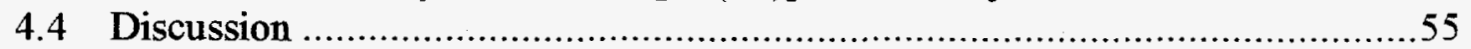

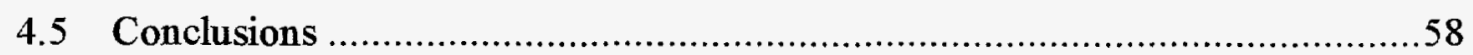

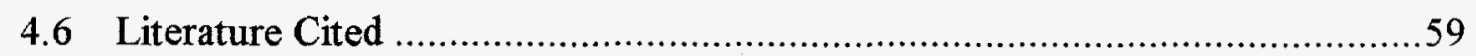

\section{Complete Oxidation of $\mathrm{CO}$ and $\mathrm{CH}_{4}$ over}

\section{Transition Metal-Fluorite Oxide Composite Catalysts}

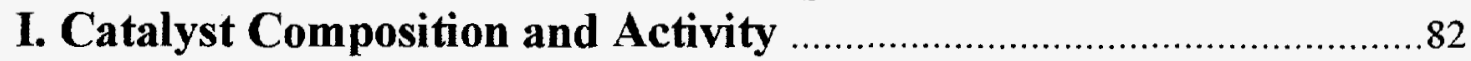

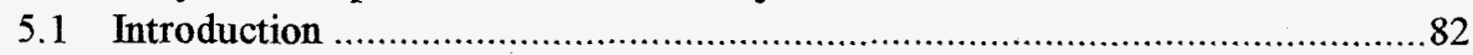

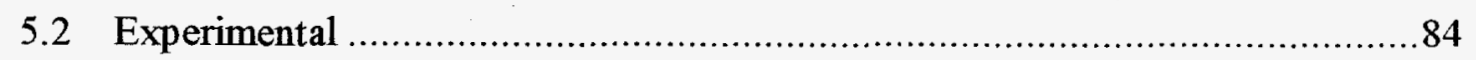

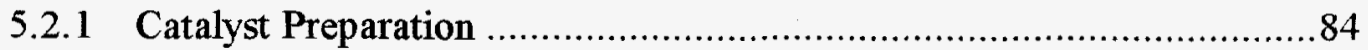

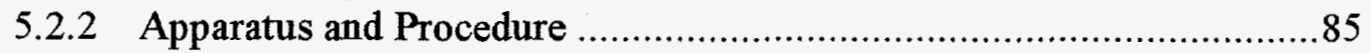

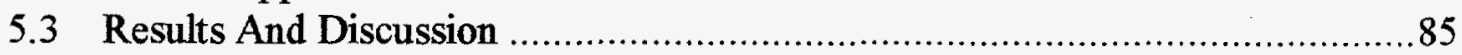

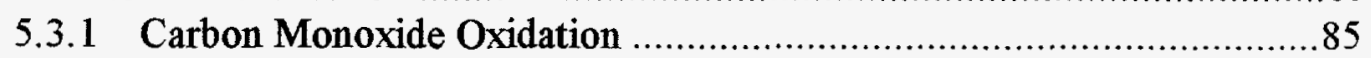

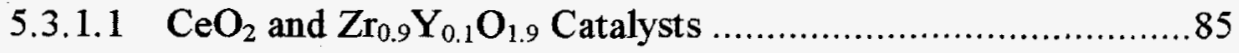

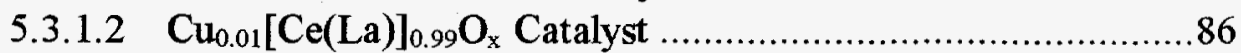

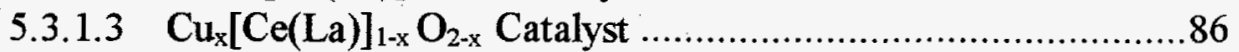

5.3.1.4 Effect of Dopant Oxides on the Catalytic Activity of

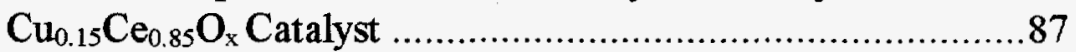

5.3.1.5 Activity Enhancement by the Concerted Effect of $\mathrm{CuO}$ and

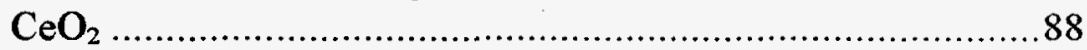

5.3.1.6 Activities of Other Transition Metal-Fluorite

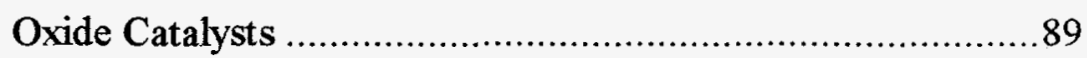

5.3.1.7 Effect of Water Vapor on Catalyst Activity .........................90

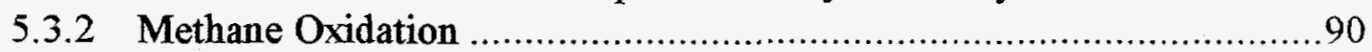

5.3.3 Simultaneous Oxidation of $\mathrm{CO}$ and $\mathrm{CH}_{4}$ over the $\mathrm{Cu}_{0.15}[\mathrm{Ce}(\mathrm{La})]_{0.85} \mathrm{O}_{\mathrm{x}}$ Catalyst..............................................92

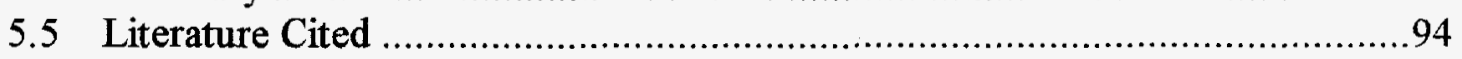




\section{Complete Oxidation of $\mathrm{CO}$ and $\mathrm{CH}_{4}$ over}

\section{Transition Metal-Fluorite Oxide Composite Catalysts}

II. Catalyst Characterization and Reaction Kinetics

6.1 Introduction

6.2 Experimental

6.2.1 Catalyst Preparation and Characterization ..................................109

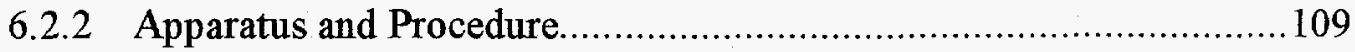

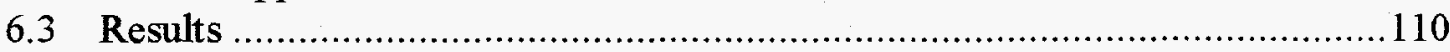

6.3.1 Catalyst Characterization ......................................................... 110

6.3.1.1 Characterization of $\mathrm{Au}_{0.05}[\mathrm{Ce}(\mathrm{La})]_{0.95} \mathrm{O}_{\mathrm{x}}$ Catalyst ..............110

6.3.1.2 XRD and STEM Analyses of Cu-Ce-O Catalyst System ......111

6.3.1.3 XPS Analyses of Cu-Ce-O Catalyst System .....................112

6.3.2 Kinetic Results .............................................................. 114

6.3.2.1 CO Oxidation Kinetics over $\mathrm{Au}_{0.05}[\mathrm{Ce}(\mathrm{La})]_{0.95} \mathrm{O}_{\mathrm{x}}$ Catalyst....114

6.3.2.2 CO Oxidation Kinetics over the $\mathrm{Cu}-\mathrm{Ce}-\mathrm{O}$ Catalysts ............114

6.3.2.3 Methane Oxidation ...................................................... 116

6.3.2.4 Verification of Kinetic Equations .................................116

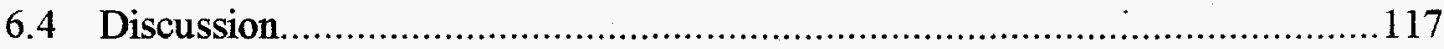

6.4.1 CO Oxidation over the $\mathrm{Au}_{0.05}[\mathrm{Ce}(\mathrm{La})]_{0.95} \mathrm{O}_{\mathrm{x}}$ Catalyst ...................117

6.4.2 CO Oxidation over the $\mathrm{Cu}-\mathrm{Ce}(\mathrm{La})-\mathrm{O}$ Catalyst ............................118

6.4.3 Strong Interaction of Copper with Cerium Oxide and Synergism .......118

6.4.4 Methane Oxidation Kinetics .................................................... 120

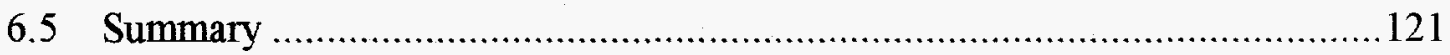

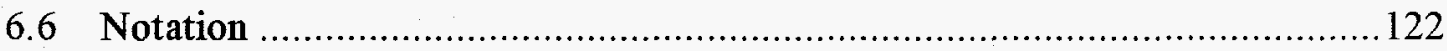

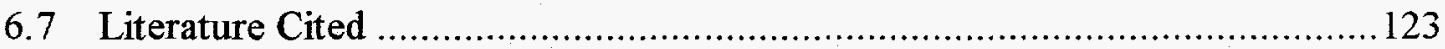

7 Conclusions and Recommendations ............................................... 146

7.1 Reduction of $\mathrm{SO}_{2}$ by $\mathrm{CO}$ to Elemental Sulfur ........................................ 146

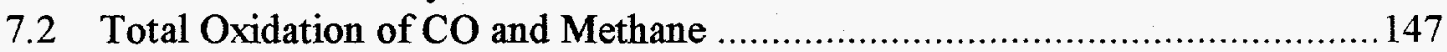

7.3 Oxidation Activity of Non-stoichiometric Cerium Oxide ........................... 148

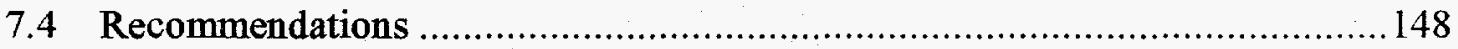

\section{DISCLAIMER}

This report was prepared as an account of work sponsored by an agency of the United States Government. Neither the United States Government nor any agency thereof, nor any of their employees, makes any warranty, express or implied, or assumes any legal liability or responsibility for the accuracy, completeness, or usefulness of any information, apparatus, product, or process disclosed, or represents that its use would not infringe privately owned rights. Reference herein to any specific commercial product, process, or service by trade name, trademark, manufacturer, or otherwise does not necessarily constitute or imply its endorsement, recommendation, or favoring by the United States Government or any agency thereof. The views and opinions of authors expressed herein do not necessarily state or reflect those of the United States Government or any agency thereof. 


\section{List of Figures}

1.1 Elemental Sulfur Recovery Scheme from the Dry Regenerative Flue Gas and Hot Coal Gas Desulfurization Processes............................................... 10

$1.2 \quad$ Crystal Structure of Fluorite Oxide …................................................... 11

2.1 A Typical pH Profile During Titration of $\mathrm{Cu}^{+2}+\mathrm{Ce}^{+3}$ Solution by Carbonate

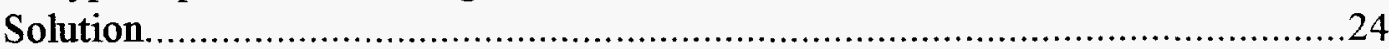

$2.2 \mathrm{dV} / \mathrm{d} \log (\mathrm{Dp})$ Desorption Pore Volume Plots for $\mathrm{Cu}_{0.15}[\mathrm{Ce}(\mathrm{La})]_{0.85} \mathrm{O}_{\mathrm{x}}$ Catalysts...24

$2.3 \mathrm{dV} / \mathrm{d} \log (\mathrm{Dp})$ Desorption Pore Volume Plots for $\mathrm{CeO}_{2}$ support and

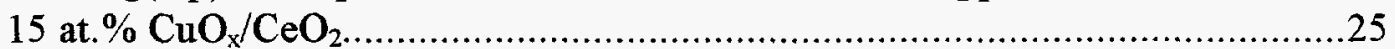

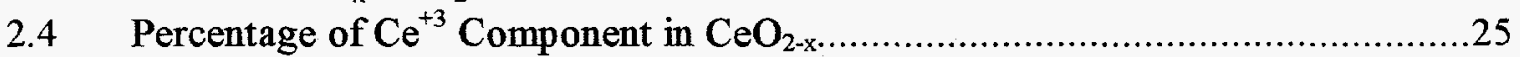

2.5 Lattice Spacing of Ceria in $\mathrm{Cu}-\mathrm{Ce}(\mathrm{La})-\mathrm{O}$ Composite Catalysts.......................26

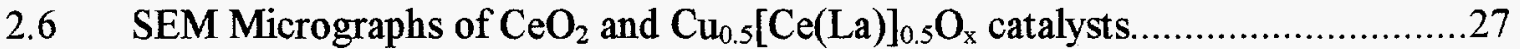

2.7 TEM Micrograph of 15 at. $\% \mathrm{CuO}_{\mathrm{x}} / \mathrm{CeO}_{2}$ catalysts....................................28

2.8 Schematic of Reactor Apparatus................................................................29

3.1 Elemental Sulfur Yield and $\mathrm{SO}_{2}$ Conversion on Bulk $\mathrm{CeO}_{2}$ Catalyst.................40

3.2 Effect of $\mathrm{Y}_{2} \mathrm{O}_{3}$ Dopant Content in Ceria on Catalyst Activity...........................40

3.3 Effect of Different Dopants in Ceria on Catalyst Activity................................41

3.4 Light-off Behavior over Doped Ceria Catalysts in the Absence of Activation......41

3.5 Effects of $\mathrm{La}_{2} \mathrm{O}_{3}$ Dopant Content and $\mathrm{MgO}$ Dopant on Catalyst Activity............42

3.6 Effect of Contact Time on the Activity of the $\mathrm{CeO}_{2}(\mathrm{La})$ Catalyst........................42

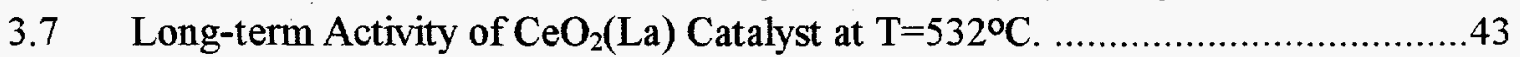

3.8 Product Distribution with Temperature on $\mathrm{CeO}_{2}(\mathrm{La})$ Catalyst in the Presence of Water Vapor.

3.9 Product Distribution with the $[\mathrm{CO}] /\left[\mathrm{SO}_{2}\right]$ Ratio on $\mathrm{CeO}_{2}(\mathrm{La})$ Catalyst in the Presence of Water Vapor at $610^{\circ} \mathrm{C}$....................................................44

3.10 Claus Reaction over $\mathrm{CeO}_{2}$ (La) Catalyst..................................................45

3.11 Hydrolysis of $\mathrm{COS}$ over $\mathrm{CeO}_{2}(\mathrm{La})$ Catalyst..........................................45

4.1 Light-off Behavior of Transition Metal-Impregnated Ceria Catalysts.................66

4.2 Fall-off Behavior and Water Vapor Effect on the Transition Metal-Impregnated Ceria Catalysts..............................................67

4.3 Long-term Test of $\mathrm{Cu} / \mathrm{CeO}_{2}$ Catalyst in Wet Gas.....................................68

$4.4 \quad \mathrm{SO}_{2}$ Reduction by $\mathrm{CO}$ over the $\mathrm{Gd}_{2} \mathrm{Zr}_{2} \mathrm{O}_{7}$ Catalyst. .....................................68

4.5 Effect of $\mathrm{CO}_{2}$ on Catalyst Activity and Selectivity. ..................................69

4.6 Effect of Experimental Conditions on Light-off Temperature of $\mathrm{Cu}_{0.15}[\mathrm{Ce}(\mathrm{La})]_{0.85} \mathrm{O}_{\mathrm{x}}$ Catalyst. ...........................................................69

4.7 Activation Profiles of 15 at. \% Cu Catalysts in Reacting Gas Mixture.................70

4.8 Product Distribution over $\mathrm{Cu}_{0.15}[\mathrm{Ce}(\mathrm{La})]_{0.85} \mathrm{O}_{\mathrm{x}}$ Catalyst versus $\mathrm{R}_{\mathrm{co}} \ldots \ldots \ldots \ldots \ldots \ldots . . \ldots 70$

4.9 Effect of Contact Time on $\mathrm{SO}_{2}$ Conversion at Various Temperatures.................71

4.10 Variation of $\mathrm{SO}_{2}$ Conversion with Contact time and Inlet $\mathrm{SO}_{2}$ Concentration over $\mathrm{Cu}_{0.15}[\mathrm{Ce}(\mathrm{La})]_{0.85} \mathrm{O}_{\mathrm{x}}$ Catalyst $\left(\mathrm{R}_{\mathrm{CO}}=2,510^{\circ} \mathrm{C}\right) \ldots \ldots \ldots \ldots \ldots \ldots . . \ldots 1$

4.11 Variation of Sulfur Yield with Reaction Temperature in $2 \% \mathrm{H}_{2} \mathrm{O}$. ...................72 
4.12 Variation of Sulfur Yield in the Presence of $2 \% \mathrm{H}_{2} \mathrm{O}$ with Contact Time............72

4.13 Variations of Sulfur Yield with Temperature and Water Vapor Content.............73

$4.14 \mathrm{X}$-ray Diffractograms of the $7.8 \mathrm{wt} \% \mathrm{CuOx} / \mathrm{CeO}_{2}$ Catalyst

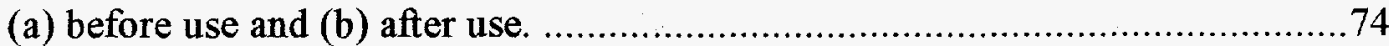

4.15 STEM/EDX Elemental Mapping of Used $\mathrm{Cu}-\mathrm{Ce}-\mathrm{O}$ Catalysts............................75

4.16 XPS of Used Cu-Ce-O Catalysts. (a) Cu2p (b) Ce3d (c) O1s (d) S2p ...............77

4.17 Temperature-Programmed Reduction Profile of $\mathrm{Cu}_{0.15}[\mathrm{Ce}(\mathrm{La})]_{0.85} \mathrm{O}_{\mathrm{x}}$

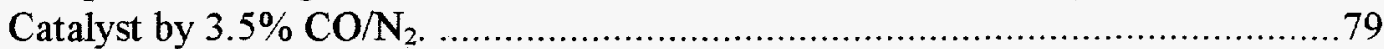

4.18 Arrhenius Plot of the Initial Reduction Rate of $\mathrm{Cu}_{0.15}[\mathrm{Ce}(\mathrm{La})]_{0.85} \mathrm{O}_{\mathrm{x}}$

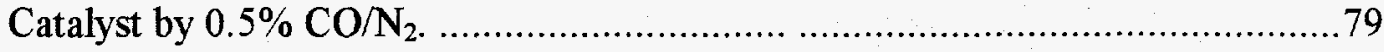

4.19 Arrhenius Plot of the Initial Reduction Rate of $\mathrm{Cu}_{0.15}[\mathrm{Ce}(\mathrm{La})]_{0.85} \mathrm{O}_{\mathrm{x}}$ Catalyst pre-

Sulfated by $1 \% \mathrm{SO}_{2}$ for $2 \mathrm{~h}$ (reducing gas: $2 \% \mathrm{CO} / \mathrm{N}_{2}$ )..............................80

4.20 COS Evolution Profile During 2\% CO/He Scavenging of Spent Catalysts. .........80

4.21 Light-off and Fall-off Temperatures of Non-stoichiometric

Cerium Oxide Catalysts for $\mathrm{SO}_{2}$ Reduction.

5.1 Light-off of CO Oxidation over Various 1 at.\% Doped Ceria Catalysts and $\mathrm{Zr}_{0.9} \mathrm{Y}_{0.1} \mathrm{O}_{1.9}$ Catalyst.

5.2 Effect of Thermal Treatment on the $\mathrm{Cu}_{0.01}[\mathrm{Ce}(\mathrm{La})]_{0.99} \mathrm{O}_{\mathrm{x}}$

Catalyst Activity for $\mathrm{CO}$ Oxidation.

5.3 Effect of Bulk Copper Content in $\mathrm{Cu}_{\mathrm{x}}[\mathrm{Ce}(\mathrm{La})]_{1-\mathrm{x}} \mathrm{O}_{2-\mathrm{x}}$ Catalyst

on CO Oxidation Activity.

5.4 XRD Pattern of the $\mathrm{Cu}-\mathrm{Ce}(\mathrm{La})-\mathrm{O}$ Catalysts.

5.5 Effect of 1 at. \% Dopant on the CO Oxidation Activity

of $\mathrm{Cu}_{0.15} \mathrm{Ce}_{0.85} \mathrm{O}_{\mathrm{x}}$ Catalyst.

5.6 Effect of La Dopant Content on the CO Oxidation Activity of $\mathrm{Cu}_{0.15} \mathrm{Ce}_{0.85} \mathrm{O}_{\mathrm{x}}$

Catalyst.

5.7 Activity Enhancement for $\mathrm{CO}$ Oxidation from Combination of $\mathrm{CeO}_{2}$ and $\mathrm{CuO} . .103$

5.8 Effect of Copper Dispersion on CO Oxidation Activity. ............................... 103

5.9 CO Oxidation over Various Composite Catalysts. ...................................... 104

5.10 Effect of Water Vapor on CO Oxidation Activity over the Catalysts

Prepared by $4 \mathrm{~h}$ Calcination at $650^{\circ} \mathrm{C}$ in Air.

5.11 Effect of Catalyst Thermal Treatment on the CO Oxidation Activity in the

Presence of Water Vapor.

5.12 Methane Oxidation over Various Composite Catalysts. .............................. 106

5.13 Effect of Dopant in the $\mathrm{Cu}_{0.15} \mathrm{Ce}_{0.85} \mathrm{O}_{\mathrm{x}}$ Catalyst

on Methane Oxidation Activity...

5.14 Simultaneous Oxidation of Methane and $\mathrm{CO}$ over the $\mathrm{Cu}_{0.15}[\mathrm{Ce}(\mathrm{La})]_{0.85} \mathrm{O}_{\mathrm{x}}$

Catalyst.

6.1a XRD Pattern of the $\mathrm{Au}_{0.05}[\mathrm{Ce}(\mathrm{La})]_{0.95} \mathrm{O}_{\mathrm{x}}$ Catalyst. ..................................... 127

6.1b XP Spectra of $\mathrm{Au} 4 \mathrm{f}$ in the $\mathrm{Au}_{0.05}[\mathrm{Ce}(\mathrm{La})]_{0.95} \mathrm{O}_{\mathrm{x}}$ Catalyst. ...............................127

6.1c STEM/EDX Elemental Maps of the $\mathrm{Au}_{0.05}[\mathrm{Ce}(\mathrm{La})]_{0.95} \mathrm{O}_{\mathrm{x}}$ Catalyst..................128

6.2 XRD Patterns of Various $\mathrm{Cu}-\mathrm{Ce}-\mathrm{O}$ Catalysts. ............................................129

6.3 Elemental Maps of Cu-Ce-O Catalysts by STEM/EDX .................................130

a $\quad \mathrm{Cu}_{0.15}[\mathrm{Ce}(\mathrm{La})]_{0.85} \mathrm{O}_{\mathrm{x}}$ Catalyst Prepared by Coprecipitation. 
b $\quad 15$ at. $\% \mathrm{CuOx} / \mathrm{CeO}_{2}$ Catalyst Prepared by Impregnation. ......................130

c $\quad 15$ at. $\% \mathrm{CuO}+\mathrm{CeO}_{2}$ Catalyst Prepared by Mixing. ................................131

d $\quad \mathrm{Cu}_{0.15}[\mathrm{Ce}(\mathrm{La})]_{0.85} \mathrm{O}_{\mathrm{x}}$ Catalyst Treated by Nitric Acid. ..........................131

e $\quad \mathrm{Cu}_{0.5}[\mathrm{Ce}(\mathrm{La})]_{0.5} \mathrm{O}_{\mathrm{x}}$ Catalyst Prepared by Coprecipitation. ..................... 132

f $\quad \mathrm{Cu}_{0.5}[\mathrm{Ce}(\mathrm{La})]_{0.5} \mathrm{O}_{\mathrm{x}}$ Catalyst Prepared by Coprecipitation. .................... 132

g X-ray Energy Disperse Spectra of an Area Shown in Figure 3f................ 133

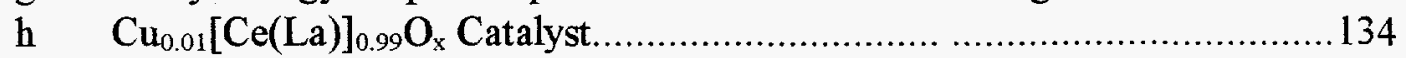

i $\quad \mathrm{Cu}_{0.01}[\mathrm{Ce}(\mathrm{La})]_{0.99} \mathrm{O}_{\mathrm{x}}$ Catalyst Further Calcined

for $3 \mathrm{~h}$ in Flowing $\mathrm{Air}$ at $860^{\circ} \mathrm{C}$....................................................... 134

6.4a Cu2p XP Spectra of Cu-Ce(La)-O Catalysts of High Copper Content...............135

$6.4 \mathrm{~b}$ Kinetic Energy Spectra of the Auger $\mathrm{L}_{3}$ VV Electron of the $\mathrm{Cu}-\mathrm{Ce}(\mathrm{La})-\mathrm{O}$

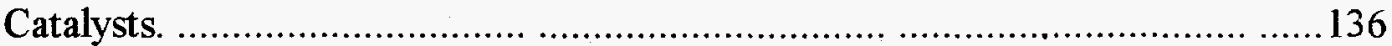

6.4c Ce3d XP Spectra of the $\mathrm{Cu}-\mathrm{Ce}(\mathrm{La})-\mathrm{O}$ Catalysts. ......................................137

$6.5 \mathrm{a} \quad \mathrm{Cu} 2 \mathrm{p}$ XP Spectra of $\mathrm{Cu}_{0.01}[\mathrm{Ce}(\mathrm{La})]_{0.99} \mathrm{O}_{\mathrm{x}}$ and $\mathrm{Cu}_{0.02}[\mathrm{Ce}(\mathrm{La})]_{0.98} \mathrm{O}_{\mathrm{x}}$ Catalysts.... 138

$6.5 \mathrm{~b}$ Kinetic Energy Spectra of the Auger $\mathrm{L}_{3} \mathrm{VV}$ Electron of $\mathrm{Cu}_{0.01}[\mathrm{Ce}(\mathrm{La})]_{0.99} \mathrm{O}_{\mathrm{x}}$ and $\mathrm{Cu}_{0.02}[\mathrm{Ce}(\mathrm{La})]_{0.98} \mathrm{O}_{\mathrm{x}}$ Catalysts..

6.6 Variation of $\mathrm{CO}$ Oxidation Rate over the $\mathrm{Au}_{0.05}[\mathrm{Ce}(\mathrm{La})]_{0.95} \mathrm{O}_{\mathrm{x}}$

Catalyst with Partial Pressure of Oxygen and $\mathrm{CO}$.

6.7 Variation of CO Oxidation Rate over the $\mathrm{Cu}_{0.15}[\mathrm{Ce}(\mathrm{La})]_{0.85} \mathrm{O}_{\mathrm{x}}$ Catalyst with

Partial Pressure of $\mathrm{CO}$ under Constant $\mathrm{P}_{\mathrm{O}}$.

6.8 Variation of $\mathrm{CO}$ Oxidation Rate over the $\mathrm{Cu}_{0.15}[\mathrm{Ce}(\mathrm{La})]_{0.85} \mathrm{O}_{\mathrm{x}}$ Catalyst with Partial Pressure of Oxygen under Constant $\mathrm{P}_{\mathrm{CO}}$.

6.9 Arrhenius Plots of Constants $\mathrm{k}$ and $\mathrm{K}$ for $\mathrm{CO}$ Oxidation over

$\mathrm{Au}_{0.05}[\mathrm{Ce}(\mathrm{La})]_{0.95} \mathrm{O}_{\mathrm{x}}$ and $\mathrm{Cu}_{0.15}[\mathrm{Ce}(\mathrm{La})]_{0.85} \mathrm{O}_{\mathrm{x}}$ Catalysts.

6.10 Arrhenius Plots of Constants $\mathrm{k}_{\mathrm{CO}}$ and $\mathrm{K}_{\mathrm{CO}}$ for $\mathrm{CO}$ Oxidation over

$\mathrm{Cu}_{0.01}[\mathrm{Ce}(\mathrm{La})]_{0.99} \mathrm{O}_{\mathrm{x}}$ Catalysts.

6.11 Correlation of Normalized Reaction Rate Constant $\left(\mathrm{k}_{\mathrm{CO}} / \mathrm{Sg}\right)$ for CO Oxidation over the $\mathrm{Cu}-\mathrm{Ce}(\mathrm{La})-\mathrm{O}$ Catalysts with Surface Copper Fraction.

6.12 Variation of the Surface Copper Fraction of the $\mathrm{Cu}-\mathrm{Ce}(\mathrm{La})-\mathrm{O}$

Catalyst with Bulk Composition and Thermal Treatment...

6.13 Variation of Methane Oxidation Rate over the $\mathrm{Cu}_{0.15}[\mathrm{Ce}(\mathrm{La})]_{0.85} \mathrm{O}_{\mathrm{x}}$

Catalyst with Partial Pressure of Methane under Constant $\mathbf{P}_{\mathrm{O}}$.

6.14 Variation of Methane Oxidation Rate over the $\mathrm{Cu}_{0.15}[\mathrm{Ce}(\mathrm{La})]_{0.85} \mathrm{O}_{\mathrm{x}}$ Catalyst with Partial Pressure of Oxygen under Constant $P_{m}$.

6.15 Arrhenius Plots of Constants $k_{m}$ and $K_{m}$ for Methane Oxidation over $\mathrm{Cu}_{0.15}[\mathrm{Ce}(\mathrm{La})]_{0.85} \mathrm{O}_{\mathrm{x}}$ Catalyst.

6.16 Comparison of Calculated Light-off Curves with Experimental Data................145

6.17 Synergistic Reaction Model for CO Oxidation over the $\mathrm{Au}-\mathrm{Ce}-\mathrm{O}$ and $\mathrm{Cu}-\mathrm{Ce}-\mathrm{O}$ Catalysts.

6.18 Interaction Model of Copper with Cerium Oxide. 


\section{List of Tables}

1.1 Solubility of the Common Alkaline Earth and Rare Earth Oxides

in Three Fluorite Oxides.

2.1 Materials Inventory for Catalyst Preparation. ............................................22

2.2 Properties of Catalyst Supports. .........................................................23

2.3 Results of $\mathrm{N}_{2} \mathrm{O}$ Adsorption Measurement for Specific Copper Area. .................23

3.1 Catalysts Tested in This Study. ..........................................................38

3.2 Variation of Oxygen Conductivity and Activation Enthalpy

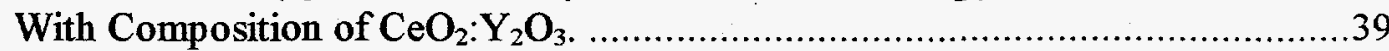

3.3 Association Enthalpy $\mathrm{h}_{\mathrm{A}}$ and Conductivity for Solid Solutions of Different

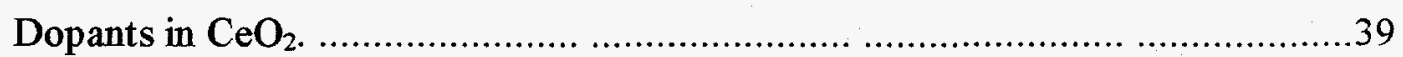

4.1 Transition Metal-Impregnated Ceria Catalysts. ........................................61

4.2 Variation of Catalyst Activity and Selectivity with Catalyst Composition in the $\mathrm{Cu}-\mathrm{Ce}-\mathrm{O}$ System.

4.3 Reduction of Sulfur Dioxide by Carbon Monoxide over Zirconate and Zirconia Catalysts.

4.4 Variation of the Surface Area of $\mathrm{Cu}_{0.15}[\mathrm{Ce}(\mathrm{La})]_{0.85} \mathrm{O}_{\mathrm{x}}$ Catalyst with Thermal Treatment.

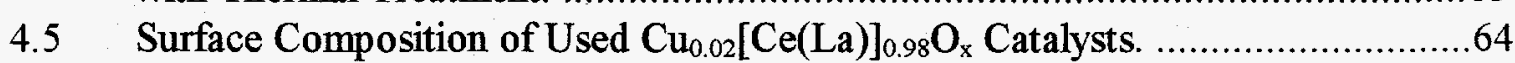

4.6 Surface Composition of Used $\mathrm{Cu}_{0.15}[\mathrm{Ce}(\mathrm{La})]_{0.85} \mathrm{O}_{\mathrm{x}}$ Catalysts............................64

4.7 XPS Binding Energies of the $\mathrm{Cu}-\mathrm{Ce}-\mathrm{O}$ Catalysts......................................65

4.8 Surface Compositional Analysis of $\mathrm{Cu}_{0.15}[\mathrm{Ce}(\mathrm{La})]_{0.85} \mathrm{O}_{\mathrm{x}}$ Catalyst by XPS..........65

5.1 Variation of the $\mathrm{Cu}_{0.01}[\mathrm{Ce}(\mathrm{La})]_{0.99} \mathrm{O}_{\mathrm{x}}$ Catalyst Surface Area and Surface Composition With Thermal Treatment in Air. ..................................................96

5.2 Particle Size and Surface Composition of $\mathrm{Cu}-\mathrm{Ce}(\mathrm{La})-\mathrm{O}$ Catalysts. ...................96

5.3 Catalyst Activity for CO Oxidation. .........................................................97

5.4 Gold-Metal Oxide Composite Catalyst Activity for CO Oxidation. ....................98

5.5 Catalyst Activity for Methane Oxidation. ..............................................98

6.1 CO Oxidation Kinetics over the Au-Oxide Catalysts. ....................................125

6.2 CO Oxidation Kinetics over the $\mathrm{Cu}-\mathrm{Ce}(\mathrm{La})-\mathrm{O}$ and Other Copper Catalysts. .....126 


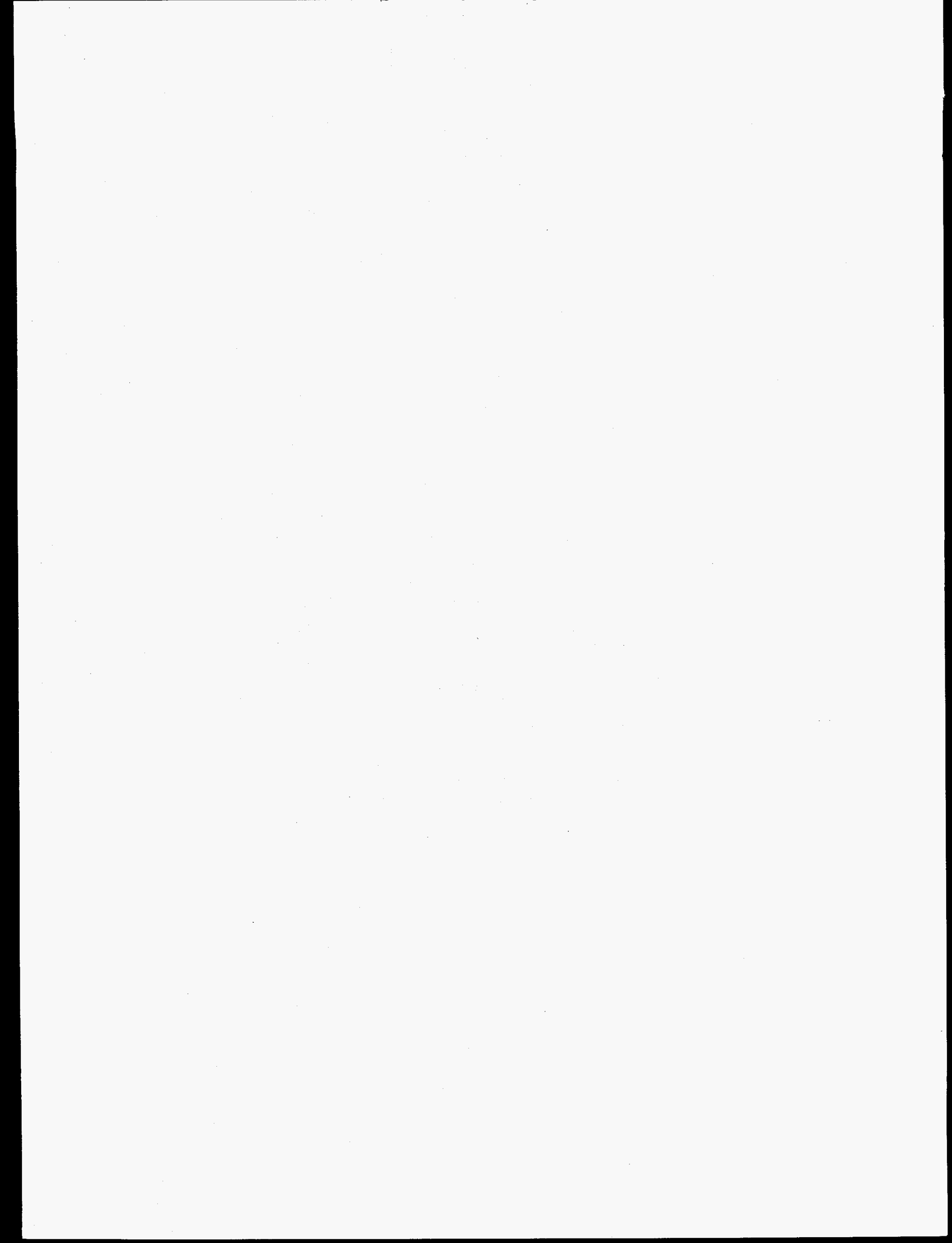




\section{Chapter 1}

\section{Introduction}

\subsection{Project Objective and Outline}

This research aims to develop and study new catalyst materials of high activity and stability for the reduction of sulfur dioxide by carbon monoxide to elemental sulfur. Direct sulfur recovery from dilute sulfur dioxide streams is integrally related to the on-going and future generation of efficient and economical (a) flue gas desulfurization process and (b) hot coal gas cleanup technology.

The research objectives include (i) evaluation of $\mathrm{CeO}_{2}$-based catalysts for direct reduction of $\mathrm{SO}_{2}$ to $\mathrm{S}$; (ii) conduction of detailed parametric studies with selected catalyst compositions; (iii) correlation of catalyst activity/selectivity with catalyst structural properties. The project objectives are extended to other catalysts to check the hypothesis of labile oxygen/vacancy mechanism and to other oxidation reactions to generalize the complete oxidation activity of the new catalysts.

This report consists of seven chapters. Chapter 1 gives detailed information of the project background, proposed new catalyst formula, and scientific discussion of the new catalyst system. The general description of experimental principles and procedure are covered in Chapter 2, while research results and discussions comprise the subsequent chapters. Chapter 3 discusses sulfur dioxide reduction by carbon monoxide over ceriabased catalysts with emphasis on correlation of catalytic activity with oxygen mobility. The structure and activity of novel transition metal-fluorite oxide composite catalysts are reported in Chapter 4. Chapters 5 and 6 include the results for total oxidation of carbon monoxide and methane: catalyst composition and activity in Chapter 5, catalyst structure and reaction kinetics in Chapter 6. Each of the Chapters 3-6 contains a brief introduction of research background and specific experimental methods as well as bibliography. Finally, the main conclusions drawn from this work and proposal for future study are summarized in Chapter 7.

\subsection{Background}

\subsubsection{Old Problems and New Challenges-Flue Gas Desulfurization}

Sulfur dioxide is a notorious environmental pollutant causing acid rain formation and various ecological damages. Sulfur dioxide is mainly generated from burning sulfurcontaining fossil fuels. About $55 \%$ of the electric power in the U.S. is produced by coalfired power plants. As a result, coal-fired power plants are the primary sources of $\mathrm{SO}_{2}$ emission. The 1990 Clean Air Act amendments call for a reduction of about $50 \%$ in these 
$\mathrm{SO}_{2}$ emissions by the end of this century. Estimates for the costs of flue gas desulfurization (FGD) systems alone by that time are \$6-8 billion for capital expenditures with additional operating expenses of $\$ 3$ billion/year. The majority of commercial flue gas desulfurization (FGD) plants in use today are based on scrubbing processes ( $92 \%$ wet scrubbers and $8 \%$ dry scrubbers). Such schemes fix the sulfur dioxide by an oxide sorbent, typically limestone $\left(\mathrm{CaCO}_{3}\right)$ or lime $(\mathrm{CaO})$. These scrubbers are fraught with problems, such as high costs, large space requirements, high energy consumption, consumption of calcium oxide, a huge amount of solid waste containing metal sulfite/sulfate. The disposal of the solid waste is becoming costly with decreasing landfills and increasing public concerns over environmental pollution.

On the other hand, the 1990 Clean Air Act amendments also require significant reduction of another major air pollutant - NOx in the flue gas emissions. Fulfillment of the Clean Air Act will require very large capital investment. Thus, it is imperative to develop highly efficient and inexpensive new FGD technologies. Recent new legislation opens up the large, lucrative market by offering the opportunity for utilities to buy and sell rights (allowances of $\mathrm{SO}_{2}$ emission) on the Chicago Board of Trade (1). This has certainly added another impetus to new technology development.

Regenerative Flue Gas Desulfurization. Several development efforts have emphasized the improvement of the scrubbing technology. Recently, emphasis is shifting toward regenerative processes coupled with simultaneous de-NOx process, with no throwaway waste $(2,3,4)$. Figure 1.1 shows the scheme of a typical dry regenerative FGD process, where sulfur dioxide and oxygen in a flue gas stream react with metal oxide sorbent to form metal sulfate at typical exhaust gas temperatures and then, the saturated oxide sorbent is regenerated by a reducing stream to oxide form for cyclic operation. The regenerative FGD process has the advantages of energy efficiency, low cost of sorbents and waste disposal. However, these advantages can be greatly offset by the treatment of the regenerator offgas containing a few percent of $\mathrm{SO}_{2}$ and probably, some residual reductant.

Recovery of elemental sulfur from the regenerator offgas is an attractive approach, because the solid sulfur product can be easily stored or transported. The Claus plant is a dominant commercial process for elemental sulfur recovery. In this process, $\mathrm{H}_{2} \mathrm{~S}$ gas stream is combusted with air in a burner to produce a stoichiometric mixture of $\mathrm{SO}_{2}$ and $\mathrm{H}_{2} \mathrm{~S}$ and then, those two compounds react over two or three catalyst beds to produce elemental sulfur. The Claus process is widely used in refineries to treat gases containing fairly high concentrations of $\mathrm{H}_{2} \mathrm{~S}$. But, this process is not suitable for the treatment of low concentration level $(<5 \%) \mathrm{SO}_{2}$-containing gases, because $\mathrm{SO}_{2}$ has to be converted into $\mathrm{H}_{2} \mathrm{~S}$ and combustion of low concentration $\mathrm{H}_{2} \mathrm{~S}$ gas is not stable in the burner. Therefore, it would be more cost-effective to replace the complex Claus plant with a high-efficiency, single-stage catalytic converter (designated as $\mathrm{SO}_{2}$-to-S) to reduce $\mathrm{SO}_{2}$ directly to elemental sulfur by using a reductant, as shown in Figure 1.1.

Integrated Gasification Combined Cycle (IGCC). Another application area of the $\mathrm{SO}_{2}$-to-S converter was explored by researchers at the Research Triangle Institute $(5,6)$ 
for IGCC power generating systems. The IGCC system has held high promise for efficient and clean utilization of coal in power generation. But, desulfurization of hot coal gas is still one of main technological challenges. As illustrated in Figure 1.1, $\mathrm{H}_{2} \mathrm{~S}$ in the hot coal gas is usually scrubbed by metal and/or metal oxide sorbent at high reaction temperatures and the resulting metal sulfide is regenerated by air calcination. A diluted $\mathrm{SO}_{2}$ stream is discharged by the regeneration process. Thus, elemental sulfur can be recovered from this gas stream through the $\mathrm{SO}_{2}$-to-S converter.

The regenerator offgas volume is typically about ten times less than the parent flue gas or coal gas flowrate. Therefore, the direct sulfur recovery will require significantly lower capital investment. In addition to the previous two application areas, the $\mathrm{SO}_{2}$-to-S converter, in general, can be used to recover elemental sulfur from any $\mathrm{SO}_{2}$-containing industrial streams as long as no excess oxidant exists.

\subsubsection{Previous and Ongoing Studies of Catalytic Reduction of Sulfur Dioxide to Elemental Sulfur}

Directly reducing $\mathrm{SO}_{2}$ into elemental sulfur by a reductant gas has considerable historical background. A comprehensive review of early work is given in a 1975 proceeding (7). The gaseous reducing agents studied so far include carbon monoxide, hydrogen, synthesis gas $\left(\mathrm{H}_{2}+\mathrm{CO}\right)$, natural gas, etc. The type and location of the primary operation (sulfur source) dictate the choice of the reductant. The Allied Corporation operated a commercial plant to reduce $\mathrm{SO}_{2}$ with $\mathrm{CH}_{4}$ to elemental sulfur over a bauxite catalyst in 1970, as the emission control system for a Canadian sulfide ore roasting facility (7). The reduction of $\mathrm{SO}_{2}$ with $\mathrm{CH}_{4}$ over an activated alumina catalyst was recently investigated by Sarlis and Berk (8). The maximum elemental sulfur yield achieved in the single reduction step was around $50 \%$. Therefore, the residual gas comprising of $\mathrm{SO}_{2}$, $\mathrm{H}_{2} \mathrm{~S}$, and COS had to go through a downstream Claus plant in order to achieve high sulfur recovery. But, this technology was only suitable for gas streams containing more than $4 \% \mathrm{SO}_{2}$. Direct reaction of $\mathrm{SO}_{2}$-rich streams $\left(>10.0 \% \mathrm{SO}_{2}\right)$ with coke at $850-900^{\circ} \mathrm{C}$ to produce elemental sulfur was also tested (9). Reduction of $\mathrm{SO}_{2}$ by natural gas was disclosed by Stiles in 1975 (10) involving a supported catalyst containing thorium oxide in combination with one or more oxides of $\mathrm{Cr}, \mathrm{Mn}, \mathrm{Ba}, \mathrm{Sr}, \mathrm{Ca}, \mathrm{Ta}$ or mixed rare earth chromites.

Most previous studies of reduction of sulfur dioxide to elemental sulfur considered use of carbon monoxide as the reductant. Various catalyst systems have been reported. These include supported transition metal catalysts $(\mathrm{Cu}, \mathrm{Pd}, \mathrm{Ag}, \mathrm{Co}, \mathrm{Fe}, \mathrm{Ni}, \mathrm{Cr}, \mathrm{Mn}$, etc.) (11,12) and $\mathrm{ABO}_{3}$ perovskite-type mixed oxide catalysts containing alkaline earth and rare earth elements as well as transition metal elements $(13,14,15)$. But, none of these catalysts reached commercial application. The major technical problems arising from reduction of sulfur dioxide by carbon monoxide are the formation of COS and low activity and low sulfur yield in the presence of water vapor. 
Two research groups have recently reported high elemental sulfur recovery from sulfur dioxide. Agarwal et al. $(5,6)$ have achieved $95 \%$ elemental sulfur yield over a proprietary catalyst with coal gas as reductant. To avoid water vapor effects, they operated the reactor at high pressures (400 psi). Chang et al. (16) have realized $90 \%$ sulfur yield over a $\gamma-\mathrm{Al}_{2} \mathrm{O}_{3}$-supported catalyst containing 0 to 8 wt. $\% \mathrm{Fe}, \mathrm{Co}, \mathrm{Ni}, \mathrm{Cr}, \mathrm{Mn}, \mathrm{Cu}, \mathrm{Mo}$, and $\mathrm{Se}$ at temperatures $\geq 400^{\circ} \mathrm{C}$ and space velocities $\leq 10,000 \mathrm{~h}^{-1}$ by using stoichiometric synthesis gas $\left(\mathrm{H}_{2} / \mathrm{CO}=0.3 \sim 3\right)$ as a reducing agent.

\subsection{Formulation of a Novel Catalyst System}

\subsubsection{Catalyst Formula}

It is believed that unique catalytic properties can be derived from appropriate combination of appropriate metal oxides. In this work we have pioneered a new catalyst combination of fluorite oxide, alkaline earth and rare earth oxides, and transition metal oxides given in the following empirical formula $(17,18)$ :

$$
\begin{aligned}
& {\left[\left(\mathrm{FO}_{2}\right)_{1-\mathrm{n}}\left(\mathrm{DO}_{\delta}\right)_{\mathrm{n}}\right]_{1-\mathrm{k}} \mathrm{M}_{\mathrm{k}}} \\
& {\left[\mathrm{Ln}_{\mathrm{x}} \mathrm{Zr}_{1-\mathrm{x}} \mathrm{O}_{2-0.5 \mathrm{x}}\right]_{1-\mathrm{k}} \mathrm{M}_{\mathrm{k}}}
\end{aligned}
$$

where $\mathrm{FO}_{2}$ is a fluorite oxide; $\mathrm{DO}_{\delta}$ represents a dopant oxide consisting of alkaline earth and rare earth oxides; $M$ is a transition metal; $L n$ is a lanthanide element from $L a$ to $\mathrm{Tb} ; \mathrm{n}$ is a number from 0 to $0.15 ; \mathrm{k}$ is a number having a value from 0.0 to about $0.25 ; \mathrm{x}$ is a number around 0.5. Fluorite oxides have a fluorite-type crystal structure (face-centered cubic lattice) shown in Figure 2.1 The large tetravalent $(+4)$ cations have an eightcoordination of oxygen ions. An unit cell contains four cations occupying opposite four corners. Common fluorite oxides are $\mathrm{CeO}_{2}, \mathrm{ZrO}_{2}, \mathrm{ThO}_{2}, \mathrm{HfO}_{2}$. In a fluorite structure, tetravalent cations can be replaced by divalent cations (e.g., $\mathrm{Mg}^{+2}, \mathrm{Ca}^{+2}, \mathrm{Sr}^{+2}$ ) or trivalent cations (e.g., $\mathrm{Sc}^{+3}, \mathrm{Y}^{+3}, \mathrm{La}^{+3}, \mathrm{Gd}^{+3}$ ). Oxygen vacancies are created by this substitution. High oxygen vacancy concentration and oxygen mobility are the most remarkable properties of these oxides. Thus, the fluorite oxides have been extensively studied as oxygen ionic conductors $(19,20)$. Solubility of various fluorite oxide-dopant oxide systems are listed in Table 1.1.

$\mathrm{Ln}_{1-\mathrm{x}} \mathrm{Zr}_{\mathrm{x}} \mathrm{O}_{2-0.5 \mathrm{x}}$ compounds in formula Equation 2 are rare earth zirconates of Pyrochlore $(P)$ structure around $x=0.5$. The $P$ structure can be considered as an ordered defect fluorite structure. Pyrochlores, such as $\mathrm{Gd}_{2} \mathrm{Zr}_{2} \mathrm{O}_{7}$, in contrast to fluorite-type oxides, are intrinsic anion conductors with substantial ionic conductivity as pure materials where there is no possibility of dopant-vacancy association $(20,21)$. Therefore, bracketed materials in the above formula are essentially oxygen ion conductors.

These materials are ceramic materials of good physical and chemical stability and are best used as catalyst supports. Transition metals are added into the catalyst to improve the electronic and surface adsorption properties. Typically, the transition metals considered in the above catalyst formulations are copper, nickel, cobalt, chromium, manganese, iron, silver, and gold. Different from conventional transition metal catalysts, the transition metals are used in minor amounts, mainly as additives in the present composite catalyst. 


\subsubsection{Main Reactions Studied in This Project}

$$
\begin{aligned}
& \mathrm{SO}_{2}+2 \mathrm{CO} \rightarrow \mathrm{S}+2 \mathrm{CO}_{2} \\
& \mathrm{CO}+1 / 2 \mathrm{O}_{2} \rightarrow \mathrm{CO}_{2} \\
& \mathrm{CH}_{4}+2 \mathrm{O}_{2} \rightarrow \mathrm{CO}_{2}+2 \mathrm{H}_{2} \mathrm{O}
\end{aligned}
$$

The above reaction (3) is the main reaction in $\mathrm{SO}_{2}$ reduction by $\mathrm{CO}$. It is a typical redox reaction in which $\mathrm{SO}_{2}$ is reduced into sulfur while $\mathrm{CO}$ is oxidized to $\mathrm{CO}_{2}$. Along with $\mathrm{SO}_{2}$ reduction by $\mathrm{CO}$, total oxidation of $\mathrm{CO}$ and $\mathrm{CH}_{4}$ were also studied in this project. The fundamental reason to include the three reactions is that all the three reactions involve oxygen transfer from one molecule to another molecule resulting stable end products, that is, complete oxidation. We tried to gain an understanding of the present new catalyst system from a point of view of generic oxidation catalysis. Practically, catalytic properties for $\mathrm{CO}$ and hydrocarbon oxidation will be useful information when the reaction streams for $\mathrm{SO}_{2}$ reduction by $\mathrm{CO}$ contain certain amounts of oxygen and/or hydrocarbons. In addition, new complete oxidation catalysts would benefit technologies in (a) gas turbine exhaust cleanup and (b) vehicle exhaust emission control.

Carbon monoxide and hydrocarbons are partial combustion products of fossil fuels and are ubiquitous air pollutants. Methane was used in this work as a model hydrocarbon compound because of its refractory nature. However, methane itself is a potent greenhouse gas and may be regulated in the near future. To date, commercial catalysts for these purposes are predominantly supported precious metals ( $\mathrm{Pt}, \mathrm{Pd})$. The high cost of precious metals and need for more active catalyst systems have driven further research in this area.

\subsubsection{Scientific Rationale}

Electronic Property. Ordinary metal oxides can be generally classified into the following two categories according to their electronic properties (22):

p-type (electron excess) conductivity$\mathrm{CoO}, \mathrm{FeO}, \mathrm{MnO}, \mathrm{NiO}, \mathrm{PdO}, \mathrm{Ag}_{2} \mathrm{O}, \mathrm{Cu}_{2} \mathrm{O}, \mathrm{Mn}_{2} \mathrm{O}_{3}, \mathrm{Cr}_{2} \mathrm{O}_{3},(\mathrm{Co}, \mathrm{Fe}, \mathrm{Mg}, \mathrm{Zn}) \mathrm{Cr}_{2} \mathrm{O}_{4}$

n-type (hole excess) conductivity-

$\mathrm{ZnO}, \mathrm{CaO}, \mathrm{MoO}_{3}, \mathrm{WO}_{3}, \mathrm{Fe}_{2} \mathrm{O}_{3}, \mathrm{~V}_{2} \mathrm{O}_{5}, \mathrm{SnO}_{2}, \mathrm{~Pb}_{2} \mathrm{O}_{3},{ }^{*} \mathrm{TiO}_{2},{ }^{*} \mathrm{ThO}_{2},{ }^{*} \mathrm{SiO}_{2}$,

${ }^{*} \mathrm{Al}_{2} \mathrm{O}_{3},{ }^{*} \mathrm{ZrO}_{2},{ }^{*} \mathrm{CeO}_{2}, \mathrm{MnO}_{2}$

* materials with very low electronic conductivity.

P-type oxides favor the adsorption process involving electron transfer from the oxide to the probe molecule, e.g., oxide $-\mathrm{e}+\mathrm{O}_{2} \rightarrow \mathrm{O}_{2}^{-}$; vice versa, the n-type oxides favor the adsorption process involving electron transfer from the probe molecule to the oxide. Fluorite oxides are n-type oxides. More accurately, they are pure oxygen ionic conductors and have very low electronic conductivity. The transition metal oxides selected in the catalyst formula Equations 1-2 are p-type oxides. In the materials science field, previous 
studies of fluorite oxides have mainly focused on improving ionic conductivity by alkaline earth and rare earth oxide dopants, while little information is available about doping the fluorite oxide with transition metals. In general, transition metals do not form solid solution with fluorite oxides. The preliminary studies by Pound 1994 (23) showed that the addition of $\mathrm{CoO}, \mathrm{NiO}$, and $\mathrm{CuO}$ improved the electronic conductivity of $\mathrm{CeO}_{2}$. Therefore, the combination of the two types of materials will facilitate adsorption processes involving any kind of electron transfer. A great amount of effort has been devoted to develop a unitary electronic catalysis theory. Now, it is generally recognized that many different factors are involved in a catalytic process so that a single explanation is unlikely. This work will emphasize the surface chemistry aspects in the reaction mechanistic discussion.

Oxygen Mobility. Two general comments given by Satterfield (24) in reviewing practical oxidation catalysts are: (i) most of the metal oxides of interest are nonstoichiometric and the state of oxidation of the catalyst can be affected by reaction conditions; (ii) with oxide catalysts, chemisorbed surface oxygen and lattice oxygen as well as oxygen mobility may play a role. Iwamoto et al. (25) investigated the oxygen adsorption properties of sixteen oxides and classified them into three categories:

(A) No oxygen adsorption over the range 10 to $550^{\circ} \mathrm{C}-\mathrm{V}_{2} \mathrm{O}_{5}, \mathrm{MoO}_{3}, \mathrm{Bi}_{2} \mathrm{O}_{3}, \mathrm{WO}_{3}$.

(B) Relatively large amounts of oxygen desorption- $\mathrm{Cr}_{2} \mathrm{O}_{3}, \mathrm{MnO}_{2}, \mathrm{Fe}_{2} \mathrm{O}_{3}, \mathrm{Co}_{3} \mathrm{O}_{4}$, $\mathrm{NiO}, \mathrm{CuO}$.

(C) Pre-evacuation at high temperatures is required to observe oxygen desorption- $\mathrm{TiO}_{2}, \mathrm{ZnO}, \mathrm{SnO}_{2}, \mathrm{Al}_{2} \mathrm{O}_{3}, \mathrm{SiO}_{2}$.

Group A oxides are selective oxidation catalysts. Group B oxides mainly catalyze the complete oxidation of olefins. Group $\mathrm{C}$ oxides are in the intermediate situation. Such comparisons lead to the assumption that the adsorbed oxygen is related to complete oxidation while the lattice oxygen is more important for selective oxidation. Effect of different oxygen species and oxygen mobility on complete catalytic oxidation of volatile organic compounds was further discussed by Spivey (26).

Perovskite-type mixed oxides, e.g., $\mathrm{LaCoO}_{3}$, of both excellent electronic and ionic conductivity properties, have been extensively studied as oxidation catalysts and electrode materials in the metal oxide fuel cell (27). Correlation of oxygen mobility with oxidation activity for perovskite-type mixed oxide catalysts has been actively pursued in the literature. Oxygen vacancy and mobility properties were also used to interpret the reaction mechanism for $\mathrm{CO}$ oxidation over the cerium oxide $(28,29)$. However, the oxygen ion conductors showed $\mathrm{CO}$ oxidation activity typically at much higher temperatures than the transition metal oxide catalysts. For reaction of $\mathrm{SO}_{2}$ with $\mathrm{CO}$ over mixed metal oxide catalysts, a redox mechanism involving participation of catalyst surface oxygen/vacancy was proposed (30-33). Although no direct correlation of catalyst activity with oxygen mobility has been established so far, the previous literature generally agrees that oxygen mobility is relevant to oxidation catalysis.

Therefore, we specifically chose oxygen ionic conducting materials as a starting point in pursuing the correlation of oxygen mobility with catalytic activity. In fact, this is one of the fundamental reasons why the above three oxidation reactions (Equations 3-5) were 
included in this work. The three oxidation reactions all involve oxygen transfer from one molecule to another. We would like to examine in what way and extent the oxygen vacancy and mobility play a role in these oxidation reactions.

Synergistic Effect. There are a number of examples that an active catalyst can be obtained by combination of different components of low or no catalytic activity. One of well-known catalyst systems is $\mathrm{Cu} / \mathrm{ZnO}$ that is active for hydrogenation of $\mathrm{CO}$ to methanol and the water-gas-shift (WGS) reaction. Regarding the fluorite oxides, composite materials of transition metal and fluorite oxides, such as $\mathrm{Cu}-\mathrm{Ce}-\mathrm{O}, \mathrm{Cu}-\mathrm{Zr}-\mathrm{O}, \mathrm{Cu}-\mathrm{Th}-\mathrm{O}$, etc., have long been known as catalysts for hydrogenation of $\mathrm{CO}$ (34). Frost's "junction effect theory" (35) offers a hypothesis that the crucial chemistry occurs entirely on the oxide phases and that the role of the metal component is simply to promote electronically the reactivity of the oxide. Baiker et al. (36) found that the $(\mathrm{Cu}, \mathrm{Ag}, \mathrm{Au}) / \mathrm{ZrO} \mathrm{rr}_{2}$ system catalyzed the hydrogenation of $\mathrm{CO}_{2}$ and the reverse WGS reaction. Crystallization of the amorphous $\mathrm{ZrO}_{2}$ resulted in significantly lower activity, which was considered as evidence of the crucial role played by the interface between $\mathrm{ZrO}_{2}$ and the group IB metal in determining catalytic activity. "Strong metal-support interaction" and reaction at interface concepts have been developed during studies of binary catalyst systems $(37,38)$.

In the environmental catalysis field, $\mathrm{CeO}_{2}$ and/or $\mathrm{ZrO}_{2}$ have been widely used in the automotive catalytic converter as additives. Comprehensive information on the role played by $\mathrm{CeO}_{2}$ in this application was reported in (39). A great amount of effort has been devoted to studying the "strong interaction" of precious metals (Pd, $\mathrm{Pt}, \mathbf{R h})$ with ceria and its effect on catalytic activity. In contrast, oxidation properties of non-precious metals and fluorite oxide composites have rarely been studied. Two of such studies involve the $\mathrm{Mn} / \mathrm{Ce}$ composite oxide for the low-temperature combustion of fats by Imamuru and Ando (40) and the $\mathrm{Cu} / \mathrm{YSZ}$ (ytrria-stabilized zirconia) catalys for CO oxidation (41).

\subsection{Outline of Present Research Approach}

Catalyst design is a long-sought objective in the catalysis field (42). Chemical reaction engineering expertise can be used to optimize the catalyst preparation procedure, catalyst pore structure, and active phase distribution. But, truly designing of catalysts from the materials of point of view is still in its infancy. In this study we will apply two important catalysis concepts, metal-support interactions and reactions at interfaces, to metal-fluorite oxide composite catalyst development. The research will focus on identification of major catalyst compositions and structures and their correlation with steady-state catalytic activity.

Among various catalyst systems given by Equations $1-2$, the $\mathrm{Cu}-\mathrm{Ce}(\mathrm{D})-\mathrm{O}$ system ( $\mathrm{D}=$ dopant) was thoroughly studied, while the other systems were briefly examined. The reasons to emphasize the $\mathrm{Cu}-\mathrm{Ce}(\mathrm{D})-\mathrm{O}$ catalyst are: (i) $\mathrm{CeO}_{2}$ has stable fluorite structure from room temperature to its melting point $\left(2600^{\circ} \mathrm{C}\right)$; (ii) fundamental information on both cerium oxide and copper is well established; (iii) cerium and copper are inexpensive elements available in various precursors. 


\subsection{Literature Cited}

1. Goldburg, C.B., and Lave, L.B., Environ. Sci. Technol. 26(11), 2076-78 (1992).

2. Kwong, K.V., Meissner, R.E., and Hong, C.C., in "The Parsons FGC Process Simultaneous Removal of $\mathrm{SO}_{\mathrm{X}}$ and $\mathrm{NO}_{\mathrm{X}}$ " Presentation at the 1990 Annual Meeting of AIChE, Chicago, nlinois, November 11-16, Chicago, Hlinois, 1990.

3. Flytzani-Stephanopoulos, M., Z. Hu, C.S. Shin, Benedek, K., He, B., and Loftus, P., "Cross-Flow, Filter-Sorbent-Catalyst for Particulate, $\mathrm{SO}_{2}$, and NOx Control", Final Report to U.S. Department of Energy, Contract No. 22-89PC89805, May 1994.

4. "PETC/Industry Partnership: the NOXSO Process", PETC Review, September, 1990.

5. Gangwal, S.K., and McMichael, W.J., 'Bench-scale testing of sulfur recovery process" in Proceedings of the Tenth Annual Gasification and Gas Stream Cleanup Systems Contractors' Review Meeting, DOE/METC-90/6115, Vol.1, DE90009689, August, 1990.

6. Gangwal, S.K, and McMichael, W.J., Agarwal, S.K., Jang, B.L., Howe, G.B., Chen, D.H., and Hopper, J.R., "DSRP, Direct Sulfur Production" in Proceedings of the Thirteenth Annual Gasification and Gas Stream Cleanup Systems Contractors" Review Meeting, 424-43, Contract No. DE-AC21-90MC27224, 1993.

7. Rinckhoff, J.B., and Pfeiffer, J.B. (eds.), "Sulfur Removal and Recovery from Industrial Processes", Advances in Chemistry Series, No.139, American Chemical Society, 1975.

8. Sarlis, J., and Berk, D., Ind. Eng. Chem. Res. 27, 1951-1954 (1988).

9. Rush, R.E., and Edwards, R.A., "Operating Experience with Three $20 \mathrm{MW}$ Prototype Flue Gas Desulfurization Processes at Gulf Power Company's Scholtz Electric Generating Station," Presented at EPA Flue Gas Desulfurization Symposium, Hollywood, Florida, November 8-11, 1977.

10. Stiles, A. B., U.S. Patent 3856459,1975

11. Ryason, P.R., et al., U.S. Patent No. 3454355.

12. Haas, L.A., et al. U.S. Patent No. 3888 970, 1975.

13. Bajars, L., U.S. Patent 3978 200, 1976.

14. Whelan, J. M., U.S Patent 4081 519, 1978.

15. Hibbert, D.B., Catal. Rev.- Sci. Eng. 34(4), 391-408 (1992).

16. Chang, S.G., Jin, Y., and Yu, Q.Q., "Catalysts for the Reduction of Sulfur Dioxide to Elemental Sulfur", Technical Report of Energy and Environmental Division, Lawrence Berkeley Laboratory.

17. Flytzani-Stephanopoulos, M., and Liu, W., "Elemental Sulfur Recovery", U.S. Patent No. 5384 301, 1995.

18. Liu, W., and Flytzani-Stephanopoulos, M., "Composite Catalysts for Carbon Monoxide and Hydrocarbons Oxidation", U.S.Patent Application, serial No. 08/142, 519 (pending).

19. Hagenmuller, P., and Van Gool, W., Solid Electrolytes, Academic Press, New York, 1978. 
20. Tuller, H.L., and Moon, P.K., Materials Science and Engineering B1 20, 171-191 (1988).

21. van Dijk, M.P., de Vries, K.J., and Burggraaf, A.J., Solid State Ionics 9\&10, 913920 (1983).

22. Jose L.G. Fierro and Juan F. Garcia De La Banda., Catal. Rev.-Sci. Eng. 28(2\&3), 265-333 (1986).

23. Pound, B.G., Solid State Ionics 52, 183-188 (1992).

24. Satterfield, C. N., Heterogeneous Catalysis in Industrial Practice, 2nd ed., McGrawHill, Inc., 1991.

25. Iwamoto, M., Yoda, Y., Yamazoe, N., and Seiyama, T., J. Phys. Chem. 82, 2564 (1978).

26. Spivey, J.J., Ind. Eng. Chem. Res. 26, 2065-2180 (1987).

27. Minh, N.Q., J. Am. Ceram. Soc. 76(3), 563-88, (1993).

28. Breysse, M., Guenin, M., Claudel, B., Latreille, H., and Veron, J., J. Catal. 27, 275280 (1972).

29. Breysse, M., Guenin, M., Claudel, B., Latreille, H., and Veron, J., J. Catal. 28, 5462 (1972).

30. Happel, J., Hnatow, M.A., Bajars, L., and Kundrath, M., Ind. Eng. Chem., Prod. Res. Dev. 14, No.3, 154-158 (1975).

31. Happel, J., Leon, A.L., Hnatow, M.A., and Bajars, L. ibid. 16, No.2, 150-154 (1977).

32. Hibbert, D.B., and Campbell, R. H., Appl. Catal. 41, 273-287 (1988).

33. Hibbert, D.B., and Campbell, R. H., Appl. Catal. 41, 289-299 (1988).

34. Wallace, W.E., France, J., and Shamsi, A.; in "Rare Earth in Modern Science and Technology" Vol.3, Plenum, New York, 1982.

35. Frost, J.C., Nature 334, 577 (1988).

36. Baiker, M.K, Maciejewski, M., Menzi, S., and Wokaun, A., in Guczi, L., Solymosi, F., and Tetenyi, P., (editors), New Frontiers in Catalysis, Proceedings of the 10th International Congress on Catalysis, Budapest, July, page 1257, 1992.

37. Baker, R.T.K., Tauster, S.J., and Dumesic, J.A., (Editors), "Strong Metal-Support Interactions", American Chemical Society, Washington, DC, 1986.

38. Stevenson, S.A., Dumesic, J.A., Baker, R.T.K., and Ruckenstein, E., (Editors), "Metal-Support Interactions in Catalysis, Sintering, and Redispersion", Van Nostrand Reinhold Company Inc., 1987.

39. Crucq, A., (editor), "Catalysis and Automotive Pollution Control II", Elsevier Science Publishers B.V., Amsterdam, 1991.

40. Imamuru, S., and Ando, M., Ind. Eng. Res. 28, 1452-1456 (1989).

41. Dow, W.P., and Huang, T.J., J. Catal. 147, 322-332 (1994).

42. Bell, A.T., in Hegedus, L.L., et al. (Editors), "Catalyst Design, Process and Perspectives", Wiley, New York, p103, 1987. 


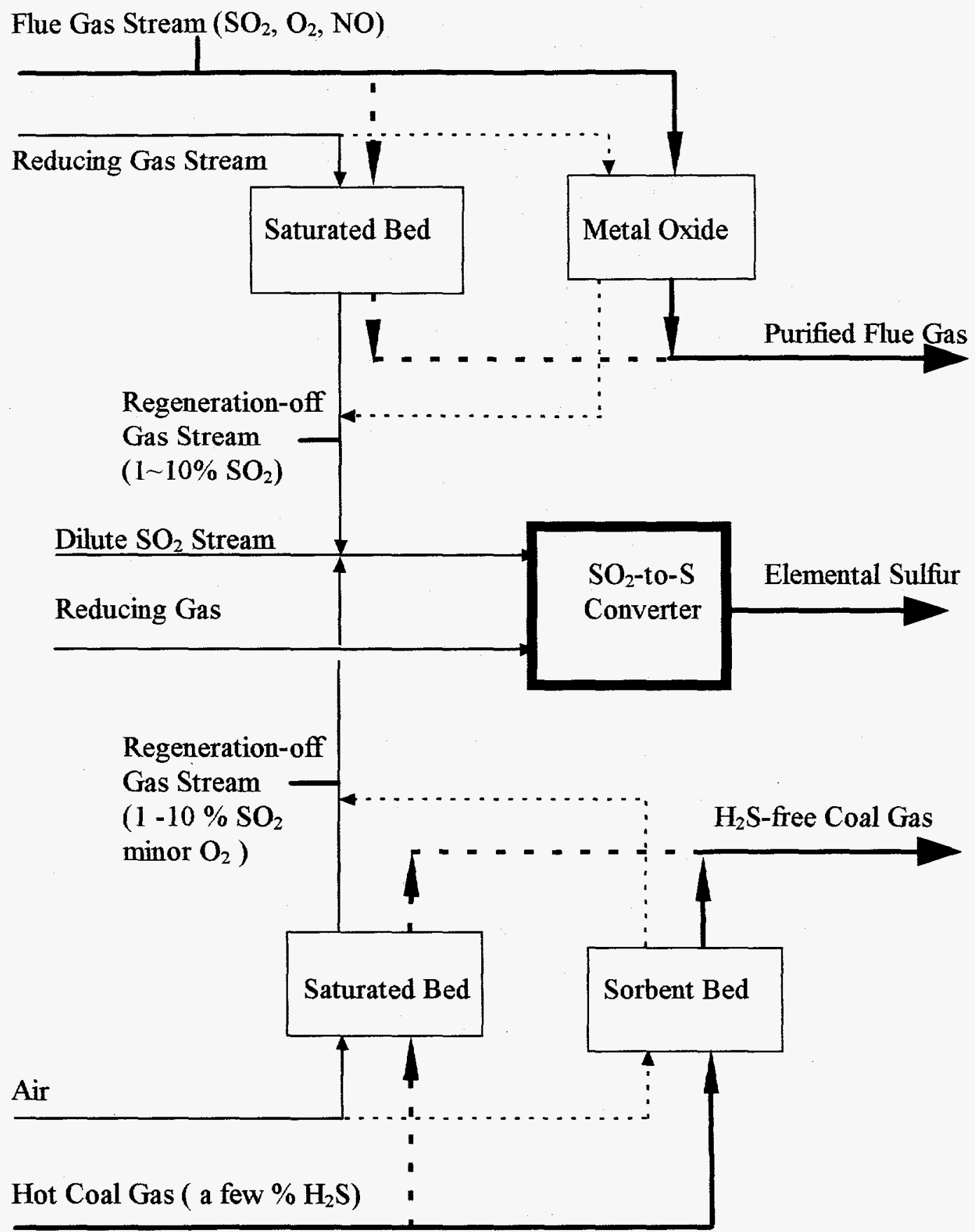

Figure 1.1 Elemental Sulfur Recovery from the Dry Regenerative Flue Gas and Hot Coal Gas Desulfurization Processes. 


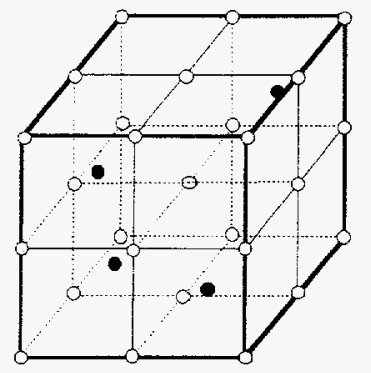

a unit cell

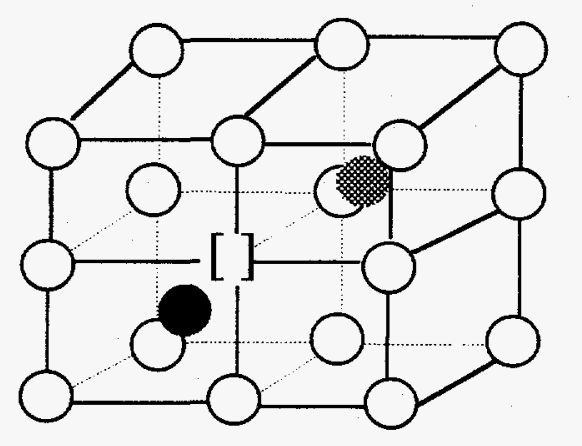

$O=\mathrm{O}^{-2}$

$\mathrm{O}=\mathrm{Ce}^{+4}$

$=\mathrm{D}^{+2}$ or +3

[]$=$ vacancy

a half unit cell

Figure 1.2 Crystal Structure of Fluorite Oxide.

Table 1.1 Solubility of the common alkaline earth and rare earth oxides in three fluorite oxides (solubility in at. \%, the temperature for preparing the solid solution ranged from 1000 to $1800^{\circ} \mathrm{C}$ ).

\begin{tabular}{llll}
\hline Dopant Oxide & $\mathrm{CeO}_{2}$ & $\mathrm{ZrO}_{2}$ & $\mathrm{ThO}_{2}$ \\
\hline $\mathrm{MgO}$ & 2 & $6-21$ & - \\
$\mathrm{CaO}$ & 23 & $14-20$ & 10 \\
$\mathrm{SrO}$ & 9 & - & 4 \\
$\mathrm{Sc}_{2} \mathrm{O}_{3}$ & 5 & $5-46$ & 0.5 \\
$\mathrm{Y}_{2} \mathrm{O}_{3}$ & 100 & 5 & 14 \\
$\mathrm{La}_{2} \mathrm{O}_{3}$ & 44 & $6-32$ & 32 \\
$\mathrm{Sm}_{2} \mathrm{O}_{3}$ & 100 & $10-50$ & 43 \\
$\mathrm{Yb}_{2} \mathrm{O}_{3}$ & 33 & $7-46$ & 5 \\
\hline
\end{tabular}

(data from Kim, D.J., J. Am. Ceram. Soc. 72(8), 1415-21 (1989)). 


\section{Chapter 2}

\section{Experimental}

\subsection{Catalyst Preparation}

\subsubsection{Precursors}

Major chemicals and their sources used in this work are listed in Table 2.1. Low purity cerium nitrate containing about $1.5 \mathrm{wt}$. \% La was used in regular catalyst synthesis. The cerium from this precursor was designated as $\mathrm{Ce}(\mathrm{La})$ in the catalyst formula throughout the report. High purity cerium nitrate $(99.99 \%$, Aldrich) was used to prepare the catalysts containing different dopant ions ( $\mathrm{Sr}, \mathrm{Sc}, \mathrm{La}, \mathrm{Gd})$. Cerium acetate (99.9\%, Aldrich), heated for $4 \mathrm{~h}$ at $750^{\circ} \mathrm{C}$ in air, was used as the primary precursor of La-free cerium oxide.

\subsubsection{Complexation Method with Citric Acid}

Courty and Marcilly (1) reviewed various preparation methods of bulk mixed oxide catalysts. The complexation method is supposed to permit production of an amorphous solid compound of homogeneous composition without phase segregation from the starting solution. This method was used in preparation of perovskite mixed oxide (2) and preparation of $\mathrm{Zn}-\mathrm{Ti}-\mathrm{O}$ binary oxide sorbents (3). In the early stage of this research work, the complexation method was used to prepare cerium oxide catalysts doped with alkaline earth and rare earth elements. The procedure included: (i) Metal nitrates and citric acid of molar ratio one were dissolved in de-ionized water separately; (ii) The citric acid solution was added into the nitrate solution dropwise under constant magnetic stirring at room temperature; (iii) The resulting mixed solution was concentrated into a viscous fluid in a rotary evaporator at $70-80^{\circ} \mathrm{C}$ and the final volume of this fluid was carefully controlled to avoid sticking of the fluid to the glassware; (iv) The fluid was transferred on a glass dish, placed in a vacuum oven where a solid foam was formed during overnight drying at 70 $80^{\circ} \mathrm{C}$ and $15 \mathrm{kPa}$; (v) The solid foam was calcined at $600^{\circ} \mathrm{C}$ in a muffle furnace under flowing air for a few hours; (vi) The resulting solid was crushed and sieved, and particles of 420-840 $\mu \mathrm{m}$ were saved for activity tests.

The catalysts prepared by this procedure are listed in Table 3.1 of the Chapter 3. This method indeed yielded high pore volume and large fraction of macropores $(>1 \mu \mathrm{m}$ in diameter). But, the resulting catalyst was bulky and had a packing density of typically 0.1 $\mathrm{g} / \mathrm{cc}$ so that a large reactor volume was required. Moreover, the preparation procedure was time-consuming, and phase segregation and foaming failure often occurred in the vacuum drying process. Therefore, the coprecipitation method was used in subsequent catalyst preparation. 


\subsubsection{Coprecipitation}

The transition metal-fluorite oxide composite catalysts were mainly synthesized by a conventional coprecipitation method consisting of the following steps: (i) Mixing aqueous salt solutions of the metals; (ii) Precipitating the metal ions with carbonate agent with online $\mathrm{pH}$ monitoring; (iii) Filtering and washing the precipitate twice with de-ionized water at 50 to $70^{\circ} \mathrm{C}$; (iv) Drying the filtered cake overnight in an oven at $100^{\circ} \mathrm{C}$; (v) Crushing the dried lump into smaller particles and heating it in a muffle furnace at 600 to $700^{\circ} \mathrm{C}$ for a few hours. Precipitation in the above procedure was the key step in determining final catalyst composition, texture, and structure. Effects of some important parameters in this step are discussed below with $\mathrm{Cu}-\mathrm{Ce}-\mathrm{O}$ as an example.

(a) Precipitation agent. Both ammonium carbonate and sodium carbonate were used as precipitation agents. The advantage of using ammonium carbonate was that no impurity metal ions were introduced because any residual ammonium carbonate easily decomposed at high calcination temperatures. The disadvantage was the formation of metal-ammonia complex that enhanced solubility of transition metal ions $\left(\mathrm{Ni}^{+2}, \mathrm{Cu}^{+2}\right.$, etc. $)$ and often caused loss of transition metals. In contrast, sodium carbonate could induce the complete precipitation of metal ions, but introduces sodium impurity ions. Residual sodium ions sometimes remained on catalyst surface even after careful washing.

(b) Precipitation process and supersaturating. Different precipitation approaches were evaluated for the $\mathrm{Cu}-\mathrm{Ce}-\mathrm{O}$ system. These included (i) pouring stoichiometric amounts of carbonate solution into mixed metal ions solution or vice versa; (ii) gradually adding carbonate solution into the metal ions solution during vigorous stirring or in $\mathrm{pH}$ increasing; (iii) gradually adding metal ions solution into the carbonate solution or in $\mathrm{pH}$ decreasing. The $\mathrm{pH}$ increasing precipitation was found to be the best procedure. Figure 2.1 shows a typical $\mathrm{pH}$ profile during precipitation. One transition region in the $\mathrm{pH}$ profile was observed with the $\mathrm{Cu}-\mathrm{Ce}-\mathrm{O}$ system, suggesting coprecipitation of $\mathrm{Cu}^{+2}$ and $\mathrm{Ce}^{+3}$ ions. The addition of carbonate solution was typically stopped at $\mathrm{pH} \sim 7$, the equivalent point.

(c) Precipitation temperature. Solubility of metal carbonates in water increases with temperature. But, increasing precipitation temperature usually gave a catalyst of small, uniform crystal sizes and good copper dispersion. Therefore, most precipitations were carried out at 60 to $75^{\circ} \mathrm{C}$.

The coprecipitation was easy to conduct, but very difficult to achieve reproducible results. The underlying fundamental problems are heterogeneity caused by selective precipitation, that is, two metal ions have different precipitation rates, and competitive nucleation and particle aggregation processes. Figure 2.2 shows the pore size distribution of $\mathrm{Cu}_{0.15}[\mathrm{Ce}(\mathrm{La})]_{0.85} \mathrm{O}_{\mathrm{x}}$ catalyst from three different batches. In batch No. 1, coprecipitation was conducted in ascending $\mathrm{pH}$ at $60-70^{\circ} \mathrm{C}$ and the resulting precipitate was immediately washed and dried. An average pore size of $206 \AA$ was achieved. In batch No. 2, carbonate solution was poured into the $\mathrm{Cu}^{+2}+\mathrm{Ce}^{+3}$ solution and the resulting precipitate was left at room temperature for $12 \mathrm{~h}$. A much smaller average pore size, $51 \AA$, was obtained from this procedure. In batch No.3, the catalyst was prepared by following 
exactly the same procedure as for the batch No.1. Yet, the resulting pore structure showed somewhat difference. Little theoretical analysis of particle growth during the aqueous phase precipitation has been reported in the literature. Therefore, the precipitation was carried out mostly based on the empirical rules.

The calcination procedure was the second important step in catalyst preparation. Metal carbonate completely decomposed into metal oxide at current calcination temperatures between 600 to $700^{\circ} \mathrm{C}$. Most catalysts were calcined in air, while some catalysts were calcined in nitrogen. $\mathrm{N}_{2}$ calcination was used to keep copper dispersed in the cerium oxide lattice. Since copper oxide and cerium oxide are immiscible, air calcination will promote the segregation of copper oxide from cerium oxide.

\subsubsection{Catalyst Support and Impregnation}

High surface area of cerium oxide is of general interest in catalysis. Fierro et al., 1985 (4) achieved $50-60 \mathrm{~m}^{2} / \mathrm{g}$ surface area by carefully controlling the thermal decomposition of amorphous $\mathrm{Ce}(\mathrm{OH})_{4}$. But, the surface area of this type of cerium oxide dramatically decreased at high sintering temperatures. Powell et el., 1988 (5) prepared cerium oxide powder by spray drying an aqueous solution of cerium nitrate, citric acid, and nitric acid. A BET surface area of $20 \mathrm{~m}^{2} / \mathrm{g}$ was realized after heating for $4 \mathrm{~h}$ at $800^{\circ} \mathrm{C}$. In this work cerium oxide of reasonable surface area and mesopore size distribution could be made from direct thermal decomposition of commercial cerium acetate (Aldrich). Figure 2.3 shows the pore size distribution of the cerium oxide prepared by 4-h thermal decomposition of cerium acetate at $750^{\circ} \mathrm{C}$, while Table 2.2 lists its physical properties. This kind of cerium oxide was used in this work as bulk cerium oxide catalyst and support for various transition metals.

$\gamma-\mathrm{Al}_{2} \mathrm{O}_{3}$ support was supplied by LaRoche and its specification is given in Table 2.2. The supported catalysts were prepared by the conventional wet impregnation method using aqueous salt solutions of the metals. The slurry of the support and solution was degassed in vacuum so that the salt solution fully filled the pores of the support during impregnation. After excess solution was drained, the sample was dried for a few days at room temperature and then heated in air for $4 \mathrm{~h}$ at $650^{\circ} \mathrm{C}$. The pore size distribution of the resulting 15 at. $\% \mathrm{CuOx} / \mathrm{CeO}_{2}$ catalyst is shown in Figure 2.3 . The impregnated catalyst basically kept the original pore structure and the BET surface area was slightly decreased.

\subsubsection{Nanocrystalline Catalysts}

Cerium oxide is generally considered to be versatile in its oxidation state $\left(\mathrm{Ce}^{+4} \leftrightarrow\right.$ $\mathrm{Ce}^{+3}$ ). The following reaction has appeared extensively in the literature.

$$
\mathrm{CeO}_{2}+\mathrm{CO}\left(\text { or } \mathrm{H}_{2}\right) \rightarrow \mathrm{CeO}_{2-\mathrm{x}}+\mathrm{CO}_{2}\left(\text { or } \mathrm{H}_{2} \mathrm{O}\right)
$$

In fact, bulk reduction of cerium oxide only occurs at 700 to $800^{\circ} \mathrm{C}$ and even surface reduction still requires a temperature around $500^{\circ} \mathrm{C}$ (6). Bulk $\mathrm{CeO}_{2}$ is a very stable compound. In contrast, no air-stable, non-stoichiometric cerium oxide has ever been synthesized, because reduced $\mathrm{CeO}_{2}$ is immediately re-oxidized when exposed to air or 
moisture. The catalytic properties of non-stoichiometric cerium oxide were first studied in this work through collaboration. Tschoepe and Ying 1994 (7) prepared non-stoichiometric cerium oxide powder in an ultrahigh vacuum (UHV) apparatus. In the UHV chamber, a metallic target was sputtered by magnetron, the metal vapor was rapidly thermalized and supersaturated in argon pressure, which led to homogeneous nucleation of nano-sized clusters in the inert gas phase, and the clusters were collected on the substrate cooled by liquid nitrogen. Then, oxygen was introduced into the chamber to oxidize the metallic clusters into oxide powder that was subsequently scraped off. Due to high operation cost and very small yield, only four catalysts were prepared by this method, i.e., pure $\mathrm{CeO}_{2-\mathrm{x}}$, 10 at. $\% \mathrm{La}$-doped $\mathrm{CeO}_{2-\mathrm{x}}, 15$ at. $\% \mathrm{Cu}$-doped $\mathrm{CeO}_{2-\mathrm{x}}$, and pure $\mathrm{CuO}$. Detailed description of the preparation and characterization of this new type of catalyst materials was reported in (7-9). The major finding was that non-stoichiometric cerium oxide prepared by this method is stable at atmospheric conditions and can keep certain non-stoichiometry properties even after air calcination at high temperature as illustrated by Figure 2.4 . Catalytic activities of the non-stoichiometric cerium oxide catalysts will be reported for comparison with the bulk catalyst.

It should be noted that the same $\mathrm{CeO}_{2}$ crystal size as prepared by the above procedure can be achieved by the regular precipitation technique followed by low calcination temperatures. The non-stoichiometry of the nanocrystalline cerium oxide probably resulted from the controlled oxidation of metallic clusters on the liquid nitrogen-cooled substrate rather than its crystal size. The cooling effect prevented metallic clusters from being fully oxidized so that intrinsic non-stoichiometry was generated in a cerium oxide particle.

\subsection{Catalyst Characterization}

\subsubsection{Compositional Analysis}

For bulk composition analysis, the catalyst powder was dissolved in concentrated hydrofluoric acid solution and then, diluted by de-ionized water, the resulting solution was analyzed by the Inductively Coupled Plasma (ICP) atomic emission spectrometry (Perkin Elmer Plasma 40). The catalyst surface composition was analyzed by X-ray Photoelectron Spectroscopy (XPS). Details of the analyses will be discussed below.

\subsubsection{Surface Area, Pore Size, and Metal Dispersion}

$\mathbf{N}_{2}$ Adsorption/Desorption. Total BET surface area was routinely measured by single-point $\mathrm{N}_{2}$ adsorption and desorption on a Micromeritics 2000 instrument. Selected catalysts were analyzed on a Micromeritics ASAP 2000 apparatus for multipoint BET surface area and pore size distribution measurements. The catalyst sample in the singlepoint measurement was pretreated by 30 -minute heating in $30 \% \mathrm{~N}_{2} / \mathrm{He}$ flow at $300^{\circ} \mathrm{C}$ and measurement typically run about ten minutes. In the multipoint measurement the catalyst was degassed in vacuum by heating for about five hours and one sample analysis took about ten hours. However, the single-point desorption gave satisfactory result of total BET surface area for the present catalysts. 
Chemisorption and Metal Dispersion. The specific surface area of supported metal catalysts is usually measured by specific chemisorption. Characterization of aluminasupported precious metal catalysts $(\mathrm{Pt}, \mathrm{Pd}, \mathrm{Rh})$ by chemisorption $\left(\mathrm{H}_{2}\right.$ or $\left.\mathrm{CO}\right)$ is well established. In contrast, specific surface area of the non-precious metals on a mixed oxide catalyst is difficult to measure. In this work, an effort was made to measure the specific copper surface area in the $\mathrm{Cu}-\mathrm{Ce}-\mathrm{O}$ composite catalyst.

Both $\mathrm{H}_{2}$ and $\mathrm{CO}$ adsorption were used in the literature to measure the metallic copper surface area $(10,11)$. Sinfelt et al. (11) found that at room temperature, the adsorption of hydrogen on copper is slow and not completed in times comparable to $1 \mathrm{~h}$. By contrast, adsorption of $\mathrm{CO}$ is fast and essentially complete in about 15 minutes and approaches saturation at pressures below $10 \mathrm{~cm}$. However, some literature even reported no irreversible $\mathrm{H}_{2}$ adsorption on copper at room temperature. The problems with using $\mathrm{CO}$ chemisorption to count surface $\mathrm{Cu}$ atoms are the extensive physical adsorption, especially when a support of high surface area is used, and the unknown $\mathrm{CO} / \mathrm{Cu}$ stoichiometry. $\mathrm{H}_{2}$ adsorption was tried in this work for copper surface area measurement in the $\mathrm{Cu}-\mathrm{Ce}-\mathrm{O}$ catalyst. The $\mathrm{Cu}-\mathrm{Ce}-\mathrm{O}$ catalysts were pre-reduced by $\mathrm{H}_{2}$ at $350^{\circ} \mathrm{C}$ for $2 \mathrm{~h}$. But, the copper surface area calculated from the amount of irreversible adsorbed $\mathrm{H}_{2}$ at room temperature was unreasonably small, which confirms little irreversible adsorption of $\mathbf{H}_{2}$ on copper.

Recent advancements in specific copper surface area measurement have involved the use of $\mathrm{N}_{2} \mathrm{O}$ to form a monolayer of chemisorbed $\mathrm{O}$ atoms on metallic $\mathrm{Cu}$ surface through the following reaction:

$$
\mathrm{Cu}+\mathrm{N}_{2} \mathrm{O} \rightarrow \mathrm{N}_{2}+[\mathrm{Cu}-\mathrm{O}-\mathrm{Cu}]
$$

The decomposition temperature of $\mathrm{N}_{2} \mathrm{O}$ is an important parameter to use this method. Scholten and Konvalinka (12) and Evans et al. (13) recommended $90-100^{\circ} \mathrm{C}$ adsorption temperature. because irreproducible results were obtained at lower temperatures and bulk oxidation was significant above $120^{\circ} \mathrm{C}$. Both single- and multiple-pulse techniques were used to carry out the measurement. The application of a single-pulse of $\mathrm{N}_{2} \mathrm{O}$ in excess of that required to oxidize all the surface copper and a temperature of $90^{\circ} \mathrm{C}$ has been shown to provide a reliable measurement of specific copper surface area. But, promotion of bulk oxidation of copper in catalysts containing oxides of chromium, zinc and aluminum can lead to an overestimate of the surface copper atoms. The frontal chromatography technique was developed by Chinchen et al. (14) to overcome the bulk oxidation problem. An improved method by Bond and Namijo (15) involves reacting $\mathrm{Cu}$ catalysts with pure $\mathrm{N}_{2} \mathrm{O}$ under conditions expected to lead to the formation of a complete layer of $\mathrm{O}$ atoms having an $\mathrm{O} / \mathrm{Cu}$ ratio of 0.5 , but without oxidation of the bulk $\mathrm{Cu}$, and the number of chemisorbed $O$ atoms is then determined by TPR. In this work, a modified TPR experimental procedure was performed on a thermal gravitational analyzer (TGA) to measure copper surface area in the $\mathrm{Cu}-\mathrm{Ce}-\mathrm{O}$ catalyst. The procedure consisted of the following steps:

(i) Holding temperature at $30^{\circ} \mathrm{C}$ in ultra high purity $\mathrm{He}$ overnight 
(ii) Reducing the copper oxide in the $\mathrm{Cu}-\mathrm{Ce}-\mathrm{O}$ catalyst to metallic copper at a heating rate of $5^{\circ} \mathrm{C} / \mathrm{min}$ up to $350^{\circ} \mathrm{C}$ in ultra high purity $5 \% \mathrm{H}_{2} / \mathrm{He}$ and holding the temperature at $350^{\circ} \mathrm{C}$ for $25 \mathrm{~min}$.

(iii) Lowering the temperature in $\mathrm{He}$ to $60^{\circ} \mathrm{C}$

(iv) Passing ultra high purity $\mathrm{N}_{2} \mathrm{O}$ flow through the sample at $60^{\circ} \mathrm{C}$ for $1.5 \mathrm{~h}$

(v) Switching to $\mathrm{He}$ for $0.5 \mathrm{~h}$ and lowering temperature to $30^{\circ} \mathrm{C}$

(vi) Reducing the catalyst at a heating rate of $5^{\circ} \mathrm{C} / \mathrm{min}$ to $350^{\circ} \mathrm{C}$ in ultra high purity $5 \% \mathrm{H}_{2} / \mathrm{He}$ and holding at $350^{\circ} \mathrm{C}$ for $25 \mathrm{~min}$.

The copper surface areas measured by this procedure are listed in Table 2.3. It can be seen that the copper surface areas were comparable to the total BET surface areas. As we will see from the STEM and XPS analyses, only a small fraction of the $\mathrm{Cu}-\mathrm{Ce}-\mathrm{O}$ catalyst area is counted for as copper and $\mathrm{H}_{2}$-reduction does not yield better copper dispersion. The number in Table 2.3 was apparently overestimated. A plausible explanation for such a result is that both cerium oxide surface and copper oxide were reduced during the TPR by $5 \% \mathrm{H}_{2} / \mathrm{He}$, and $\mathrm{N}_{2} \mathrm{O}$ reacted with both metallic $\mathrm{Cu}$ surface and the reduced cerium oxide.

$$
\mathrm{CeO}_{2-\mathrm{x}}+\mathrm{x} \mathrm{N}_{2} \mathrm{O} \rightarrow \mathrm{CeO}_{2}+\mathrm{xN}_{2}
$$

No method was found in this work to allow a reliable measurement of the specific copper surface area in the $\mathrm{Cu}-\mathrm{Ce}-\mathrm{O}$ catalyst. Therefore, copper dispersion, specific surface activity per copper, and turn-over frequency are not reported in this.

\subsubsection{X-ray Powder Diffraction (XRD)}

XRD analysis has been routinely used in this work for crystal phase identification based on diffraction peak position and pattern. In addition, two specific uses of the XRD analyses are measurements of miscibility of two kinds of oxides and crystal particle size. According to Vegard's rule, if metal oxide $B$ is soluble in metal oxide A, the lattice spacing change of the metal oxide A imparted by the metal oxide B is proportional to the concentration of the metal oxide $B$ in the lattice.

$$
\Delta d_{h k l}=\text { const } \cdot C_{B}
$$

Figure 2.5 shows that ceria lattice spacing monotonically declines with nominal copper content in the $\mathrm{Cu}-\mathrm{Ce}(\mathrm{La})-\mathrm{O}$ composite catalyst calcined in $\mathrm{N}_{2}$, which suggests that some copper was dissolved in ceria lattice. However, the lattice spacing was changed after the catalyst was calcined in air at $750^{\circ} \mathrm{C}$ because of the intrinsic insolubility. Crystal particle size can be calculated according to XRD peak broadening $(16,17)$. The accurate calculation needs to correct the internal lattice strain by using two peaks and instrumental broadening. Only simple Sherrer's equation with one XRD peak at 2 theta less than $40^{\circ}$ was used for the particle size calculation in this work. At such low 2 theta values, this estimate usually gives satisfactory results.

$$
d_{p}=\frac{0.9 \lambda}{B \cdot \operatorname{Cos} \theta}
$$


where $d_{p}$ is the diameter of a crystal, $\lambda$ is the wavelength of X-ray, $\theta$ is the X-ray reflection angle, $B$ is the full width of peak at half maximum (FWHM) in radians and estimated by Warren's method:

$$
\mathrm{B}^{2}=\mathrm{B}_{\mathrm{M}}^{2}-\mathrm{B}_{\mathrm{S}}^{2}
$$

where $B_{M}$ is the measured peak width, $B s$ is the instrumental broadening and was around $0.05^{\circ}$ for the system used in this work.

XRD analyses in this work were all performed on a Rigaku $300 \mathrm{X}$-ray Diffractometer with a Rotating Anode Generators, monochromatic detector, and DEC VAX Station II computer for complete control and data recording as well as for data processing. Sample preparation consisted of grinding catalyst powder as fine as possible, well mixing the power with a resin solution, pouring the slurry on a glass square, and drying the sample in an oven. Copper $K \alpha 1$ radiation was used with power setting of $50 \mathrm{kV}$ and $200 \mathrm{~mA}$. For crystal phase survey, typical operation parameters were divergence slit of $1^{\circ}$, scattering slit of $1^{\circ}$, receiving slit of $0.3^{\circ}$, and scan rate of $10^{\circ} / \mathrm{min}$ with $0.02^{\circ}$ data interval. For lattice structural analysis, typical operation parameters were divergence slit of $1^{\circ}$, scattering slit of $1^{\circ}$ receiving slit of $0.15^{\circ}$, and $0.02^{\circ}$ data interval with 2 seconds acquisition time at each point.

\subsubsection{Spectroscopic Studies}

X-ray Photoelectron Spectroscopy (XPS). XPS is among the most frequently used techniques in catalysis (18-20). It yields information on the elemental composition and the oxidation state of elements. All XPS analyses were performed on a Perkin Elmer 5100 system with $2 \mathrm{~mm}$ spatial resolution. This system was configured with an Argon plasma gun for catalyst surface etching and depth profiling, and a dual anode X-ray source $(\mathrm{Mg}$ $\mathrm{K} \alpha \& \mathrm{Al} \mathrm{K} \alpha$ ). However, this apparatus does not include a pre-treatment chamber that allows in-situ thermal treatment of samples and no cooling system inside the XPS vacuum chamber. All measurements were carried out at room temperature and without any sample pretreatment. A Mg K $\alpha \mathrm{X}$-ray source was primarily used in this work and the incident photo energy, $\mathrm{h} v$, is $1253.6 \mathrm{eV}$. The $\mathrm{X}$-ray generator power was typically set at $15 \mathrm{kV}$ and $20 \mathrm{~mA}$. Sample preparation consisted of attaching a small piece of adhesive tape on a square of tantalum foil and pressing catalyst powder on the tape. Since the materials studied in this work do not have good electronic conductivity, the electrostatic charging was pronounced so that an energy shift from 4 to $6 \mathrm{eV}$ was observed. Fortunately, $\mathrm{C} 1 \mathrm{~s}$ peak was found in all measurements resulting from hydrocarbon moiety in the sample, and was used as an internal standard. Therefore, all binding energies were adjusted relative to $\mathrm{C} 1 \mathrm{~s}$ at $284.6 \mathrm{eV}$.

An approximate and general expression for calculation of the atomic fraction of any constituent in a sample is given by equation 12 :

$$
C_{X}=\frac{I_{x} / S_{x}}{\sum_{i} I_{i} / S_{i}}
$$


where $\mathrm{Cx}$ is the atomic fraction of constituent, $\mathrm{x}$; $\mathrm{I}$ is the peak area of a specific peak; $S_{x}$ is the atomic sensitivity factor that is usually given in the instrument manual. The above equation is accurate when the sample is homogeneous and the sensitivity factor matrix, $\left\{\mathrm{S}_{\mathrm{i}}\right\}$, is independent for all materials. For a porous catalyst sample, interference from catalyst pores should be kept in mind. Application of equation 12 to the measurement of dispersion of supported particles should be cautious, because XPS has a 2-mm spatial resolution that a physical mixture of small particles $(<<2 \mathrm{~mm}$, without any dispersion) can yield high atomic fraction. However, the surface composition given by XPS is a valuable number in comparison of catalysts of similar structure.

Electron Microscopy. Scanning electron microscopy (SEM) was performed on a Cambridge Stereoscan 240 MK.3 instrument. Catalyst morphology and composition can be easily obtained by SEM. Figure 2.6 shows two typical SEM micrographs. The top picture is for the $\mathrm{Ce}(\mathrm{La}) \mathrm{O}_{2}$ catalyst prepared by complexation, while the bottom is for the $\mathrm{Cu}_{0.5}[\mathrm{Ce}(\mathrm{La})]_{0.5} \mathrm{O}_{\mathrm{x}}$ catalyst prepared by precipitation. Numerous macropores were observed with the complexation-made catalyst. The precipitated catalyst looked more dense and homogeneous. However, low magnification of SEM micrographs gave very limited information of catalyst microstructure (in tens of nm scale). Energy dispersive Xray (EDX) analysis of SEM can give an accurate atomic composition as low as a few percent and the measured value was consistent with the ICP-AE analysis. But, the smallest dimension analyzed by the SEM/EDX was about $1 \mu \mathrm{m}$. At such scale, most of catalysts appeared homogeneous. In summary, SEM/EDX analyses did not yield really useful information for the present catalyst system.

High resolution transmission electron microscopy (HRTEM) analyses were performed on Akashi EM002B system of the proved point-to-point resolution of $0.18 \mathrm{~nm}$. HRTEM is commonly used for studying supported catalysts, especially, precious metal catalysts. Figure 2.7 shows a HRTEM micrograph of the 15 at. $\% \mathrm{CuOx} / \mathrm{CeO}_{2}$ catalyst. $\mathrm{CuO}$ particles cannot be distinguished from $\mathrm{CeO}_{2}$ particles in the HRTEM picture, because cerium is much heavier than copper. This drawback rendered the HRTEM analysis not suitable for microstructure study of the present $\mathrm{Cu}-\mathrm{Ce}-\mathrm{O}$ catalyst.

Scanning transmission electron microscopy (STEM) combines high magnification and microanalysis capability. It tumed out to be an effective tool for the present catalyst characterization and was extensively used in this work. A few STEM analyses were performed on a Vacuum Generators HB-5 system. Most of the analyses were performed on a state-of-the-art Vacuum Generators HB603 system that operates at $300 \mathrm{kV}$ and has a $\mathrm{X}$-ray microprobe of $0.14 \mathrm{~nm}$ optimum resolution. The STEM microprobe can be located at different positions of a small particle $(\mathrm{ca} .10 \mathrm{~nm}$ ) for elemental analysis and can also be used to simultaneously map several elements of a given region. Elemental mapping was carried out on a $128 \times 128$ and $256 \times 256$ data matrix. Higher data density gives better compositional resolution but requires longer acquisition time. Although optimum resolution of the microprobe is $0.14 \mathrm{~nm}$, the highest magnification achieved in the present STEM analyses was $1 \times 10^{6}$. Image drifting with on-stream measurement time became severe at high magnification, which affected accurate elemental mapping. In addition, sample contamination and thickness also hindered microanalysis at atomic level. 
Two methods, dusting and microtoming, were used for STEM sample preparation. The microtoming procedure is outlined as follows: very small amounts of catalyst powder as fine as possible was embedded in a resin matrix; the resin was ultramicrotomed to slices of 80 to $120 \mathrm{~nm}$; the slices were supported on a nickel grid and coated with carbon. Detailed procedure was described by $\mathrm{Zhao}$ in the STEM analyses of the $\mathrm{Mo}-\mathrm{Co}-\mathrm{Ni} / \mathrm{Al}_{2} \mathrm{O}_{3}$ catalysts (21). This procedure was time-consuming. Later, it was found that simply dusting catalyst powder on a nickel grid coated by a carbon film can give satisfactory results. It is noted that the sample preparation for HRTEM analysis was the same as for the STEM except for the use of a copper grid instead of the nickel grid.

\subsection{Apparatus and Procedure}

The schematic of reaction apparatus is shown in Figure 2.8. All catalysts were tested in a laboratory-scale, quartz tube packed bed reactor with a porous quartz frit placed at the middle for supporting the catalyst. The $0.6 \mathrm{~cm}$ I.D $\times 50 \mathrm{~cm}$ long reactor was used in regular catalyst test, while a $1.0 \mathrm{~cm}$ I.D. reactor was used for high volume of catalyst loading. The reactor tube was heated by a Lindberg furnace. The reaction temperature was monitored by a quartz tube-sheathed K-type thermocouple placed at the top of the packed bed and controlled by a Wizard temperature controller. The reacting gases, all certified calibration gas mixtures with helium(Matheson), were measured with rotameters or mass flow controllers mixed prior to the reactor inlet. The resulting gas mixture flowed downward through the packed bed. Water vapor was introduced with helium bubbling through a heated water bath. The pressure drop of gas flowing through the assembly was small. Thus, experiments were carried out at nearly atmospheric pressure. Elemental sulfur produced by $\mathrm{SO}_{2}$ and $\mathrm{CO}$ reaction was condensed out in a cold trap installed at the outlet of the reactor. A filter was installed at the entrance of GC gas sample loop to remove particulate. Product gas was analyzed by a HP5880A Gas Chromatograph (GC) with a Thermal Conductivity Detector (TCD). A typical $0.5 \mathrm{ml}$ gas was injected into GC column by an automatic sampling valve. Helium was used as the GC carrier and reference gas, each at $30 \mathrm{cc} / \mathrm{min}$.

A 1/4" O.D. x 6' long packed column of Chromosil 310(from SUPELCO) operated at $60^{\circ} \mathrm{C}$ provided base-base separation of $\mathrm{CO}, \mathrm{CO}_{2}, \mathrm{COS}, \mathrm{H}_{2} \mathrm{~S}, \mathrm{CS}_{2}$, and $\mathrm{SO}_{2}$. This column was primarily used in reaction of $\mathrm{SO}_{2}$ and $\mathrm{CO} . \mathrm{CO}_{2}$ concentration was analyzed by this column in oxidation of $\mathrm{CO}$ and methane by air. But, two additional SS(stainless steel) columns, $10 \mathrm{ft} \times 1 / 8$ " packed by $80 / 100$ carbosphere and $5 \mathrm{ft} \times 1 / 8$ " packed by $80 / 100$ Hayesep T, both from ALTECH, were occasionally used to check carbon balance in oxidation of $\mathrm{CO}$ and methane. The Carbosphere column at a temperature program from $30^{\circ} \mathrm{C}$ to $225^{\circ} \mathrm{C}$ at $25^{\circ} \mathrm{C} / \mathrm{min}$ separated $\mathrm{N}_{2}, \mathrm{CO}, \mathrm{CH}_{4}, \mathrm{CO}_{2}, \mathrm{C}_{2} \mathrm{H}_{4}, \mathrm{C}_{2} \mathrm{H}_{4}, \mathrm{C}_{2} \mathrm{H}_{6}$. The Hayesep $\mathrm{T}$ column at constant temperature $32^{\circ} \mathrm{C}$ separated air, $\mathrm{CH}_{4}, \mathrm{CO}_{2}, \mathrm{C}_{2} \mathrm{H}_{2}, \mathrm{C}_{2} \mathrm{H}_{4}, \mathrm{C}_{2} \mathrm{H}_{6}$. No $\mathrm{C}_{2}$ and $\mathrm{CO}$ species were detected in methane oxidation and no hydrocarbon compounds were found in $\mathrm{CO}$ oxidation in the presence of water vapor. Thus, carbon balance was easily achieved in oxidation of $\mathrm{CO}$ and $\mathrm{CH}_{4}$. Because Carbosphere and Hayesep $\mathrm{T}$ columns required long analysis time, regular gas analysis was performed with the 
Chromosil 310 column. The TCD showed linear response to all the compounds mentioned above and a detection limit of less than $100 \mathrm{ppm}$ by volume.

\subsection{Literature Cited}

1. Courty, P., and Marcilly, C., "A Scientific Approach to the Preparation of Bulk Mixed Oxide Catalysts" In Preparation of Catalysts III; Poncelet, G.; Grange, P.; Jacobs, P.A.; Ed.; Elsevier Science Publishers: Amsterdam, The Netherlands, pp485$519,1983$.

2. Baythoun, M.S.G., and Sale, F.R J. of Mater. Sci. 17, 2757-2769 (1982).

3. Lew, S., Ph.D. Thesis, Massachusetts Institute of Technology, 1991.

4. Fierro, J.L.G., Mendioroz, S., and Olivan, A.M. J. of Colloid and Interface Science 107(1), 60-69 (1985).

5. Powell, B. R., Bloink, R. L., and Eickel, C. C., "Preparation of Cerium Oxide Powders for Catalyst Supports", J. Am. Ceram. Soc. 71(2), C-104-C-106 (1988).

6. Yao, H.C., and Yu Yao, Y.F., J. Catal. 86, 254 (1984).

7. Tschöpe, A. and Ying, J.Y, J. Nanostr. Mater. 4[5], 617 (1994).

8. Tschope, A., Ying, J.Y., Amonlirdviman, K, and Trudeau, M.L., in Mater. Res. Soc. Symp. Proc., "Molecularly Designed Ultrafine/Nanostructured Materials", Materials Research Society, Pittsburgh, PA, in press.

9. Trudeau, M.L., Tschope, A., and Ying, J.Y., Surf. Interf. Anal., in press (1995).

10. Emmett, P.H., and Skau, N., J. Amer. Chem. Soc. 65, 1029 (1943).

11. Sinfelt, J.H., Taylor, W.F., and Yates, D.J.C., J. Phys. Chem. 69, 95 (1965).

12. Scholten, J.J.F., and Konvalinka, J.A., Trans. Faraday Soc. 65, 2465 (1965).

13. Evans, J.W., Wainwright, M.S., Bridgwater, A.J., and Young, D.J., Appl. Catal. 7, 75 (1983).

14. Chinchen, G.C., Waugh, K.C., and Whan, D.A., Appl. Catal. 25, 101 (1986).

15. Bond, G.C., and Namijo, S.N., J. Catal. 118, 507-510 (1989).

16. Cullity, B.D., Elements of X-ray Diffraction, Addison-Wesley Pub. Co., Reading, Massachusetts, 1978.

17. Matyl, R.J., Schwartz, L.H., and Butt, J.B., "Particle Size, Particle Size Distribution, and Related Measurements of Supported Metal Catalysts", Catal. Rev. - Sci. Eng., 29(1), 41-99 (1987).

18. Niemantsverdriet, J.W., Spectroscopy in Catalysis-An Introduction, VCH, 1993

19. Briggs, D., and Seah, M.P., (Eds.), Practical Surface Analysis by Auger and X-ray Photoelectron Spectroscopy, Wiley, New York, 1983.

20. Wagner, C.D., Riggs, W.M., Davis, L.E., Moulder, J.F., and Muilenburg, G.E., Handbook of X-ray Photoelectron Spectroscopy, Perkin Elmer, Eden Prairie, Minnesota, 1979.

21. Zhao, X., Sc.D. Thesis, Massachusetts Institute of Technology, 1992. 
Table 2.1 Materials Inventory for Catalyst Preparation.

\begin{tabular}{lll}
\hline Elements & Precursors & Sources \\
\hline $\mathrm{Au}$ & chloroauric acid $\left(\mathrm{HAuCl}_{4}\right)$ & Aldrich \\
$\mathrm{Ce}$ & cerium nitrate hexahydrate $(99 \%)$, containing ca. & Aldrich \\
$\mathrm{Ce}$ & cerium acetate hydrate, $99.9 \%$ & \\
$\mathrm{Ce}$ & cerium nitrate hexahydrate, $99.99 \%$ & Aldrich \\
$\mathrm{CO}_{3}{ }^{-2}$ & sodium carbonate, A.C.S. grade & Aldrich \\
$\mathrm{CO}_{3}{ }^{-2}$ & ammonium carbonate, A.C.S. grade & Fisher Scientific \\
$\mathrm{Cr}$ & chromium(III) nitrate, $98.5 \%$ & Fisher Scientific \\
$\mathrm{Co}$ & cobalt(II) nitrate hydrate, $99.99 \%$ & Johnson Matthey \\
$\mathrm{Cu}$ & copper(II) nitrate, A.C.S. grade & Aldrich \\
$\mathrm{Gd}$ & gadolinium nitrate, $99.9 \%$ & Johnson Matthey \\
$\mathrm{Mn}$ & manganese(II) nitrate tetrahydrate, $98 \%$ & Johnson Matthey \\
$\mathrm{Ni}$ & nickel nitrate, A.C.S. grade & Fluka \\
$\mathrm{Pt}$ & hydrogen hexachloroplatinate(IV) hydrate, & Fisher Scientific \\
$\mathrm{Tb}$ & A.C.S. grade & Aldrich \\
$\mathrm{Y}$ & terbium(III) nitrate pentahydrate, 99.9\% & Aldrich \\
$\mathrm{Zr}$ & yttrium nitrate pentahydrate, $99.9 \%$ & Aldrich \\
\hline & zirconium dichloride oxide hydrate, $99.9 \%$ & Johnson Matthey \\
& & \\
\hline
\end{tabular}


Table 2.2 Properties of Catalyst Supports.

\begin{tabular}{lll}
\hline Items & $\gamma-\mathrm{Al}_{2} \mathrm{O}_{3}$ & $\mathrm{CeO}_{2}$ \\
\hline source & LaRoche & cerium acetate \\
\hline Properties: & & \\
particle size, $\mu \mathrm{m}$ & 72 & 100 \\
surface area, $\mathrm{m}^{2} / \mathrm{g}$ & 300 & 24 \\
pore volume, $\mathrm{cc} / \mathrm{g}$ & $\mathrm{ca} .1 .0$ & $\mathrm{ca} .0 .5$ \\
packing density, g/cc & 0.6 & 1.0 \\
\hline
\end{tabular}

Table 2.3 Results of $\mathrm{N}_{2} \mathrm{O}$ Adsorption Measurement for Specific Copper Area.

\begin{tabular}{lllll}
\hline samples & $\begin{array}{l}\text { initial sample } \\
\text { weight } \\
(\mathrm{mg})\end{array}$ & $\begin{array}{l}\text { BET } \\
\text { surface } \\
\text { area } \\
\left(\mathrm{m}^{2} / \mathrm{g}\right)\end{array}$ & $\begin{array}{l}\text { adsorbed } \\
\text { oxygen } \\
\text { mmole }\end{array}$ & $\begin{array}{l}\text { copper } \\
\text { surface area } \\
\left(\mathrm{m}^{2} / \mathrm{g}\right)^{*}\end{array}$ \\
\hline 15 at. $\% \mathrm{CuO}+\mathrm{CeO}_{2}$ & 26.9 & 18 & $5.6 \times 10^{-3}$ & 17 \\
15 at. $\% \mathrm{CuOx} / \mathrm{CeO}_{2}$ & 31.1 & 21 & $4.4 \times 10^{-3}$ & 12 \\
$\mathrm{Cu} .15[\mathrm{Ce}(\mathrm{La})]_{0.85} \mathrm{O}_{8}$ & 19.3 & 45 & $1.0 \times 10^{-2}$ & 42 \\
14 at. $\% \mathrm{CuO} / \mathrm{Al}_{2} \mathrm{O}_{3}$ & 17.4 & 137 & $1.1 \times 10^{-2}$ & 51 \\
\hline
\end{tabular}

*assuming $\mathrm{Cu} / \mathrm{O}_{\mathrm{ad}}=2 / 1$ and copper surface area of $1.47 \times 10^{19} \mathrm{atoms} / \mathrm{m}^{2}$ or $6.8 \times 10^{-20}$ $\mathrm{m}^{2} / \mathrm{atom}$. 


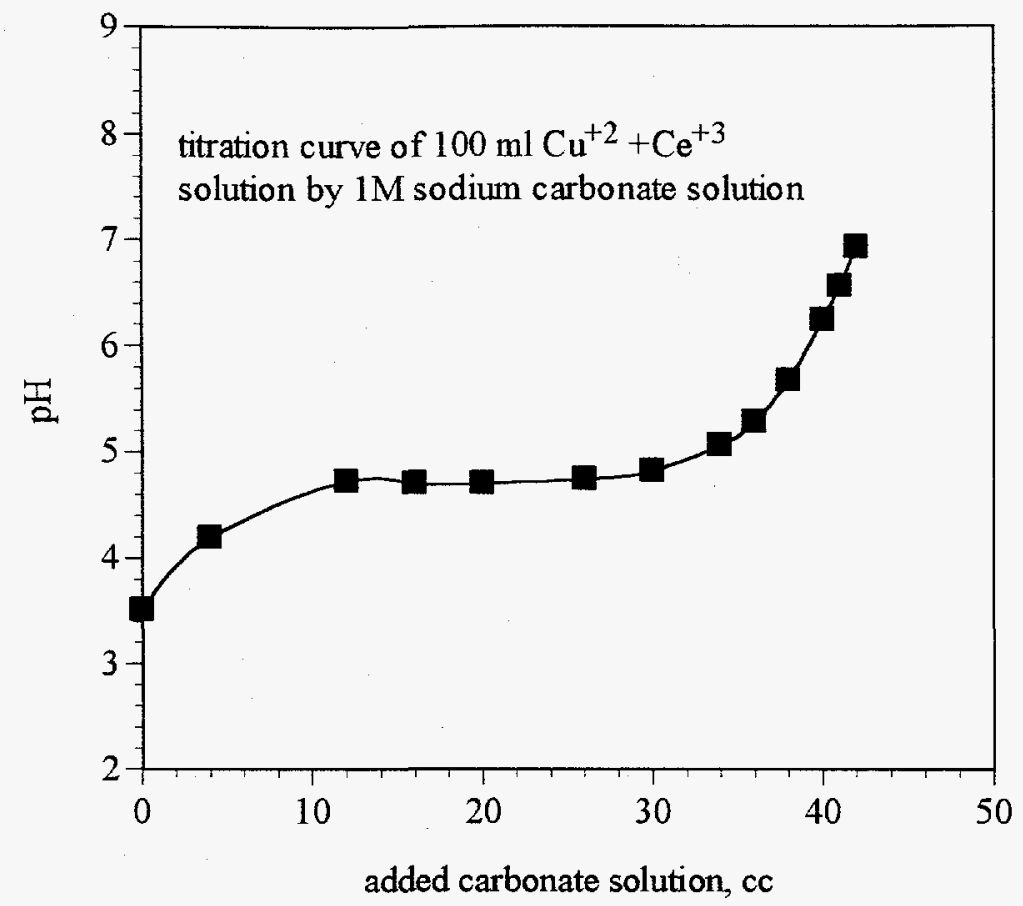

Figure 2.1 A Typical pH Profile During Titration of $\mathrm{Cu}^{+2}+\mathrm{Ce}^{+3}$ Solution by Carbonate Solution.

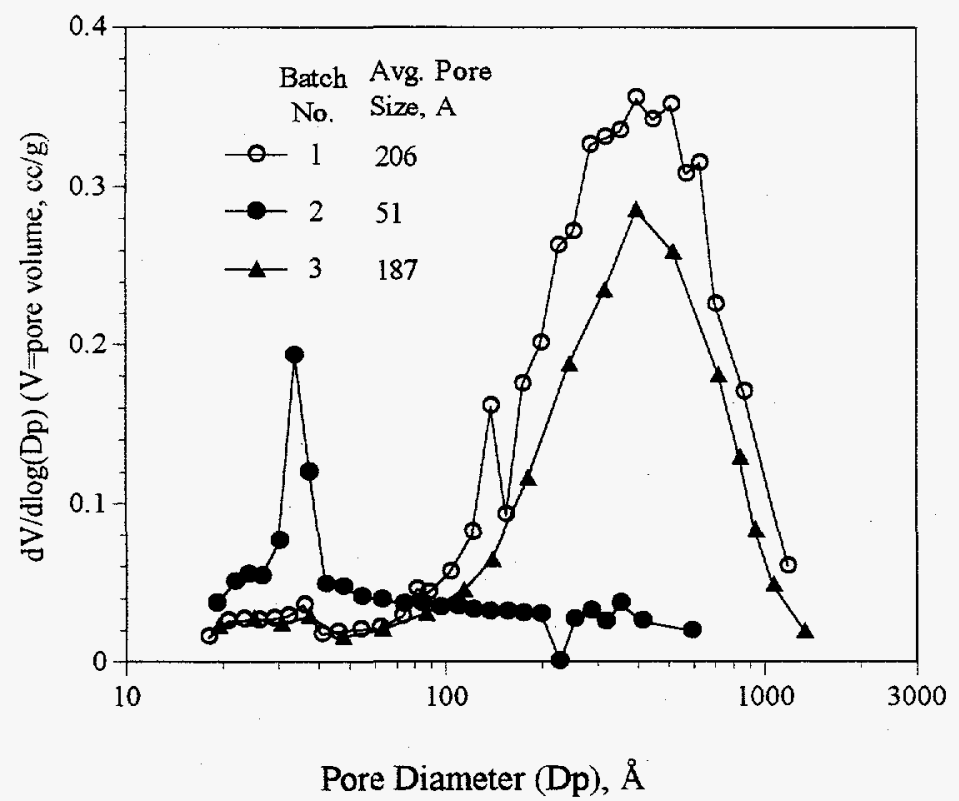

Figure 2.2 $\mathrm{dV} / \mathrm{d} \log \left(\mathrm{D}_{\mathrm{p}}\right)$ Desorption Pore Volume Plots for $\mathrm{Cu}_{0.15}[\mathrm{Ce}(\mathrm{La})]_{0.85} \mathrm{O}_{\mathrm{x}}$ Catalysts. 


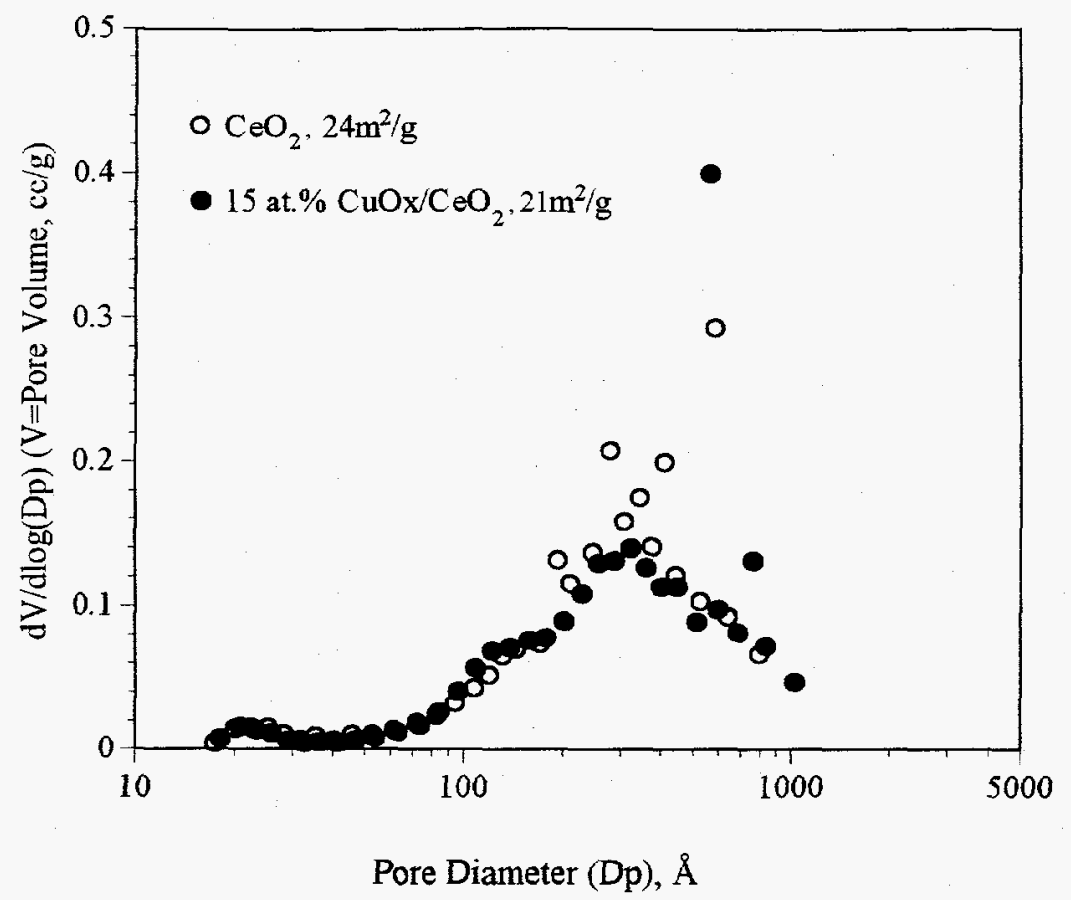

Figure 2.3 dV/dlog $\left(D_{p}\right)$ Desorption Pore Volume Plots For $\mathrm{CeO}_{2}$ Support and 15 at.\% $\mathrm{CuOx} / \mathrm{CeO}_{2}$.

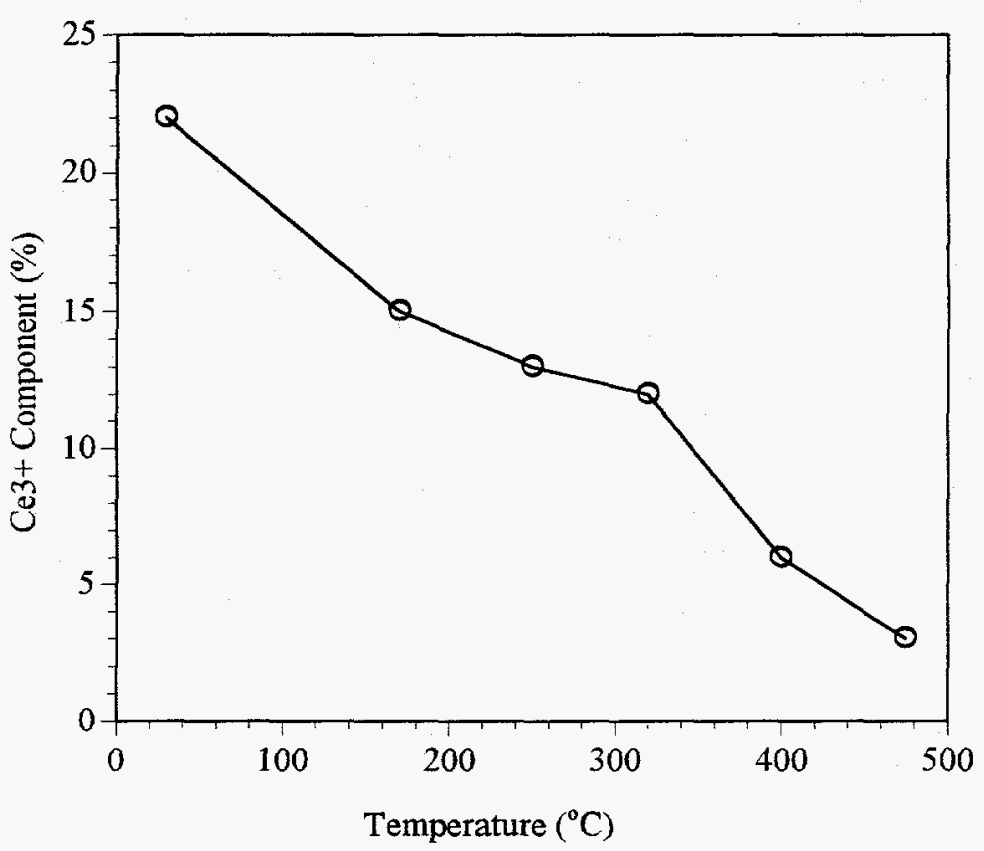

Figure 2.4 Percentage of $\mathrm{Ce}^{3+}$-Component in $\mathrm{CeO}_{2-x}$ Determined by Deconvolution of The Ce-3d Core Level XPS Spectrum after Annealing in $1 \mathrm{Kpa} \mathrm{Of} 1 \% \mathrm{CO}_{2} / \mathrm{He}$ at the Temperatures Indicated (8). 


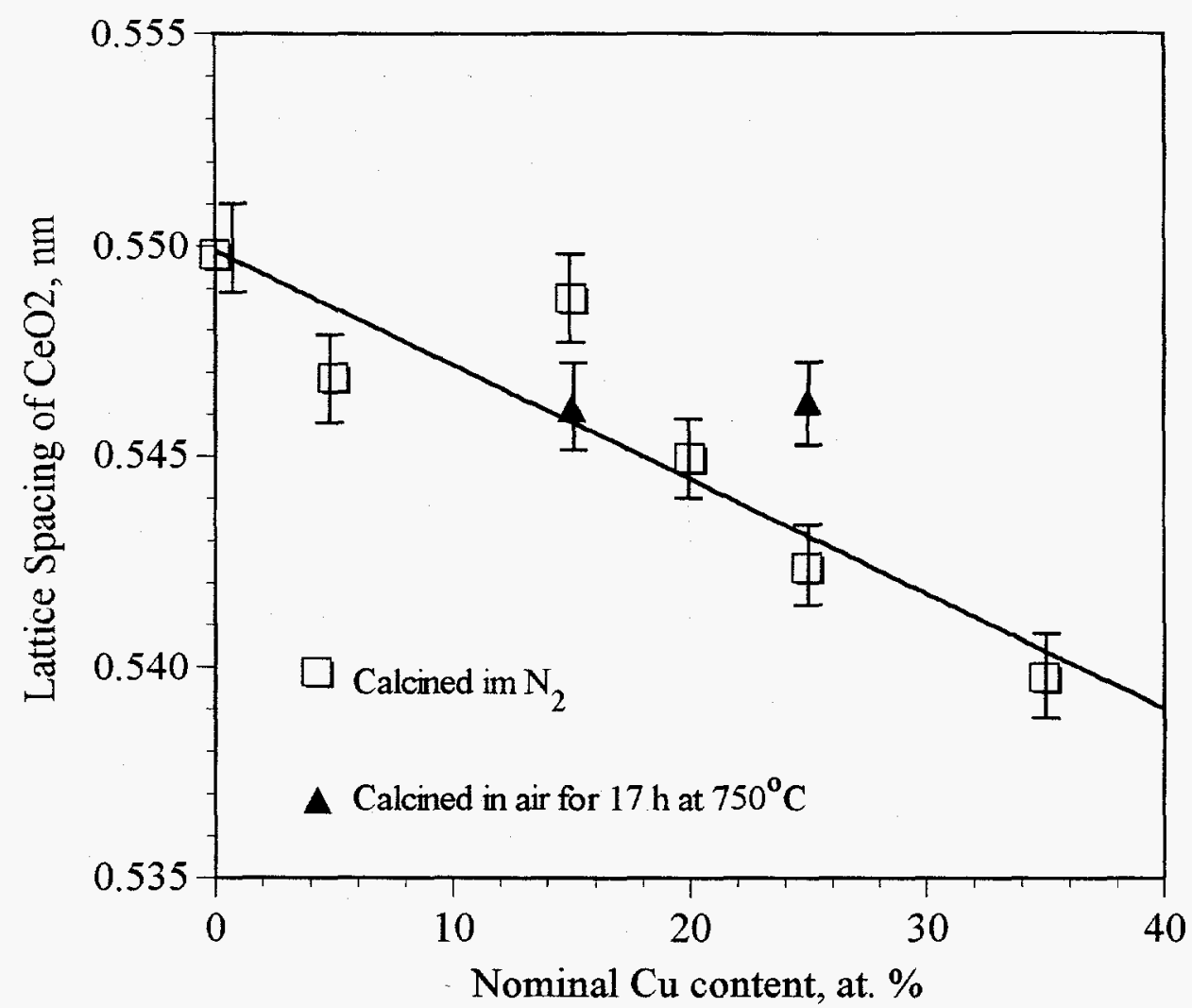

Figure 2.5 Lattice Spacing of Ceria in $\mathrm{Cu}-\mathrm{Ce}(\mathrm{La})-\mathrm{O}$ Composite Catalysts Prepared by Coprecipitation and Calcined in $\mathrm{N}_{2}$ at $600^{\circ} \mathrm{C}$. 

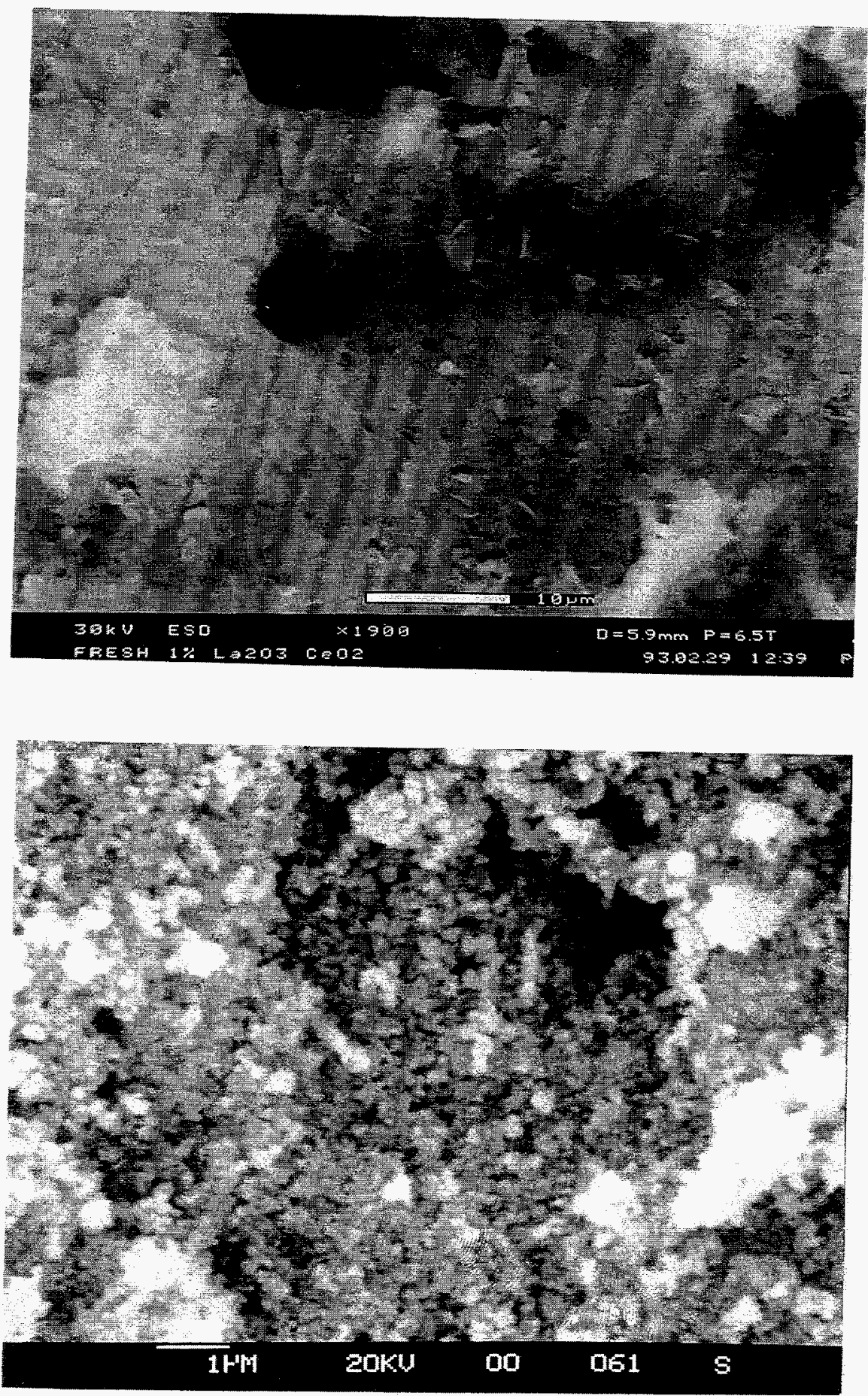

Figure 2.6 SEM Micrographs. Top: $\mathrm{Ce}(\mathrm{La}) \mathrm{O}_{2}$ prepared by complexation; Bottom: $\mathrm{Cu}_{0.5}[\mathrm{Ce}(\mathrm{La})]_{0.5} \mathrm{O}_{\mathrm{x}}$ prepared by coprecipitation. 



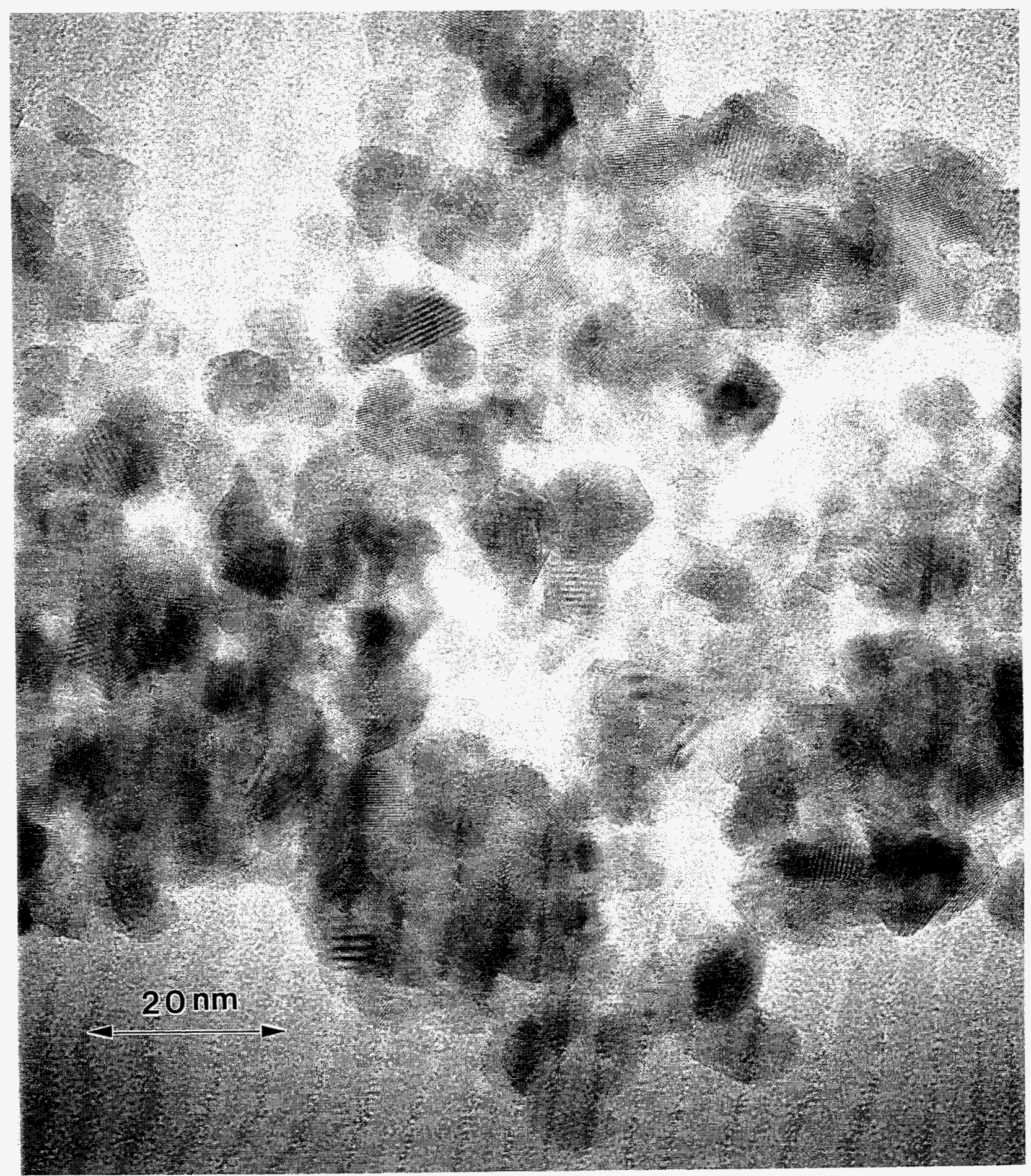

Figure 2.7 TEM Micrograph of 15 at. $\% \mathrm{CuOx} / \mathrm{CeO}_{2}$ Catalyst. 



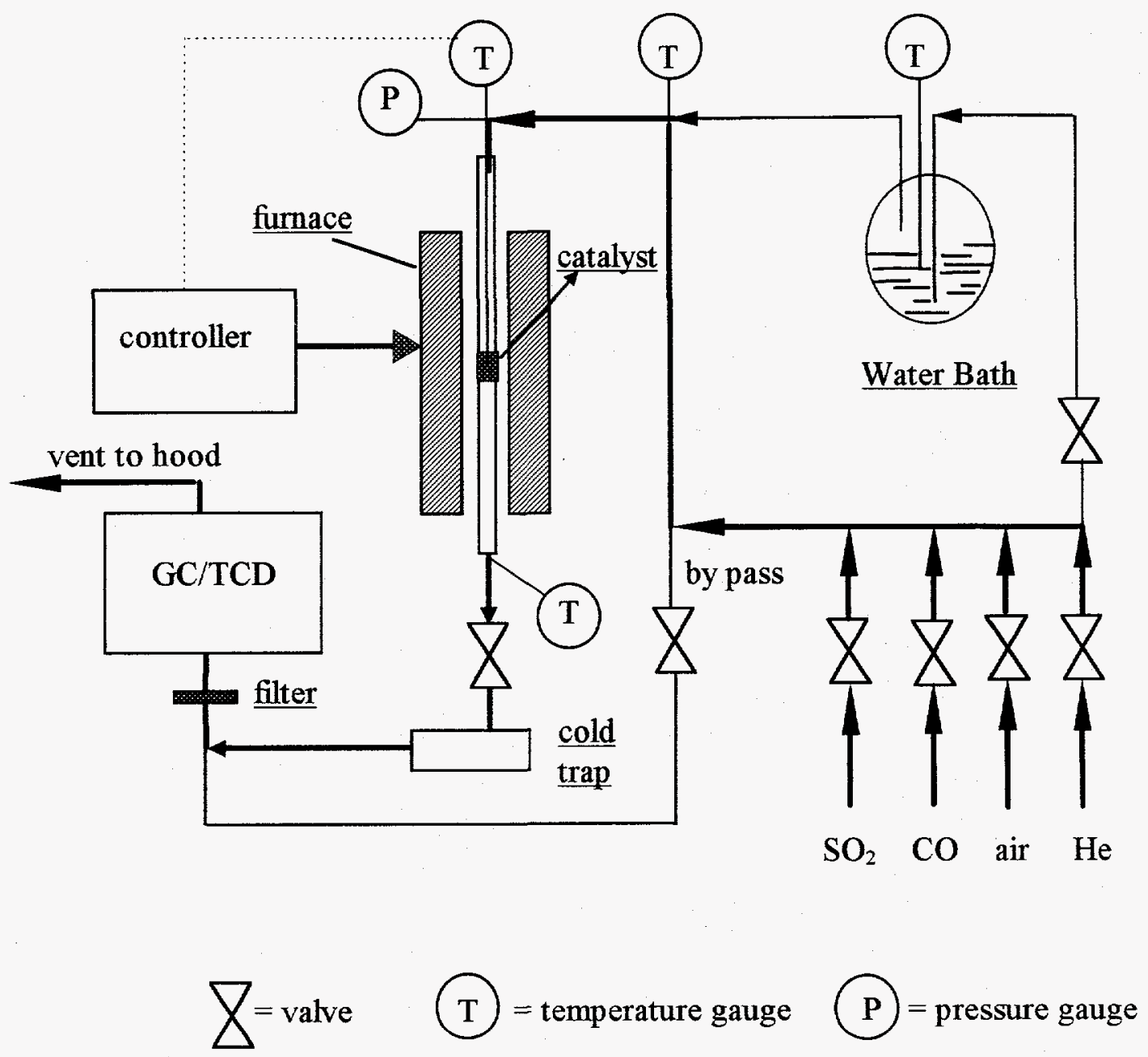

Figure 2.8 Schematic of Reactor Apparatus. 


\section{Chapter 3}

\section{Reduction of $\mathrm{SO}_{2}$ by $\mathrm{CO}$ to Elemental Sulfur over Ceria Catalysts}

\subsection{Introduction}

The direct reduction of $\mathrm{SO}_{2}$ by $\mathrm{CO}$ to elemental sulfur is thermodynamically favorable but it proceeds very slowly in the absence of a catalyst. A secondary undesirable reaction can occur between $\mathrm{CO}$ and elemental sulfur forming $\mathrm{COS}$, which may also reduce $\mathrm{SO}_{2}$ to elemental sulfur through reaction 3 . $\mathrm{COS}$ is more toxic than $\mathrm{SO}_{2}$ and its production should be minimized in a sulfur recovery process.

$$
\begin{aligned}
& \mathrm{SO}_{2}+2 \mathrm{CO} \rightarrow 2 \mathrm{CO}_{2}+1 / \mathrm{xS}_{\mathrm{X}} \\
& \mathrm{CO}+1 / \mathrm{x} \mathrm{S} \rightarrow \mathrm{COS} \\
& 2 \mathrm{COS}+\mathrm{SO}_{2} \rightarrow 2 \mathrm{CO}_{2}+3 / \mathrm{x} \mathrm{S}_{\mathbf{X}}
\end{aligned}
$$

The redox reaction mechanism has been proposed for the $\mathrm{SO}_{2}$ reduction by $\mathrm{CO}(1-3)$. According to this mechanism, the reductant removes oxygen from the catalyst surface while the oxidant gives up its oxygen to the catalyst, so that the catalyst surface is constantly reduced/oxidized during the course of the reaction. Bulk cerium oxide has been identified as an active catalyst for the $\mathrm{SO}_{2}$ reduction in our previous work (4). It is well known that $\mathrm{CeO}_{2}$ has high oxygen vacancy concentration, and these properties can be further enhanced by doping other metal ions into its fluorite-type crystal lattice. The present studies attempt to test if the catalytic activity of $\mathrm{CeO}_{2}$ can be improved by incorporating dopant ions into its lattice, and to explore other $\mathrm{CeO}_{2}$-containing catalysts.

\subsection{Experimental}

All bulk catalysts tested here were prepared by the well-known amorphous citrate method and are listed in Table 3.1. This method provides well dispersed mixed oxides or mixed oxide compounds. The resulting catalyst has large fraction of macropores $(>1 \mathrm{~mm}$ in diameter) which facilitates pore diffusion. The detailed preparation procedure was gave in Chapter 2. Particles between 20 to 35 mesh $(420-840 \mu \mathrm{m})$ were typically used in the tests. All activity tests were carried out in a laboratory-scale, packed bed flow reactor, which consists of a $1.0 \mathrm{~cm}$ I.D. $x 50 \mathrm{~cm}$ long quartz tube with a porous quartz frit placed at the middle for supporting the catalyst. The detailed description of the reactor apparatus was presented in Chapter 2 . The fresh and used catalysts were typically activated by heating 
for one hour in $10 \% \mathrm{CO} / \mathrm{He}$ at $600^{\circ} \mathrm{C}$. After activation, the reacting gases were introduced and the reaction temperature was raised to about $650^{\circ} \mathrm{C}$. When a steady-state reaction was reached, the temperature was lowered in steps of about $50^{\circ} \mathrm{C}$ until the reaction was quenched. In catalysts evaluation test, the inlet gases of $1 \% \mathrm{SO}_{2}$ and $2 \% \mathrm{CO}$ were used, while the total flow rate was kept at $200 \mathrm{sccm}$. The packed height of catalyst bed was around $7 \mathrm{~mm}$ and the contact time was 0.01 to $0.05 \mathrm{~g} \cdot \mathrm{s} / \mathrm{cc}(\mathrm{STP})$. The elemental sulfur yield, i.e., the fraction of inlet $\mathrm{SO}_{2}$ converted into elemental sulfur, was derived from the material balance of carbon and sulfur, and occasionally checked by titration of the sulfur collected in the cold trap.

\subsection{Results and Discussion}

\subsection{1 $\mathrm{CeO}_{2}$ Catalyst}

Figure 3.1 shows the experimental results of $\mathrm{SO}_{2}$ reduction by $\mathrm{CO}$ on the bulk $\mathrm{CeO}_{2}$ catalyst prepared in this work (Table 3.1). When a feed gas of lower $\mathrm{CO}$ content than the stoichiometric was used, any $\mathrm{SO}_{2}$ reacted was converted into elemental sulfur. When the $\mathrm{CO}$ content exceeded the stoichiometric amount, $100 \% \mathrm{SO}_{2}$ conversion was achieved at lower reaction temperature, but $\mathrm{COS}$ became a major product. For example, when the $\mathrm{CO}$ to $\mathrm{SO}_{2}$ ratio was 3 , the $\mathrm{SO}_{2}$ conversion was $100 \%$ with $36-62 \%$ yield of elemental sulfur over the temperature range of 530 to $700^{\circ} \mathrm{C}$ and corresponding $64-38 \%$ of COS yield. The elemental sulfur yield increased with the reaction temperature.

In the following discussion and figures, only the elemental sulfur yield will be presented. Because a feed gas of nearly stoichiometric composition was used and the COS formation was always negligible in these studies, the elemental sulfur yield corresponds with the $\mathrm{SO}_{2}$ conversion.

\subsubsection{Doped $\mathrm{CeO}_{2}$ Catalysts}

It is well known that the oxygen vacancy concentration of $\mathrm{CeO}_{2}$ can be enhanced by introducing di- or tri-valent metal ions into its lattice. $\mathrm{Y}_{2} \mathrm{O}_{3}$ was studied as a dopant by Wang et al. (5). Some of their results are listed in Table 3.2. Both the oxygen ion conductivity and activation enthalpy varied with the $\mathrm{Y}_{2} \mathrm{O}_{3}$ dopant concentration. $1 \%$ $\mathrm{Y}_{2} \mathrm{O}_{3}$ dopant generated the highest oxygen conductivity and the lowest activation enthalpy. $\mathrm{Y}_{2} \mathrm{O}_{3}$-doped cerium oxide catalysts (Table 3.1) were prepared and tested in this work. Figure 3.2 shows the effect of the $\mathrm{Y}_{2} \mathrm{O}_{3}$ dopant on the catalyst activity. The $1 \%$ $\mathrm{Y}_{2} \mathrm{O}_{3}$ doped ceria catalyst $\left(\mathrm{CeO}_{2}(\mathrm{Y})\right)$ showed higher activity than either the pure $\mathrm{CeO}_{2}$ or a $10 \% \mathrm{Y}_{2} \mathrm{O}_{3}$-doped ceria $\left(\mathrm{CeO}_{2}(10 \mathrm{Y})\right)$. Thus, more than $95 \%$ elemental sulfur yield was obtained over the $\mathrm{CeO}_{2}(\mathrm{Y})$ at $600^{\circ} \mathrm{C}$, that is, at $50^{\circ} \mathrm{C}$ lower temperature than for the other two catalysts. 
When two tri-valent metal ions are introduced in the $\mathrm{CeO}_{2}$ crystal structure, one oxygen vacancy is created,

$$
\mathrm{V}_{\mathrm{O}}+2 \mathrm{D} \leftrightarrow \mathrm{D} \cdots \mathrm{V}_{\mathrm{O}} \cdots \mathrm{D}
$$

where $V_{O}$ and $D$ denote the oxygen vacancy and trivalent dopant cation, respectively. The dopant ion and the created oxygen vacancies form associated pairs as denoted by $D \cdots V_{O} \cdots D$. Different dopants will bring about different crystal structure change and interaction of vacancy-ion pair, thus resulting in different oxygen mobility. Table 3.3 lists some experimental results from the studies by Gerhardt-Anderson and Nowick (6), together with the calculated association enthalpy by Butler et al. (7). The $1 \% \mathrm{Sc}_{2} \mathrm{O}_{3}$ dopant in $\mathrm{CeO}_{2}$ generated the strongest vacancy-ion association and had the lowest oxygen conductivity among trivalent ion-doped ceria. The $\mathrm{CeO}_{2}(\mathrm{La})$ had comparable oxygen conductivity to $\mathrm{CeO}_{2}(\mathrm{Y})$ at low temperature, but bad a little lower association enthalpy than the $\mathrm{CeO}_{2}(\mathrm{Y})$. The experimental results of $\mathrm{SO}_{2}$ reduction by $\mathrm{CO}$ on the bulk cerium oxide catalyst doped with these elements are compared in Figure 3.3 on the same total surface area basis. More than $95 \%$ sulfur yield was obtained at $600^{\circ} \mathrm{C}$ for all three catalysts. When the reaction temperature was lowered, the sulfur yields on the $\mathrm{CeO}_{2}(\mathrm{Sc})$ and $\mathrm{CeO}_{2}(\mathrm{La})$ catalysts fell off steeply at about $600^{\circ} \mathrm{C}$ and $560^{\circ} \mathrm{C}$, respectively, while the sulfur yield on the $\mathrm{CeO}_{2}(\mathrm{Y})$ catalyst decreased gradually from $600^{\circ} \mathrm{C}$. The $\mathrm{CeO}_{2}(\mathrm{La})$ catalyst showed the highest activity.

Figure 3.4 shows the light-off behavior of the reaction of $\mathrm{SO}_{2}$ with $\mathrm{CO}$ over different catalysts. For this study, we started with the fresh catalyst without any pretreatment by a reducing agent and raised the reaction temperature from 500 to $700^{\circ} \mathrm{C}$ in a $50^{\circ} \mathrm{C}$-step, holding at each temperature for half an hour. The reaction was lighted off at the same temperature (around $650^{\circ} \mathrm{C}$ ) over all the $\mathrm{La}_{2} \mathrm{O}_{3}$-doped ceria catalysts, independent of dopant content and the amount of catalyst used. But, the reaction did not light-off on the $\mathrm{CeO}_{2}(\mathrm{Sc})$ catalyst even at temperatures as high as $690^{\circ} \mathrm{C}$. After one-hour heating under the reaction atmosphere at $690^{\circ} \mathrm{C}$, the $\mathrm{CeO}_{2}(\mathrm{Sc})$ catalyst still appeared pale yellow (as fresh ceria), while an activated(reduced) catalyst had a dark blue color. This experiment indicated that the $\mathrm{La}_{2} \mathrm{O}_{3}$-doped catalyst can be used without activation by a reductant gas, but, higher reaction temperature is needed to initiate the reaction.

The effect of $\mathrm{La}_{2} \mathrm{O}_{3}$ dopant concentration on the fall-off behavior is shown in Figure 3.5. Increasing the dopant concentration from $1 \%$ to 35 at. $\%$ did not improve the catalyst performance. On the other hand, incorporation of 5 at. $\% \mathrm{MgO}$ into the $1 \% \mathrm{La}_{2} \mathrm{O}_{3}$-doped ceria greatly decreased the catalytic activity. The fall-off temperature over $\mathrm{CeO}_{2}(5 \mathrm{Mg}+\mathrm{La})$ catalyst is about $50^{\circ} \mathrm{C}$ higher than that on the $\mathrm{CeO}_{2}(\mathrm{La})$. XRD analysis revealed the existence of only the fluorite ceria crystal phase in these oxide compounds. The vacancy association energy in $\mathrm{MgO}$-doped ceria is $1.23 \mathrm{eV}$, much bigher than that in the $\mathrm{La}_{2} \mathrm{O}_{3}$-doped ceria, $0.26 \mathrm{eV}$, as shown in Table 3.3. This strong association stabilized 
the oxygen vacancy and thus capped outside oxygen on the $\mathrm{CeO}_{2}(5 \mathrm{Mg}+\mathrm{La})$ catalyst surface. Higher temperature would be needed to remove the more strongly bonded surface capped oxygen to maintain the reduction/oxidation cycle. This issue will be further addressed later. The $\mathrm{CeO}_{2}(\mathrm{La})$ catalyst was used in further studies because of its superior performance.

\subsubsection{CeO2(La) Catalyst}

Figure 3.6 shows the effect of contact time on the elemental sulfur yield over the $\mathrm{CeO}_{2}$ (La) catalyst. The contact time did not change the product selectivity. More than $95 \%$ sulfur yield was always achieved under complete $\mathrm{SO}_{2}$ conversion. The elemental sulfur yield curve fell off at a lower temperature when a longer contact time was used. However, above a value of $0.02 \mathrm{~g} \cdot \mathrm{s} / \mathrm{cc}(\mathrm{STP})$ contact time, the fall-off temperature stays at about $500^{\circ} \mathrm{C}$. This is the temperature associated with the reduction of surface capping oxygen of ceria according to Yao and Yao's studies (8). Therefore, when the reaction temperature is below $500^{\circ} \mathrm{C}, \mathrm{CO}$ cannot reduce the catalyst surface to provide the active sites for $\mathrm{SO}_{2}$ reduction. The catalyst showed good stability as indicated by Figure 3.7. No deactivation was observed during a 11 -hour steady-state run at $532^{\circ} \mathrm{C}$. As stated before, only a small amount of COS was formed with the dry feed gas of nearly stoichiometric composition.

For the same contact time, $0.02 \mathrm{~g} \cdot \mathrm{s} / \mathrm{cc}(\mathrm{STP})$, the fall-off temperature over the $\mathrm{CeO}_{2}(\mathrm{La})$ catalyst shown in Figure 3.5 is about $50^{\circ} \mathrm{C}$ higher than that in Figure 3.6. The feed gas used in the studies shown in Figure 3.5 was contaminated by a small amount of water vapor $(\sim 400 \mathrm{ppm})$. This indicated that the catalyst may be poisoned by water vapor.

\subsubsection{Water Vapor Effects}

The introduction of water vapor in the reacting atmosphere may affect the catalytic activity by adsorption on the catalyst surface, and change the product distribution through the following reactions:

$$
\begin{aligned}
& \mathrm{COS}+\mathrm{H}_{2} \mathrm{O} \rightarrow \mathrm{H}_{2} \mathrm{~S}+\mathrm{CO}_{2} \\
& \mathrm{CO}+\mathrm{H}_{2} \mathrm{O} \rightarrow \mathrm{H}_{2}+\mathrm{CO}_{2} \\
& \mathrm{H}_{2}+[\mathrm{S}] \rightarrow \mathrm{H}_{2} \mathrm{~S} \\
& 3 / \mathrm{x} \mathrm{S} \mathrm{S}_{\mathrm{X}}+2 \mathrm{H}_{2} \mathrm{O} \rightarrow 2 \mathrm{H}_{2} \mathrm{~S}+\mathrm{SO}_{2}
\end{aligned}
$$

The $[\mathrm{S}]$ in reaction 6 indicates any kind of sulfur source, such as metal sulfide and adsorbed surface sulfur. The reactions 4-7 listed above are thermodynamically feasible under present conditions.

The effects of water vapor on the $\mathrm{SO}_{2}$ reduction by $\mathrm{CO}$ are illustrated in Figure 3.8. Upon the addition of $3 \% \mathrm{H}_{2} \mathrm{O}$, three small peaks of $\mathrm{CO}_{2}, \mathrm{H}_{2} \mathrm{~S}$, and $\mathrm{SO}_{2}$, appeared simultaneously. The $\mathrm{CO}_{2}$ peak may result from the reaction of $\mathrm{H}_{2} \mathrm{O}$ with adsorbed $\mathrm{CO}$ on 
the catalyst surface, and the $\mathrm{H}_{2} \mathrm{~S}$ and $\mathrm{SO}_{2}$ peaks may be produced by the reverse Claus reaction of adsorbed surface sulfur and $\mathrm{H}_{2} \mathrm{O}$. In the presence of $3 \% \mathrm{H}_{2} \mathrm{O}$, sulfur compounds in the product stream consisted of $\mathrm{H}_{2} \mathrm{~S}, \mathrm{SO}_{2}$ and elemental sulfur, while $\mathrm{COS}$ was negligible. The ratio of $\mathrm{H}_{2} \mathrm{~S}$ to $\mathrm{SO}_{2}$ was approximately stoichiometric, because in the feed gas the stoichiometric ratio of $[\mathrm{CO}] /\left[\mathrm{SO}_{2}\right]=2$ was used. When the reaction temperature was lowered from 660 to $617^{\circ} \mathrm{C}$, no apparent product distribution change was seen. When the temperature was lowered to $580^{\circ} \mathrm{C}$, the $\mathrm{H}_{2} \mathrm{~S}$ decreased a little while the $\mathrm{SO}_{2}$ increased a little. The catalyst quickly deactivated when the temperature was further lowered to $540^{\circ} \mathrm{C}$, while no deactivation was observed for the dry feed gas at this temperature(see Figure 3.6). Li et al. $(9,10)$ in their studies of $\mathrm{CO}$ adsorption on ceria found that surface $\mathrm{OH}$ groups inhibit $\mathrm{CO}$ adsorption and that $\mathrm{CO}$ adsorption depends on the degree of surface dehydroxylation. Apparently, then, in the present study the water vapor lowered the catalyst activity for $\mathrm{SO}_{2}$ and $\mathrm{CO}$ reaction by taking up the active surface sites for $\mathrm{CO}$ chemisorption. The overall effect of water vapor is displayed as partial poisoning of the catalyst and promotion of $\mathrm{H}_{2} \mathrm{~S}$ formation.

The variation of product gas distribution with the $[\mathrm{CO}] /\left[\mathrm{SO}_{2}\right]$ ratio is shown in Figure 3.9. The $\mathrm{H}_{2} \mathrm{~S}$ formation increased with the [CO]/[ $\left.\mathrm{SO}_{2}\right]$ ratio; conversely, the $\mathrm{SO}_{2}$ concentration decreased with the $[\mathrm{CO}] /\left[\mathrm{SO}_{2}\right]$. The maximum elemental sulfur yield was obtained around the stoichiometric $[\mathrm{CO}] /\left[\mathrm{SO}_{2}\right]$ ratio. In the region of $[\mathrm{CO}] /\left[\mathrm{SO}_{2}\right]>2$, $\mathrm{H}_{2} \mathrm{~S}$ may be produced by hydrolysis of $\mathrm{COS}$ and the reaction of the adsorbed sulfur on the catalyst surface with hydrogen from the WGS reaction. In the region of $[\mathrm{CO}] /\left[\mathrm{SO}_{2}\right]<2$, $\mathrm{COS}$ formation is negligible and thus, the $\mathrm{H}_{2} \mathrm{~S}$ may come mainly from the reaction of surface sulfur with hydrogen. Because more reductant gas was consumed to produce $\mathrm{H}_{2} \mathrm{~S}$ than elemental sulfur, there was not enough reductant left for the reduction of $\mathrm{SO}_{2}$ so that some of the inlet $\mathrm{SO}_{2}$ was not reduced. This became more obvious when less $\mathrm{CO}$ was used in the feed gas. Although the reverse Claus reaction 7 is thermodynamically feasible at high temperature, this reaction would give a simultaneous production of $\mathrm{H}_{2} \mathrm{~S}$ and $\mathrm{SO}_{2}$. This is not the case as shown in Figure 3.9. Further testing showed that at a given temperature the $\mathrm{H}_{2} \mathrm{~S}$ formation increased with the water vapor content. In a practical application, since the $\mathrm{H}_{2} \mathrm{~S}$ and $\mathrm{SO}_{2}$ in the product stream are in stoichiometric amount when the $[\mathrm{CO}] /\left[\mathrm{SO}_{2}\right]$ is around 2 , a downstream Claus reactor may be directly used to convert the $\mathrm{H}_{2} \mathrm{~S}$ and $\mathrm{SO}_{2}$ into elemental sulfur. Alternatively, for a dry regenerative flue gas desulfurization process, the product gas from the sulfur recovery unit can be recycled to the burner after condensation and collection of sulfur.

\subsection{5 $\mathrm{CeO}_{2}(\mathrm{La})$ is an Active Catalyst for Claus Reaction and COS Hydrolysis}

Catalytic activity of $\mathrm{CeO}_{2}(\mathrm{La})$ for Claus reaction and the water vapor effect are illustrated by Figure 3.10. More than $80 \%$ inlet $\mathrm{SO}_{2}$ was converted into elemental sulfur 
around $230^{\circ} \mathrm{C}$ in the absence of $\mathrm{H}_{2} \mathrm{O}$. Upon addition of $13 \% \mathrm{H}_{2} \mathrm{O}, \mathrm{SO}_{2}$ increased by $65 \%$ of its inlet concentration while $90 \%$ of the inlet $\mathrm{H}_{2} \mathrm{~S}$ disappeared. The excess $\mathrm{SO}_{2}$ is postulated to come from the following reactions:

$$
\begin{aligned}
& \mathrm{H}_{2} \mathrm{~S}_{\mathrm{ads}}+2 \mathrm{H}_{2} \mathrm{O} \rightarrow \mathrm{SO}_{2}+3 \mathrm{H}_{2} \\
& \mathrm{~S}_{\mathrm{ads}}+2 \mathrm{H}_{2} \mathrm{O} \rightarrow \mathrm{SO}_{2}+2 \mathrm{H}_{2}
\end{aligned}
$$

where $S_{\text {ads }}$ was the sulfur produced by the previous Claus reaction and deposited on the catalyst. The catalyst lost its activity immediately when exposed to $\mathrm{H}_{2} \mathrm{O}$. Its activity cannot be recovered by stopping $\mathrm{H}_{2} \mathrm{O}$. The catalyst became activated only when the temperature was raised over $500^{\circ} \mathrm{C}$. There was a burst of $\mathrm{SO}_{2}$ around $500^{\circ} \mathrm{C}$ during temperature rise, where twice the inlet $\mathrm{SO}_{2}$ was released with consumption of $78 \%$ of the inlet $\mathrm{H}_{2} \mathrm{~S}$. This may be explained by oxidization of $\mathrm{H}_{2} \mathrm{~S}$ by adsorbed $\mathrm{H}_{2} \mathrm{O}$. It seems that the previously adsorbed $\mathrm{H}_{2} \mathrm{O}$ on the catalyst desorbs only at high temperatures $\left(>500^{\circ} \mathrm{C}\right)$. The catalyst was completely re-activated after removal of the adsorbed $\mathrm{H}_{2} \mathrm{O}$. Figure 3.11 shows that complete conversion of $\operatorname{COS}$ to $\mathrm{H}_{2} \mathrm{~S}$ was achieved at temperatures above $270^{\circ} \mathrm{C}$

\subsection{Mechanistic Consideration}

Two reaction mechanisms have been proposed for the reduction of $\mathrm{SO}_{2}$ by $\mathrm{CO}$, namely the redox mechanism $(1,2)$ and the COS intermediate mechanism (11-13). According to the latter, $\mathrm{CO}$ first forms a $\mathrm{COS}$ intermediate with the sulfided catalyst, and then $\mathrm{COS}$ reduces $\mathrm{SO}_{2}$ to elemental sulfur. The evidence used to argue in favor of this mechanism is (i) XRD-detected metal sulfide in the used catalyst, and (ii) COS formation upon passing $\mathrm{CO}$ gas through the catalyst bed. In the present study, only the ceria $\left(\mathrm{CeO}_{2}\right)$ crystal phase was found in the fresh and used ceria catalyst by XRD analysis. In another test, when the steady-state reaction over the $\mathrm{CeO}_{2}(\mathrm{La})$ catalyst was reached at $650^{\circ} \mathrm{C}$, the feed gas was switched to $\mathrm{He}$, and after a ten-minute flush, $\mathrm{CO}$ was allowed to scavenge the catalyst surface for half a hour. No COS was detected in the exit gas stream. The same results were obtained at $600^{\circ} \mathrm{C}$ and $550^{\circ} \mathrm{C}$. Furthermore, a significant amount of $\mathrm{CO}_{2}$ was released during the regeneration of a spent ceria catalyst with $\mathrm{CO}$, while no $\mathrm{COS}$ was observed. These results argue against the $\mathrm{COS}$ intermediate mechanism for $\mathrm{SO}_{2}$ reduction by $\mathrm{CO}$ over ceria catalysts. However, our tests have shown that $\mathrm{CeO}_{2}(\mathrm{La})$ is also a good catalyst for the reduction of $\mathrm{SO}_{2}$ by $\mathrm{COS}$, with more than $96 \% \mathrm{SO}_{2}$ converted to elemental sulfur over the temperature range from 390 to $650^{\circ} \mathrm{C}$.

We propose that the $\mathrm{SO}_{2}$ reduction by $\mathrm{CO}$ on ceria proceeds via the redox mechanism:

$$
\begin{aligned}
& \text { Cat-O }+\mathrm{CO} \rightarrow \text { Cat- }[]+\mathrm{CO}_{2} \\
& \text { Cat- }[]+\mathrm{SO}_{2} \rightarrow \text { Cat-O }+\mathrm{SO} \\
& \text { Cat- }[]+\mathrm{SO} \rightarrow \text { Cat-O }+\mathrm{S}
\end{aligned}
$$


We found that the catalyst had to be pre-reduced to initiate the reduction/oxidation cycle at low temperature. This is evidenced by the catalyst color change. The fresh $\mathrm{CeO}_{2}$ was pale yellow and had no activity. The activated catalyst appeared dark blue, which is the characteristic color of partially reduced $\mathrm{CeO}_{2}$. The reaction proceeds easily on the catalyst pretreated by a reducing agent, such as $\mathrm{CO}$. In contrast, the reaction is difficult to start in the reacting atmosphere due to the presence of both a reductant $(\mathrm{CO})$ and an oxidant $\left(\mathrm{SO}_{2}\right)$, and may need high temperature (Figure 3.4). As one oxygen vacancy is created by the release of one $\mathrm{CO}_{2}$ molecule, the $\mathrm{SO}_{2}$ donates its oxygen to that vacancy to form a SO group. The SO is mobile on the surface until it finds another vacancy to donate its oxygen or a vacancy may migrate to a neighboring site to accept its oxygen. High oxygen mobility in the catalyst will facilitate the oxygen transfer from one site to another on the surface or from the bulk to the surface. However, the oxygen vacancy can be taken up by other molecules existing in the reacting gas phase, such as $\mathrm{H}_{2} \mathrm{O}$ and $\mathrm{O}_{2}$. The more strongly these impurity oxygen atoms attach to the vacancy, the more severe a poisoning effect they will bring about. The creation of oxygen vacancies on the surface is, then, a key step.

Incorporation of dopant ions into ceria lattice enhances the oxygen vacancy concentration and mobility. But, the vacancies created by the dopant on a fresh catalyst surface are always capped by the oxygen atoms from ambient oxygen or water. Therefore, the capping oxygen has to be removed to activate the catalyst. The oxygen vacancy and the dopant ion are associated in pairs by a certain energy. The stronger this association, the lower the vacancy energy state is and the more strongly the vacancy is capped by an outside oxygen. In other words, strong association increases the difficulty of removing the capping oxygen. The $\mathrm{CeO}_{2}(\mathrm{La})$ material of lower association energy than the $\mathrm{CeO}_{2}(\mathrm{Y})$, showed higher activity, although these two catalysts have the same oxygen ion conductivity(Table 3.3 and Figure 3.3). The $\mathrm{CeO}_{2}(\mathrm{Sc})$ has the highest vacancy-ion association energy among tri-valent ion-doped ceria so that the reaction cannot proceed(Figure 3.4) without removing the strongly capped surface oxygen in a highly reducing atmosphere. As discussed earlier, the vacancy association energy in the $\mathrm{MgO}$ doped ceria is $1.23 \mathrm{eV}$ (Table 3.3), even greater than that of the $\mathrm{CeO}_{2}(\mathrm{Sc}), 0.67 \mathrm{eV}$. Apparently, the addition of 5 at.\% $\mathrm{MgO}$ into the $\mathrm{CeO}_{2}(\mathrm{La})$ greatly stabilized the oxygen vacancy and decreased the catalytic activity(Figure 3.5). Table 3.3 indicates that the association energy increases with dopant content. Therefore, increasing the dopant concentration does not necessarily enhance the catalytic activity. This is evidenced by the data shown in Figure 3.5, where increasing $\mathrm{La}_{2} \mathrm{O}_{3}$ dopant from 1 to 35 at.\% had no effect on the catalyst performance. For a catalyst, surface adsorption/desorption processes are always important in addition to these oxygen vacancy and mobility properties. Because $\mathrm{MgO}$ is a more basic oxide than $\mathrm{La}_{2} \mathrm{O}_{3}$ and $\mathrm{La}_{2} \mathrm{O}_{3}$ is more basic than $\mathrm{CeO}_{2}$, the present results indicate that the acid/base properties of the catalyst play little role in the reduction of $\mathrm{SO}_{2}$ by $\mathrm{CO}$. 


\subsection{Conclusions}

Cerium oxide is an active catalyst for $\mathrm{SO}_{2}$ reduction by $\mathrm{CO}$ and its activity can be enhanced by doping $\mathrm{La}_{2} \mathrm{O}_{3}$ into its lattice. More than $95 \%$ elemental sulfur recovery can be achieved on $\mathrm{CeO}_{2}$-based catalysts at reaction temperatures about $500^{\circ} \mathrm{C}$ or higher when the feed gas has the stoichiometric composition. The reaction of $\mathrm{SO}_{2}$ with $\mathrm{CO}$ on the catalyst appears to proceed according to the redox mechanism. The results of our work demonstrate a correlation of the catalytic activity with the oxygen vacancy mobility and energetics in a doped ceria catalyst. Water vapor partially poisons the ceria catalysts and promotes the production of $\mathrm{H}_{2} \mathrm{~S}$. The elemental sulfur yield is lowered in the presence of water. Further work with transition metal modified cerium oxide catalysts will be reported in the next chapter.

\subsection{Literature Cited}

1. Happel, J.; Leon, A.L.; Hnatow, M.A.; Bajars, L. Ind. Eng. Chem., Prod. Res. Dev. 16, 150-154 (1977).

2. Hibbert, D.B.; Campbell, R.H. Appl. Catal. 41, 289-299 (1988).

3. Hibbert, D.B.; Campbell, R.H. Appl. Catal. 41, 273-287 (1988).

4. Flytzani-Stephanopoulos, M.; Hu, Z. U.S. Patent 5242 673, 1993.

5. Wang, D.Y.; Park, D.S.; Griffith, J.; Nowick, A.S. Solid State Ionics 2, 95-105 (1981).

6. Gerhardt-Anderson, R; Nowick, A.S. Solid State Ionics 5, 547-550 (1981).

7. Butler, V.; Catlow, C.R.A.; Fender, B.E.F.; Harding, J.H. Solid State Ionics 8, 109113 (1983).

8. Yao, H.C.; Yao, Y.F.Y. J. Catal. 86, 254-265 (1984).

9. Li, C.; Sakata, Y.; Arai, T.; Domen, K.; Maruya, K.; Onishi, T. J. Chem. Soc., Faraday Trans. 1, 85, 929-943 (1989).

10. Li, C.; Sakata, Y.; Arai, T.; Domen, K; Maruya, K.; Onishi, T. J. Chem. Soc., Faraday Trans. 1, 85, 1451-1461 (1989).

11. Haas, L.A.; Khalafalla, S.E. J. Catal. 29, 264-269 (1973).

12. Haas, L.A.; Khalafalla, S.E. J. Catal. 30, 451-459 (1973).

13. Baglio, J.A. Ind. Eng. Chem. Prod. Res. Dev. 21, 38-41 (1982). 
Table 3.1 Catalysts Tested in This Study.

\begin{tabular}{|c|c|c|c|c|}
\hline \multirow{2}{*}{ No. } & \multirow{2}{*}{ Catalyst } & \multirow{2}{*}{ Composition $^{a}$} & \multicolumn{2}{|c|}{ Surface Area $\left(\mathrm{m}^{2} / \mathrm{g}\right)$} \\
\hline & & & fresh $^{b}$ & used $^{\mathrm{c}}$ \\
\hline 1. & $\mathrm{CeO}_{2}$ & $\mathrm{CeO}_{2}$ & 34.0 & 29.0 \\
\hline 2. & $\mathrm{CeO}_{2}(\mathrm{Y})$ & 1 at. $\% Y$ & $27 / 23^{d}$ & $9.5 / 20^{d}$ \\
\hline 3. & $\mathrm{CeO}_{2}(10 \mathrm{Y})$ & 10 at. $\% Y$ & $19.8^{d}$ & $19.3^{d}$ \\
\hline 4. & $\mathrm{CeO}_{2}(\mathrm{Sc})$ & 1 at. $\% \mathrm{Sc}$ & $47 / 30^{d}$ & $30 / 27^{d}$ \\
\hline 5. & $\mathrm{CeO}_{2}(\mathrm{La})$ & 1 at. $\% \mathrm{La}$ & 34.0 & 19.5 \\
\hline 6. & $\mathrm{CeO}_{2}(6 \mathrm{La})$ & 6 at. $\% \mathrm{La}$ & 32.6 & 22.8 \\
\hline 7. & $\mathrm{CeO}_{2}(20 \mathrm{La})$ & 20 at. $\%$ La & 37.5 & 19.4 \\
\hline 8. & $\mathrm{CeO}_{2}(35 \mathrm{La})$ & 35 at. $\% \mathrm{La}$ & 28.8 & 17.2 \\
\hline 9. & $\mathrm{CeO}_{2}(5 \mathrm{Mg}+\mathrm{La})$ & 5 at. $\% \mathrm{Mg}+1$ at. $\% \mathrm{La}$ & 30.2 & 22.4 \\
\hline
\end{tabular}

a. "at. \%" denotes the corresponding metal atomic percentage.

b. Measured before use.

c. Measured after about 6-hour reaction time on-stream.

d. Fresh catalysts were further calcined for $15 \mathrm{~h}$ at $750^{\circ} \mathrm{C}$ after $3-\mathrm{h}$ calcination at $600^{\circ} \mathrm{C}$. 
Table 3.2 Variation of Oxygen Conductivity and Activation Enthalpy With Composition of $\mathrm{CeO}_{2}: \mathrm{Y}_{2} \mathrm{O}_{3}$ (data from Wang et al. (5)).

\begin{tabular}{|c|c|c|c|}
\hline \multirow{2}{*}{ mole $\% \mathrm{Y}_{2} \mathrm{O}_{3}$} & \multirow{2}{*}{$\frac{\mathrm{H}_{\sigma}(\mathrm{ev})^{\mathrm{a}}}{\text { at } 180^{\circ} \mathrm{C}}$} & \multicolumn{2}{|c|}{$\sigma(\mathrm{S} / \mathrm{cm})$} \\
\hline & & at $180^{\circ} \mathrm{C}$ & at $580^{\circ} \mathrm{C}$ \\
\hline $0.0 \%$ & 0.92 & $3 \times 10^{-8}$ & $2 \times 10^{-4}$ \\
\hline $1 \%$ & 0.79 & $1.8 \times 10^{-6}$ & $8 \times 10^{-3}$ \\
\hline $10 \%$ & 1.15 & $1.5 \times 10^{-7}$ & $4.5 \times 10^{-3}$ \\
\hline
\end{tabular}

a. $\mathrm{H}_{\sigma}$ related to $\sigma$ by $\sigma \mathrm{T} \propto \exp \left(-\mathrm{H}_{\sigma} / \mathrm{RT}\right)$.

Table 3.3 Association Enthalpy $\mathbf{h}_{\mathrm{A}}$ and Conductivity for Solid Solutions of Different Dopants in $\mathrm{CeO}_{2}$ (data from Gerhart-Anderson and Nowick (6)).

\begin{tabular}{|c|c|c|c|c|}
\hline \multirow[t]{2}{*}{ Dopant } & \multirow{2}{*}{$\begin{array}{l}\text { Ionic radius } \\
(\AA)\end{array}$} & \multicolumn{2}{|c|}{$\mathrm{h}_{\mathrm{A}}(\mathrm{ev})^{\mathrm{a}}$} & \multirow{2}{*}{$\begin{array}{l}\sigma(\mathrm{S} / \mathrm{cm}) \text { at } 400^{\circ} \mathrm{C} \\
\text { for } 1 \% \mathrm{D}_{2} \mathrm{O}_{3}\end{array}$} \\
\hline & & $1 \% \mathrm{D}_{2} \mathrm{O}_{3}$ & $6 \% \mathrm{D}_{2} \mathrm{O}_{3}$ & \\
\hline $\mathrm{La}^{+3}$ & 1.18 & $0.14 / 0.26^{b}$ & 0.18 & $3.3 \times 10^{-4}$ \\
\hline $\mathrm{Gd}^{+3}$ & 1.06 & $0.12 / 0.17^{b}$ & 0.16 & $5.3 \times 10^{-4}$ \\
\hline $\mathrm{Y}^{+3}$ & 1.01 & $0.21 / 0.38^{b}$ & 0.26 & $3.3 \times 10^{-4}$ \\
\hline $\mathrm{Sc}^{+2}$ & 0.87 & $0.67 / 0.62^{b}$ & - & $4.4 \times 10^{-7}$ \\
\hline $\mathrm{Mg}^{+2}$ & 0.89 & $1.23^{\mathrm{b}}$ & - & - \\
\hline $\mathrm{Ca}^{+2}$ & 1.12 & $1.12^{b}$ & - & - \\
\hline
\end{tabular}

a. $\mathrm{h}_{\mathrm{A}}$ is related to $\sigma$ by $\sigma \mathrm{T} \propto \exp \left(-\left(\mathrm{h}_{\mathrm{A}}+\mathrm{h}_{\mathrm{m}}\right) / \mathrm{RT}\right)$

b. data were calculated by Butler et al. (7). 


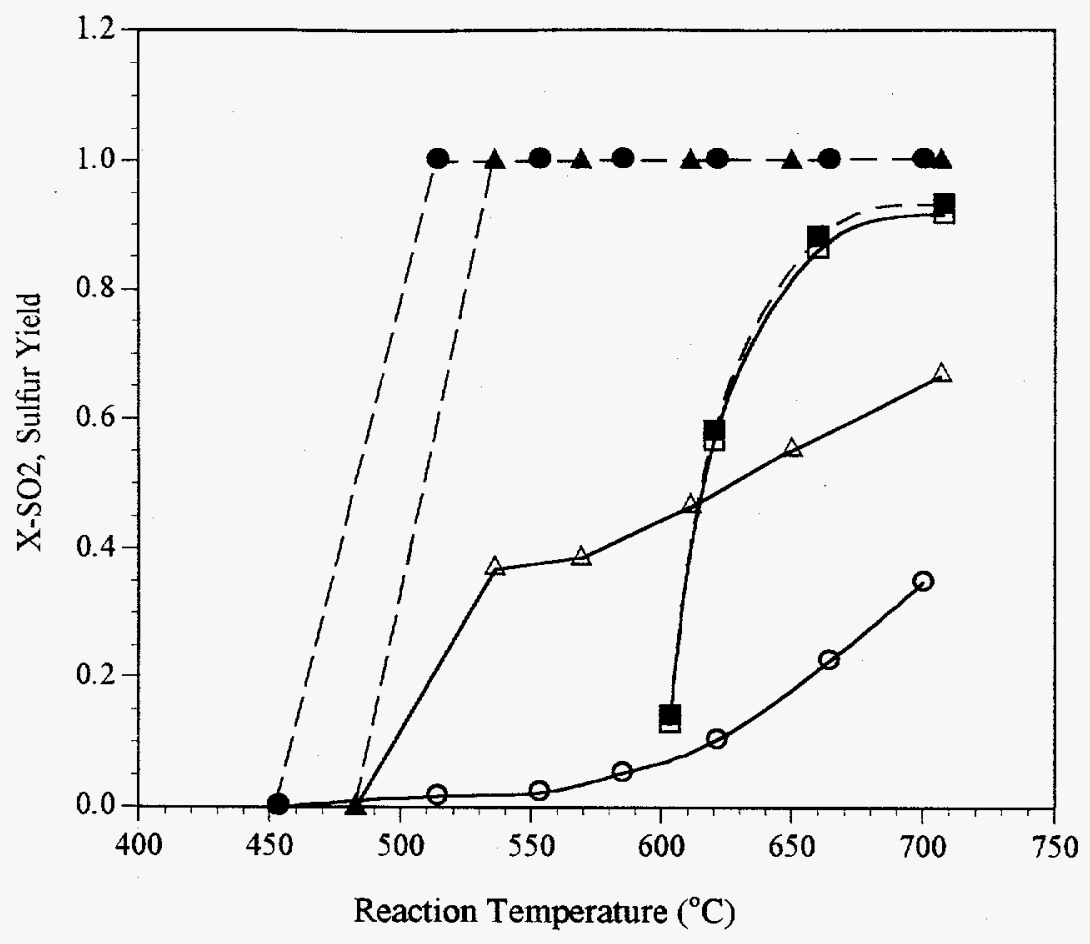

Figure 3.1 Elemental Sulfur Yield and $\mathrm{SO}_{2}$ Conversion on $\mathrm{Bulk} \mathrm{CeO}_{2}$ Catalyst $\left(\mathbf{R}_{\mathrm{CO}}=[\mathrm{CO}] /\left[\mathrm{SO}_{2}\right] ; 1 \% \mathrm{SO}_{2}, 0.017 \mathrm{~s} \cdot \mathrm{g} / \mathrm{cc}(\mathrm{STP})\right) . \mathbf{R}_{\mathrm{CO}}=4: 0 \quad \mathbf{0} ; \mathbf{R}_{\mathrm{CO}}=3: \Delta \Delta ; \mathbf{R}_{\mathrm{CO}}=1.9:$ $\square$ (filled symbols for $\mathrm{SO}_{2}$ conversion, unfilled ones for sulfur yield).

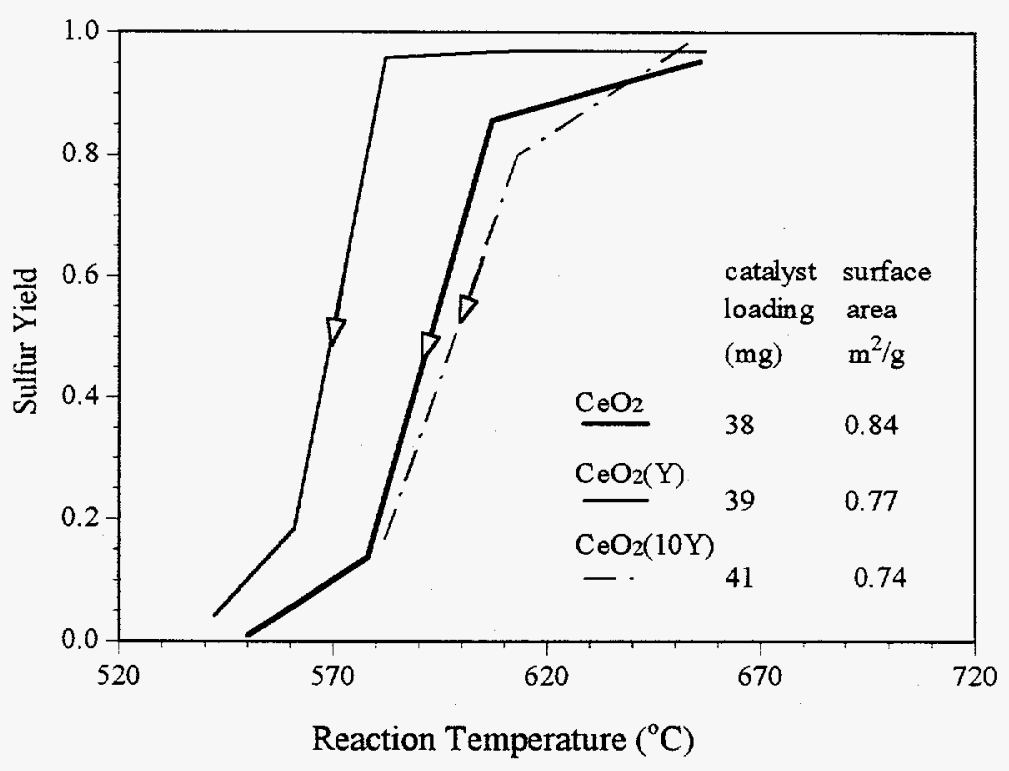

Figure 3.2 Effect of $\mathrm{Y}_{2} \mathrm{O}_{3}$ Dopant Content in Ceria on Catalyst Activity $\left([\mathrm{CO}] /\left[\mathrm{SO}_{2}\right]=2 ; 1 \% \mathrm{SO}_{2}, 0.012 \mathrm{~s} \cdot \mathrm{g} / \mathrm{cc}(\mathrm{STP})\right)$. 


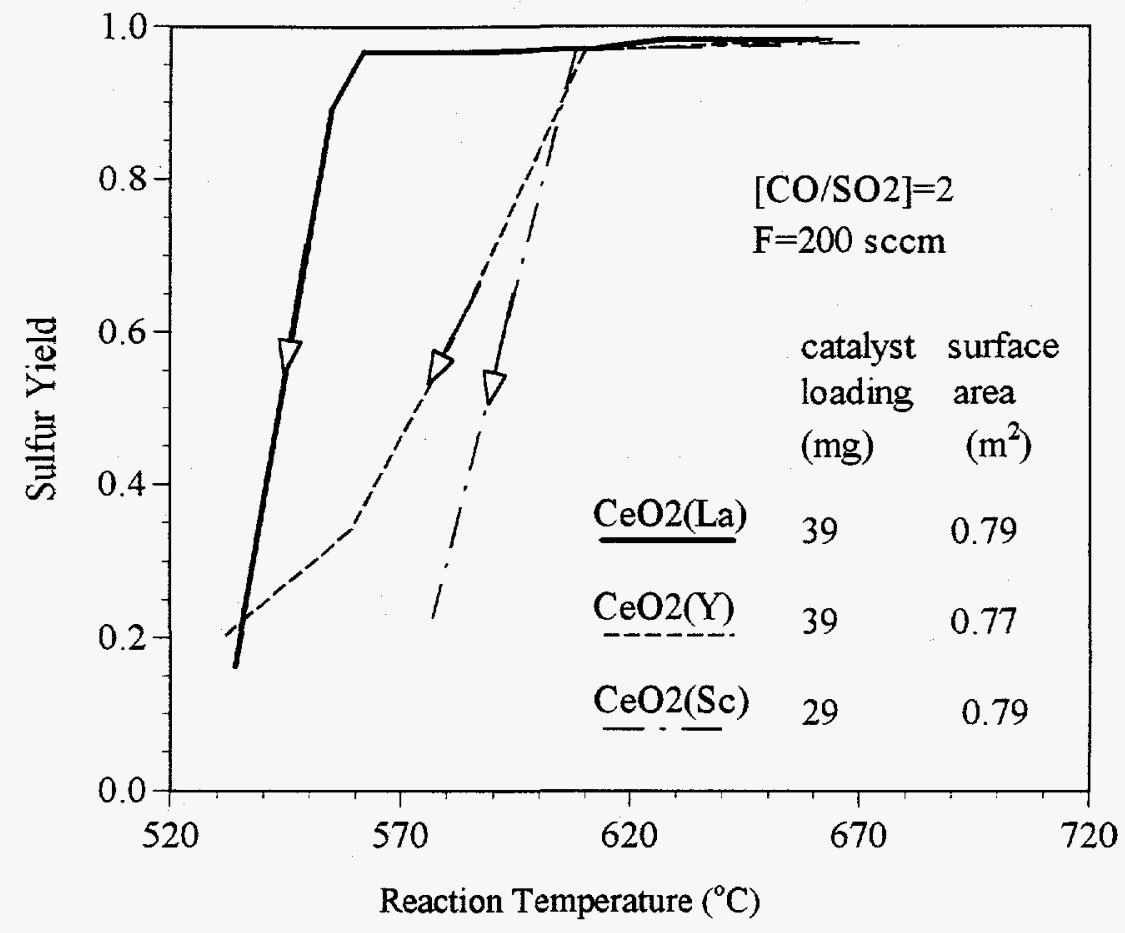

Figure 3.3 Effect of Different Dopants in Ceria on Catalyst Activity.

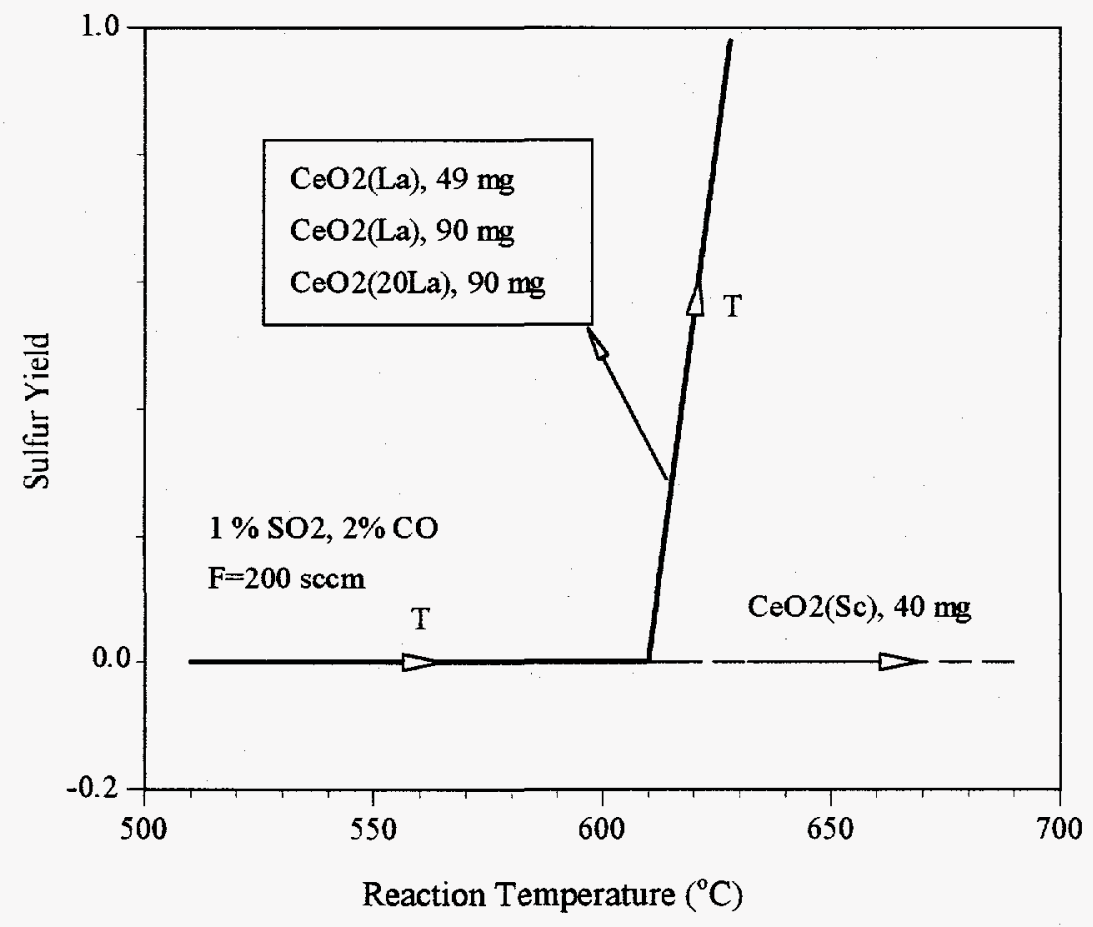

Figure 3.4 Light-off Behavior over Doped Ceria Catalysts in the Absence of Activation. 


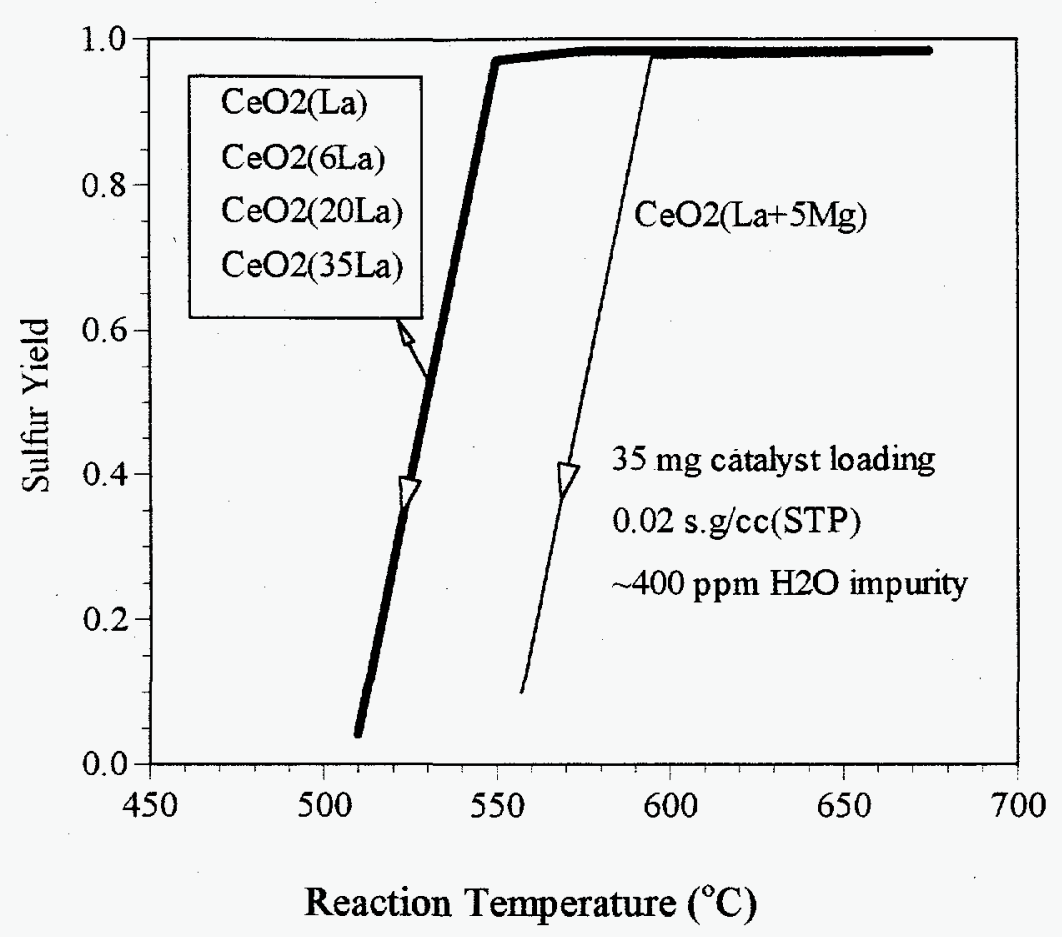

Figure 3.5 Effects of $\mathrm{La}_{2} \mathrm{O}_{3}$ Dopant Content and $\mathrm{MgO}$ Dopant on Catalyst Activity.

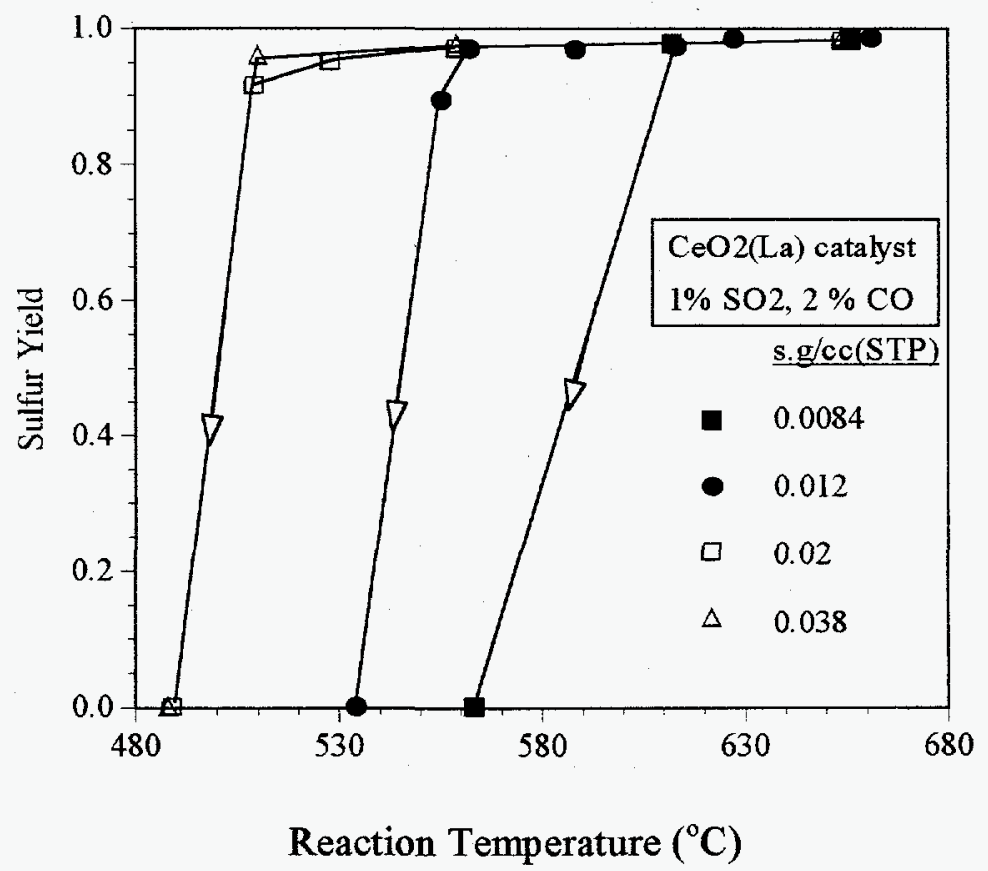

Figure 3.6 Effect of Contact Time on Sulfur Yield over the $\mathrm{CeO}_{2}(\mathrm{La})$ Catalyst. 
Chapter 3

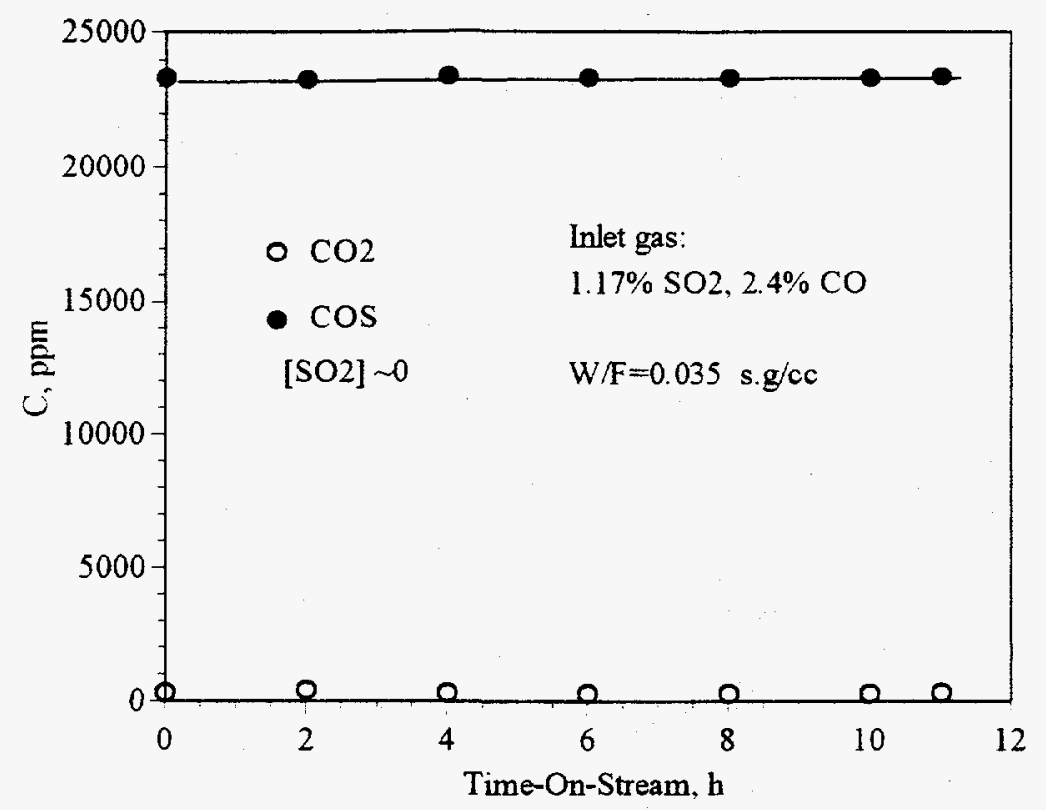

Figure 3.7 Long-term Activity of $\mathrm{CeO}_{2}(\mathrm{La})$ Catalyst at $\mathrm{T}=532^{\circ} \mathrm{C}$.

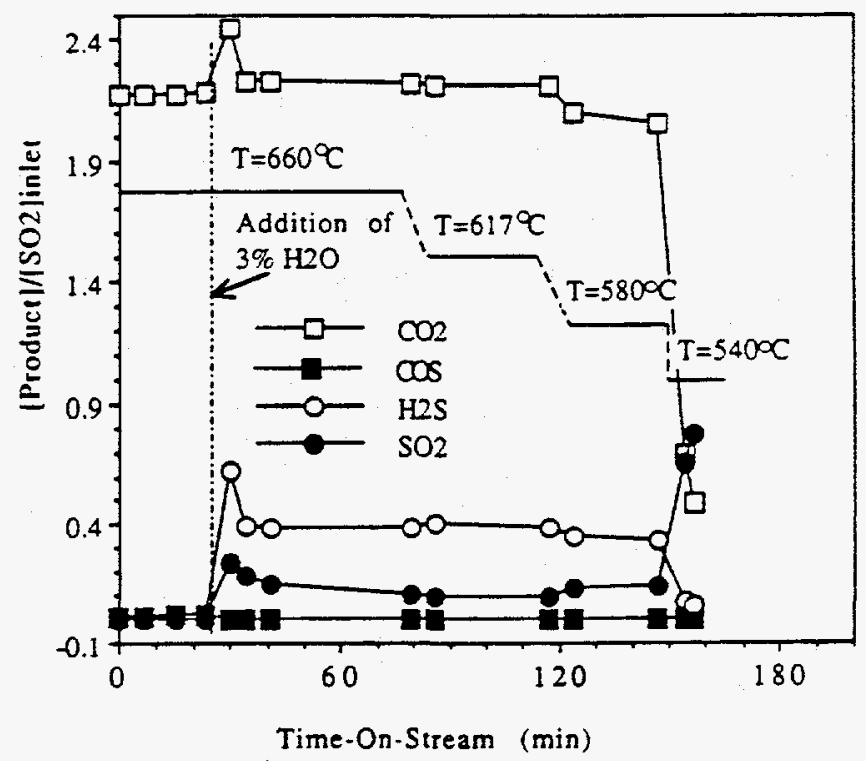

Figure 3.8 Product Distribution with Temperature on $\mathrm{CeO}_{2}(\mathrm{La})$ Catalyst in the Presence of Water Vapor $\left(1.07 \% \mathrm{SO}_{2}, 2.2 \% \mathrm{CO}, 3 \% \mathrm{H}_{2} \mathrm{O} ; 0.043 \mathrm{~s} \cdot \mathrm{g} / \mathrm{cc}\right)$. 


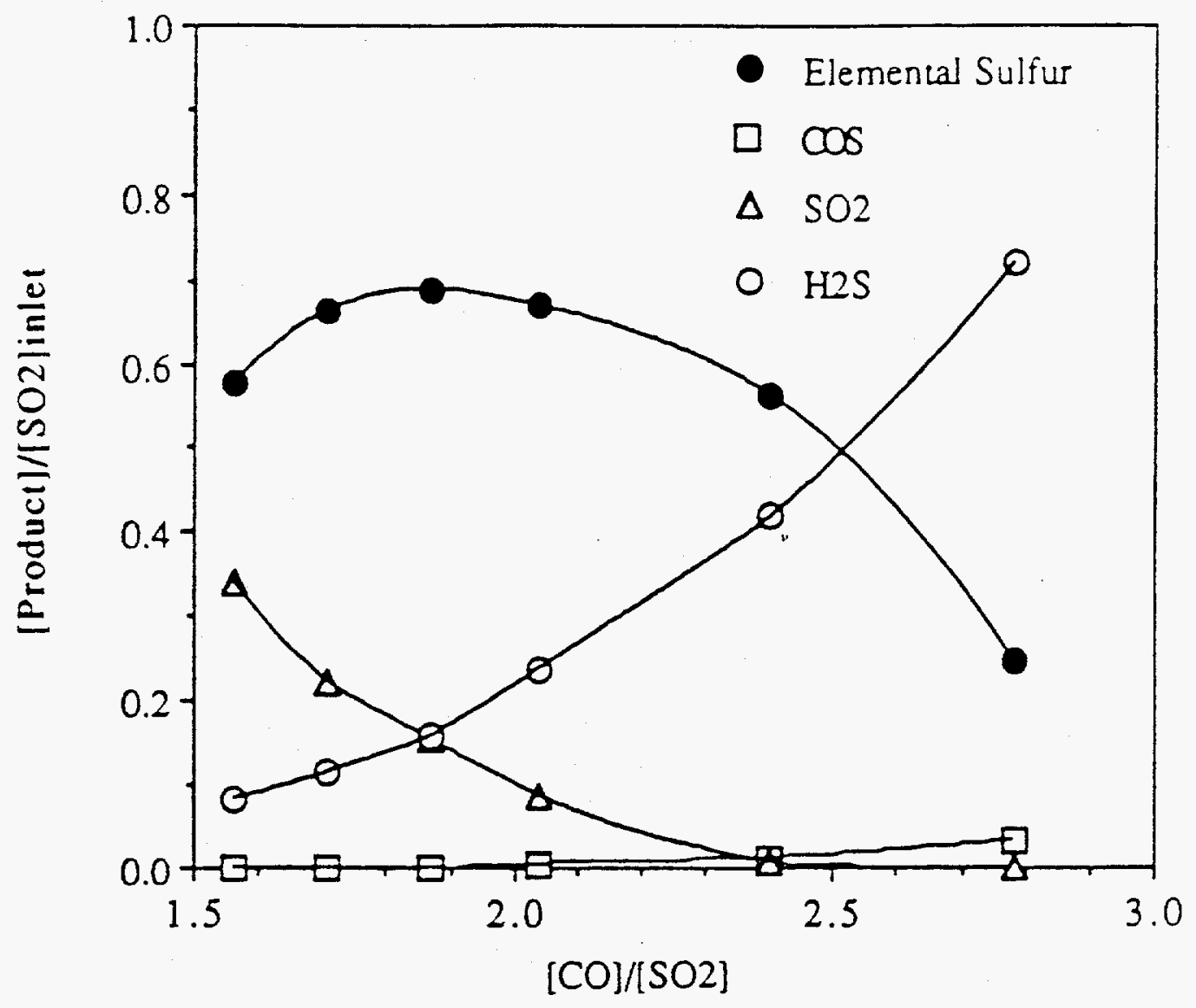

Figure 3.9 Product Distribution with the $[\mathrm{CO}] /\left[\mathrm{SO}_{2}\right]$ Ratio on $\mathrm{CeO}_{2}(\mathrm{La})$ Catalyst in the Presence of Water Vapor at $610^{\circ} \mathrm{C}\left(1 \% \mathrm{SO}_{2}, 1.5 \% \mathrm{H}_{2} \mathrm{O} ; 0.043 \mathrm{~s} \cdot \mathrm{g} / \mathrm{cc}\right)$. 


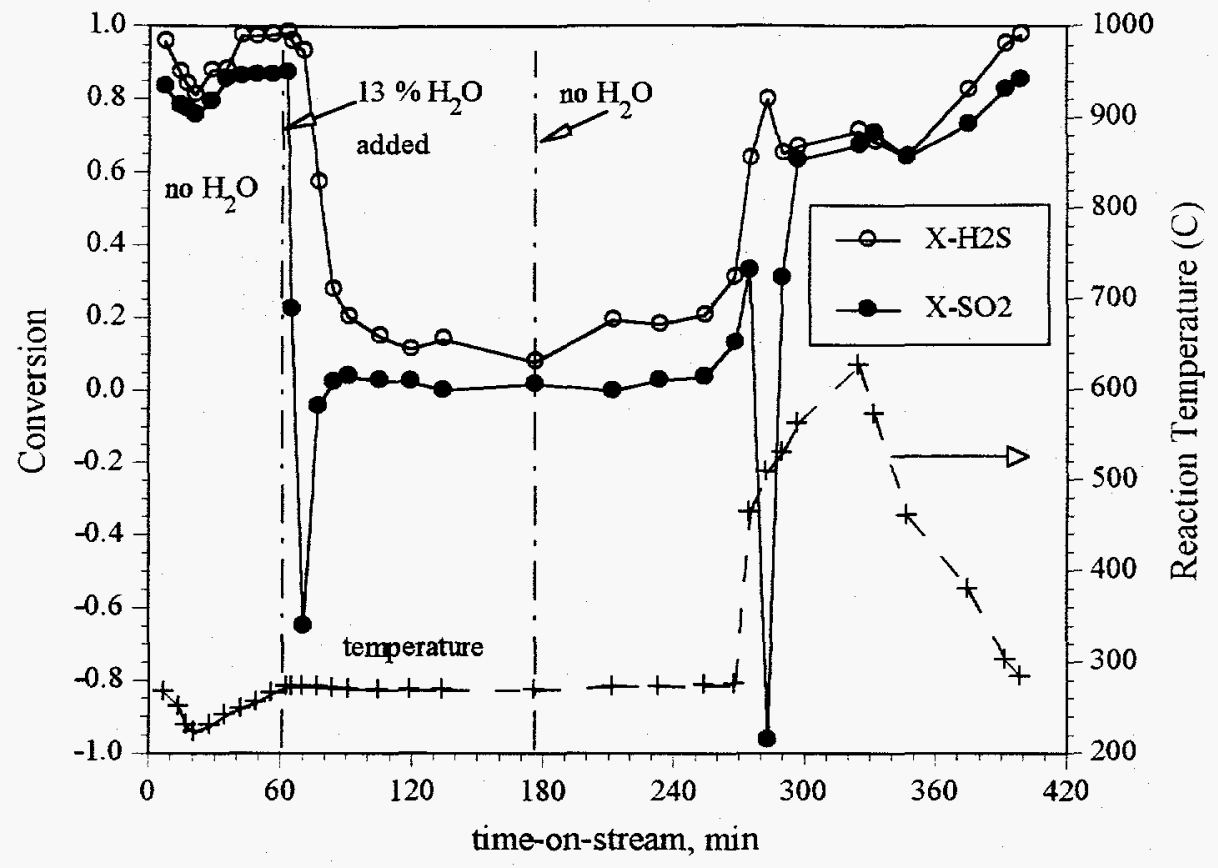

Figure 3.10 $\mathrm{v} / \mathrm{v} / \mathrm{h}$ ).

Claus Reaction over $\mathrm{CeO}_{2}(\mathrm{La})$ Catalyst $\left(0.52 \% \mathrm{SO}_{2}, 0.94 \% \mathrm{H}_{2} \mathrm{~S}, 1200\right.$

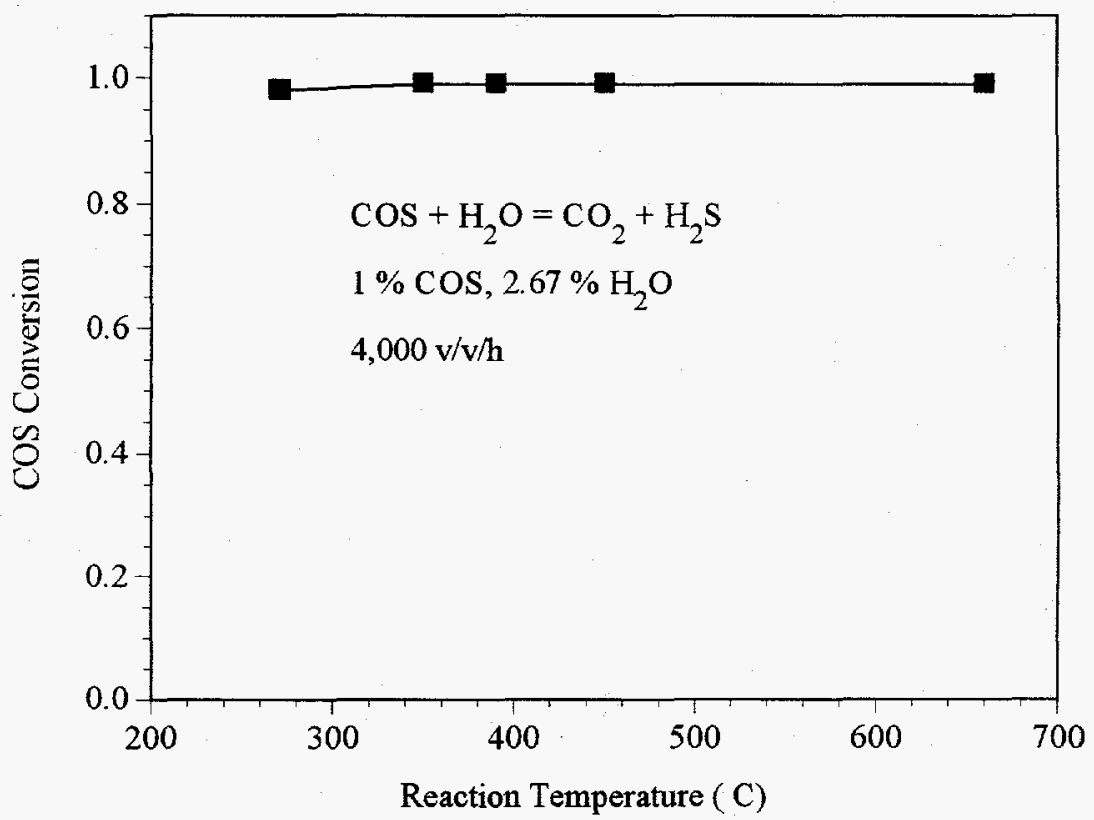

Figure 3.11 Hydrolysis of $\mathrm{COS}$ over $\mathrm{CeO}_{2}(\mathrm{La})$ Catalyst. 


\section{Chapter 4}

\section{Reduction of $\mathrm{SO}_{2}$ by $\mathrm{CO}$ to Elemental Sulfur over Composite Oxide Catalysts}

\subsection{Introduction}

The overall reactions involved in direct reduction of $\mathrm{SO}_{2}$ by $\mathrm{CO}$ to elemental sulfur are as follows:

$$
\begin{aligned}
& \mathrm{SO}_{2}+2 \mathrm{CO} \rightarrow 2 \mathrm{CO}_{2}+1 / x \mathrm{~S}_{\mathrm{X}} \\
& \mathrm{CO}+1 / \mathrm{x} \mathrm{S} \rightarrow \mathrm{COS} \\
& 2 \mathrm{COS}+\mathrm{SO}_{2} \rightarrow 2 \mathrm{CO}_{2}+3 / \mathrm{xS}_{\mathbf{X}}
\end{aligned}
$$

where $x=2-8$ or higher. At high temperatures, predominantly gaseous elemental sulfur, $S_{2}$, is produced through equation 1 . The presence of water vapor in the feed gas may have a major effect on both the catalytic activity and product selectivity by poisoning the catalyst and/or promoting the following reactions:

$$
\begin{aligned}
& \mathrm{CO}+\mathrm{H}_{2} \mathrm{O} \rightarrow \mathrm{H}_{2}+\mathrm{CO}_{2} \\
& \mathrm{COS}+\mathrm{H}_{2} \mathrm{O} \rightarrow \mathrm{H}_{2} \mathrm{~S}+\mathrm{CO}_{2} \\
& \mathrm{H}_{2}+[\mathrm{S}] \rightarrow \mathrm{H}_{2} \mathrm{~S} \\
& 3 / x \mathrm{~S}_{\mathbf{X}}+2 \mathrm{H}_{2} \mathrm{O} \rightarrow 2 \mathrm{H}_{2} \mathrm{~S}+\mathrm{SO}_{2}
\end{aligned}
$$

Reactions 1-7 have favorable thermodynamics at the conditions of interest to this work(atmospheric pressure, 300 to $700^{\circ} \mathrm{C}$ ). The challenge to realize the one-stage elemental sulfur recovery scheme is to develop a catalyst which is not poisoned by water or other gas impurities and to maximize the yield of elemental sulfur. In the previous chapter we reported that cerium oxide, a fluorite oxide well known for its high oxygen vacancy concentration and mobility, is an active catalyst and its activity can be further enhanced by doping it with lanthanum oxide. However, alkaline earth and rare earth oxide dopants did not improve the resistance of ceria towards water poisoning. In the present study, we have modified the ceria with transition metals, examined other oxygen ion conducting materials as potential catalysts, evaluated catalyst activity and selectivity as a function of catalyst type and operating conditions, including the effect of water vapor, extensively characterized the $\mathrm{Cu}-\mathrm{Ce}-\mathrm{O}$ catalyst system, and studied the reaction kinetics. 


\subsection{Experimental}

Apparatus and Procedure. All catalysts were tested in a $0.6 \mathrm{~cm}$ I.D. $x 50 \mathrm{~cm}$ quartz tube packed bed flow reactor apparatus described in Chapter 2. A fresh catalyst was evaluated by a two-step test procedure. In the first step, the reactant gas mixture was introduced into the reactor at about $500^{\circ} \mathrm{C}$ and the reaction temperature was raised by about $50^{\circ} \mathrm{C}$-increments after a steady-state reaction was reached at each temperature. The reaction light-off temperature was thus identified, at which the reaction occurred with $\mathrm{SO}_{2}$ conversion exceeding $90 \%$. In the second step, the reaction temperature was lowered in steps of about $50^{\circ} \mathrm{C}$ from a high temperature until conversion was significantly decreased. Hysteresis effects between the light-off and fall-off branches were followed in this sequence of steps. The effect of water on the catalyst activity and selectivity was examined by adding about $2 \%$ water vapor into the reactant gas mixture. Unless specifically noted, catalyst tests were typically performed with $150 \mathrm{mg}$ catalyst loaded in the reactor, gas flow rate set at $100 \mathrm{sccm}$ and comprising $1 \% \mathrm{SO}_{2}, 2 \% \mathrm{CO}$ by volume, and balance helium. The contact time was $0.09 \mathrm{~g} \cdot \mathrm{s} / \mathrm{cc}(\mathrm{STP})$. Each catalyst has different packing density so that the space velocity varied with the individual catalyst tested. Sulfur dioxide conversion, $\mathrm{X}-\mathrm{SO}_{2}$, elemental sulfur yield, $\mathrm{Y}$-sulfur, and $\mathrm{R}_{\mathrm{CO}}$ ratio are defined by following equations:

$$
\begin{aligned}
& \mathrm{X}-\mathrm{SO}_{2}=\left\{\left[\mathrm{SO}_{2}\right]_{0}-\left[\mathrm{SO}_{2}\right]\right\} /\left[\mathrm{SO}_{2}\right]_{\circ} \\
& \mathrm{Y} \text {-sulfur }=[\mathrm{S}] /\left[\mathrm{SO}_{2}\right]_{\circ} \\
& \mathrm{R}_{\mathrm{CO}}=[\mathrm{CO}]_{0} /\left[\mathrm{SO}_{2}\right]_{\mathrm{o}}
\end{aligned}
$$

where $\left[\mathrm{SO}_{2}\right]_{0}$ and $[\mathrm{CO}]_{0}$ are the inlet sulfur dioxide and carbon monoxide concentrations, respectively, while $\left[\mathrm{SO}_{2}\right]$ and $[\mathrm{S}]$ are the outlet sulfur dioxide and elemental sulfur concentrations, respectively. Sulfur product was calculated from the material balance of carbon and sulfur, and occasionally checked by titration of the sulfur collected in the cold trap.

Kinetic measurements were also conducted in a fixed bed microreactor of $6 \mathrm{~mm}$ I.D. $\mathrm{SO}_{2}$ conversion was controlled by catalyst loading and gas flow rate. The catalyst loading varied from 6 to $300 \mathrm{mg}$, while the flow rate varied from 100 to $400 \mathrm{sccm}$. Separate experiments confirmed that inter- and intra-particle mass transfer under the present conditions were eliminated. Blank test also showed that $\mathrm{SO}_{2}$ conversion in the absence of catalyst was less than $2 \%$ at temperatures below $650^{\circ} \mathrm{C}$. The small amounts of catalyst were usually diluted by quartz particles so that a packed height about $5 \mathrm{~mm}$ was achieved. For all kinetics measurements, the catalyst was pre-conditioned for $2 \mathrm{~h}$ at $650^{\circ} \mathrm{C}$ in $1 \%$ $\mathrm{SO}_{2}$ and $2 \% \mathrm{CO}$ mixture. The steady-state reaction conversion was recorded. Generally, no apparent conversion decline within $30 \mathrm{~min}$ was considered as steady state. The steady state was easily achieved at high reaction temperatures. At low temperatures, a longer time varied from a few hours to one day was needed to reach a steady state when the reaction condition was changed. 
Catalyst. Both bulk composite and impregnated oxide catalysts were prepared in this study. The composite catalysts were prepared by coprecipitating aqueous salt solutions of the metals with ammonium carbonate. The precipitates were washed twice with hot deionized water and then dried for about $12 \mathrm{~h}$ at $110^{\circ} \mathrm{C}$. The dried samples were further heated for a few hours in stagnant air at $650^{\circ} \mathrm{C}$. The particle sizes used for activity tests were $-35+100$ mesh $(420-149 \mu \mathrm{m})$ except for tests with zirconia catalysts where -250 mesh $(<63 \mu \mathrm{m})$ particles were used. For kinetics measurements, particles of a average size of $100 \mu \mathrm{m}$ were used. The supported catalysts were prepared by conventional wet impregnation of the support with aqueous salt solutions of the metals. The slurry of the support and solution was degassed in vacuum so that the salt solution fully filled the pores of the support during impregnation. Then, the excess solution was filtered. The wetted samples were dried for two days at room temperature and then heated for four hours at $650-700^{\circ} \mathrm{C}$ in a muffle furnace. The $\mathrm{Cu} / \gamma-\mathrm{Al}_{2} \mathrm{O}_{3}$ catalyst was prepared by reduction of $\mathrm{CuO} / \gamma-\mathrm{Al}_{2} \mathrm{O}_{3}$ with $10 \% \mathrm{CO} / \mathrm{He}$ at $300^{\circ} \mathrm{C}$.

Microstructure of the used catalyst was analyzed by Scanning transmission electron microscopy (STEM) on a Vacuum Generators HB603 instrument. The catalyst surface properties were characterized by X-ray photoelectron spectroscopy (XPS) on a Perkin Elmer 5100 instrument. The catalyst reducibility was investigated on a Cahn TG 121 thermogravimetric analyzer with a MKS quadrupole mass spectrometer attached for gas analysis.

\subsection{Results}

\subsubsection{Transition Metal-Impregnated Ceria Catalysts}

Figure 4.1 shows the light-off curves of sulfur dioxide reaction with carbon monoxide over the transition metal-impregnated ceria catalysts. The light-off temperatures are $500^{\circ} \mathrm{C}$ on the $\mathrm{Cu} / \mathrm{CeO}_{2}$ and $\mathrm{Ni} / \mathrm{CeO}_{2}$ catalysts, $550^{\circ} \mathrm{C}$ on the $\mathrm{Pt} / \mathrm{CeO}_{2}$, and $600^{\circ} \mathrm{C}$ on the $\mathrm{Co} / \mathrm{CeO}_{2}$ and $\mathrm{Mn} / \mathrm{CeO}_{2}$. A light-off temperature higher than $600^{\circ} \mathrm{C}$ was found for unmodified ceria and for $\mathrm{Cr} / \mathrm{CeO}_{2}$ catalysts. Thus, addition of transition metals significantly lowered the light-off temperature of ceria. The fall-off behavior on these catalysts as well as water vapor effects are plotted in Figure 4.2. In these tests, ceria and $\mathrm{Cr} / \mathrm{CeO}_{2}$ were activated by reduction with $10 \% \mathrm{CO} / \mathrm{He}$ at $600^{\circ} \mathrm{C}$. The reaction starts to fall off around $550^{\circ} \mathrm{C}$ on ceria and below $500^{\circ} \mathrm{C}$ on the other catalysts. The $\mathrm{Cr} / \mathrm{CeO}_{2}$ shows a low fall-off temperature, although it was difficult to activate it in the reaction mixture(Figure 4.1). However, this catalyst completely deactivated upon addition of water at $550^{\circ} \mathrm{C}$ as did ceria. The other catalysts were still active in the presence of water. The sulfur yield at $510^{\circ} \mathrm{C}$ was higher on the $\mathrm{Cu}, \mathrm{Co}$, Ni-impregnated ceria catalysts $(\sim 0.7)$ than on the Mn, Pt-impregnated ceria (0.4-0.6). Table 4.1 lists the numeric values of sulfur yield and $\mathrm{SO}_{2}$ conversion in tests with the dry and wet reactant gas mixtures shown in Figures 4.1-2. It is seen that in the dry gas almost all the sulfur dioxide was converted to 
elemental sulfur. However, the elemental sulfur yield decreased from a typical 0.96 (dry gas) to $0.4-0.7$ (wet gas) due to the formation of hydrogen sulfide.

Figure 4.3 shows the variation of gaseous product distribution with time-on-stream on the $\mathrm{Cu} / \mathrm{CeO}_{2}$ catalyst at $510^{\circ} \mathrm{C}$ in the presence of water. Formation of $\mathrm{H}_{2} \mathrm{~S}$ according to reactions (4) and (6) consumed some reductant $\mathrm{CO}$, resulting in sub-stoichiometric amount for the reduction of $\mathrm{SO}_{2}$. The ratio of $\mathrm{H}_{2} \mathrm{~S}$ to $\mathrm{SO}_{2}$ concentration in the product gas was around stoichiometric, which means that nearly complete conversion of the inlet $\mathrm{CO}$ took place. Figure 4.3 also indicates that the $\mathrm{Cu} / \mathrm{CeO}_{2}$ catalyst is stable under the reacting conditions, since no apparent deactivation was observed during a 25 -hour run. This promising catalyst system was used for detailed studies of the $\mathrm{SO}_{2}$ reaction with $\mathrm{CO}$.

\subsubsection{Effect of Copper Content on the Catalyst Activity and Selectivity of the $\mathrm{Cu}-\mathrm{Ce}-\mathrm{O}$ System}

Two series of $\mathrm{Cu}-\mathrm{Ce}-\mathrm{O}$ catalysts, listed in Table 4.2, were prepared by coprecipitation and impregnation methods, respectively, to evaluate the effect of copper content on the catalyst activity and selectivity. The La-doped ceria and alumina-supported copper catalysts are also included in Table 4.2 for comparison. The bulk $\mathrm{Cu}-\mathrm{Ce}-\mathrm{O}$ composite catalyst typically has a surface area around $30 \mathrm{~m}^{2} / \mathrm{g}$, while the impregnated ceria catalyst has a surface area slightly lower than the $\mathrm{CeO}_{2}$ support $\left(24 \mathrm{~m}^{2} / \mathrm{g}\right)$. The $\mathrm{Cu} / \mathrm{Al}_{2} \mathrm{O}_{3}$ catalysts have much higher surface area $\left(\sim 130 \mathrm{~m}^{2} / \mathrm{g}\right)$ due to the $\gamma$-alumina support. Since the $\mathrm{SO}_{2}$ conversion increases very fast with the reaction temperature, only experimental results at relatively low temperatures are included in Table 4.2 to compare the activity and selectivity. The light-off temperature on all the $\mathrm{Cu}-\mathrm{Ce}-\mathrm{O}$ catalysts was approximately $500^{\circ} \mathrm{C}$, while the light-off temperatures on the $\mathrm{Cu} / \mathrm{Al}_{2} \mathrm{O}_{3}$ catalysts and La-doped ceria were $560^{\circ} \mathrm{C}$ and $610^{\circ} \mathrm{C}$, respectively.

The impregnated and bulk $\mathrm{Cu}-\mathrm{Ce}-\mathrm{O}$ catalysts show similar overall behavior and the catalyst activity is not sensitive to the copper content in the catalyst. However, there is a trend for the selectivity toward elemental sulfur to decrease as the copper content increases. In the presence of $2 \%$ water, hydrogen sulfide instead of carbonyl sulfide becomes a major byproduct over the $\mathrm{Cu}-\mathrm{Ce}-\mathrm{O}$ catalyst. The elemental sulfur yield drops from a typical $95 \%$ in the dry gas to about $70 \%$ in the wet gas. The $\mathrm{Cu} / \gamma-\mathrm{Al}_{2} \mathrm{O}_{3}$ catalyst has a little higher activity than the $\mathrm{CuO} / \gamma-\mathrm{Al}_{2} \mathrm{O}_{3}$, but, both catalysts are much less active than the $\mathrm{Cu}-\mathrm{Ce}-\mathrm{O}$ catalysts. Also, in contrast to the $\mathrm{Cu}-\mathrm{Ce}-\mathrm{O}$, the copper/alumina catalyst favors the formation of $\operatorname{COS}$ in the presence of water as has been reported in the literature (1) and verified in this work.

\subsubsection{Zirconate and Zirconia Catalysts}

Zirconium oxide has the fluorite type structure of ceria and is similar to ceria in many physical properties, such as high oxygen mobility and oxygen ion vacancy concentration, 
but, zirconia is much more difficult to be reduced than ceria. Yttrium-stabilized zirconia is a well known oxygen ion conductor (2). Mixed oxides of lanthanide elements and zirconium were reported by Bajars (3) as catalysts for sulfur dioxide reduction by $\mathrm{CO}$. In addition, $\mathrm{Zr}_{2} \mathrm{Ln}_{2} \mathrm{O}_{7}$-type zirconates ( $\mathrm{Ln}=$ lanthanide element from $\mathrm{La}$ to $\mathrm{Tb}$ ) of pyrochlore structure, notably, $\mathrm{Gd}_{2} \mathrm{Zr}_{2} \mathrm{O}_{7}$, are known as another class of oxygen ion conductors (4).

Several zirconates $(\mathrm{Ce}, \mathrm{Tb}, \mathrm{Gd})$ and zirconia-based oxides were prepared and tested in this work under the same conditions as the ceria-based catalysts. The results are summarized in Table 4.3. The zirconates have surface areas from about 30 to $50 \mathrm{~m}^{2} / \mathrm{g}$. Ydoped zirconia has much higher surface area than the $\mathrm{Cu}$-doped zirconia, which may reflect the known stabilization effect yttrium imparts to the zirconia crystal structure. The zirconia-based catalysts consist largely of mesopores(tens $\AA$ in dia.). Therefore, small particles, less than $63 \mu \mathrm{m}$, were used in the tests of the $\mathrm{ZrO}_{2}$-based catalysts to overcome pore diffusion resistance. The light-off temperature over the $\mathrm{Ce}, \mathrm{Tb}$ and Gd-zirconates was around $700^{\circ} \mathrm{C}$, higher than that for ceria. After the reaction was initiated at high temperature, however, the zirconate catalyst could maintain its high activity as the reaction temperature was lowered to $470^{\circ} \mathrm{C}$. The performance of the $\mathrm{Gd}_{2} \mathrm{Zr}_{2} \mathrm{O}_{7}$ catalyst system is illustrated in Figure 4.4. More than $95 \%$ elemental sulfur yield was obtained over the temperature range 470 to $700^{\circ} \mathrm{C}$ in the dry gas. After the addition of $2 \%$ water into the reactant gas at $560^{\circ} \mathrm{C}$, the $\mathrm{Ce}_{2} \mathrm{Zr}_{2} \mathrm{O}_{7}$ and $\mathrm{Tb}_{2} \mathrm{Zr}_{2} \mathrm{O}_{7}$ catalysts were quickly deactivated; only the $\mathrm{Gd}_{2} \mathrm{Zr}_{2} \mathrm{O}_{7}$ catalyst remained active. As the temperature was decreased to $510^{\circ} \mathrm{C}$, this catalyst was also deactivated in the presence of water(Figure 4.4). Therefore, $\mathrm{Gd}_{2} \mathrm{Zr}_{2} \mathrm{O}_{7}$ is the most active among the three zirconate catalysts tested. The activity of this catalyst can be promoted by copper as indicated by the data of Table 4.3.

The yttria-doped zirconia catalyst, $\mathrm{Zr}_{0.9} \mathrm{Y}_{0.1} \mathrm{O}_{\mathrm{x}}$, has a $610^{\circ} \mathrm{C}$ light-off temperature, same as the La-doped ceria. The light-off temperature was lowered to $510^{\circ} \mathrm{C}$ by the addition of copper. The slightly lower $\mathrm{SO}_{2}$ conversion observed on the $\mathrm{Cu}-\mathrm{Zr}(\mathrm{Y})-\mathrm{O}$ catalyst(Table 4.3) compared to $\mathrm{Cu}-\mathrm{Ce}(\mathrm{La})-\mathrm{O}$ at the same reaction temperature(Table 4.3) may be due to pore diffusion limitation in the former catalyst system. Overall, zirconia is similar to ceria in its catalytic properties for the reduction of sulfur dioxide by carbon monoxide.

\subsubsection{Effect of Carbon Dioxide on Catalyst Activity and Selectivity}

Carbon dioxide is produced by the present reaction and may also be present in the feed gas stream. Thus, its effect on catalyst activity and selectivity was briefly checked in this work. As shown in Figure 4.5, addition of about $3 \%$ carbon dioxide into the reactant gas mixture at $510^{\circ} \mathrm{C}$ almost completely suppressed the reaction on the $\mathrm{Ce}_{0.9} \mathrm{La}_{0.1} \mathrm{O}_{\mathrm{x}}$ catalyst. The $\mathrm{SO}_{2}$ conversion dropped from about 1.0 to 0.1 , while the sulfur yield decreased from 0.96 to trace amounts. The catalyst activity was restored in the presence 
of carbon dioxide only when the temperature was raised to $600^{\circ} \mathrm{C}$. However, the elemental sulfur yield was decreased to 0.81 because $\mathrm{CO}_{2}$ lowered the $\mathrm{SO}_{2}$ conversion and promoted the production of carbonyl sulfide(Figure 4.5). In contrast, addition of $\mathrm{CO}_{2}$ at $510^{\circ} \mathrm{C}$ did not suppress the reaction on the $7.8 \mathrm{wt} . \% \mathrm{Cu} / \mathrm{CeO}_{2}$ catalyst. This catalyst can maintain its activity even at the lower temperature of $465^{\circ} \mathrm{C}$. Sulfur yield was decreased by a few percent as a result of promoted COS production and lower $\mathrm{SO}_{2}$ conversion. These results show that copper can enhance the resistance of the ceria catalyst to carbon dioxide poisoning.

\subsubsection{Bulk Cu0.15[Ce(La) $]_{0.85} \mathrm{O}_{\mathrm{x}}$ Catalyst}

The $\mathrm{Cu}_{0.15}[\mathrm{Ce}(\mathrm{La})]_{0.85} \mathrm{O}_{\mathrm{x}}$ catalyst was chosen for further studies. This catalyst showed no apparent deactivation during a $35-\mathrm{h}$ run in the presence of $2 \%$ water at $470^{\circ} \mathrm{C}$. The variation of surface area with temperature is shown in Table 4.4.

Light-off over $\mathrm{Cu}_{0.15}[\mathrm{Ce}(\mathrm{La})]_{0.85} \mathrm{O}_{\mathrm{x}}$ Catalyst. Light-off and fall-off behavior of various catalysts were reported above as major reaction characteristics. The light-off behavior of the $\mathrm{Cu}-\mathrm{Ce}-\mathrm{O}$ catalyst was carefully examined with the $\mathrm{Cu}_{0.15}[\mathrm{Ce}(\mathrm{La})]_{0.85} \mathrm{O}_{\mathrm{x}}$ as a model catalyst. Figure 4.6 shows light-off curves of the $\mathrm{Cu}_{0.15}[\mathrm{Ce}(\mathrm{La})]_{0.85} \mathrm{O}_{\mathrm{x}}$ catalyst under various reaction conditions. The light-off over this catalyst occurred at the temperature range from 440 to $465^{\circ} \mathrm{C}$ irrespective of initial $\mathrm{SO}_{2}$ concentration and contact times. This confirmed that the light-off temperature was determined by the intrinsic kinetics property of the catalyst and not caused by heat release effect in this exothermic reaction. Thus, the light-off temperature can be used as a crude criterion in the catalyst activity ranking. It is noted that the same $\mathrm{SO}_{2}$ conversion was achieved at a temperature indicated by the thermocouple placed on the top of the catalyst bed or inserted inside the catalyst bed. The temperature gradient in the packed bed was diminished by the small reactor tube $(6 \mathrm{~mm})$ and shallow catalyst bed $(<10 \mathrm{~mm})$. Although the light-off temperature is not affected by the reaction conditions, the lowest light-off temperature was observed with a catalyst pre-reduced by $\mathrm{CO}$. This effect is further illustrated by the activation profiles in Figure 4.7 where nano- $\mathrm{Cu}_{0.15} \mathrm{Ce}_{0.85} \mathrm{O}_{\mathrm{x}}$ catalyst, prepared by inert gas phase condensation and controlled oxidation to non-stoichiometric cerium oxide, shows an activation process more rapid than the corresponding bulk catalyst and comparable to the pre-reduced bulk catalyst.

$\mathrm{SO}_{2}$ Conversion. Effect of $[\mathrm{CO}] /\left[\mathrm{SO}_{2}\right]$ ratio in the feed gas, $\mathrm{R}_{\mathrm{CO}}$, on product distribution over the $\mathrm{Cu}_{0.15}[\mathrm{Ce}(\mathrm{La})]_{0.85} \mathrm{O}_{\mathrm{x}}$ catalyst is shown in Figure 4.8. Under constant contact time and reaction temperature, $\mathrm{SO}_{2}$ conversion rapidly increased with $\mathrm{R}_{c o}$. $\mathrm{COS}$ formation over the $\mathrm{Cu}_{0.15}[\mathrm{Ce}(\mathrm{La})]_{0.85} \mathrm{O}_{\mathrm{x}}$ catalyst was minor at low $\mathrm{SO}_{2}$ conversions but became significant at high $\mathrm{SO}_{2}$ conversions if $\mathrm{R}_{\mathrm{CO}}$ greater than 2 . Variation of conversion with contact time at different temperatures is plotted in Figure 4.9. The conversion starts to decline from 0.99 at contact times shorter than about $0.045 \mathrm{~g} \cdot \mathrm{s} / \mathrm{cc}(\mathrm{STP})$ at $510^{\circ} \mathrm{C}$. No effect of contact time on selectivity was observed. Considering these results, reaction 
kinetics over the $\mathrm{Cu}_{0.15}[\mathrm{Ce}(\mathrm{La})]_{0.85} \mathrm{O}_{\mathrm{x}}$ catalyst was investigated by varying $\mathrm{SO}_{2}$ concentration with $\mathbf{R}_{\mathrm{CO}}$ being fixed at 2 . Under such reaction composition, selectivity to sulfur was always about $95 \%$. Therefore, only $\mathrm{SO}_{2}$ conversion is reported in the following results. Figure 4.10 shows typical plots of $\mathrm{SO}_{2}$ conversion at $510^{\circ} \mathrm{C}$ versus contact time for different inlet $\mathrm{SO}_{2}$ concentration. These data were fitted by the same first-order equation. Resulting rate constant was a weak function of $\left[\mathrm{SO}_{2}\right]_{\text {inlet }}$.

Water Vapor Effect on the $\mathrm{Cu}_{0.15}[\mathrm{Ce}(\mathrm{La})]_{0.85} \mathrm{O}_{\mathbf{x}}$ Catalyst. The effect of temperature on product distribution in the presence of $2 \% \mathrm{H}_{2} \mathrm{O}$ is shown in Figure 4.11. The difference between $\mathrm{SO}_{2}$ conversion and sulfur yield in Figure 4.11 mainly comprised of $\mathrm{H}_{2} \mathrm{~S}$. The temperature showed no effect on sulfur yield from 560 to $450^{\circ} \mathrm{C}$ over which $\mathrm{SO}_{2}$ conversion kept constant. Sulfur yield declined with $\mathrm{SO}_{2}$ conversion when temperature was decreased from 450 to $435^{\circ} \mathrm{C}$. Effect of contact time on sulfur yield is illustrated in Figure 4.12. For all three temperatures tested $\left(470^{\circ} \mathrm{C}, 510^{\circ} \mathrm{C}\right.$, and $\left.560^{\circ} \mathrm{C}\right)$, difference between $\mathrm{SO}_{2}$ conversion and sulfur yield was not affected as the contact time decreased from 0.09 to $0.022 \mathrm{~s} \cdot \mathrm{g} / \mathrm{cc}$. These results indicate that production of $\mathrm{H}_{2} \mathrm{~S}$ occurs simultaneously with $\mathrm{SO}_{2}$ conversion. Sulfur yield cannot be optimized by modifying operation conditions, temperature, contact time.

Although only three $\mathrm{SO}_{2}$ conversion data points are available in Figure 4.12 , its variation still nicely fell into the first order conversion line. Effect of water vapor content on sulfur yield is shown in Figure 4.13. Sulfur yield sharply decreased from ca. 0.76 to ca. 0.53 as water vapor was raised from $2 \%$ to $4 \%$. However, further increasing water vapor content did not cause a major change in sulfur yield. Sulfur yield was maintained at 0.45 level in the presence of 8 or $13 \% \mathrm{H}_{2} \mathrm{O}$. It is noted again that difference between $\mathrm{SO}_{2}$ conversion and sulfur yield was mainly due to production of $\mathrm{H}_{2} \mathrm{~S}$. COS formation was always minor in the presence of water vapor. Because stoichiometric feed gas was employed, the produced $\mathrm{H}_{2} \mathrm{~S}$ relative to un-reacted $\mathrm{SO}_{2}$ was always kept at the stoichiometric ratio as long as complete $\mathrm{CO}$ conversion occurred. Figure 4.13 shows that $\mathrm{SO}_{2}$ conversion and sulfur yield levels were flat at high temperatures. The higher the water vapor content in the feed gas, the more rapidly did $\mathrm{SO}_{2}$ conversion and sulfur yield fall off as temperature was lowered. Therefore, water vapor also had some inhibition effect on catalyst activity.

\subsubsection{Catalyst Characterization}

The comprehensive information on fresh catalyst structure will be presented in Chapter 6. The catalyst structure and composition usually changed after use for $\mathrm{SO}_{2}$ and $\mathrm{CO}$ reaction due to the introduction of sulfur. XRD analyses of the fresh composite $\mathrm{Cu}-\mathrm{Ce}-\mathrm{O}$ catalysts identified two crystal phases, fluorite-type and copper oxide, in catalysts containing over 15 at.\% copper, and only the fluorite structure in the composites containing less than 15 at.\% $\mathrm{Cu}$. Also in the $\mathrm{Y}$-doped and $\mathrm{Cu}$-doped zirconia catalysts, only the fluorite-type structure was found. Two small copper oxide peaks were found in the fresh 7.8 wt. $\% \mathrm{CuO}_{\mathrm{x}} / \mathrm{CeO}_{2}$ catalyst as shown in Figure 4.14 , but, these two peaks disappeared in the used catalyst. The distinct fluorite-type diffraction pattern was found in 
both the used and fresh $\mathrm{Cu}-\mathrm{Ce}-\mathrm{O}$ catalysts, which indicates that the fluorite oxide was stable in the present reaction conditions.

Elemental distributions ( $\mathrm{S}, \mathrm{Cu}, \mathrm{Ce}, \mathrm{O})$ in the used $\mathrm{Cu}-\mathrm{Ce}-\mathrm{O}$ catalysts were extensively studied with STEM X-ray microprobe. Figure 4.15a shows the elemental maps for the $\mathrm{Cu}_{0.02}[\mathrm{Ce}(\mathrm{La})]_{0.98} \mathrm{O}_{\mathrm{x}}$ catalyst after 2-day test. No bulk copper oxide or sulfide particles were observed with this catalyst. Copper remained well dispersed in cerium oxide matrix after use. The existence of small amounts of sulfur was revealed. But, the sulfur content was too low for its distribution map to be unambiguously discriminated against background noise. Figures $4.15 \mathrm{~b}-\mathrm{c}$ show typical elemental distributions in a used $\mathrm{Cu}_{0.15}[\mathrm{Ce}(\mathrm{La})]_{0.85} \mathrm{O}_{\mathrm{x}}$ catalyst. Three major structural characteristics are: (i) bulk copper particles formed segregated copper sulfide crystals; (ii) copper and sulfur extensively distributed on cerium oxide matrix; (iii) cerium oxide was the backbone of the catalyst structure.

Catalyst surface composition and property were analyzed by XPS. Tables 4.5-6 list the surface compositions of the used $\mathrm{Cu}_{0.02}[\mathrm{Ce}(\mathrm{La})]_{0.98} \mathrm{O}_{\mathrm{x}}$ and $\mathrm{Cu}_{0.15}[\mathrm{Ce}(\mathrm{La})]_{0.85} \mathrm{O}_{\mathrm{x}}$ catalysts, respectively. The surface composition of the top portion of the $\mathrm{Cu}_{0.02}[\mathrm{Ce}(\mathrm{La})]_{0.98} \mathrm{O}_{\mathrm{x}}$ catalyst bed is similar to that of the bottom portion and the catalyst tested for $6 \mathrm{~h}$ has similar composition to the one used for a much longer time. Two O1s peaks were found in all three $\mathrm{Cu}_{0.02}[\mathrm{Ce}(\mathrm{La})]_{0.98} \mathrm{O}_{\mathrm{x}}$ samples that suggest two kinds of oxygen species in the catalyst. The nature of the oxygen species will be discussed later. Copper content was close to the XPS detection limit. But, it is clear that there is more sulfur than that needed for copper sulfide formation. Carbon species were found in all the XPS measurements and it came from carbonaceous compound deposition. A simple calculation found that there is more oxygen detected on the catalyst surface than the stoichiometric amount of metal oxide (assume $\mathrm{Ce}=\mathrm{CeO}_{2}$ and $\mathrm{Cu}=\mathrm{CuO}$ ). The excess oxygen may be associated with sulfur element. Recall the light-off curves in Figure 4.6 where the $\mathrm{Cu}_{0.15}[\mathrm{Ce}(\mathrm{La})]_{0.85} \mathrm{O}_{\mathrm{x}}$ catalyst showed no activity at $433^{\circ} \mathrm{C}$ but became completely activated at high temperatures, such as $510^{\circ} \mathrm{C}$. The surface composition listed in Table 4.6 shows that the un-activated catalyst contained more sulfur and oxygen but less cerium than the activated one.

Figures 4.16a-d show the XP spectra of $\mathrm{Ce} 3 \mathrm{~d}, \mathrm{Cu} 2 \mathrm{p}, \mathrm{O} 1 \mathrm{~s}$, and $\mathrm{S} 2 \mathrm{p}$ core electrons. The binding energy of $\mathrm{Ce} 3 \mathrm{~d} 5 / 2$ is usually not affected by cerium oxidation state. Different cerium species are distinguished by their spectra pattern. The Ce3d spectra in Figure 4.16a for the un-activated $\mathrm{Cu}_{0.15}[\mathrm{Ce}(\mathrm{La})]_{0.85} \mathrm{O}_{\mathrm{x}}$ catalyst look the same as the cerium sulfate measured by Loof et al., 1991 (5). The Ce3d spectra for the activated $\mathrm{Cu}_{0.02}[\mathrm{Ce}(\mathrm{La})]_{0.98} \mathrm{O}_{\mathrm{x}}$ looks more like cerium oxide, while the activated $\mathrm{Cu}_{0.15}[\mathrm{Ce}(\mathrm{La})]_{0.85} \mathrm{O}_{\mathrm{x}}$ catalysts contains some sulfate component. The presence of $\mathrm{Ce}^{+3}$ cannot be identified by the XPS because of its low intensity. $\mathrm{Cu}_{2} \mathrm{~S}$ cannot be discriminated from $\mathrm{Cu}_{2} \mathrm{O}$ because both of them have the same binding energy and $\mathrm{L}_{3} \mathrm{VV}$ Auger kinetic energy (6). The $\mathrm{Cu} 2 \mathrm{p} 3 / 2$ peak at $935.6 \mathrm{eV}$ is assigned to copper sulfate. The Ols spectra indicate two kinds of oxygen species. In accordance with the literature data, the components at ca. $529.4 \mathrm{eV}$ and ca. $532 \mathrm{eV}$ are assigned to metal oxides and metal sulfates, respectively. Similarly, the S2p components at 167.0 to $168.9 \mathrm{eV}$ and at 162.1 to $162.6 \mathrm{eV}$ are assigned to metal sulfate and metal sulfide, respectively. Based on the present results, it is postulated that in a working catalyst some 
of copper is associated with copper sulfide, while some of cerium is associated with sulfate. An activated catalyst usually comprised of both metal sulfate and sulfide, while the un-activated 15 at. \% catalyst surface was totally covered by sulfate.

The surface was enriched in copper after use. Table 4.8 shows that the $\mathrm{Cu} / \mathrm{Ce}$ and $\mathrm{S} / \mathrm{Cu}$ ratios measured by XPS for a $\mathrm{Cu}_{0.15}[\mathrm{Ce}(\mathrm{La})]_{0.85} \mathrm{O}_{\mathrm{x}}$ catalyst after two-day test decreased by argon ion sputtering of the surface, but the $\mathrm{S} / \mathrm{Cu}$ did not reach a zero value because of interference from the catalyst pores.

\subsubsection{Reducibility of the $\mathrm{Cu}_{0.15}[\mathrm{Ce}(\mathrm{La})]_{0.85} \mathrm{O}_{\mathrm{x}}$ Catalyst}

Reducibility of the $\mathrm{Cu}_{0.15}[\mathrm{Ce}(\mathrm{La})]_{0.85} \mathrm{O}_{\mathrm{x}}$ catalyst by $\mathrm{CO}$ was investigated on a thermogravimetric analyzer coupled with a mass spectrometer. Figure 4.17 shows a typical temperature-programmed reduction profile of the catalyst in $3.5 \% \mathrm{CO} / \mathrm{N}_{2}$. The reduction started at ca. $80^{\circ} \mathrm{C}$. The doublet peak appeared around $120^{\circ} \mathrm{C}$ and $145^{\circ} \mathrm{C}$, respectively. There was no peak found around $500^{\circ} \mathrm{C}$ that is usually observed with bulk $\mathrm{CeO}_{2}$ and caused by reduction of surface capping oxygen according to $\mathrm{Yao}$ and $\mathrm{Yao}$ (7). The continuous weight loss was accompanied with the evolution of $\mathrm{CO}_{2}$ as measured by mass spectrometry. TPR studies of bulk $\mathrm{CuO}$ materials $(8,9)$ found that the reduction peaks appeared between 200 to $300^{\circ} \mathrm{C}$. Therefore, the presence of cerium oxide significantly lowered copper oxide reduction temperature. This profile looks the same as the one found for precious metal $(\mathrm{Pt}, \mathrm{Rh}) / \mathrm{CeO}_{2}$ system (10), suggesting strong synergism between copper and cerium oxide. The initial reduction rates, defined by the following equation, were measured under constant temperatures for the following kinetic analysis:

$$
\mathrm{R}_{\mathrm{w}}=-\frac{\mathrm{dW}}{\mathrm{W}_{\mathrm{o}} \mathrm{dt}} \mid \mathrm{t}=0
$$

This rate is plotted versus reduction temperature over the range of 100 to $600^{\circ} \mathrm{C}$ in Figure 4.18 in an Arrhenius form. The resulting activation energy, $12 \mathrm{~kJ} / \mathrm{mol}$, is a very small number. $\mathrm{SO}_{2}$ sorption on the $\mathrm{Cu}_{0.15}[\mathrm{Ce}(\mathrm{La})]_{0.85} \mathrm{O}_{\mathrm{x}}$ catalyst and reducibility of the sulfated catalyst were investigated as follows: flushing the reactor system with $\mathrm{N}_{2}$, achieving a stable baseline, introducing $1 \% \mathrm{SO}_{2} / \mathrm{N}_{2}$ into the reactor, about half a hour later, switching the $\mathrm{SO}_{2}$ stream to $2 \% \mathrm{CO} / \mathrm{N}_{2}$. Although no oxygen was fed, the catalyst showed rapid weight gain upon introduction of $\mathrm{SO}_{2}$. This indicates that $\mathrm{SO}_{2}$ reacted with catalyst surface oxygen, because cerium oxide has high oxygen storage ability. Even in the presence of oxygen, Hedges and $\mathrm{Yeh}$ (11) found that $\mathrm{SO}_{2}$ uptake rate on the $\mathrm{CeO}_{2} / \mathrm{Al}_{2} \mathrm{O}_{2}$ sorbent was independent of $\mathrm{P}_{\mathrm{O} 2}$. Therefore, the cerium oxide surface oxygen is active for sulfate formation. Reducibility of the catalysts after sulfation was dramatically decreased. No apparent reduction was observed below $450^{\circ} \mathrm{C}$, as opposed to the significant and rapid reduction with the fresh sample below this temperature. The Arrhenius plot of the initial reduction rate of the sulfated catalyst is shown in Figure 4.19. Clearly, two reduction regions exist. Below $550^{\circ} \mathrm{C}$, reduction rate steeply increases with temperature, resulting in an activation energy of $239 \mathrm{~kJ} / \mathrm{mol}$. Above $550^{\circ} \mathrm{C}$, the activation energy is only $9.8 \mathrm{~kJ} / \mathrm{mol}$ comparable to that for fresh catalysts. 


\subsection{Discussion}

Previous studies have suggested that the reduction of sulfur dioxide by carbon monoxide proceeds via a redox mechanism.

$$
\begin{aligned}
& \text { Cat- }[]+\mathrm{SO}_{2} \rightarrow \text { Cat-O }+\mathrm{SO} \\
& \text { Cat-O }+\mathrm{CO} \rightarrow \text { Cat- }[]+\mathrm{CO}_{2} \\
& \text { Cat- }[]+\mathrm{SO} \rightarrow \text { Cat-O }+\mathrm{S}
\end{aligned}
$$

Accordingly, the reaction is initiated by the creation of an oxygen vacancy. As an oxygen vacancy is created, $\mathrm{SO}_{2}$ donates one oxygen to that vacancy to form a $\mathrm{SO}$ group. The SO may be mobile on the surface until it finds another vacancy to donate its oxygen or a vacancy may migrate to a neighboring site to accept its oxygen. High oxygen mobility in the catalyst would facilitate the oxygen transfer on the surface or from the bulk to the surface. Therefore, oxygen vacancy and mobility seem to be important properties for an active catalyst. The active catalysts previously reported (12-15), La-Ti-O and La-Co-O perovskite mixed oxides, generally possess such properties. Ceria and zirconia studied in this work are well known for their oxygen vacancy and mobility properties. Ceria has a very stable fluorite-type structure, while the fluorite structure of zirconia can be stabilized by the use of oxide dopants. The oxygen vacancy in a fluorite oxide is created by replacing the metal ion ( $\mathrm{Ce}^{+4}$ or $\mathrm{Zr}^{+4}$ ) in the lattice with other di or tri-valent metal ions. Rare earth zirconates $\left(\mathrm{Ln}_{2} \mathrm{Zr}_{2} \mathrm{O}_{7}\right)$ having oxygen mobility properties were also found to be active catalysts in this work. All these results support the present mechanistic argument.

However, the oxygen vacancy can be taken up by other oxygen-containing molecules, such as $\mathrm{CO}_{2}$ or $\mathrm{H}_{2} \mathrm{O}$. The stronger the association of these impurity oxidants with the vacancy, the more they will inhibit the reaction. Thus, creation of oxygen vacancies on the surface is a key step. Incorporation of alkaline and rare earth dopant oxides into the ceria lattice enhances the oxygen vacancy concentration and mobility. But, the created vacancies are usually capped by an outside oxygen and the strong vacancy-dopant ion association stabilizes the capping oxygen. The capping oxygen has to be removed to bring about oxygen vacancy and initiate the redox reaction. For ceria, temperature-programmed reduction by hydrogen (7) has found that the surface capping oxygen can be removed at about $500^{\circ} \mathrm{C}$. Higher reduction temperature may be needed in the presence of $\mathrm{SO}_{2}$ due to its strong bonding to the surface. It is also known that $\mathrm{CO}$ adsorption on ceria is inhibited by water $(16,17)$. The introduction of transition metals may provide surface sites for $\mathrm{CO}$ adsorption and facilitate the reduction of the fluorite oxide surface through strong metalsupport interaction as found in the $\mathrm{Pt}-\mathrm{CeO}_{2}$ system $(8,10)$ :

$$
\text { Cat-M } \cdots \mathrm{CO}+\text { Cat-O } \rightarrow \text { Cat-M }+ \text { Cat- }[]+\mathrm{CO}_{2}
$$

In the above equation, "Cat-" represents the catalyst surface and " $M$ " is a metal site. The produced oxygen vacancy through Equation 11, Cat- [] , can further react according to the redox reaction scheme (8)-(10). This assumption was validated by the fact that the catalytic activity of ceria or zirconia and resistance to water or carbon dioxide poisoning 
were significantly enhanced by the addition of transition metals, such as copper. XPS studies showed that copper in the $\mathrm{Cu}-\mathrm{Ce}-\mathrm{O}$ catalyst tends to be stabilized in a reduced oxidation state $\left(\mathrm{Cu}^{+1}\right)$ instead of $\mathrm{CuO}$, while it is well known that $\mathrm{CO}$ strongly adsorbs on $\mathrm{Cu}^{+1}$ sites. Preliminary temperature-programmed reduction experiments indicated that addition of copper can initiate the reduction of surface capping oxygen of ceria at low temperatures. These data suggest that there is a strong interaction between copper (oxide) and ceria. For the $\mathrm{Cu}-\mathrm{Ce}-\mathrm{O}$ system, both coprecipitation and impregnation preparation methods gave rise to an active catalyst. The catalyst activity was not sensitive to the copper content, but the selectivity tended to decrease with the copper content. XRD analysis identified the $\mathrm{CuO}$ phase when the copper content was over 15 at. \%. STEM analysis revealed bimodal size distribution of copper on ceria. Only small amounts of copper are needed to promote the catalytic properties of ceria, and the excess copper (oxide) can form aggregates.

As reported in the literature $(14,18)$, the transition metal will likely be sulfided by the elemental sulfur product:

$$
\text { Cat-M }+\mathrm{S}_{\mathrm{X}} \rightarrow \text { Cat-MS }_{\mathrm{X}}
$$

Copper sulfide was found on a used $\mathrm{Cu}-\mathrm{Ce}-\mathrm{O}$ catalyst by XPS surface compositional analysis, but was not detected by XRD analysis, possibly because it is dispersed in ceria in amorphous form or because copper sulfide crystals did not grow on the stable ceria surface. The fluorite oxide showed high stability in the present study. For example, ceria kept its fluorite-type crystal structure after a $48 \mathrm{~h}$ test run. STEM elemental mapping showed that the sulfur on the catalyst was extensively associated with copper. The formation of copper sulfide extracted copper from the bulk so that the surface was enriched in copper on the used catalyst. Copper sulfide may play a similar role to copper in promoting the reducibility of the fluorite oxide. But, the deposited sulfur may react with $\mathrm{CO}$ to form $\mathrm{COS}$ through following equation:

$$
\text { Cat-MS } \mathrm{X}_{\mathrm{X}}+\mathrm{CO} \rightarrow \mathrm{Cat}-\mathrm{M}+\mathrm{COS}
$$

Therefore, an adsorbed $\mathrm{CO}$ molecule can pick up oxygen through equation (10) and sulfur through equation (14). We believe that $\operatorname{COS}$ formation is the result of these two competitive processes and it prevails in the following two cases: (i) when excess $\mathrm{CO}$ exists and the oxidant is not sufficient to oxidize it, the extra $\mathrm{CO}$ reacts with sulfur to form $\mathrm{COS}$; (ii) when the surface oxygen is more strongly bound than sulfur, the adsorbed $\mathrm{CO}$ picks up sulfur to form $\mathrm{COS}$. The reaction of $\mathrm{CO}$ and the deposited sulfur is further illustrated by Figure 4.20 , where $\mathrm{COS}$ evolution profiles are shown for $2 \% \mathrm{CO} / \mathrm{He}$ scavenging of the used catalysts following a helium flush. A simple exponential decay of $\operatorname{COS}(t)$ predicted by assuming a formation rate ${ }^{{ }} \operatorname{COS}{ }^{=k_{s}}[S]_{\text {surf. }}$. ${ }_{C O}$ fits well the data of Figure 4.20.

In addition to reactions $10-11, \mathrm{SO}_{2}$ can also react with the surface capping oxygen to form surface sulfate:

$$
\mathrm{SO}_{2}+2 \mathrm{O}_{\text {cat }} \stackrel{\text { strong }}{\longrightarrow} \mathrm{SO}_{4, \text { cat }}
$$


The surface sulfate is strongly bonded to the catalyst surface. In the presence of $\mathrm{CO}$, the sulfate may be reduced by $\mathrm{CO}$ back to $\mathrm{SO}_{2}$ through the following reaction:

$$
\mathrm{SO}_{4, \text { cat }}+2 \mathrm{CO} \stackrel{\text { slow }}{\longrightarrow} \mathrm{SO}_{2}+2 \mathrm{CO}_{2}+2 \mathrm{~V}_{\mathrm{O} \text {, cat }}
$$

But, the reaction (26) is a very slow step. Based on the present results and literature information, we think that surface capping oxygen in the above reactions is supplied from cerium oxide. Cerium oxide has high oxygen storage capacity and its surface oxygen cannot be flushed away by an inert gas stream such as helium. The formation of surface sulfate on cerium oxide does not require the presence of gaseous oxygen. A working catalyst comprises partially reduced cerium oxide surface and sulfated surface. Because the cerium oxide is immediately capped by sulfate species upon the introduction of the reacting gas mixture at low temperatures, a hysteresis effect was observed with this reaction and the light-off temperature essentially represents a temperature at which the catalyst surface could be regenerated. The light-off temperature around $450^{\circ} \mathrm{C}$ is consistent with the TPR result that apparent reduction of the sulfated surface starts to occur around $450^{\circ} \mathrm{C}$.

The above mechanistic discussion is strongly confirmed by the experimental results with non-stoichiometric cerium oxide (19), $\mathrm{CeO}_{2-x}$. Figure 4.21 compares light-off and fall-off temperatures of nanocrystalline $\mathrm{CeO}_{2-x}$ catalysts with those of precipitated catalysts. $\mathrm{CeO}_{2-x}$ catalysts have partially reduced surface and high concentration of oxygen vacancies and quasi-free electrons. Accordingly, light-off temperature on the $\mathrm{CeO}_{2-\mathrm{x}}$ catalyst was decreased by ca. $100^{\circ} \mathrm{C}$. A little hysteresis effect was observed with the bare $\mathrm{CeO}_{2-\mathrm{x}}$ catalyst and negligible hysteresis effect with the $\mathrm{La}$-doped $\mathrm{CeO}_{2-\mathrm{x}}$ catalyst. The bare $\mathrm{CeO}_{2-x}$ and $\mathrm{La}$-doped $\mathrm{CeO}_{2-x}$ catalysts showed even better performance than $\mathrm{Cu}$-promoted $\mathrm{CeO}_{2}$ prepared by precipitation. The significantly reduced light-off temperature and hysteresis effect of the $\mathrm{CeO}_{2 \cdot x}$ catalysts clearly demonstrate the importance of partially reduced cerium oxide surface in maintaining the redox reaction cycle.

The role copper played in the $\mathrm{Cu}-\mathrm{Ce}-\mathrm{O}$ catalyst probably is to promote the reducibility of cerium oxide and provide surface sites for $\mathrm{CO}$ adsorption. The promotion effect of copper to the surface reduction of fresh catalysts is clearly demonstrated by the TPR result. The $\mathrm{Cu}^{+1}$ species were observed by XPS with the fresh catalyst. But, the catalyst surface became complex in the $\mathrm{CO}+\mathrm{SO}_{2}$ reacting atmosphere. $\mathrm{CuO}$ particles formed copper sulfide crystals that have overall small surface area and little contribution to the catalytic activity. It is not known at the present time how copper ions and clusters in the cerium oxide matrix are affected by sulfur compounds. According to a recent study by Badley et al. (20) on $\mathrm{SO}_{2}$ and $\mathrm{CO}$ adsorption on $\mathrm{Cu} / \mathrm{Al}_{2} \mathrm{O}_{3}, \mathrm{SO}_{2}$ can block $\mathrm{CO}$ adsorption on $\mathrm{Cu}^{+2}$ sites but not $\mathrm{Cu}^{+1}$ sites, while the pre-adsorption of $\mathrm{CO}$ does not prevent $\mathrm{SO}_{2}$ adsorption. Therefore, copper may still provide strong sites such as $\mathrm{Cu}^{+1}$ for $\mathrm{CO}$ adsorption even in the presence of $\mathrm{SO}_{2}$.

Water vapor does not poison the $\mathrm{Cu}-\mathrm{Ce}(\mathrm{La})-\mathrm{O}$ catalyst but can react with $\mathrm{CO}$ to produce hydrogen, that is, the water-gas-shift (WGS) reaction can proceed over the $\mathrm{Cu}$ $\mathrm{Ce}(\mathrm{La})-\mathrm{O}$ catalyst. This secondary reaction reduces amount of $\mathrm{CO}$ available for $\mathrm{SO}_{2}$ 
reduction. In addition, produced hydrogen can react with the surface sulfur to produce $\mathrm{H}_{2} \mathrm{~S}$.

$$
\begin{aligned}
& \mathrm{CO}_{\mathrm{ad}}+\mathrm{H}_{2} \mathrm{O}_{\mathrm{ad}} \rightarrow \mathrm{CO}_{2}+\mathrm{H}_{2 \mathrm{ad}} \\
& \mathrm{H}_{2, \mathrm{ad}}+[\mathrm{S}]_{\mathrm{ad}} \rightarrow \mathrm{H}_{2} \mathrm{~S}_{\mathrm{ad}}
\end{aligned}
$$

The present parametric studies suggest that all the above reactions occur on the surface. The bulk reaction process is negligible. Therefore, sulfur yield is controlled by the surface reactions and could not be maximized by varying the reactor operation conditions. It is known that the WGS reaction proceeds on metal oxide catalysts through a redox mechanism (21). Similar to the reaction scheme for $\mathrm{SO}_{2}$ reduction by $\mathrm{CO}$, the creation of surface oxygen vacancy by $\mathrm{CO}$ reduction is considered to be the rate-determining step. Therefore, the WGS reaction inevitably occurs on the present catalyst. The $\mathrm{H}_{2} \mathrm{O}$ molecule will compete with $\mathrm{SO}_{2}$ to donate its oxygen to the vacancy. As a result, $\mathrm{H}_{2}$ production or $\mathrm{H}_{2} \mathrm{~S}$ production increases rapidly with partial pressure of water vapor. But, further increasing water vapor content beyond $8 \%$ did not cause significant change of product distribution. This information suggests that the WGS reaction may involve adsorbed $\mathrm{H}_{2} \mathrm{O}$. Because of the high redox activity of the $\mathrm{Cu}-\mathrm{Ce}(\mathrm{La})-\mathrm{O}$ catalyst, complete $\mathrm{CO}$ conversion was still achieved in the presence of water vapor. As long as stoichiometric $\mathrm{SO}_{2}$ and $\mathrm{CO}$ composition is used, the produced $\mathrm{H}_{2} \mathrm{~S}$ and un-reacted $\mathrm{SO}_{2}$ in the reactor effluent stream will also be in stoichiometric ratio. Therefore, high sulfur recovery may be achieved by using a down stream Claus reactor.

\subsection{Conclusion}

In this work, we have found that fluorite type oxides, ceria and zirconia, are active catalysts for reduction of $\mathrm{SO}_{2}$ by $\mathrm{CO}$ with high selectivity to elemental sulfur over carbonyl sulfide. The activity of these oxides may result from their high oxygen vacancy concentration and mobility properties that are needed for a redox reaction mechanism. Addition of active transition metals such as copper to the fluorite oxide significantly lowered the reaction light-off temperature and enhanced the catalyst resistance toward water vapor and carbon dioxide poisoning. Sulfur yield over the $\mathrm{Cu}-\mathrm{Ce}-\mathrm{O}$ catalysts was a strong function of $R_{\mathrm{CO}}$. More than $95 \%$ selectivity to sulfur was achieved on both catalysts with a reacting gas mixture of $\mathrm{R}_{\mathrm{CO}} \leq 2$. Analyses of the $\mathrm{Cu}-\mathrm{Ce}-\mathrm{O}$ system showed that the fluorite crystal structure of ceria is stable at the present reaction conditions and copper dispersion is stabilized by the ceria matrix. An active $\mathrm{Cu}-\mathrm{Ce}-\mathrm{O}$ catalyst can be prepared by either coprecipitation or impregnation. The catalyst activity is not sensitive to the copper content.

The reaction mechanism was discussed within the redox framework with the surface reduction as an initiation step. $\mathrm{SO}_{2}$ participated the redox reaction and also formed surface sulfate with the surface capping oxygen. Bulk $\mathrm{CuO}$ particles in the catalyst formed metal sulfide crystals that were active for COS production. But, copper was considerably dispersed in the cerium oxide matrix after reaction. A working catalyst consisted of partially sulfated cerium oxide surface and partially sulfided copper. Copper and cerium oxide are considered to provide $\mathrm{CO}$ adsorption sites and oxygen vacancy sites, 
respectively. Combination of copper and cerium oxide significantly enhanced reducibility of both copper oxide and cerium oxide. In the presence of water vapor, $\mathrm{H}_{2} \mathrm{O}$ molecules competed with $\mathrm{SO}_{2}$ to donate oxygen to the vacancy site favoring the water-gas-shift (WGS) reaction. Hydrogen produced from the WGS reaction promoted $\mathrm{H}_{2} \mathrm{~S}$ production. Sulfur yield was determined by the reaction stoichiometry and could not be optimized by changing the reactor operation conditions.

\subsection{Literature Cited}

1. Querido, R., and Short, W.L., Ind. Eng. Chem., Process Des. Develop. 12, 10-18 (1973).

2. Hagemuller, P., and Van Gool, W., Solid Electrolytes, Academic Press, New York, 1978.

3. Bajars, L., U.S. Patent 3978 200, 1976.

4. Tuller, H.L., and Moon, P.K., Materials Science and Engineering B1, 171-201 (1988).

5. Loof, P., Kasemo, B., Bjomkvist, L., Andersson, S., and Frestad, A., in Crucq, A. (editor), Catalysis and Automotive Pollution Control П, 1991 Elsevier Science Publishers B.V., Amsterdam, pp 153-273.

6. Wagner, C.D., Rigg, W.M., Davis, L.E., Moulder, J.F., and Muilenberg, G.E., Handbook of X-ray Photoelectron Spectroscopy, Perkin-Elmer, 1978.

7. Yao, H.C., and Yao, Y.F.Y., J. Catal. 86, 254-265 (1984).

8. Fierro, G., Jacono, M. L., Inversi, M., Porta, P., Lavecchia, R., and Cioci, F., "A study of anomalous temperature-programmed reduction profiles of $\mathrm{Cu}_{2} \mathrm{O}, \mathrm{CuO}$, and CuO-ZnO", J. Catal. 148, 709-721 (1994).

9. Boyce, A. L., Graville, S. R., Sermon, P. A., and Vong, M.S.W., "Reduction of CuO-containing catalysts, CuO: I \&I, XRD and XPS", React. Kinet. Catal. Lett. 434(1), 1-18 (1991).

10. Nunan, J.G., Silver, R.G., and Bradley, S.A., in Silver, R.G., Sawyer, J.E., and Summers, J.C., (Eds.) Catalytic Control of Air Pollution, ACS Symposium Series 495, American Chemical Society, Washington, DC 1992, Chapter 17.

11. Hedges, S.W., and Yeh, J.T., Environmental Progress 11(2), 98-103 (1992).

12. Whelan, J.M., U.S.Patent 4081 520, 1977.

13. Hibbert, D.B., and Campbell, R.H., Appl. Catal. 41, 273-287 (1988).

14. Hibbert, D.B., and Campbell, R.H., Appl. Catal. 41, 289-299 (1988).

15. Hibbert, D.B., Catal. Rev. - Sci. Eng. 34, 391-408 (1992).

16. Li, C., Sakata, Y., Arai, T., Domen, K., Maruya, K., and Onishi, T., J. Chem. Soc., Faraday Trans. 1 85, 929-943 (1989).

17. Li, C., Sakata, Y., Arai, T., Domen, K., Maruya, K, and Onishi, T., J. Chem. Soc., Faraday Trans. 1 85, 1451-1461 (1989).

18. Baglio, J.A., Ind. Eng. Chem. Prod. Res. Dev. 21, 38-41 (1982). 
19. Tschöpe, A., Liu, W., Flytzani-Stephanopoulos, M., and Ying, J.Y., J. Catal. 1995, in press.

20. Badley, M.B., Rochester, C.H., Hutchings, G.J., and King, F., "FTIR Spectroscopic Study of Thiophene, $\mathrm{SO}_{2}$, and $\mathrm{CO}$ Adsorption on $\mathrm{Cu} / \mathrm{Al}_{2} \mathrm{O}_{3}$ Catalysts" J. Catal. 148, 438-452 (1994).

21. Kung, H., "Transition Metal Oxide: Surface Chemistry and Catalysis" in Delmon, B. and Yates, J.T., (Editors), Studies in Surface Science and Catalysis, Vol. 45, p245, Elsevier, 1989. 
Table 4.1 Transition Metal-Impregnated Ceria Catalysts.

\begin{tabular}{|c|c|c|c|c|}
\hline \multicolumn{2}{|l|}{ Catalyst } & \multirow{2}{*}{$\begin{array}{l}\text { Light-off } \\
\mathrm{T}_{90 \%}{ }^{\mathrm{c}}\left({ }^{\circ} \mathrm{C}\right)\end{array}$} & \multicolumn{2}{|c|}{$\mathrm{Y}$-sulfur $/ \mathrm{X}-\mathrm{SO}_{2} \mathrm{f}_{\text {at }} 510^{\circ} \mathrm{C}$} \\
\hline Composition & surface area $\left(\mathrm{m}^{2} / \mathrm{g}\right)$ & & dry gas ${ }^{d}$ & wet gas ${ }^{\mathrm{e}}$ \\
\hline $\mathrm{CeO}_{2}$ & 24 & $>600$ & $0.04 / 0.12$ & $0.0 / 0.0$ \\
\hline $\mathrm{Cu} / \mathrm{CeO}_{2}{ }^{\mathrm{a}}$ & 21.4 & 500 & $0.97 / 0.99$ & $0.73 / 0.91$ \\
\hline $\mathrm{Ni} / \mathrm{CeO}_{2}{ }^{\mathrm{a}}$ & 22.7 & 500 & $0.97 / 0.98$ & $0.69 / 0.78$ \\
\hline $\mathrm{Pt} / \mathrm{CeO}_{2}{ }^{\mathrm{b}}$ & 22.9 & 550 & $0.66 / 0.68$ & $0.42 / 0.44$ \\
\hline $\mathrm{Mn} / \mathrm{CeO}_{2}{ }^{\mathrm{a}}$ & 20.8 & 600 & $0.95 / 0.97$ & $0.60 / 0.66$ \\
\hline $\mathrm{Co} / \mathrm{CeO}_{2}{ }^{\mathrm{a}}$ & 22.5 & 600 & $0.96 / 0.98$ & $0.73 / 0.88$ \\
\hline $\mathrm{Cr} / \mathrm{CeO}_{2}{ }^{\mathrm{a}}$ & 16.3 & $>600$ & $0.96 / 0.97$ & $0.0 / 0.0$ \\
\hline
\end{tabular}

a. $\mathrm{CeO}_{2}$ was impregnated with $0.5 \mathrm{M}$ metal nitrate solution. The atomic transition metal content in the resulting catalyst $\left(\mathrm{n}_{M} /\left(\mathrm{n}_{M}{ }^{+n_{C e}}\right) \times 100 \%\right)$ is about $13 \%$.

b. $\mathrm{CeO}_{2}$ was impregnated with $10 \mathrm{mg} \mathrm{Pt/cc} \mathrm{hydrogen} \mathrm{hexachloroplatinate(IV)} \mathrm{hydrate}$ solution.

c. reaction temperature at which $90 \%$ conversion occurred during temperature-rise test.

d. reacting gas mixture consisted of $1 \% \mathrm{SO}_{2}, 2 \% \mathrm{CO}$, balance helium.

e. $2 \% \mathrm{H}_{2} \mathrm{O}$ was added into reacting gas mixture.

f. sulfur yield/ $\mathrm{SO}_{2}$ conversion; see text. 
Table 4.2 Variation of Catalyst Activity and Selectivity with Catalyst Composition in the $\mathrm{Cu}-\mathrm{Ce}-\mathrm{O}$ System.

\begin{tabular}{|c|c|c|c|c|c|}
\hline \multicolumn{2}{|l|}{ Catalyst } & \multicolumn{4}{|c|}{$\mathrm{Y}$-sulfur $/ \mathrm{X}-\mathrm{SO}_{2} \mathrm{f}$} \\
\hline \multirow[t]{2}{*}{ Composition } & \multirow{2}{*}{$\begin{array}{c}\text { surface area } \\
\mathrm{m}^{2} / \mathrm{g}\end{array}$} & \multicolumn{2}{|c|}{ dry gas $^{d}$} & \multicolumn{2}{|l|}{ wet gase } \\
\hline & & $465^{\circ} \mathrm{C}$ & $510^{\circ} \mathrm{C}$ & $470^{\circ} \mathrm{C}$ & $510^{\circ} \mathrm{C}$ \\
\hline \multicolumn{6}{|l|}{ Composite Catalyst $^{a}$} \\
\hline $\mathrm{La}_{0.1} \mathrm{Ce}_{0.9} \mathrm{O}_{\mathrm{x}}$ & 28.5 & $0.06 / 0.20$ & $0.97 / 1.00$ & - & $0.0 / 0.0$ \\
\hline $\mathrm{Cu}_{0.01}[\mathrm{Ce}(\mathrm{La})]_{0.99} \mathrm{O}_{\mathrm{x}}$ & 57.0 & $0.97 / 1.00$ & $0.97 / 1.00$ & $0.65 / 0.81$ & $0.66 / 0.90$ \\
\hline $\mathrm{Cu}_{0.05}[\mathrm{Ce}(\mathrm{La})]_{0.95} \mathrm{O}_{\mathrm{x}}$ & 57.0 & $0.83 / 0.92$ & $0.95 / 0.98$ & $0.53 / 0.71$ & $0.61 / 0.87$ \\
\hline $\mathrm{Cu}_{0.15}[\mathrm{Ce}(\mathrm{La})]_{0.85} \mathrm{O}_{\mathrm{x}}$ & 30.7 & $0.97 / 0.99$ & $0.97 / 1.00$ & $0.69 / 0.90$ & - \\
\hline $\mathrm{Cu}_{0.20}[\mathrm{Ce}(\mathrm{La})]_{0.80} \mathrm{O}_{\mathrm{x}}$ & 37.1 & $0.86 / 0.89$ & $0.93 / 0.96$ & $0.72 / 0.89$ & $0.73 / 0.91$ \\
\hline $\mathrm{Cu}_{0.25}[\mathrm{Ce}(\mathrm{La})]_{0.75} \mathrm{O}_{\mathrm{x}}$ & 30.2 & $0.93 / 0.97$ & $0.94 / 1.00$ & $0.64 / 0.84$ & $0.69 / 0.92$ \\
\hline $\mathrm{Cu}_{0.35}[\mathrm{Ce}(\mathrm{La})]_{0.65} \mathrm{O}_{\mathrm{x}}$ & 33.8 & $0.93 / 0.98$ & $0.94 / 1.00$ & $0.67 / 0.88$ & - \\
\hline \multicolumn{6}{|l|}{ Impregnated Catalyst } \\
\hline $\mathrm{CeO}_{2}$ support & 24.0 & $0 / 0.0$ & $0.04 / 0.12$ & - & $0.0 / 0.0$ \\
\hline 3.5 wt. $\% \mathrm{CuOx} / \mathrm{CeO}_{2}$ & 22.0 & $0.93 / 0.97$ & $0.94 / 1.00$ & $0.60 / 0.77$ & $0.73 / 0.93$ \\
\hline 7.8 wt. $\% \mathrm{CuOx} / \mathrm{CeO}_{2}$ & 21.0 & $0.84 / 0.92$ & $0.95 / 0.99$ & $0.56 / 0.73$ & $0.68 / 0.91$ \\
\hline 21 wt. $\% \mathrm{CuO} / \gamma-\mathrm{Al}_{2} \mathrm{O}_{3}$ & 137 & $0.38 / 0.42$ & $0.56 / 0.57$ & - & - \\
\hline $\mathrm{Cu} / \gamma-\mathrm{Al}_{2} \mathrm{O}_{3}{ }^{\mathrm{c}}$ & 137 & - & $0.77 / 0.81$ & - & $0.38 / 0.61$ \\
\hline
\end{tabular}

a. catalysts were prepared by coprecipitation. (La) denotes that the cerium nitrate precursor used contained about $1.38 \mathrm{wt} \%$ lanthanum.

b. catalysts were prepared by impregnation. wt. \% denotes the weight percent of copper.

c. prepared by reducing the $21 \mathrm{wt} \% \mathrm{CuO} / \gamma-\mathrm{Al}_{2} \mathrm{O}_{3}$ with $10 \% \mathrm{CO} / \mathrm{He}$ at $300^{\circ} \mathrm{C}$.

d. reacting gas mixture consisted of $1 \% \mathrm{SO}_{2}, 2 \% \mathrm{CO}$, balance helium.

e. $2 \% \mathrm{H}_{2} \mathrm{O}$ was added into reacting gas mixture.

f. sulfur yield/ $\mathrm{SO}_{2}$ conversion; see text. 
Table 4.3 Reduction of Sulfur Dioxide by Carbon Monoxide over Zirconate and Zirconia Catalysts.

\begin{tabular}{|c|c|c|c|c|}
\hline \multicolumn{2}{|l|}{ Catalyst } & \multirow{2}{*}{$\begin{array}{l}\text { Light-off } \\
\mathrm{T}_{90 \%}\left({ }^{\circ} \mathrm{C}\right)\end{array}$} & \multicolumn{2}{|c|}{$\mathrm{Y}$-sulfur $/ \mathrm{X}-\mathrm{SO}_{2}^{\mathrm{d}}\left(510^{\circ} \mathrm{C}\right)$} \\
\hline Composition $^{\mathrm{a}}$ & surface area $\left(\mathrm{m}^{2} / \mathrm{g}\right)$ & & dry gas ${ }^{b}$ & wet gas $c$ \\
\hline $\mathrm{Gd}_{2} \mathrm{Zr}_{2} \mathrm{O}_{7}$ & 37.8 & 700 & $0.95 / 0.99$ & $0.0 / 0.0$ \\
\hline $\mathrm{Tb}_{2} \mathrm{Zr}_{2} \mathrm{O}_{7}$ & 50.8 & 700 & $0.97 / 0.99$ & - \\
\hline $\mathrm{Ce}_{2} \mathrm{Zr}_{2} \mathrm{O}_{7}$ & 37.0 & 700 & $0.96 / 1.00$ & - \\
\hline$\left(\mathrm{Gd}_{2} \mathrm{Zr}_{2}\right)_{0.85} \mathrm{Cu}_{0.15} \mathrm{O}_{\mathrm{x}}$ & 28.2 & 510 & $0.97 / 0.99$ & $0.59 / 0.81$ \\
\hline $\mathrm{Zr}_{0.9} \mathrm{Y}_{0.1} \mathrm{O}_{\mathrm{x}}$ & 41.7 & 610 & $0.54 / 0.58$ & - \\
\hline$\left[\mathrm{Zr}_{0.9} \mathrm{Y}_{0.1}\right]_{0.85} \mathrm{Cu}_{0.15} \mathrm{O}_{\mathrm{x}}$ & 65.0 & 510 & $0.87 / 0.90$ & - \\
\hline $\mathrm{Zr}_{0.8} \mathrm{Cu}_{0.2} \mathrm{O}_{\mathrm{x}}$ & 17.8 & 510 & $0.92 / 0.96$ & $0.70 / 0.87$ \\
\hline
\end{tabular}

a. catalysts were prepared by coprecipitation.

b. reacting gas mixture consisted of $1 \% \mathrm{SO}_{2}, 2 \% \mathrm{CO}$, balance helium.

c. $2 \% \mathrm{H}_{2} \mathrm{O}$ was added into reacting gas mixture.

d. sulfur yield/ $/ \mathrm{SO}_{2}$ conversion; see text.

Table 4.4 Variation of the Surface Area of $\mathrm{Cu}_{0.15}[\mathrm{Ce}(\mathrm{La})]_{0.85} \mathrm{O}_{\mathrm{X}}$ Catalyst with Thermal Treatment.

\begin{tabular}{llllll}
\hline & fresh catalyst & $\begin{array}{l}\text { tested } 12 \mathrm{~h} \\
\text { in dry gas } \\
\text { at } \sim 500^{\circ} \mathrm{C}\end{array}$ & $\begin{array}{l}\text { tested } 37 \mathrm{~h} \\
\text { in wet gas } \\
\text { at } \sim 500^{\circ} \mathrm{C}\end{array}$ & $\begin{array}{l}\text { tested } 18 \mathrm{~h} \\
\text { in dry gas } \\
\text { at } \sim 750^{\circ} \mathrm{C}\end{array}$ & $\begin{array}{l}\text { calcined } 17 \\
\mathrm{~h} \text { in air at } \\
\sim 750^{\circ} \mathrm{C}\end{array}$ \\
\hline $\mathrm{Sg}_{\mathrm{g}}\left(\mathrm{m}^{2} / \mathrm{g}\right)$ & 30.7 & 26.4 & 26.8 & 22.8 & 22.6 \\
\hline
\end{tabular}

a. dry reactant gas mixture consisted of $1 \% \mathrm{SO}_{2}, 2 \% \mathrm{CO}$, balance helium.

b. $2 \% \mathrm{H}_{2} \mathrm{O}$ was added into the dry reactant gas mixture. 
Table 4.5 Surface composition of used $\mathrm{Cu}_{0.02}[\mathrm{Ce}(\mathrm{La})]_{0.98} \mathrm{O}_{\mathrm{x}}$ catalysts.

\begin{tabular}{lccc}
\hline \multirow{2}{*}{ elements } & \multicolumn{2}{c}{ Used for $6 \mathrm{~h}$ at $440^{\circ} \mathrm{C}$} & \multicolumn{2}{c}{$\begin{array}{c}\text { Used for two days at } \\
\text { top portion }\end{array}$} & $\begin{array}{lcc}\text { bottom portion } \\
\text { different temperatures }\end{array}$ \\
\hline Ce3d & 23.2 & 22.4 & 25.2 \\
Cu2p3 & 2.6 & 3.2 & 5.3 \\
S2p & 5.9 & 8.3 & 5.6 \\
O1s & 68.2 & 66.1 & 63.9 \\
- fraction of $529.6 \mathrm{eV}$ & $57 \%$ & $61 \%$ & $55 \%$ \\
- fraction of $532.1 \mathrm{eV}$ & $43 \%$ & $39 \%$ & $45 \%$ \\
\hline
\end{tabular}

Table 4.6 Surface composition of used $\mathrm{Cu}_{0.15}[\mathrm{Ce}(\mathrm{La})]_{0.85} \mathrm{O}_{\mathrm{x}}$ catalysts.

\begin{tabular}{lcc}
\hline elements & tested for $2 \mathrm{~h}$ at $433^{\circ} \mathrm{C}$ & tested for $2 \mathrm{~h}$ at $510^{\circ} \mathrm{C}$ \\
\hline Ce3d & 9.9 & 23.1 \\
$\mathrm{Cu} 2 \mathrm{p} 3$ & 7.3 & 9.2 \\
$\mathrm{~S} 2 \mathrm{p}$ & 13.7 & 6.8 \\
O1s & 69.1 & 60.8 \\
-fraction of $529.6 \mathrm{eV}$ & $0 \%$ & $46 \%$ \\
-fraction of $532.1 \mathrm{eV}$ & $100 \%$ & $54 \%$ \\
\hline
\end{tabular}


Table 4.7 XPS binding energies of the $\mathrm{Cu}-\mathrm{Ce}-\mathrm{O}$ catalysts.

\begin{tabular}{|c|c|c|c|c|c|c|}
\hline \multirow{2}{*}{$\begin{array}{l}\text { Catalysts } \\
\mathrm{Cu}_{0.15}[\mathrm{Ce}(\mathrm{La})]_{0.85} \mathrm{O}_{\mathbf{x}}\end{array}$} & \multicolumn{2}{|c|}{$\mathrm{Cu} 2 \mathrm{p} 3$} & \multicolumn{2}{|c|}{ O1s } & \multicolumn{2}{|c|}{$\mathrm{S} 2 \mathrm{p}$} \\
\hline & & & & & & \\
\hline tested for long term & 932.2 & - & 529.2 & 531.6 & 168.0 & 162.6 \\
\hline tested at $510^{\circ} \mathrm{C}$ & 932.9 & 934.5 & 529.6 & 532.1 & 168.8 & 162.1 \\
\hline tested at $433^{\circ} \mathrm{C}$ & - & $933.8 / 935.6$ & - & 532.1 & 167.0 & - \\
\hline \multicolumn{7}{|l|}{$\mathrm{Cu}_{0.02}[\mathrm{Ce}(\mathrm{La})]_{0.98} \mathrm{O}_{\mathrm{x}}$} \\
\hline tested for long term & - & - & 529.4 & 532.0 & 168.9 & - \\
\hline tested at $440^{\circ} \mathrm{C}$ (bot.) & $933.1^{*}$ & 933.1 & 529.4 & 531.8 & 168.2 & 162.5 \\
\hline tested at $440^{\circ} \mathrm{C}$ (top) & - & - & 529.5 & 531.9 & 168.5 & 162.5 \\
\hline assignment & $\mathrm{Cu}^{+1}$ & $\mathrm{Cu}^{+2}$ & $\begin{array}{l}\text { metal } \\
\text { oxide }\end{array}$ & sulfate & $\begin{array}{l}\text { metal } \\
\text { sulfate }\end{array}$ & $\begin{array}{l}\text { metal } \\
\text { sulfide }\end{array}$ \\
\hline
\end{tabular}

*also contains $930.0 \mathrm{eV}$ component-isolated $\mathrm{Cu}$ ions.

Table 4.8 Surface Compositional Analysis of $\mathrm{Cu}_{0.15}[\mathrm{Ce}(\mathrm{La})]_{0.85} \mathrm{O}_{\mathrm{x}}$ Catalyst by XPS after tested for two days.

\begin{tabular}{lll}
\hline Atomic ratio & $\mathrm{Cu} / \mathrm{Ce}$ & $\mathrm{S} / \mathrm{Cu}$ \\
\hline bulk material $^{\mathrm{a}}$ & 0.176 & 0 \\
fresh catalyst & 0.133 & 0 \\
used catalyst & 0.364 & 1.59 \\
1-min $\mathrm{Ar}^{+}$sputtering & 0.206 & 1.36 \\
7-min $\mathrm{Ar}^{+}$sputtering & 0.151 & 1.15 \\
\hline
\end{tabular}

a. based on stoichiometry. 


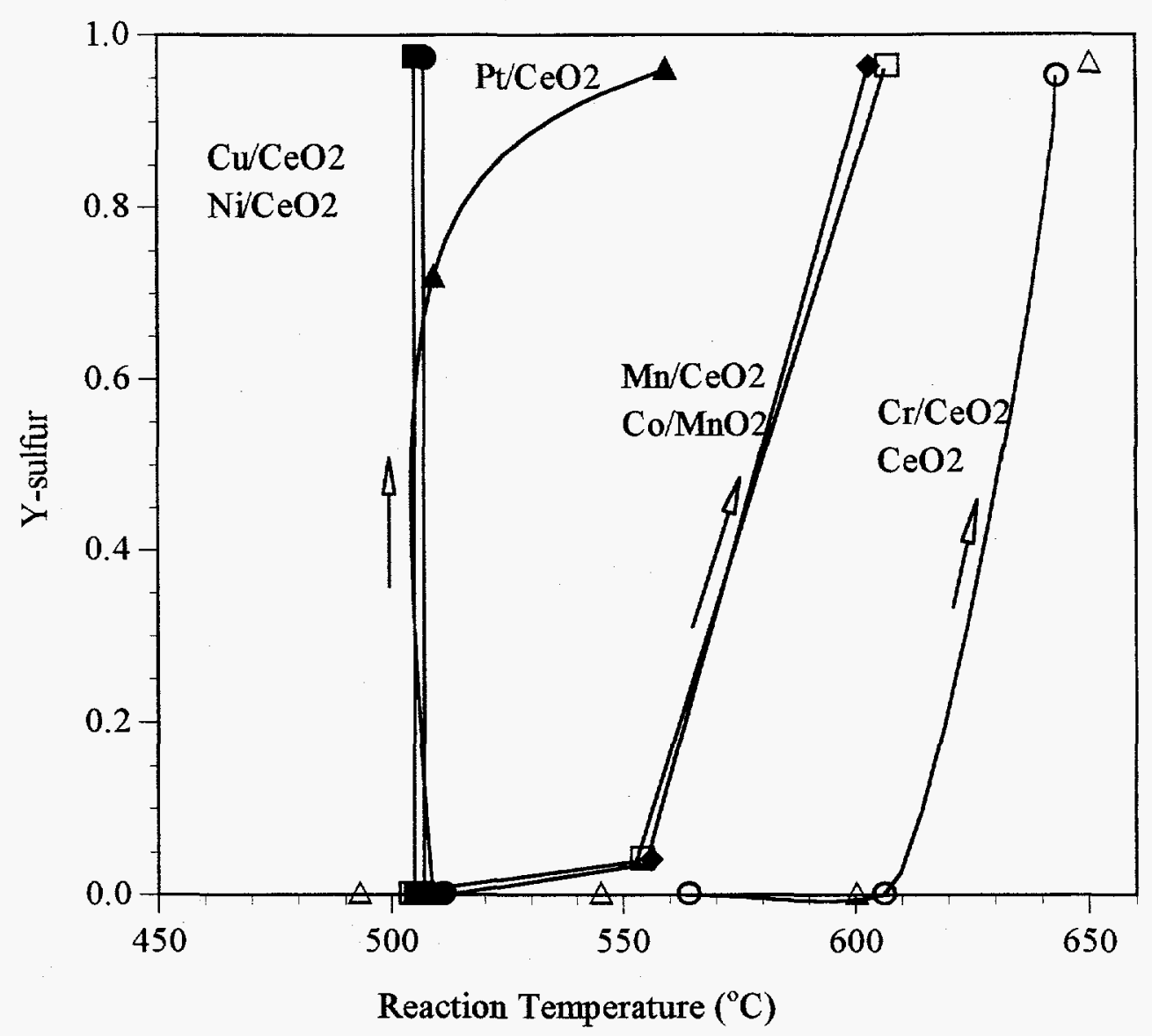

Figure 4.1 Light-off Behavior on the Transition Metal-Impregnated Ceria Catalysts ( $1 \%$ $\mathrm{SO}_{2}, 2 \% \mathrm{CO}, 97 \% \mathrm{He}$ ). 


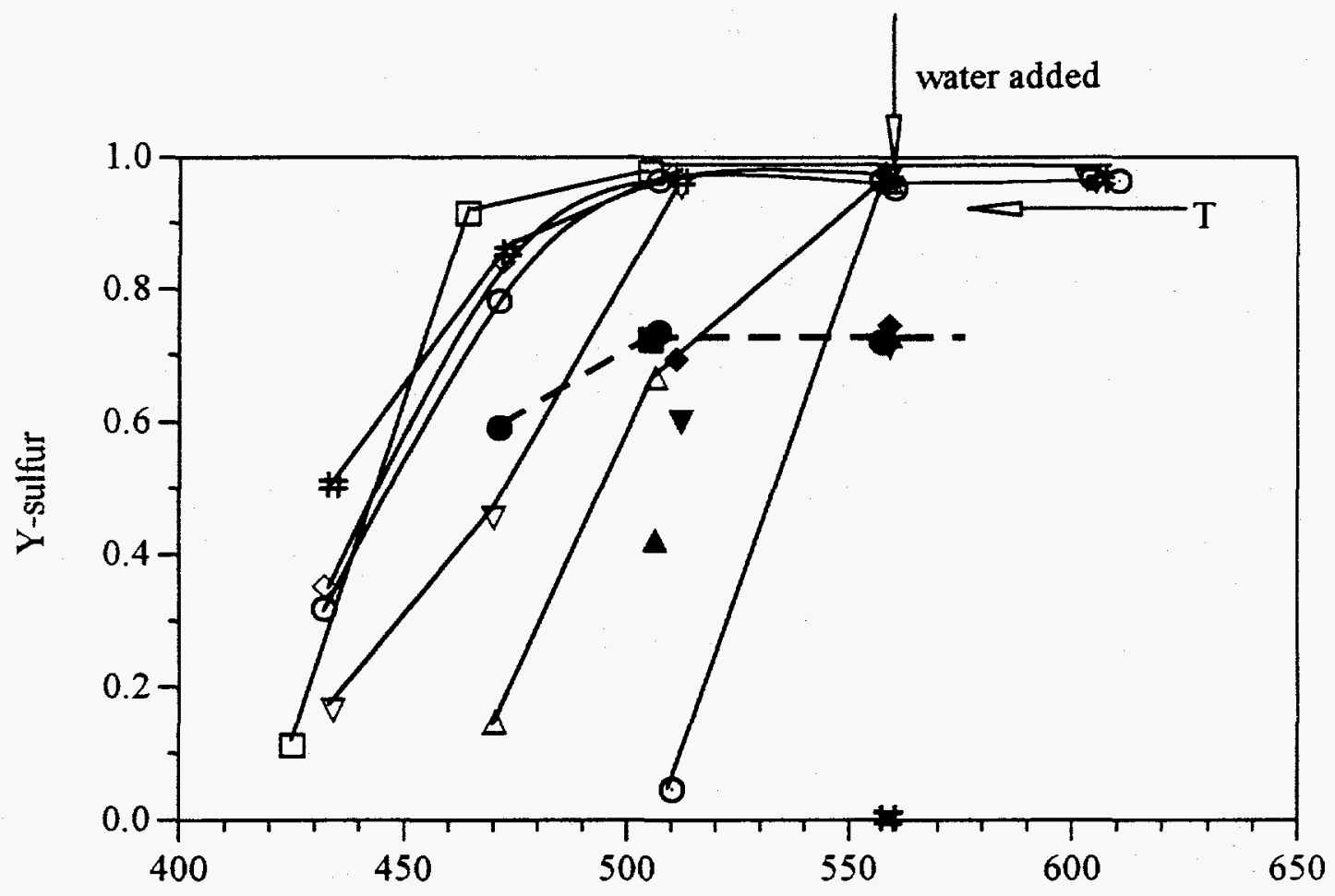

\section{Reaction Temperature $\left({ }^{\circ} \mathrm{C}\right)$}

Figure 4.2 Fall-off Behavior and Water Vapor Effect on the Transition MetalImpregnated Ceria Catalysts. $\square=\mathrm{Cu} / \mathrm{CeO}_{2}, \diamond=\mathrm{Ni} / \mathrm{CeO}_{2}, \Delta=\mathrm{Pt} / \mathrm{CeO}_{2}, \nabla=\mathrm{Mn} / \mathrm{CeO}_{2}$, $\mathrm{O}=\mathrm{Co} / \mathrm{CeO}_{2}, \#=\mathrm{Cr} / \mathrm{CeO}_{2}, \odot=\mathrm{CeO}_{2}$. Unfilled symbols for dry gas $\left(1 \% \mathrm{SO}_{2}, 2 \%\right.$ $\mathrm{CO}, 97 \% \mathrm{He})$, The filled ones for wet gas $\left(1 \% \mathrm{SO}_{2}, 2 \% \mathrm{CO}, 2 \% \mathrm{H}_{2} \mathrm{O}, 95 \% \mathrm{He}\right)$. 


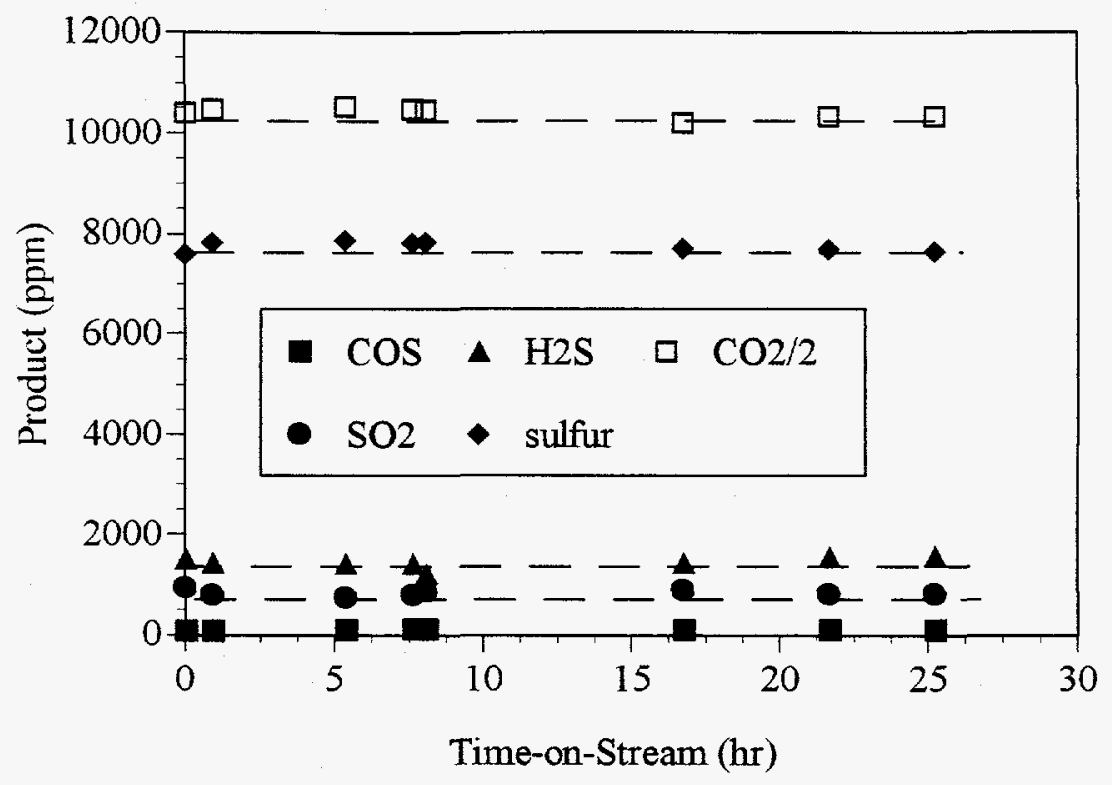

Figure 4.3 Long-term Test of $\mathrm{Cu} / \mathrm{CeO}_{2}$ Catalyst in Wet $\mathrm{Gas}\left(1 \% \mathrm{SO}_{2}, 2.1 \% \mathrm{CO}, 2 \%\right.$ $\mathrm{H}_{2} \mathrm{O}, 95 \% \mathrm{He} ; 100 \mathrm{sccm}, 505^{\circ} \mathrm{C}, 307 \mathrm{mg}$ catalyst loading).

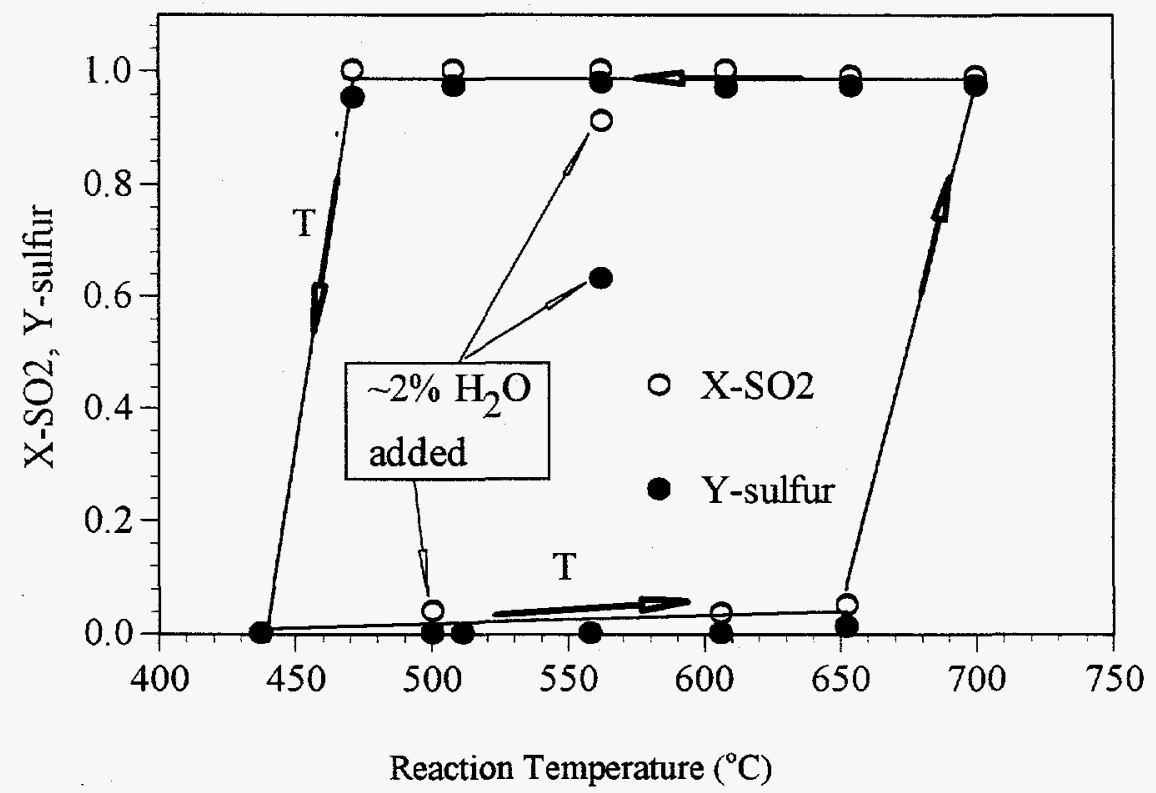

Figure 4.4 $\mathrm{SO}_{2}$ Reduction by $\mathrm{CO}$ over the $\mathrm{Gd}_{2} \mathrm{Zr}_{2} \mathrm{O}_{7}$ Catalyst $\left(1 \% \mathrm{SO}_{2}, 2 \% \mathrm{CO}\right)$. 


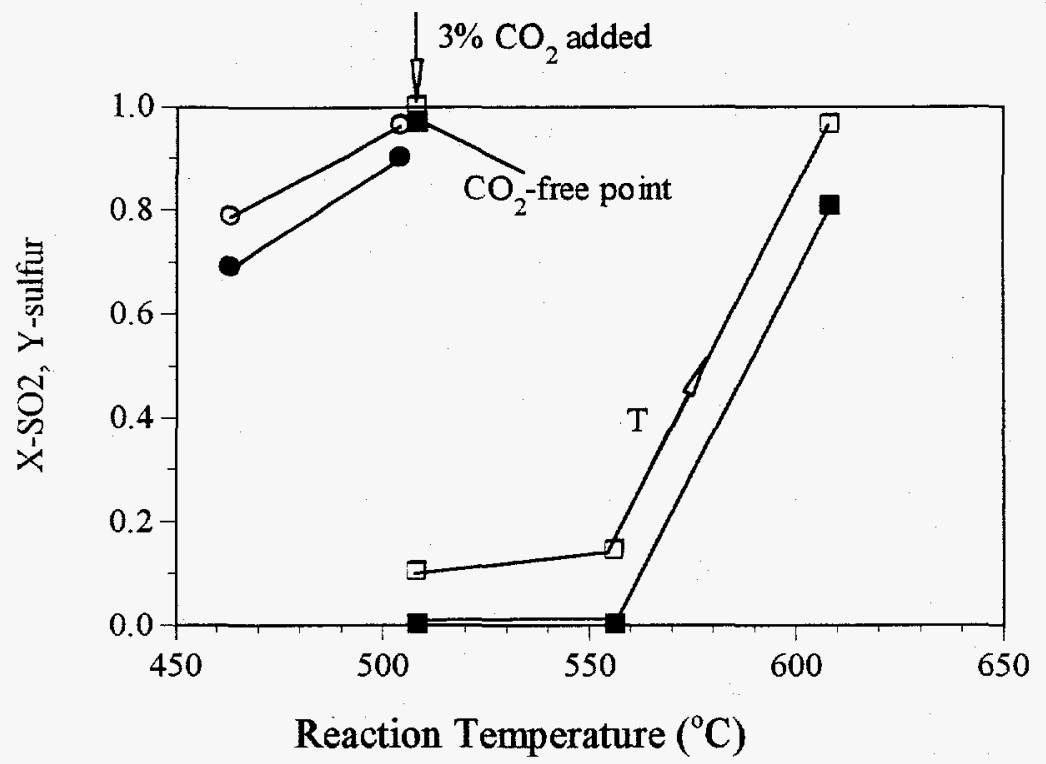

Figure 4.5 Effect of $\mathrm{CO}_{2}$ on Catalyst Activity and Selectivity $\left(1 \% \mathrm{SO}_{2}, 2 \% \mathrm{CO}, 3 \%\right.$ $\mathrm{CO}_{2}, 94 \% \mathrm{He}$ ). $\square=\mathrm{La}_{0.1} \mathrm{Ce}_{0.9} \mathrm{O}_{1.95}, \mathrm{O}=\mathrm{Cu} / \mathrm{CeO}_{2}$. Unfilled symbols for $\mathrm{X}-\mathrm{SO}_{2}$ and the filled ones for Y-sulfur $(\boldsymbol{\square}, \bullet)$.

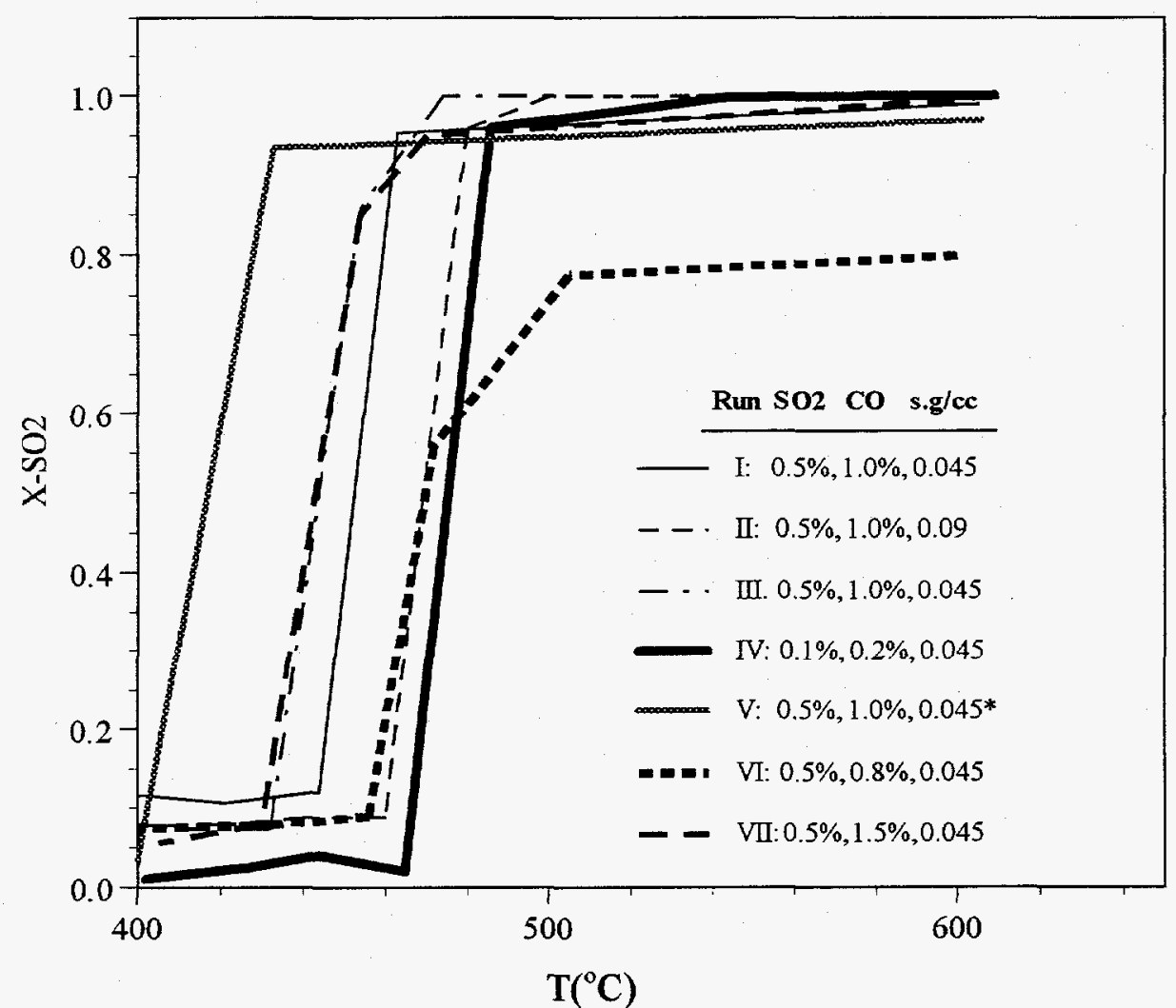

Figure 4.6 Effect of experimental conditions on light-off temperature of $\mathrm{Cu}_{0.15}[\mathrm{Ce}(\mathrm{La})]_{0.85} \mathrm{O}_{\mathrm{x}}$ catalyst $\left({ }^{*}\right.$ pre-reduced in $2 \% \mathrm{CO} / \mathrm{He}$ for $1 \mathrm{~h}$ at $\left.400^{\circ} \mathrm{C}\right)$. 


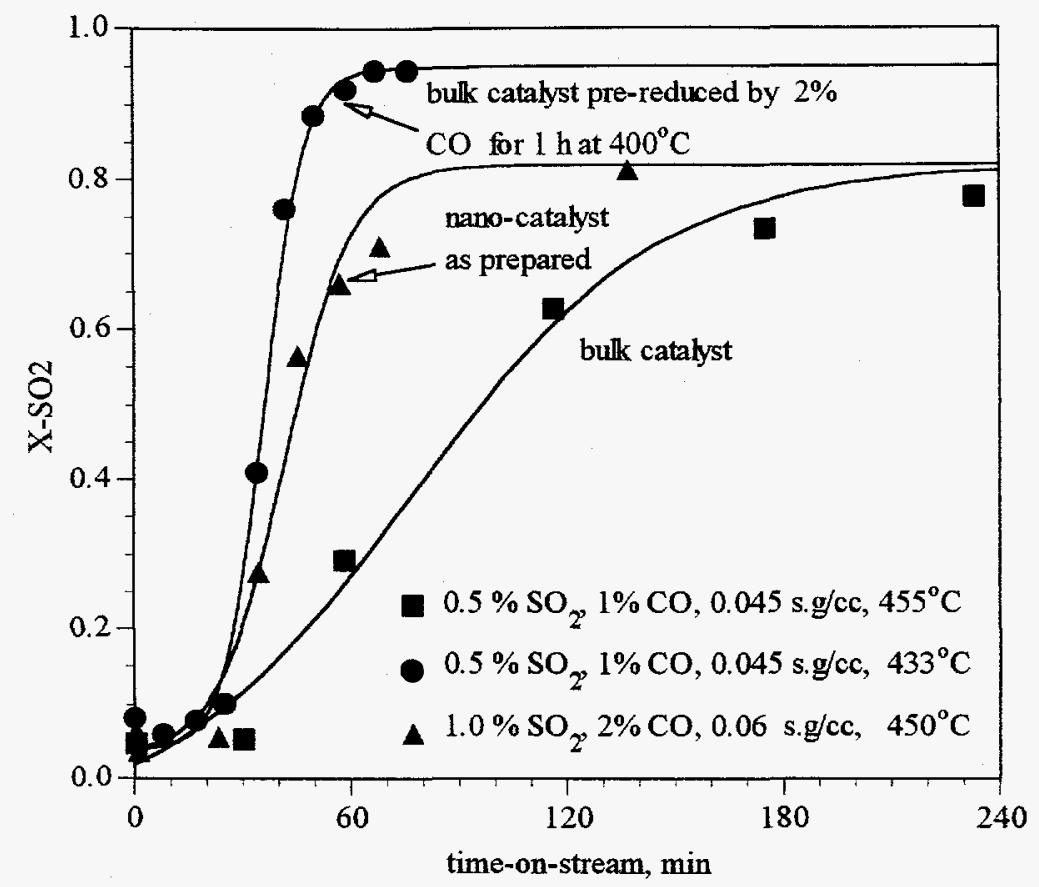

Figure 4.7 Activation profiles of 15 at. \% $\mathrm{Cu}$-containing $\mathrm{Cu}-\mathrm{Ce}-\mathrm{O}$ catalyst in the reacting gas mixture.

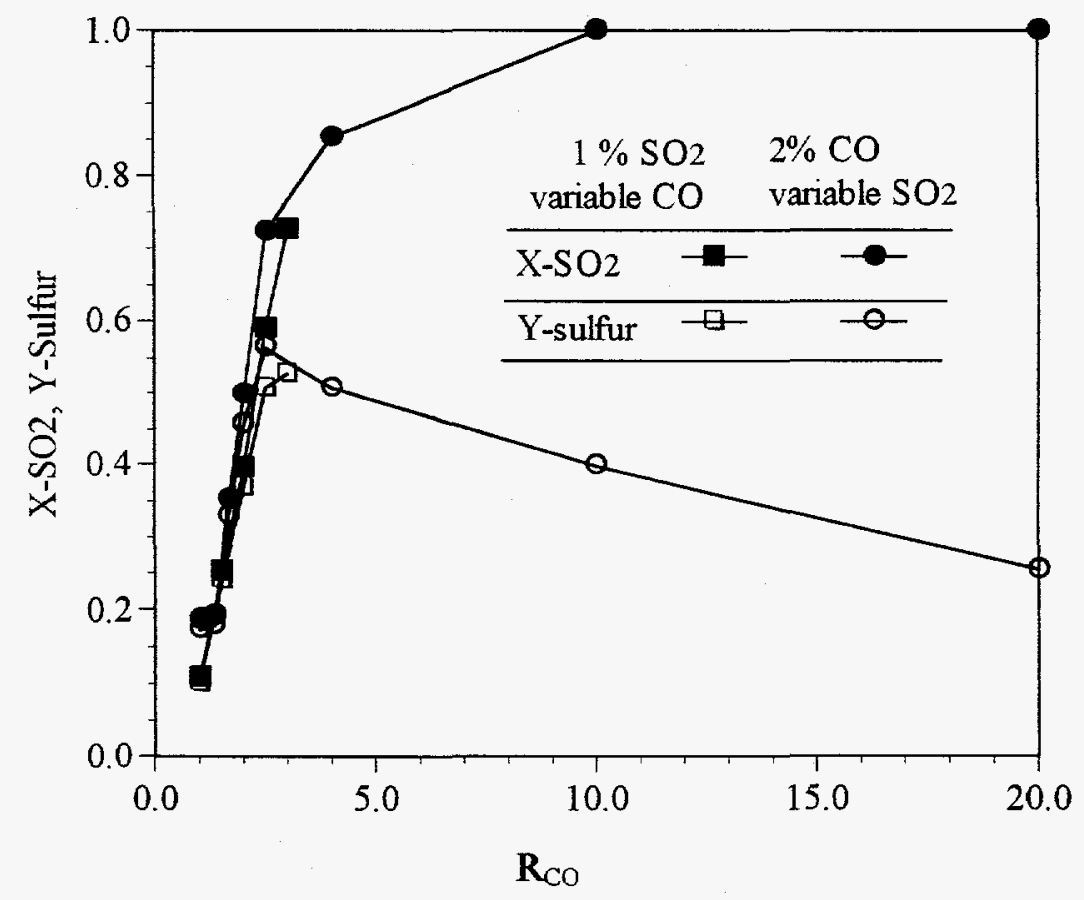

Figure 4.8 Product distribution over $\mathrm{Cu}_{0.15}[\mathrm{Ce}(\mathrm{La})]_{0.85} \mathrm{O}_{\mathrm{x}}$ catalyst versus $\mathrm{R}_{\mathrm{Co}}(0.0113$ $\left.\mathrm{s} \cdot \mathrm{g} / \mathrm{cc}, 470^{\circ} \mathrm{C}\right)$. 


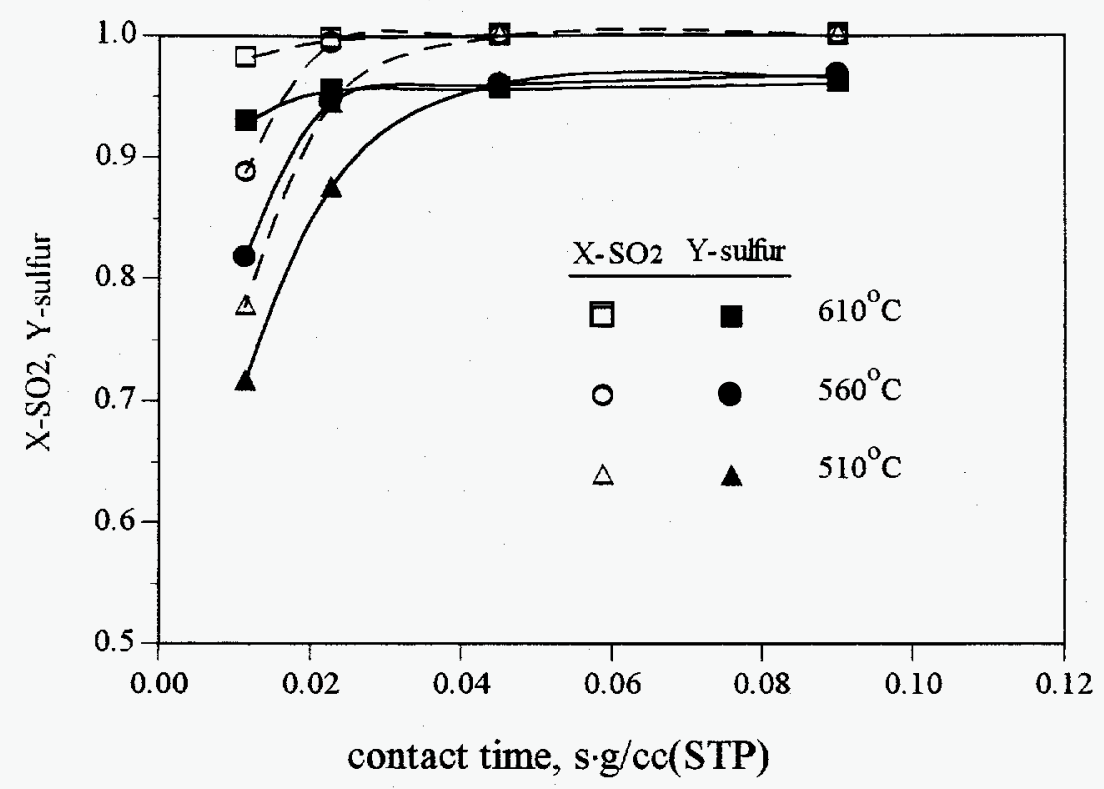

Figure 4.9 Effect of Contact Time on $\mathrm{SO}_{2}$ Conversion at Various Temperatures ( $1 \%$ $\mathrm{SO}_{2}, 2 \% \mathrm{CO}, 97 \% \mathrm{He} ; \mathrm{Cu}_{0.15}[\mathrm{Ce}(\mathrm{La})]_{0.85} \mathrm{O}_{\mathrm{X}}$ Catalyst $)$.

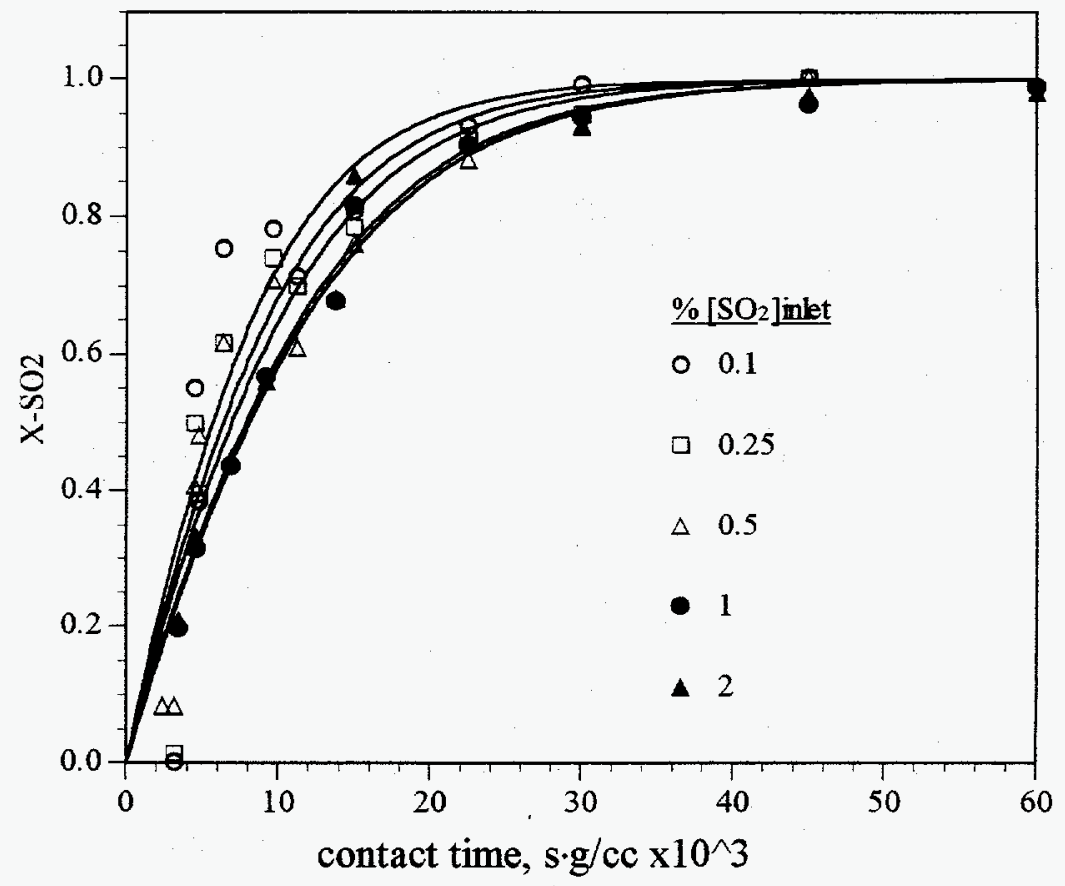

Figure 4.10 Variation of $\mathrm{SO}_{2}$ conversion with contact time and inlet $\mathrm{SO}_{2}$ concentration over $\mathrm{Cu}_{0.15}[\mathrm{Ce}(\mathrm{La})]_{0.85} \mathrm{O}_{\mathrm{x}}$ catalyst $\left(\mathrm{R}_{\mathrm{CO}}=2,510^{\circ} \mathrm{C}\right)$. 


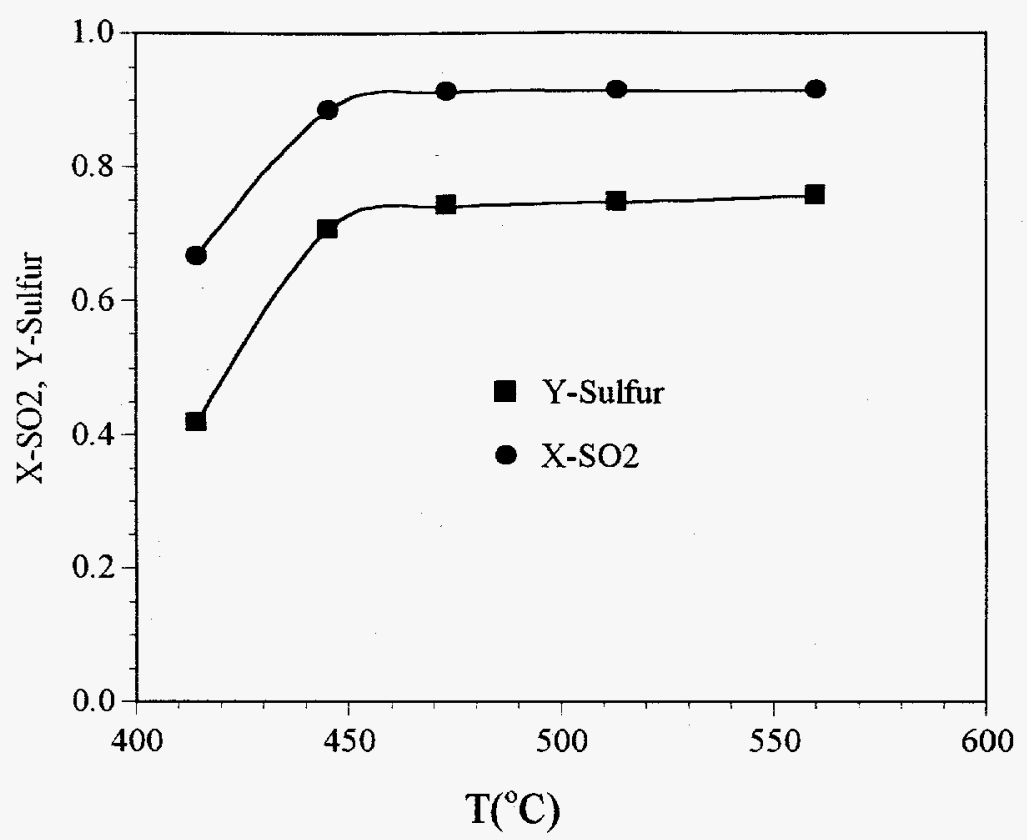

Figure 4.11 Variation of sulfur yield on $\mathrm{Cu}_{0.15}[\mathrm{Ce}(\mathrm{La})]_{0.85} \mathrm{O}_{x}$ catalyst with reaction temperature in the presence of $2 \% \mathrm{H}_{2} \mathrm{O}\left(0.09 \mathrm{~s} \cdot \mathrm{g} / \mathrm{cc}, 1.15 \% \mathrm{SO}_{2}, 2.4 \% \mathrm{CO}\right)$.

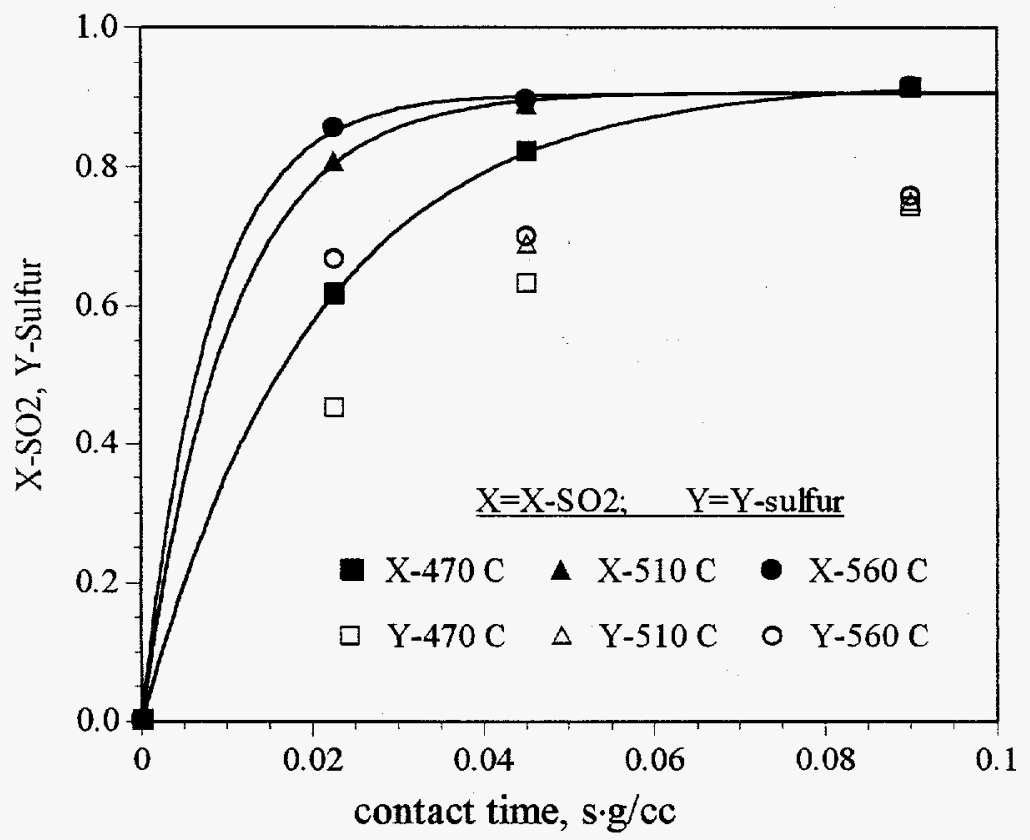

Figure 4.12 Variation of sulfur yield in the presence of $2 \% \mathrm{H}_{2} \mathrm{O}$ with contact time $\left(0.09 \mathrm{~s} \cdot \mathrm{g} / \mathrm{cc}, 1.15 \% \mathrm{SO}_{2}, 2.4 \% \mathrm{CO}, \mathrm{Cu}_{0.15}[\mathrm{Ce}(\mathrm{La})]_{0.85} \mathrm{O}_{\mathrm{x}}\right.$ catalyst $)$. 


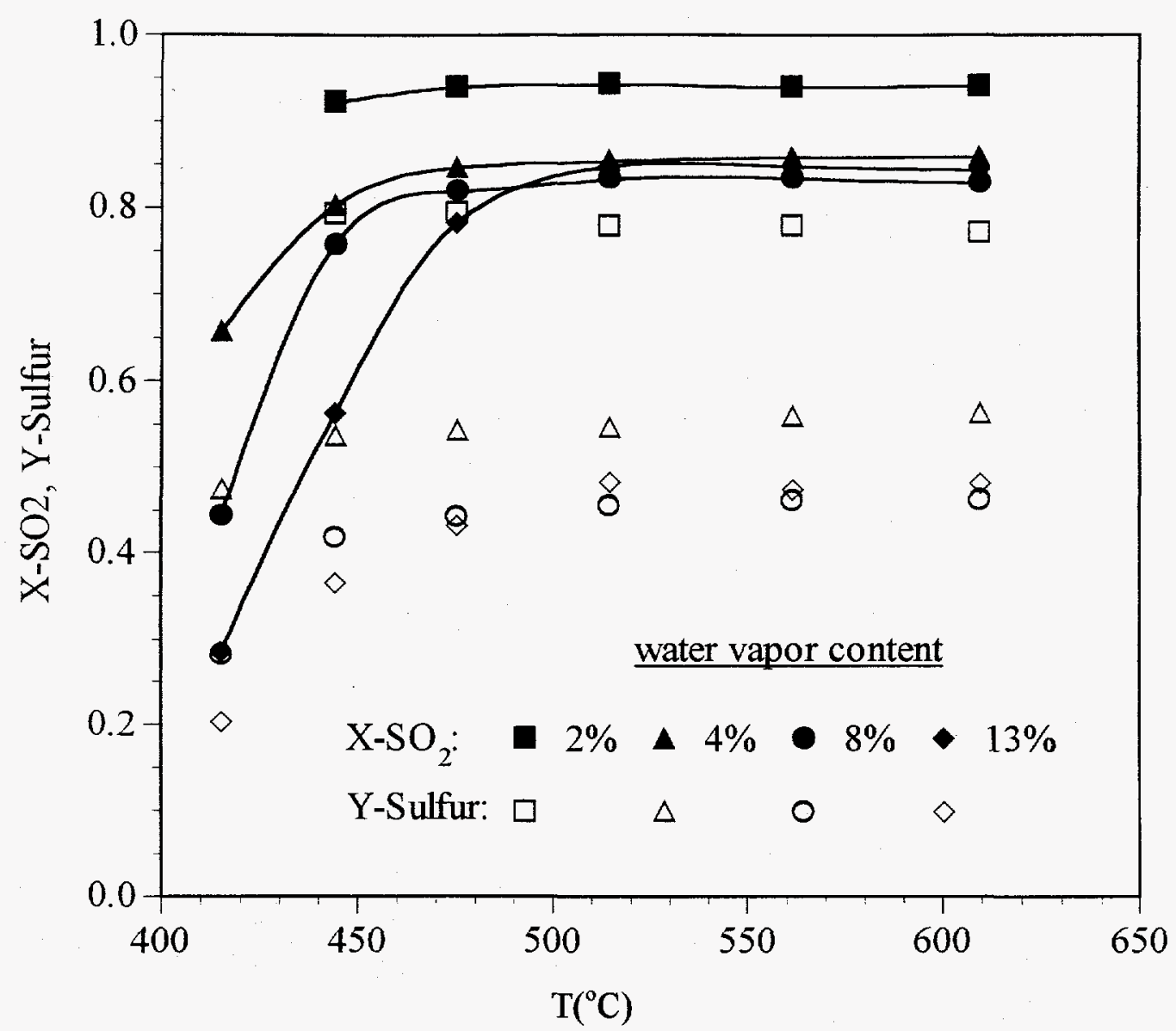

Figure 4.13 Variations of sulfur yield with temperature and water vapor content $\left(0.09 \mathrm{~s} \cdot \mathrm{g} / \mathrm{cc}, 1 \% \mathrm{SO}_{2}, 2 \% \mathrm{CO}, \mathrm{Cu}_{0.15}[\mathrm{Ce}(\mathrm{La})]_{0.85} \mathrm{O}_{\mathrm{x}}\right.$ catalyst $)$. 


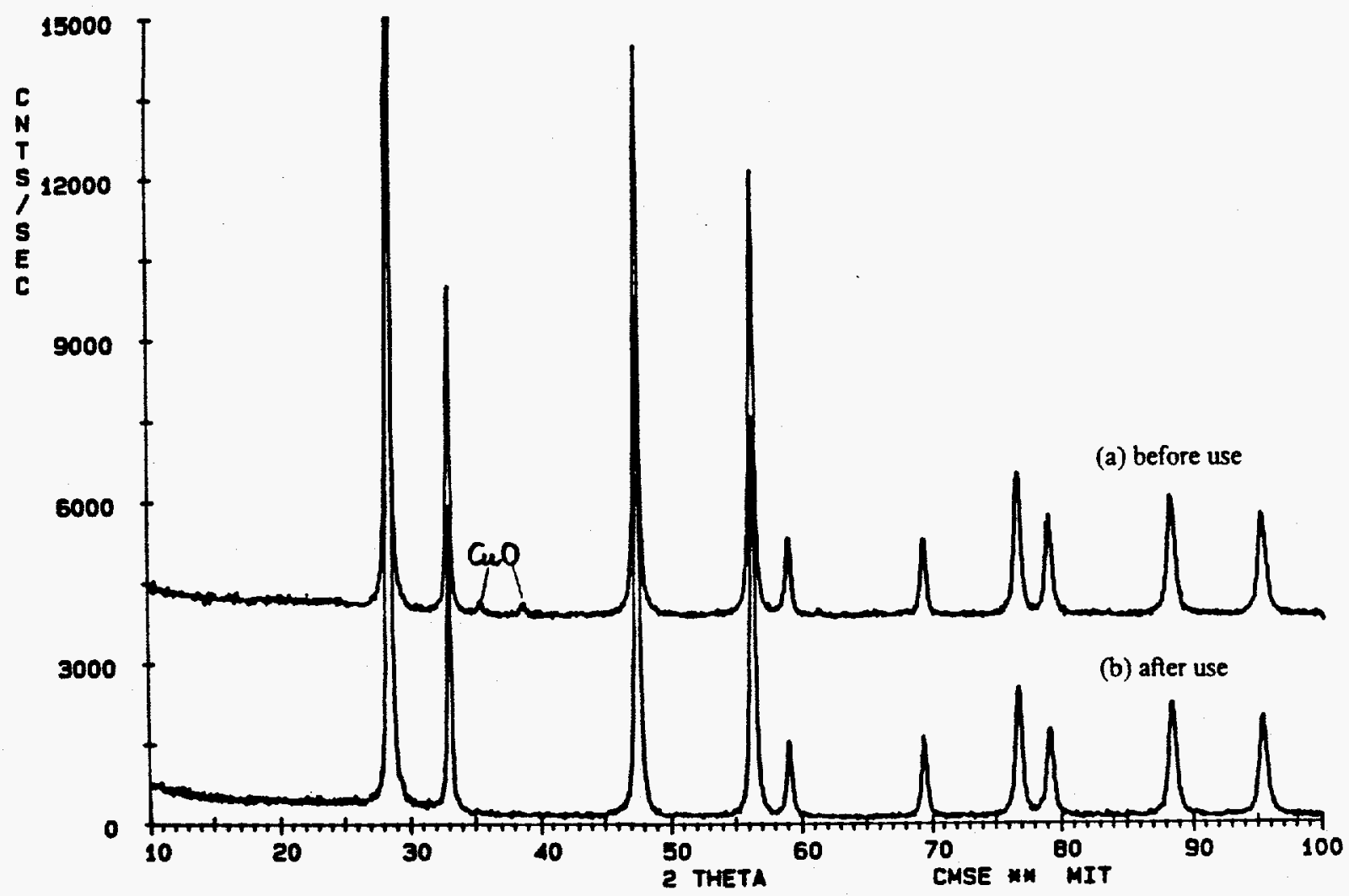

Figure 4.14 X-ray Diffractogram of the $7.8 \mathrm{wt} . \% \mathrm{CuOx} / \mathrm{CeO}_{2}$ Catalyst (a) before use (b) after use. 

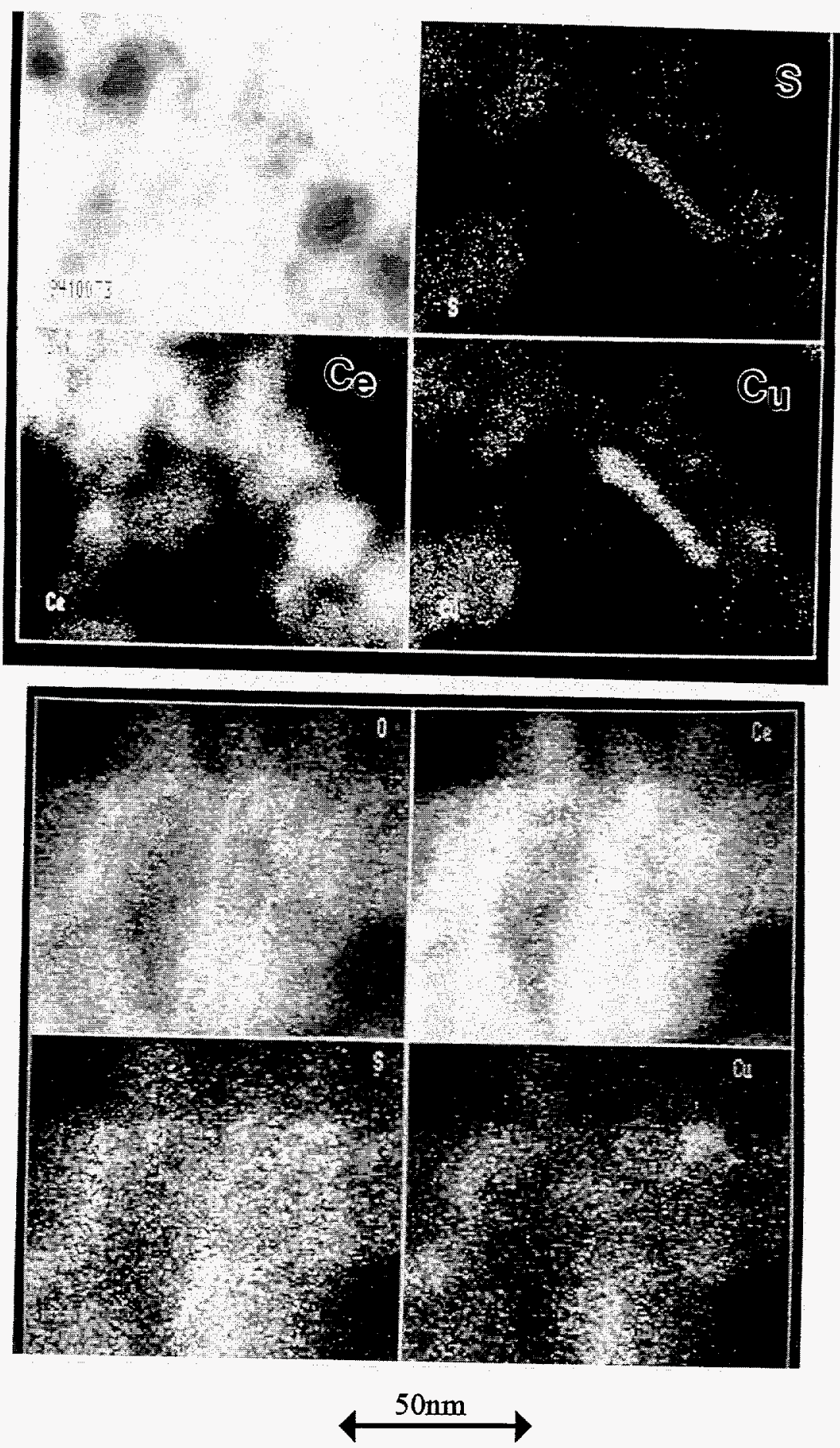

(a) $\mathrm{Cu}_{0.15}[\mathrm{Ce}(\mathrm{La})]_{0.85} \mathrm{O}_{\mathrm{x}}$

Figure 4.15 STEM elemental maps of the $\mathrm{Cu}-\mathrm{Ce}(\mathrm{La})-\mathrm{O}$ catalyst used for $\mathrm{SO}_{2}$ and $\mathrm{CO}$ reaction. 



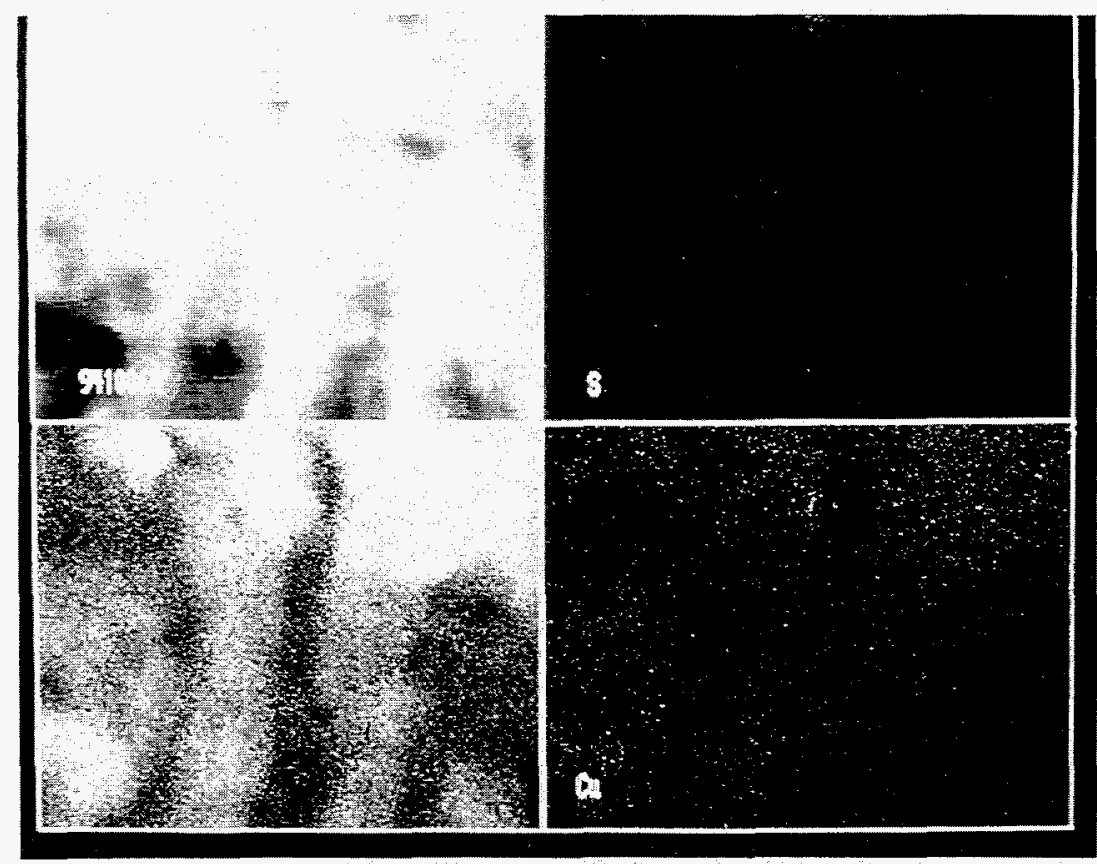

\begin{tabular}{|l|l|}
\hline Image & $\mathbf{S}$ \\
\hline $\mathrm{Ce}$ & $\mathbf{C u}$ \\
\hline
\end{tabular}

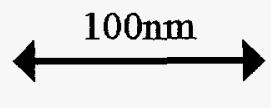

(b) $\quad \mathrm{Cu}_{0.02}[\mathrm{Ce}(\mathrm{La})]_{0.98} \mathrm{O}_{\mathrm{x}}$

Figure 4.15 STEM elemental maps of the $\mathrm{Cu}-\mathrm{Ce}(\mathrm{La})-\mathrm{O}$ catalyst used for $\mathrm{SO}_{2}$ and $\mathrm{CO}$ reaction. 



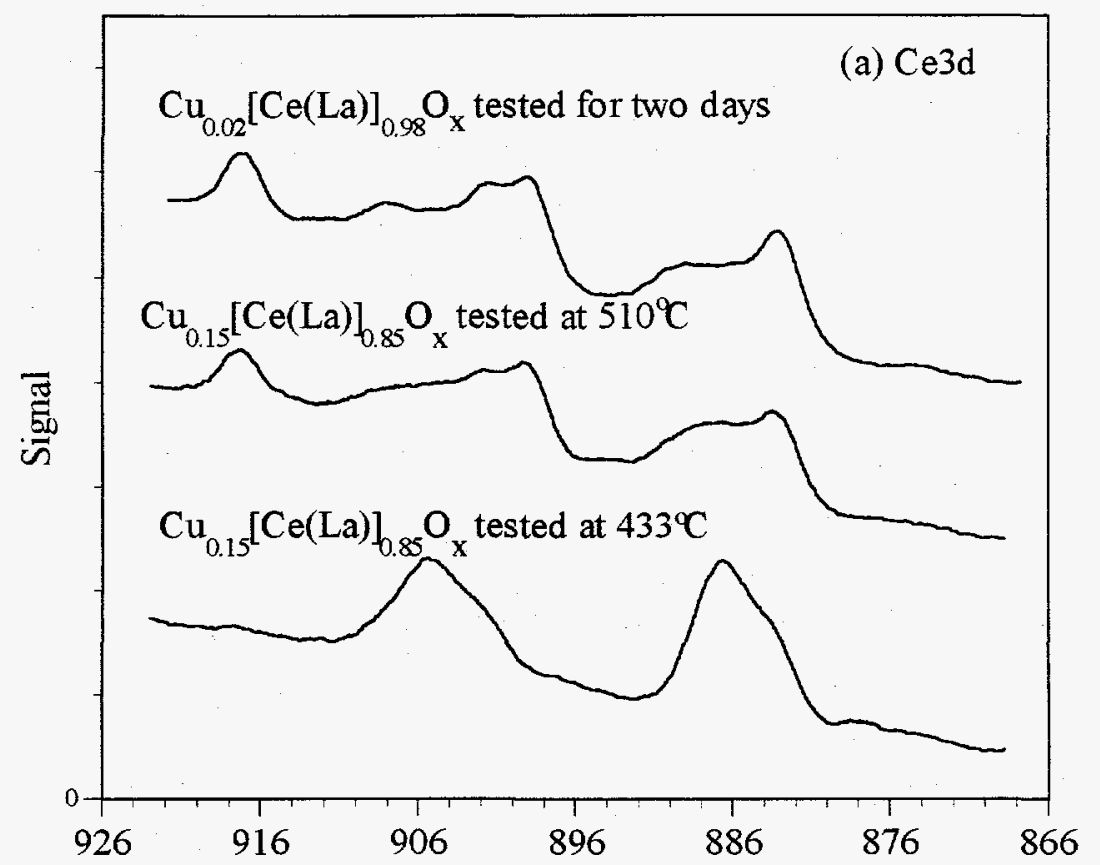

Binding Energy, eV

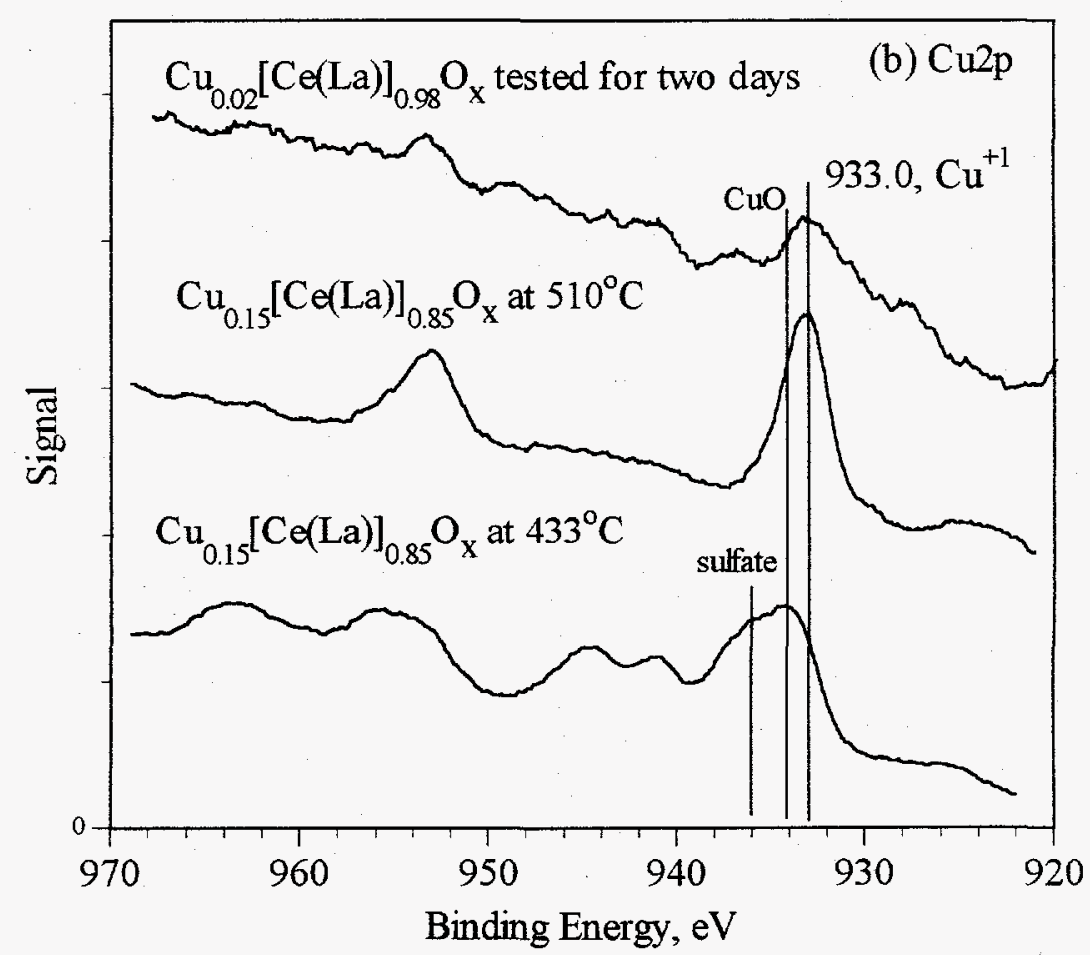

Figure 4.16 XPS of the $\mathrm{Cu}-\mathrm{Ce}(\mathrm{La})-\mathrm{O}$ catalyst used for $\mathrm{SO}_{2}$ and $\mathrm{CO}$ reaction. 

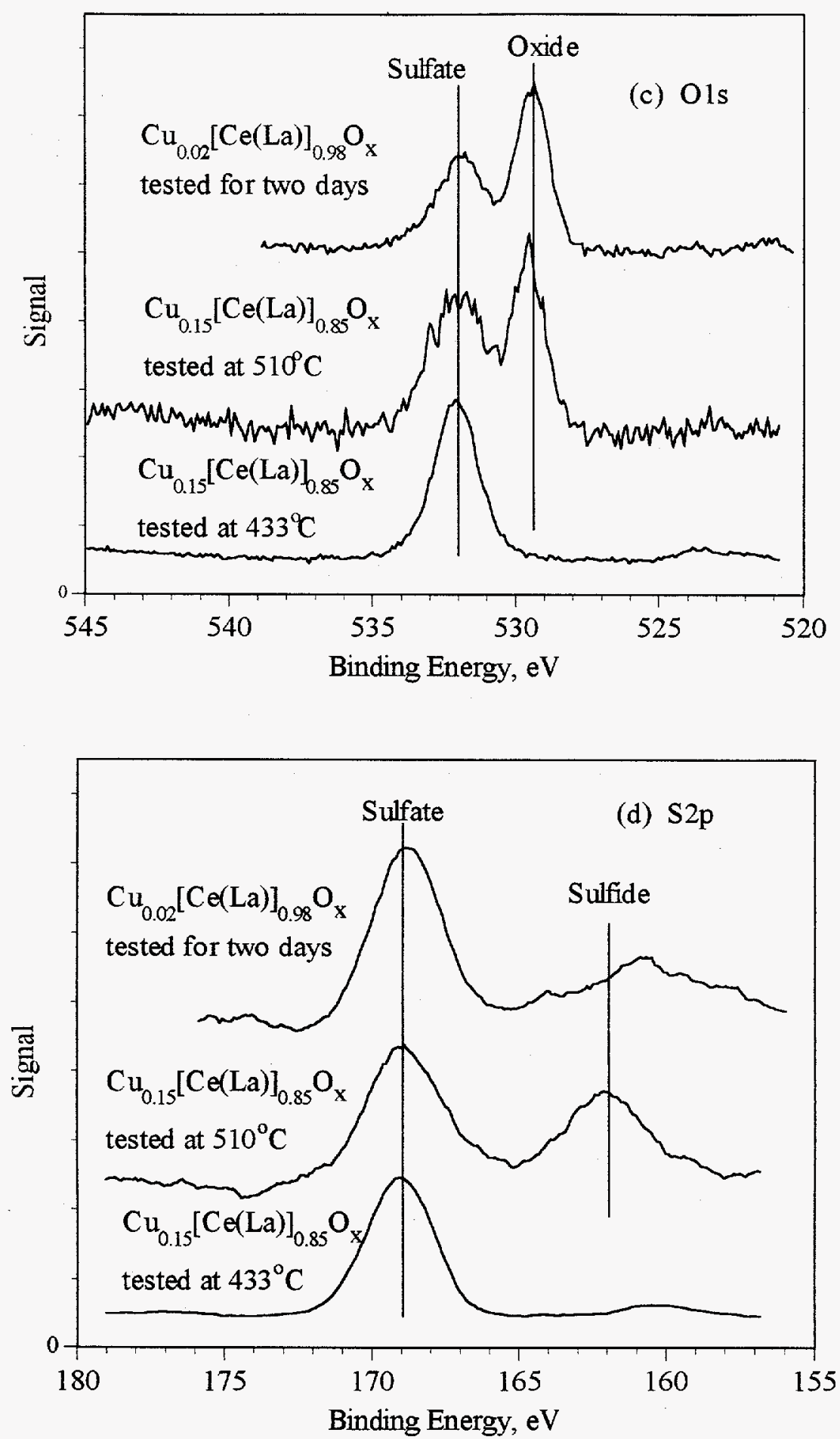

Figure 4.16 XPS of the $\mathrm{Cu}-\mathrm{Ce}(\mathrm{La})-\mathrm{O}$ catalyst used for $\mathrm{SO}_{2}$ and $\mathrm{CO}$ reaction. 


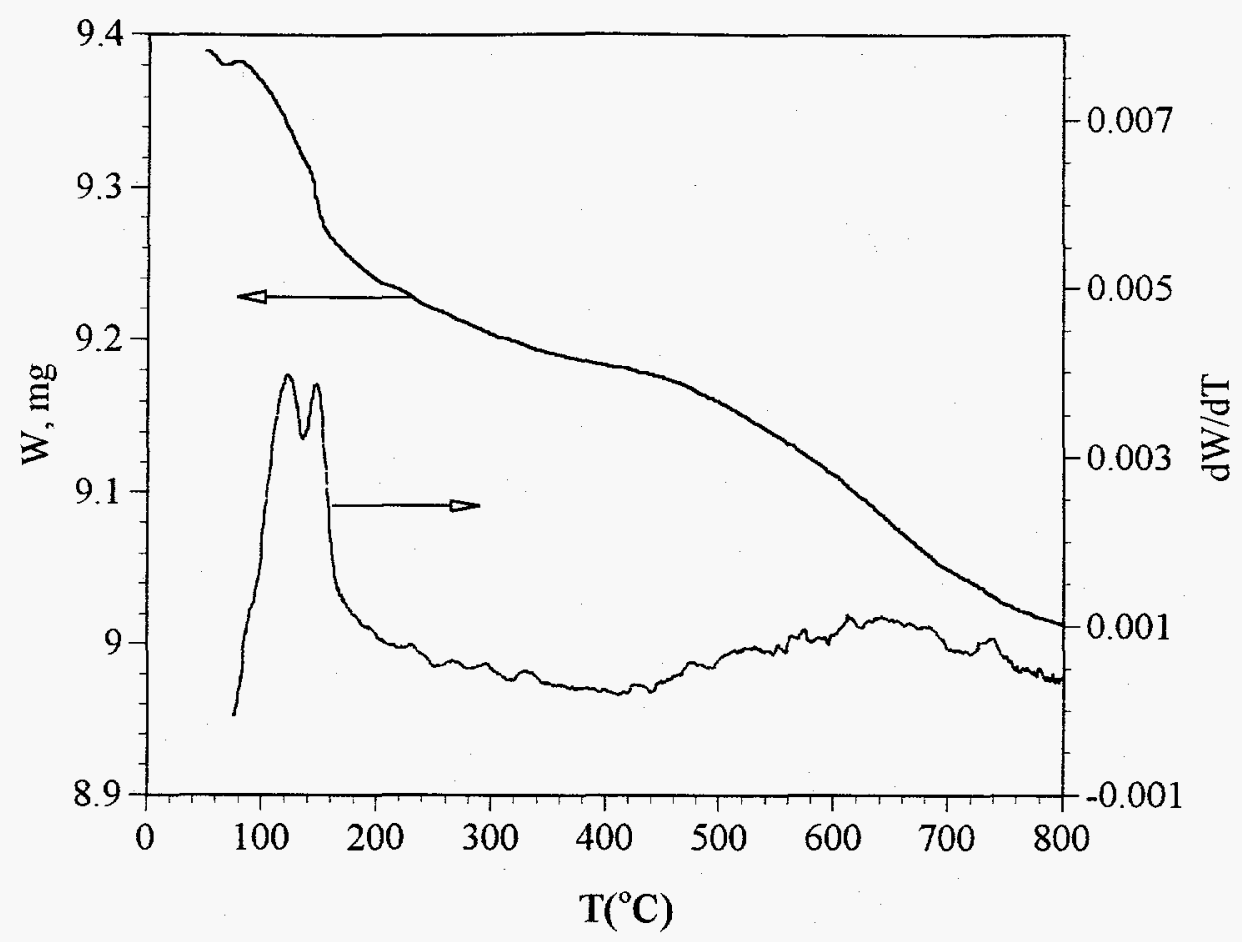

Figure 4.17 Temperature-programmed reduction profile of $\mathrm{Cu}_{0.15}[\mathrm{Ce}(\mathrm{La})]_{0.85} \mathrm{O}_{\mathrm{x}}$ catalyst by $3.5 \% \mathrm{CO} / \mathrm{N}_{2}$.

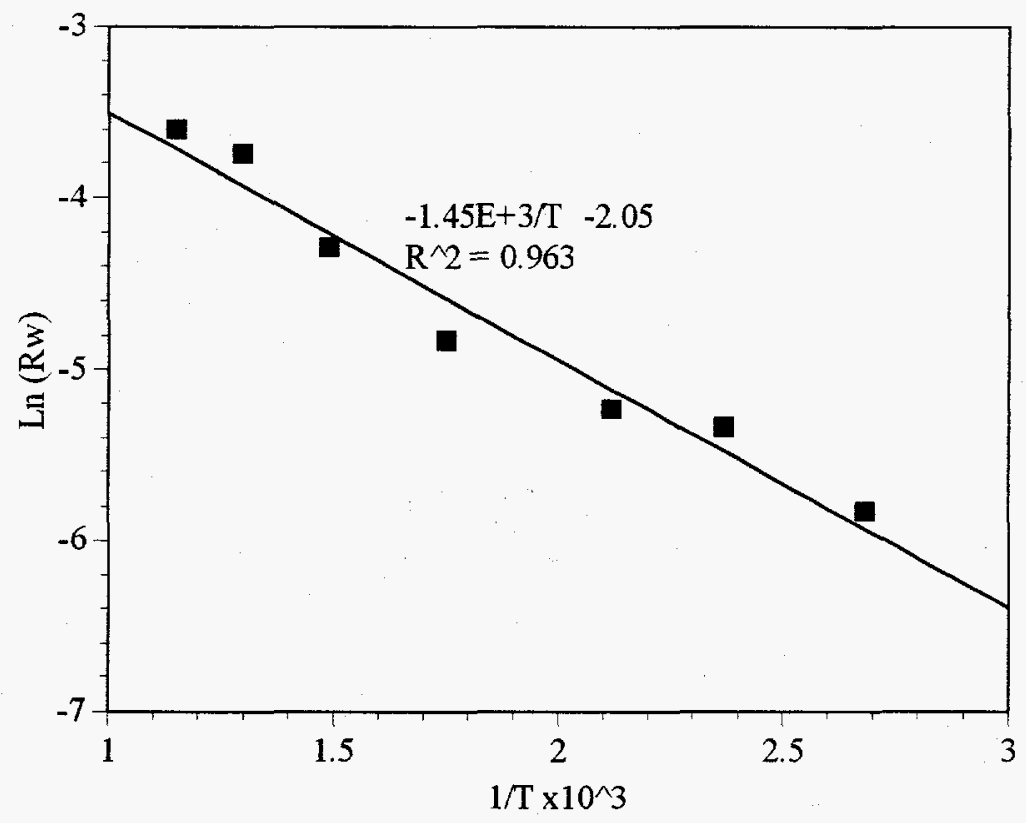

Figure 4.18 Arrhenius plot of the initial reduction rate of $\mathrm{Cu}_{0.15}[\mathrm{Ce}(\mathrm{La})]_{0.85} \mathrm{O}_{\mathrm{x}}$ catalyst by $0.5 \% \mathrm{CO} / \mathrm{N}_{2}$. 


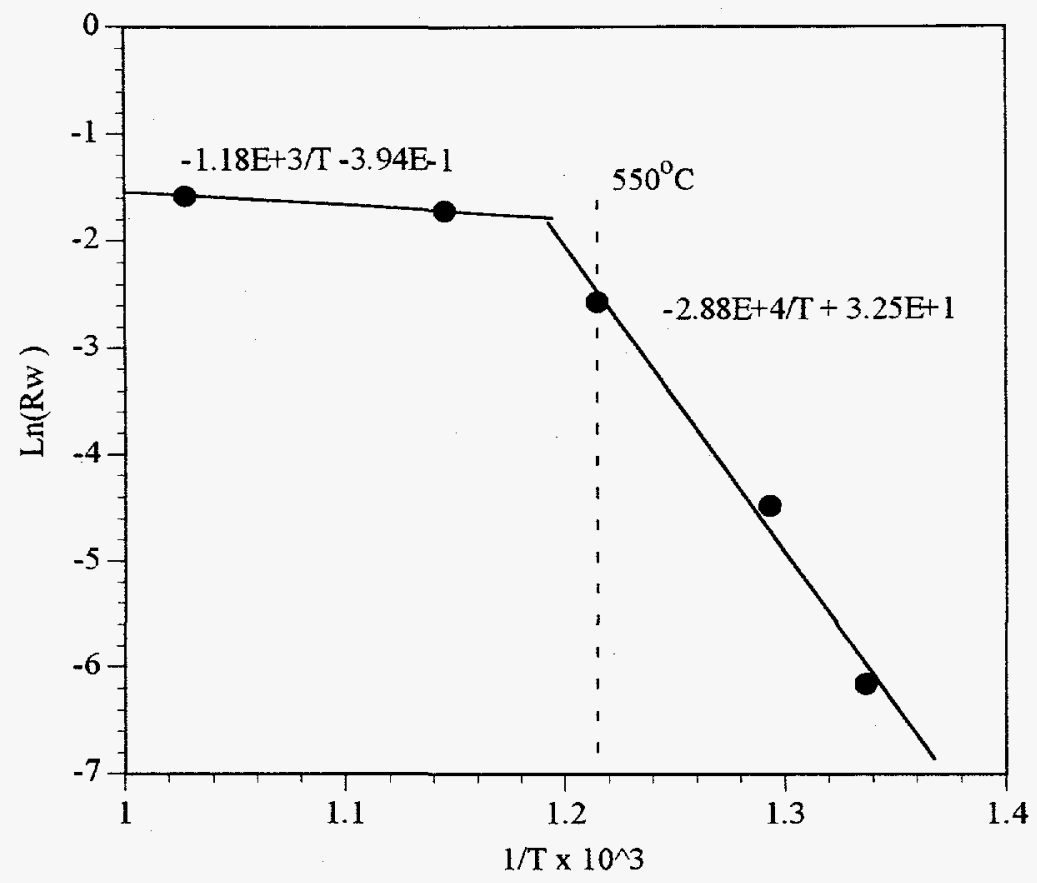

Figure 4.19 Arrhenius plot of the initial reduction rate of $\mathrm{Cu}_{0.15}[\mathrm{Ce}(\mathrm{La})]_{0.85} \mathrm{O}_{\mathrm{x}}$ catalyst pre-sulfated by $1 \% \mathrm{SO}_{2}$ for $2 \mathrm{~h}$ (reducing gas: $2 \% \mathrm{CO} / \mathrm{N}_{2}$ ).

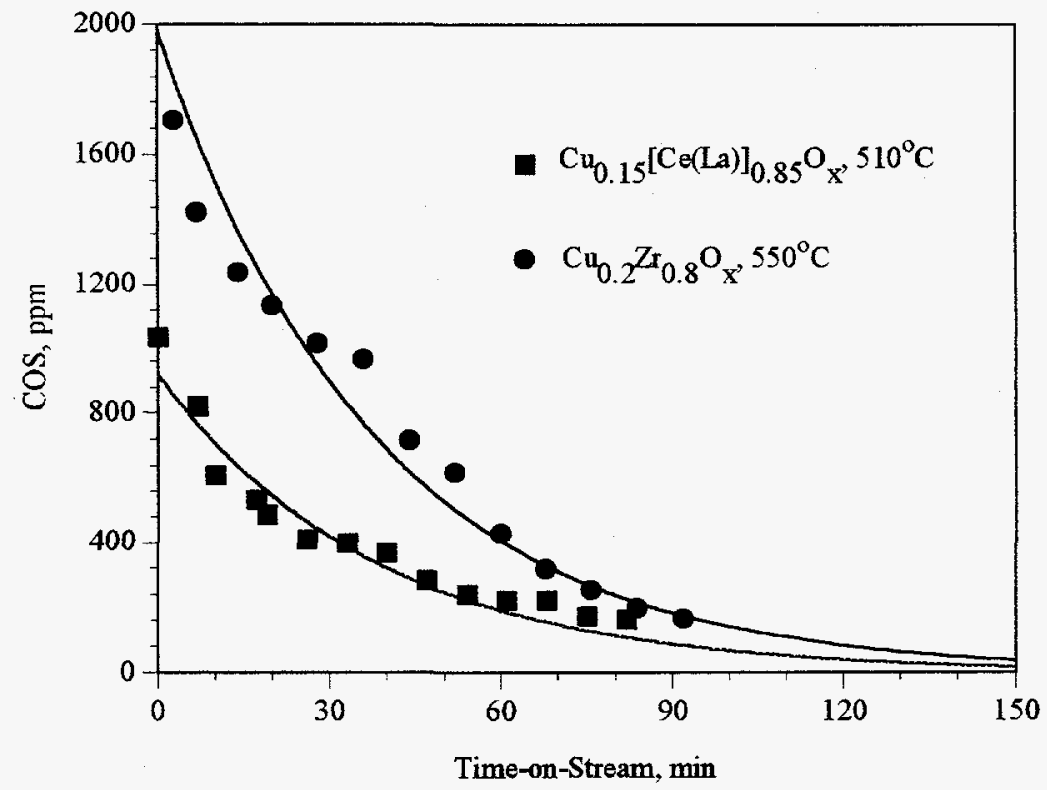

Figure 4.20 COS Evolution Profile During $2 \% \mathrm{CO} / \mathrm{He}$ Scavenging of Spent Catalysts. 


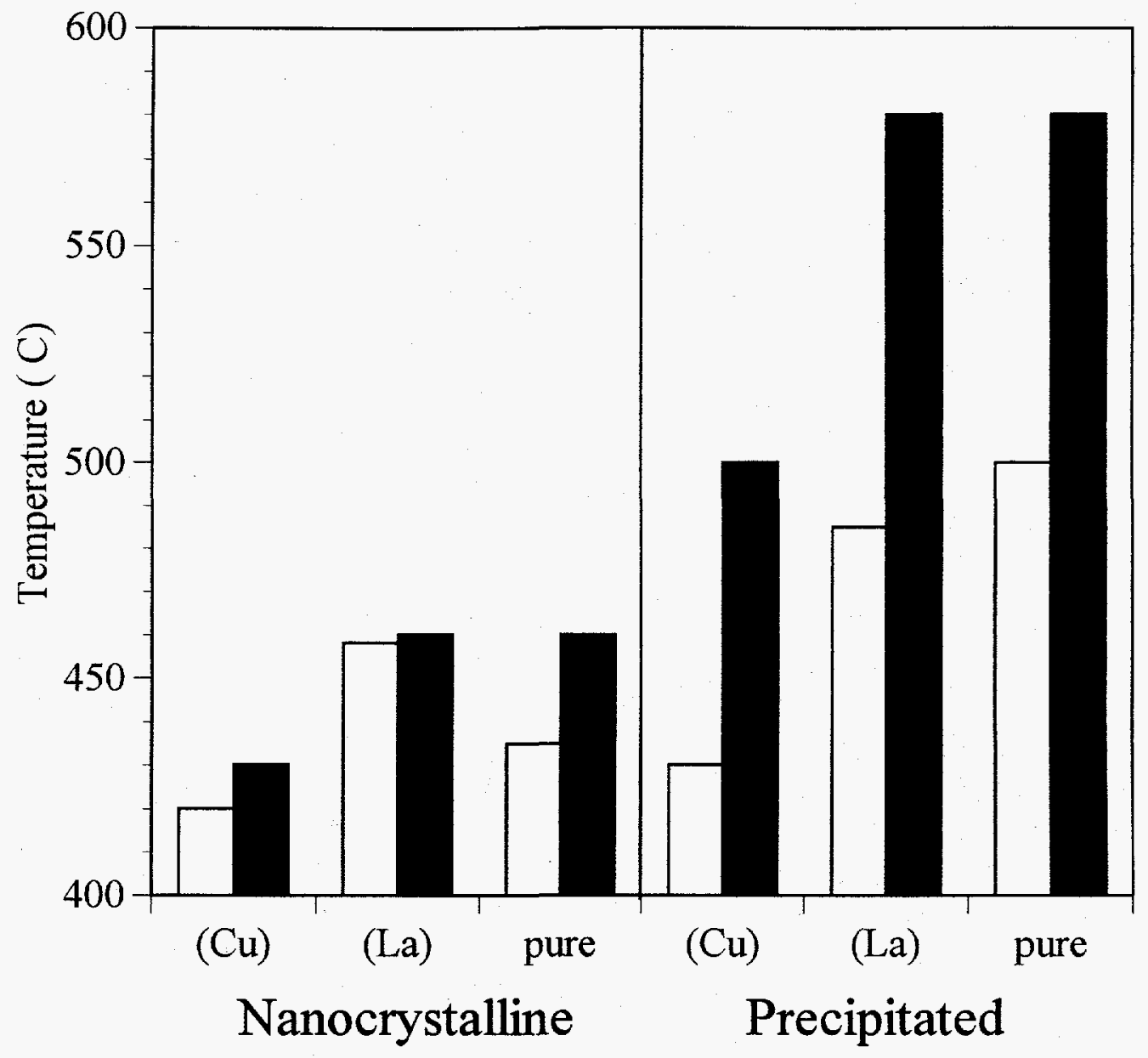

Figure 4.21 Light-off (filled bars) and fall-off (open bars) temperatures of precipitated and non-stoichiometric cerium oxide catalysts for $\mathrm{SO}_{2}$ reduction by $\mathrm{CO}\left(1 \% \mathrm{SO}_{2}, 2 \% \mathrm{CO}\right.$, $0.09 \mathrm{~s} \cdot \mathrm{g} / \mathrm{cc}$ ). 


\section{Chapter 5}

\section{Complete Oxidation of Carbon Monoxide and Methane over Transition Metal-Fluorite Oxide Composite Catalysts I. Catalyst Composition and Activity}

\subsection{Introduction}

Carbon monoxide and gaseous hydrocarbons are ubiquitous air pollutants emitted by many sources. Complete oxidation of these pollutants to carbon dioxide and water over active catalysts is used to meet continually changing environmental regulations in an economic way. Precious metals (Pt, Pd) are well known complete oxidation catalysts with high activity and stability, and are widely used for exhaust gas emission control. The high cost of precious metals and their sensitivity to sulfur poisoning have long motivated the search for substitute catalysts. A variety of transition metal oxides and mixed metal oxides have been examined. However, base metal oxide catalysts are generally less active and stable in the presence of water vapor and sulfur compounds than the precious metal catalysts. Methane is the most refractory hydrocarbon and thus, is often used as a model hydrocarbon compound for activity tests. In addition, methane itself is a potent greenhouse gas and the emission control of unburned methane from exhaust gases may be regulated in the future.

The fluorite-type oxides, such as ceria, zirconia, thoria, etc., have face-centered-cubic (FCC) crystal structure in which each tetravalent metal ion is surrounded by eight equivalent nearest $\mathrm{O}^{-2}$ ions forming the vertices of a cube. Oxygen vacancies are created when a fluorite oxide is doped by divalent or trivalent impurity ions. Thus, the fluorite oxides have been extensively studied as oxygen ion conducting materials $(1,2)$ due to their high oxygen vacancy concentration and mobility properties. In the catalysis field, the fluorite oxides have been occasionally explored as catalysts for oxidation of carbon monoxide and methane. $\mathrm{CeO}_{2}-\mathrm{La}_{2} \mathrm{O}_{3}, \mathrm{CeO}_{2}-\mathrm{ThO}_{2}$, and $\mathrm{UO}_{2}-\mathrm{ThO}_{2}$ oxides were tested as carbon monoxide oxidation catalysts long time ago (3-6). A redox mechanism involving lattice oxygen/oxygen vacancy participation was proposed for carbon monoxide oxidation on cerium oxide $(7,8)$. A recent atomic simulation of carbon monoxide oxidation mechanism on cerium oxide (9) suggested that the surface oxygen of cerium oxide is more active than the bulk oxygen. Cerium oxide or zirconium oxide modified with other base metal oxides was tested for the oxidative coupling of methane $(10,11)$. For example, Ba- 
doped $\mathrm{CeO}_{2}$ was found to be an active catalyst with high selectivity to $\mathrm{C}_{2}$ species (11). Some other oxygen solid electrolytes including $\mathrm{Zr}-\mathrm{Y}-\mathrm{O}$ were examined for the complete oxidation of carbon monoxide and methane from an electronic point of view (12). Typically, the fluorite-type oxides showed catalytic oxidation activity at high temperatures.

It is generally agreed that oxidation of carbon monoxide and hydrocarbons over oxide catalysts involves surface oxygen/oxygen vacancy participation $(7,10,11,13,14)$ and the oxygen mobility of metal oxide catalysts has something to do with catalytic activity. In our previous studies of the reduction of sulfur dioxide by carbon monoxide to elemental sulfur $(15,16)$, or, alternatively, the oxidation of carbon monoxide by sulfur dioxide, we found that cerium oxide and zirconium oxide are active catalysts. The oxidation of carbon monoxide by sulfur dioxide is considered to proceed via a redox mechanism involving the surface oxygen/oxygen vacancy participation. The activity of cerium oxide for this reaction was enhanced by addition of small amounts of rare earth oxide dopants (15). Further activity enhancement and catalyst resistance to water vapor and carbon dioxide poisoning were achieved by doping the fluorite oxide with transition metals, such as copper, cobalt, nickel, etc. (16). Thus, we postulated that a general oxidation catalyst may be achieved by promoting fluorite oxides with active transition metals such as copper. In such a catalyst configuration, the transition metals are used in minor amounts and stabilized in the fluorite oxide matrix, while the fluorite oxide is the essential and major catalyst component and not an inert support. We have found that this type of catalyst was highly active for the complete oxidation of carbon monoxide and methane in a preliminary study (17).

Cerium oxide has been widely used in the automotive three-way catalytic converter as an oxygen storage medium and thermal stabilizer. The interaction of ceria with precious metals ( $\mathrm{Pd}, \mathrm{Pt}, \mathrm{Rh}$ ) and its effect on the catalytic activity have been intensively studied $(18,19)$. By contrast, little information is available to date on the interaction of fluorite oxides with base metal catalysts and their application to complete oxidation of carbon monoxide and methane. A recent paper (20) studied the effect of oxygen vacancies in yttria-stabilized zirconia (YSZ) support on the properties of copper catalyst for carbon monoxide oxidation. Several binary mixtures of transition metals and fluorite oxides have been proposed in the literature as methanol synthesis catalysts (21). However, an active catalyst for this application generally comprises the transition metal as the major component. From a materials point of view, alkaline earth and rare earth oxides have considerable solubility in fluorite oxides (22), while transition metal oxides have little or no solubility (23).

In the present study, we systematically examined the $\mathrm{Cu}-\mathrm{Ce}-\mathrm{O}$ composite oxide for carbon monoxide oxidation and the complete oxidation of methane, and briefly surveyed some other transition metal-fluorite oxide systems. The reasons for more emphasis on the $\mathrm{Cu}-\mathrm{Ce}-\mathrm{O}$ system are: (i) $\mathrm{CeO}_{2}$ has a stable fluorite-type crystal structure from room temperature up to its melting point $\left(2600^{\circ} \mathrm{C}\right)$; (ii) copper is known as an active oxidation catalyst; (iii) both cerium and copper oxide precursors are readily available commercially. 


\subsection{Experimental}

\subsubsection{Catalyst Preparation}

The bulk composite catalysts were prepared by coprecipitating aqueous salt solutions of the metals with ammonium carbonate or sodium carbonate. The ammonium carbonate was a good precipitation agent and did not introduce impurity metal ions, but the formation of metal-ammonia complex often caused some slippage of transition metals. If sodium carbonate was used, the precipitate had to be carefully washed to remove residual sodium. The precipitates were washed twice with hot deionized water and then dried for about 12 hours at $110^{\circ} \mathrm{C}$. The dried samples were typically heated for about $4 \mathrm{~h}$ at $650^{\circ} \mathrm{C}$ in air, unless specifically noted. Low purity $(99 \%$, Aldrich) cerium nitrate containing about $1.5 \mathrm{wt} \%$ lanthanum, corresponding to an atomic ratio of $\mathrm{La}$ to $(\mathrm{La}+\mathrm{Ce})$ of about 0.045 , was used in the typical catalyst preparation. The cerium from this precursor was designated as $\mathrm{Ce}(\mathrm{La})$ in the catalyst formula throughout the paper. High purity $(99.99 \%$, Aldrich) cerium nitrate was used to prepare the catalysts containing different dopant ions ( $\mathrm{Sr}, \mathrm{Sc}, \mathrm{La}, \mathrm{Gd})$. Cerium acetate $\left(99.9 \%\right.$, Aldrich), heated for $4 \mathrm{~h}$ at $750^{\circ} \mathrm{C}$ in air, was used as the primary precursor of La-free cerium oxide. Chloroauric acid $\left(\mathrm{HAuCl}_{4}\right)$, hydrogen hexachloroplatinate(IV) hydrate, and zirconium dichloride oxide hydrate were used as $\mathrm{Au}$, $\mathrm{Pt}$, and $\mathrm{Zr}$ precursors, respectively, while the AR grade metal nitrates were used for all other metals.

$\gamma-\mathrm{Al}_{2} \mathrm{O}_{3}$ was supplied by LaRoche. Bulk $\mathrm{CuO}$ was prepared by thermal decomposition of copper carbonate in air $\left(4 \mathrm{~h}\right.$ at $\left.650^{\circ} \mathrm{C}\right)$. The supported catalysts were prepared by the conventional wet impregnation method using aqueous salt solutions of the metals. The slurry of the support and solution was degassed in vacuum so that the salt solution fully filled the pores of the support during impregnation. After excess solution was drained, the sample was dried for a few days at room temperature and then heated in air for $4 \mathrm{~h}$ at $650^{\circ} \mathrm{C}$. The physical mixture of ceria and copper oxide, $\mathrm{CuO}+\mathrm{CeO}_{2}$, was prepared by blending the $\mathrm{CuO}$ and $\mathrm{CeO}_{2}$ powders with water in an ultrasonic water bath for 10 minutes and followed by drying at $300^{\circ} \mathrm{C}$ for $1 \mathrm{~h}$. For bulk composition analysis, the catalyst powder was dissolved in hydrofluoric acid and diluted by deionized water, the resulting solution was analyzed by the Inductively Coupled Plasma(ICP) atomic emission spectrometry(Perkin Elmer Plasma 40). Catalyst surface composition was analyzed by Xray Photoelectron Spectroscopy(XPS) on a Perkin Elmer XPS 5100 system. The catalyst characterization was performed by single-point desorption of nitrogen on a Micromeritics Flow Sorb II 2300 apparatus for BET surface area measurement and X-ray powder diffraction(XRD) on a Rigaku 300 X-ray Diffractometer for crystalline phase identification. Throughout this paper, the at $\%$ denotes the ratio of a specific metal ion to the total metal ions in a given catalyst( $x 100 \%)$. The catalysts prepared by the coprecipitation and impregnation methods were denoted by $\mathrm{Cu}_{\mathrm{x}}[\mathrm{Ce}(\mathrm{La})]_{1-\mathrm{x}} \mathrm{O}_{2-\mathrm{x}}$ and $\mathrm{CuO}_{\mathrm{x}} / \mathrm{CeO}_{2}$, respectively. 


\subsubsection{Apparatus and Procedure}

Typically, catalysts were tested in a laboratory-scale packed bed flow reactor consisting of a $0.6 \mathrm{~cm}$ I.D. $\times 50 \mathrm{~cm}$ long quartz tube with a porous quartz frit placed at the middle for supporting the catalyst. Occasionally, a $1.0 \mathrm{~cm}$ I.D tube reactor was used when large catalyst volume was needed. The reactor tube was heated by a Lindberg furnace. Flowing air was used to cool the outside surface of the reactor tube when the test was conducted at low temperatures $\left(<100^{\circ} \mathrm{C}\right)$. The reaction temperature was monitored by a quartz-sheathed K-type thermocouple placed at the top of the packed catalyst bed and controlled by a Wizard temperature controller. $\mathrm{CO}$ and $\mathrm{CH}_{4}$ reacting gases were certified calibration gas mixtures balanced by helium(from Matheson). Air and helium(all from AIRCO) were used as oxidizing gas and diluent, respectively. The gas streams were measured with rotameters and mixed prior to the reactor inlet. The resulting gas mixture without further purification flowed downward through the packed catalyst bed. Water vapor was introduced with helium bubbling through a heated water bath. The pressure drop of gas flowing through the assembly was small. Thus, experiments were carried out at nearly atmospheric pressure. The product gas stream was analyzed by a HP5880A Gas Chromatography(GC) with a Thermal Conductivity Detector(TCD). The carbon balance was checked by simultaneous measurement of the reactant and products. Unless specifically noted, the catalyst loading was $150 \mathrm{mg}$ which resulted in a packed bed height of typically $5 \mathrm{~mm}$ for $\mathrm{CeO}_{2}$-based catalysts and $2-3 \mathrm{~mm}$ for $\mathrm{ZrO}_{2}$-based catalysts in the 0.6 $\mathrm{cm}$ I.D. reactor. The total gas flow rate was set at $100 \mathrm{sccm}$ consisting of $2 \% \mathrm{CO}$ or $2 \%$ $\mathrm{CH}_{4}, 16 \% \mathrm{O}_{2}$, and balance $\mathrm{He}$ and $\mathrm{N}_{2}$. Thus, the contact time was $0.09 \mathrm{~g} \cdot \mathrm{s} / \mathrm{cc}(\mathrm{STP})$ and the space velocity was typically $42,000 \mathrm{~h}^{-1}$ for the $\mathrm{CeO}_{2}$-based catalysts. The prepared catalysts were directly tested without any pre-treatment unless specifically noted. The activity measurement was conducted in an ascending temperature manner so that the lightoff behavior was recorded. No hysteresis effect was observed in these tests. The catalyst activity was ranked based on the light-off temperature at which $50 \%$ conversion occurred. The specific reaction rate was measured in a differential reactor mode with conversion not exceeding $10 \%$ by choosing appropriate catalyst loading and flow rate. The $\mathrm{SiC}$ powder was used as an inert mixer to keep approximately the same packing height when small amounts of the catalyst tested.

\subsection{Results and Discussion}

\subsubsection{Carbon Monoxide Oxidation}

\subsubsection{1 $\mathrm{CeO}_{2}$ and $\mathrm{Zr}_{0.9} \mathbf{Y}_{0.1} \mathbf{O}_{1.9}$ Catalysts}

Figure 5.1 shows the light-off curves of $\mathrm{CO}$ oxidation over various $\mathrm{CeO}_{2}$ catalysts containing different dopants as well as the $\mathrm{Zr}_{0.9} \mathrm{Y}_{0.1} \mathrm{O}_{1.9}\left(0.05 \mathrm{Y}_{2} \mathrm{O}_{3}-0.9 \mathrm{ZrO}_{2}\right)$ catalyst. The undoped $\mathrm{CeO}_{2}$ had an activity similar to the La- and $\mathrm{Sr}$-doped catalysts, but higher activity than the $\mathrm{Sc}$ or $\mathrm{Gd}$-doped catalysts. The $\mathrm{Zr}_{0.9} \mathrm{Y}_{0.1} \mathrm{O}_{1.9}$ catalyst had activity comparable to the $\mathrm{CeO}_{2}$ catalysts at low temperatures and lower at high temperatures. In summary, all these catalysts showed relatively low activity with light-off temperatures ( $50 \%$ conversion) over 
the range of 360 to $440^{\circ} \mathrm{C}$. According to the oxygen vacancy formation theory (24), one oxygen vacancy is created when one divalent $\left(D^{2+}\right)$ or two trivalent $\left(\mathrm{D}^{3+}\right)$ dopant ions are introduced into fluorite crystal lattices. The resulting oxygen vacancy and the parent dopant ions are energetically associated pairs. The higher the association energy the lower the oxygen vacancy mobility. The association energies in $\mathrm{CeO}_{2}$ doped with various alkaline or rare earth oxides were experimentally measured and calculated $(24,25)$. The association energy increases in the order $\mathrm{Gd}<\mathrm{La}<\mathrm{Sc}<\mathrm{Sr}$. The oxygen mobility in the doped $\mathrm{CeO}_{2}$ catalysts was found to correlate well with the catalytic activity for the reduction of sulfur dioxide by $\mathrm{CO}$ (15). But, the present activity results show that the activity of the doped $\mathrm{CeO}_{2}$ catalysts for $\mathrm{CO}$ oxidation did not correlate with either the bulk oxygen vacancy concentration or oxygen mobility. In contrast to the alkaline earth and rare earth oxide dopants, 1 at. $\% \mathrm{Cu}$ dopant significantly increased the catalytic activity of $[\mathrm{Ce}(\mathrm{La})] \mathrm{O}_{2}$ and lowered the light-off temperature to $135^{\circ} \mathrm{C}$ (Figure 5.1). Thus, this catalyst was chosen for further study.

\subsubsection{2 $\mathrm{Cu}_{0.01}[\mathrm{Ce}(\mathrm{La})]_{0.99} \mathrm{O}_{\mathrm{x}}$ Catalyst.}

The fresh $\mathrm{Cu}_{0.01}[\mathrm{Ce}(\mathrm{La})]_{0.99} \mathrm{O}_{\mathrm{x}}$ catalyst shown in Figure 5.1 was prepared by $4 \mathrm{~h}$ calcination at $600^{\circ} \mathrm{C}$ in $\mathrm{N}_{2}$. This different calcination procedure was used in an attempt to keep copper ions inside the cerium oxide lattice, because copper oxide is immiscible with cerium oxide. However, further calcination of this catalyst in flowing air turned out to be beneficial to the catalyst activity. Figure 5.2 shows the light-off curve shifted to lower temperature after the catalyst was treated at higher temperature $\left(660^{\circ} \mathrm{C}, 760^{\circ} \mathrm{C}, 860^{\circ} \mathrm{C}\right)$. But, the light-off curves converge at high conversions. Table 5.1 lists the catalyst surface area and surface composition after different thermal treatments. The catalyst surface was significantly enriched in copper as the heating temperature increased, while La was slightly enriched on the surface. The surface area decreased from the fresh value of 57 to $27.3 \mathrm{~m}^{2} / \mathrm{g}$ after the catalyst was heated for $3 \mathrm{~h}$ at $860^{\circ} \mathrm{C}$, while the light-off temperature $(50 \%$ conversion) decreased from 150 to $80^{\circ} \mathrm{C}$. These results show that copper oxide is not soluble in $\mathrm{CeO}_{2}$, since calcining the catalyst in air drove the copper from the bulk to the surface, and the copper enrichment of the catalyst surface may have contributed to the activity increase. In contrast, the solubility of lanthanum oxide in cerium oxide was confirmed.

\subsubsection{3 $\mathrm{Cu}_{\mathrm{x}}[\mathrm{Ce}(\mathrm{La})]_{1-\mathrm{x}} \mathrm{O}_{2-\mathrm{x}}$ Catalyst}

Figure 5.3 shows the light-off curves over various bulk $\mathrm{Cu}_{\mathrm{x}}[\mathrm{Ce}(\mathrm{La})]_{1-\mathrm{x}} \mathrm{O}_{2-\mathrm{x}}$ catalysts prepared by coprecipitation. The experimental data for the catalysts with different bulk copper levels from 2 to 50 at.\% are approximately represented by a single light-off curve, that is, the catalytic activity was not affected by the bulk copper content. The light-off temperatures were typically $80^{\circ} \mathrm{C}$. Figure 5.4 shows the XRD pattems of these catalysts. At low copper content, there were no visible peaks due to the $\mathrm{CuO}$ crystal phase. As the copper content increased, the $\mathrm{CuO}$ peaks became apparent. We also see that the $\mathrm{CuO}$ peak width is generally narrower than that of $\mathrm{CeO}_{2}$ peak, although the intensity of the 
$\mathrm{CuO}$ peak is smaller. The crystal particle sizes of $\mathrm{CuO}$ and $\mathrm{CeO}_{2}$ were estimated by peak broadening (26) with the Scherrer's equation and listed in Table 5.2. Table 5.2 also lists the surface composition determined by XPS. It is interesting that at low bulk copper content the surface copper content was higher than the bulk average, but the surface copper no longer increased for bulk copper content higher than ca. 15 at. \%. It appears that copper is finely dispersed in $\mathrm{CeO}_{2}$ at low copper contents, and when saturation is reached at higher copper contents, the excess copper formed bulk $\mathrm{CuO}$ particles that do not contribute to the XPS signal(or "invisible" to XPS).

On the basis of the activity results, we propose that the catalyst activity derives primarily from the combination of finely dispersed copper-cerium oxide system, while the $\mathrm{CuO}$ particles have negligible contribution. This hypothesis was confirmed by the following experiment. Bulk $\mathrm{CuO}$ can be easily dissolved in nitric acid. Thus, the bulk $\mathrm{CuO}$ particles in the $\mathrm{Cu}_{\mathrm{x}}[\mathrm{Ce}(\mathrm{La})]_{1-x} \mathrm{O}_{2-\mathrm{x}}$ catalyst were removed by immersing the sample in nitric acid for $14 \mathrm{~h}$ and followed by filtering, washing with de-ionized water and drying at $650^{\circ} \mathrm{C}$ for $1 \mathrm{~h}$. The catalyst compositions after this treatment are shown in Table 5.2. The higher the initial bulk copper content the more copper was removed by this process resulting in similar bulk composition (as determined by ICP) for three copper-containing catalysts: 15 , 25 and 50 at. \% in spite of large initial composition difference. XRD analyses of the nitric acid-treated catalysts revealed absence of the $\mathrm{CuO}$ phase as shown in Figure 5.4. The surface composition of the treated 50 at. \% Cu catalyst is similar to the 2 at. \% $\mathrm{Cu}$ catalyst. Figure 5.3 shows negligible difference in the catalytic activities between the fresh and the nitric acid-treated catalysts. Thus, we conclude that copper clusters, invisible by XRD and stabilized by strong interaction with $\mathrm{CeO}_{2}$, mainly contribute to the catalytic activity. Only a small amount of copper(a few percent) is needed to promote the $\mathrm{CO}$ oxidation activity of $\mathrm{CeO}_{2}$, and excess copper forms bulk $\mathrm{CuO}$ particles having little contribution to catalyst activity. The bulk copper content needed for uniform surface coverage of a $\mathrm{CeO}_{2}$ catalyst with $30 \mathrm{~m}^{2} / \mathrm{g}$ surface area was calculated to be 8.5 at. \% by assuming monolayer $\mathrm{Cu}^{+2}$ ions of radius equal to $0.087 \mathrm{~nm}$. This fact and the surface composition listed in Tables 1 and 2 suggest that only small fraction of copper in the $\mathrm{Cu}-\mathrm{Ce}-\mathrm{O}$ catalyst of high level copper content is dispersed on cerium oxide surface. Further details of catalyst microstructure are given in Part II of this paper (27).

\subsubsection{Effect of Dopant Oxides on the Catalytic Activity of $\mathrm{Cu}_{0.15} \mathrm{Ce}_{0.85} \mathrm{O}_{\mathbf{x}}$ Catalyst}

The effect of 1 at.\% alkaline earth or rare earth dopant oxide on the $\mathrm{CO}$ oxidation activity of the $\mathrm{Cu}_{0.15} \mathrm{Ce}_{0.85} \mathrm{O}_{\mathrm{x}}$ catalyst is shown in Figure 5.5. The light-off curves on all the catalysts virtually overlapped. It seems that 1 at.\% dopant( $\mathrm{La}, \mathrm{Sr}, \mathrm{Gd}, \mathrm{La})$ had little effect on the $\mathrm{CO}$ oxidation activity of the $\mathrm{Cu}_{0.15} \mathrm{Ce}_{0.85} \mathrm{O}_{\mathrm{x}}$ catalyst, similar to the case of the bulk $\mathrm{CeO}_{2}$ catalyst (Figure 5.1). The effect of $\mathrm{La}$ dopant content on the $\mathrm{Cu}_{0.15} \mathrm{Ce}_{0.85} \mathrm{O}_{\mathrm{x}}$ catalyst activity is shown in Figure 5.6. La dopant had a negative effect on the catalytic activity when its doping level reached 10 at.\%. The surface La content of this catalyst was about 18 at \%. Thus, the activity decrease may be due to excessive La-enrichment of the catalyst surface. The variation of the activity at low La doping level was probably caused by some 
variability in catalyst preparation. Typically, the activity measurement showed good reproducibility, while the catalyst preparation by coprecipitation had fair reproducibility with about $\pm 10^{\circ} \mathrm{C}$ variation in the light-off temperature. It is also noted that $\mathrm{Na}$ impurity introduced in the coprecipitation with sodium carbonate had a detrimental effect on the catalytic activity. However, the catalysts prepared with ammonium carbonate and sodium carbonate showed similar activity as long as the $\mathrm{Na}$ ions were carefully washed away.

\subsubsection{Activity Enhancement by the Concerted Effect of $\mathrm{CuO}$ and $\mathrm{CeO}_{2}$}

The experimental results presented so far have indicated that the $\mathrm{Cu}-\mathrm{Ce}-\mathrm{O}$ type mixed oxide is a highly active catalyst for $\mathrm{CO}$ oxidation, as full conversion to $\mathrm{CO}_{2}$ over this catalyst occurred around $100^{\circ} \mathrm{C}$. The catalyst activity is due to the synergistic effect between $\mathrm{CuO}$ and $\mathrm{CeO}_{2}$ as illustrated by Figure 5.7. Bulk $\mathrm{CeO}_{2}$ catalyst had low activity at low temperatures, while bulk $\mathrm{CuO}$ is known as an active catalyst for $\mathrm{CO}$ oxidation with a light-off temperature $(50 \%$ conversion $)$ around $140^{\circ} \mathrm{C}$ as measured in this work. When the same bulk $\mathrm{CuO}$ powder was mixed with the $\mathrm{CeO}_{2}$ powder according to the procedure described earlier with an atomic ratio of 15:85, the light-off curve shifted to low temperatures by about $80^{\circ} \mathrm{C}$. The 15 at. $\% \mathrm{Cu}$-containing bulk catalyst $\mathrm{Cu}_{0.15}[\mathrm{Ce}(\mathrm{La})]_{0.85} \mathrm{O}_{\mathrm{x}}$ and the impregnated 15 at. $\% \mathrm{CuO}_{x} / \mathrm{CeO}_{2}$ catalysts showed only slightly higher activity than the physical mixture.

The bulk $\mathrm{CuO}$ had much lower surface area than the $\mathrm{Cu}-\mathrm{Ce}-\mathrm{O}$ catalyst. To clarify that the activity enhancement effect was due to the interaction of $\mathrm{CuO}$ and $\mathrm{CeO}_{2}$, additional tests were run as shown in Figure 5.8. The light-off curves on the $\mathrm{Cu}_{0.15}[\mathrm{Ce}(\mathrm{La})]_{0.85} \mathrm{O}_{\mathrm{x}}$ and bulk $\mathrm{CuO}$ catalysts in Figure 5.8 were measured on the same total BET surface area basis. The light-off temperature on the $\mathrm{Cu}_{0.15}[\mathrm{Ce}(\mathrm{La})]_{0.85} \mathrm{O}_{\mathrm{x}}$ catalyst was still about $70^{\circ} \mathrm{C}$ lower than that on the bulk $\mathrm{CuO}$. Compared to Figure 5.7, the light-off curve on the bulk $\mathrm{CuO}$ catalyst was not affected as the $\mathrm{CuO}$ loading increased from 150 to $1000 \mathrm{mg}$. The 14 at.\% $\mathrm{CuO} / \gamma-\mathrm{Al}_{2} \mathrm{O}_{3}$ catalyst had significantly lower activity than the bulk $\mathrm{CuO}$, but comparable activity to the literature data. This may be explained by the known formation of copper aluminate in alumina-supported copper oxide catalyst. The specific copper surface area of this catalyst measured by $\mathrm{N}_{2} \mathrm{O}$ decomposition was about $50 \mathrm{~m}^{2} / \mathrm{g}$. The copper dispersion effect was also examined in Figure 5.8 with 3.2 at.\% Cu-ZSM-5 and 3.1 at.\% Ce plus 1 at. $\% \mathrm{Cu}, \mathrm{Ce}-\mathrm{Cu}-\mathrm{ZSM}-5$ catalysts. Compared to the 2 at.\% $\mathrm{Cu}$-containing $\mathrm{Cu}-\mathrm{Ce}$ (La)-O catalysts (Figure 5.3), these ion-exchanged zeolite catalysts had very low activity at temperatures lower than $250^{\circ} \mathrm{C}$. Copper dispersion in these two catalysts, however, is high, because copper ions are associated with $\mathrm{Al}$ ions in the ZSM-5 frame work (28). The results in Figures 7 and 8 clearly indicate that the $\mathrm{Cu}-\mathrm{Ce}-\mathrm{O}$ catalyst has much higher activity than other copper-based catalysts on the basis of either unit catalyst weight or total surface area. While good metal dispersion is, in general, necessary to obtain an active catalyst, high copper dispersion alone is not sufficient to achieve an active $\mathrm{CO}$ oxidation catalyst; the enhanced activity of the $\mathrm{Cu}-\mathrm{Ce}-\mathrm{O}$ composite catalyst must result from the interaction of copper and $\mathrm{CeO}_{2}$ or a "concerted effect" between these two kinds of materials. 
The reaction rate on the $\mathrm{Cu}_{0.15}[\mathrm{Ce}(\mathrm{La})]_{0.85} \mathrm{O}_{\mathrm{x}}$ catalyst is compared with those on some well-known $\mathrm{CO}$ oxidation catalysts reported in the literature $(29,30,31)$ in Table 5.3. Manganese-based mixed oxides have long been known as low temperature $\mathrm{CO}$ oxidation catalysts. Copper oxide is also one of the most studied oxidation catalysts. The reaction rate on the $\mathrm{Cu}_{0.15}[\mathrm{Ce}(\mathrm{La})]_{0.85} \mathrm{O}_{\mathrm{x}}$ is a few times higher than that on the Mn-based catalysts and 300 times higher than the $\mathrm{Cu} / \delta$-alumina catalyst. Recently, Rajadurai and Carberry (31) reported the perovskite-type mixed oxide, $\mathrm{La}_{0.8} \mathrm{Sr}_{0.2} \mathrm{CrO}_{3-\delta}$, as an active $\mathrm{CO}$ oxidation catalyst rivaling the platinum catalysts. Table 5.3 shows that the $\mathrm{Cu}_{0.15}[\mathrm{Ce}(\mathrm{La})]_{0.85} \mathrm{O}_{\mathrm{x}}$ has a reaction rate per unit catalyst weight comparable to the Pt/alumina catalyst and much higher than $\mathrm{La}_{0.8} \mathrm{Sr}_{0.2} \mathrm{CrO}_{3-\delta .}$. The conventional $\mathrm{N}_{2} \mathrm{O}$ decomposition method (32) was tried to measure the specific copper surface area in the $\mathrm{Cu}-\mathrm{Ce}(\mathrm{La})-\mathrm{O}$ catalyst. However, we were not able to get a reliable measurement due to the strong interaction between $\mathrm{Cu}$ and $[\mathrm{Ce}(\mathrm{La})] \mathrm{O}_{2}$. The specific copper surface area in the $\mathrm{Cu}_{0.15}[\mathrm{Ce}(\mathrm{La})]_{0.85} \mathrm{O}_{\mathrm{x}}$ catalyst was roughly estimated by multiplying the BET surface area by the surface atomic fraction of copper in Table 5.2. Table 5.3 shows that the specific reaction rate on the $\mathrm{Cu}_{0.15}[\mathrm{Ce}(\mathrm{La})]_{0.85} \mathrm{O}_{\mathrm{x}}$ is comparable to the $\mathrm{Pt} /$ alumina and the $\mathrm{La}_{0.8} \mathrm{Sr}_{0.2} \mathrm{CrO}_{3-\delta}$. Therefore, the $\mathrm{Cu}-\mathrm{Ce}-\mathrm{O}$ system has both low light-off temperatures and high intrinsic activity for $\mathrm{CO}$ oxidation.

\subsubsection{Activities of Other Transition Metal-Fluorite Oxide Catalysts}

So far we have considered the $\mathrm{Cu}-\mathrm{Ce}(\mathrm{D})-\mathrm{O}$ system where $\mathrm{D}$ denotes a dopant element. Next, the CO oxidation over other transition metal-fluorite oxide systems will be briefly discussed. Several light-off curves are shown in Figure 5.9. The $\mathrm{Au}_{0.05}[\mathrm{Ce}(\mathrm{La})]_{0.95} \mathrm{O}_{\mathrm{x}}$ catalyst prepared by calcination in air for $1 \mathrm{~h}$ at $500^{\circ} \mathrm{C}$ followed by 1 $\mathrm{h}$ at $600^{\circ} \mathrm{C}$ exhibited the highest activity. Complete $\mathrm{CO}$ oxidation over this catalyst occurred at room temperature $\left(26^{\circ} \mathrm{C}\right)$. $\mathrm{Pt}-\mathrm{Ce}(\mathrm{La})-\mathrm{O}, \mathrm{Cu}-\mathrm{Zr}-\mathrm{O}$, and $\mathrm{Cu}-\mathrm{Zr}(\mathrm{Y})-\mathrm{O}$ catalysts showed comparable activity, slightly higher than the $\mathrm{Co}-\mathrm{Ce}(\mathrm{La})-\mathrm{O}$ catalyst. But, all these catalysts except for the $\mathrm{Au}-\mathrm{Ce}(\mathrm{La})-\mathrm{O}$ were less active than the $\mathrm{Cu}-\mathrm{Ce}(\mathrm{La})-\mathrm{O}$ catalyst. Fine gold particles supported on $\mathrm{Co}_{3} \mathrm{O}_{4}, \alpha-\mathrm{Fe}_{2} \mathrm{O}_{3}$, and $\mathrm{TiO}_{2}$ were found to be excellent low temperature $\mathrm{CO}$ oxidation catalysts by Haruta (33). The high activity was considered due to active catalytic sites formed at the boundary of gold particle and metal oxide where $\mathrm{CO}$ adsorbed on gold reacted with the oxygen adsorbed on the metal oxide. The activity of the present $\mathrm{Au}_{0.05}[\mathrm{Ce}(\mathrm{La})]_{0.95} \mathrm{O}_{\mathrm{x}}$ catalyst was compared with the $\mathrm{Au} / \alpha-\mathrm{Fe}_{2} \mathrm{O}_{3}$ in Table 5.4. The activity of the $\mathrm{Au}_{0.05}[\mathrm{Ce}(\mathrm{La})]_{0.95} \mathrm{O}_{\mathrm{x}}$ catalyst was slightly lower than that of the $\mathrm{Au} / \alpha-$ $\mathrm{Fe}_{2} \mathrm{O}_{3}$, which may be due to the bigger gold particle size in the $\mathrm{Au}_{0.05}[\mathrm{Ce}(\mathrm{La})]_{0.95} \mathrm{O}_{\mathrm{x}}$ catalyst. In contrast to the $\mathrm{Cu}-\mathrm{Ce}(\mathrm{La})-\mathrm{O}$ system where finely dispersed copper cannot be dissolved in nitric or hydrochloric acid due to the strong interaction with cerium oxide, the gold particles in the $\mathrm{Au}_{0.05}[\mathrm{Ce}(\mathrm{La})]_{0.95} \mathrm{O}_{\mathrm{x}}$ catalyst can be dissolved in hydrochloric acid, while bulk gold is insoluble. This implies that the small gold particles in the $[\mathrm{Ce}(\mathrm{La})] \mathrm{O}_{2}$ matrix indeed have some particular properties. It is noteworthy that the $\mathrm{Au}_{0.05}[\mathrm{Ce}(\mathrm{La})]_{0.95} \mathrm{O}_{\mathrm{x}}$ catalyst showed good stability. The catalyst maintained its high activity after being subjected to a $3-\mathrm{h}$ treatment at $650^{\circ} \mathrm{C}$ either in flowing air or $25 \%$ $\mathrm{H}_{2} / \mathrm{He}$. No deactivation was observed in a 4-day run at room temperature with the 
reacting gas saturated with water vapor. The water vapor effect on the other catalysts is addressed in the following section.

\subsubsection{Effect of Water Vapor on Catalyst Activity}

Water vapor generally inhibits or poisons the oxidation activity of base metal oxide catalysts and imposes a second challenge beyond that of boosting the activity of the nonprecious metal oxide catalysts. The extensive search of base metal catalysts as alternatives to precious metals for exhaust gas treatment in the 1960 s identified copper oxide, mixed with chromium oxide and/or rare earth oxides, to be an active catalyst $(34,35)$. However, the copper catalyst was severely deactivated upon addition of water vapor due to changes in the nature of surface copper (36). Perovskite-like compounds $\mathrm{RE}_{1-\mathrm{x}} \mathrm{Pb}_{\mathrm{x}} \mathrm{MnO}_{3}$ and $\mathrm{RECoO}(\mathrm{RE}=\mathrm{La}, \mathrm{Pr}$ or $\mathrm{Nd})$ were pioneered as oxidation catalysts for the automotive exhaust treatment in the early 1970s (37). Although these mixed oxides later showed lower activity than the precious metal catalyst and propensity to water vapor poisoning $(38,39)$, they have indeed stimulated intensive studies of this type catalyst.

The water vapor effect on the present catalysts was examined and typical results are shown in Figure 5.10. Water vapor effects on the bulk $\mathrm{CuO}$ and the 14 at. $\% \mathrm{CuO} / \gamma-\mathrm{Al}_{2} \mathrm{O}_{3}$ catalysts are also included in Figure 5.10 for comparison. The water vapor content in exhaust gas streams is usually around $15 \%$. Excess water vapor, 32\%, was used in our tests to study its effect. In Figure 5.10, the $\mathrm{CO}$ conversion on the bulk $\mathrm{CuO}$ catalyst decreased to 0.1 from 0.99 within about $2 \mathrm{~h}$ after the addition of water vapor at $340^{\circ} \mathrm{C}$. The conversion recovered to only $0.352 \mathrm{~h}$ later after the reacting gas was switched back to the dry feed gas. The conversion over the $\mathrm{CuO} / \gamma-\mathrm{Al}_{2} \mathrm{O}_{3}$ catalyst also decreased monotonically at a rate of about $0.03 / \mathrm{h}$ in the presence of water vapor. In contrast, no deactivation was observed over the $\mathrm{Cu}-\mathrm{Ce}(\mathrm{La})-\mathrm{O}, \mathrm{Co}-\mathrm{Ce}(\mathrm{La})-\mathrm{O}$ and $\mathrm{Cu}-\mathrm{Zr}(\mathrm{Y})-\mathrm{O}$ catalysts under the same experimental conditions. It is noted that the preceding calcination process during catalyst preparation had a strong effect on the $\mathrm{Cu}-\mathrm{Ce}(\mathrm{La})-\mathrm{O}$ catalyst activity in the presence of water vapor as illustrated by Figure 5.11. On the $\mathrm{Cu}_{0.01}[\mathrm{Ce}(\mathrm{La})]_{0.99} \mathrm{O}_{\mathrm{x}}$ and $\mathrm{Cu}_{0.5}[\mathrm{Ce}(\mathrm{La})]_{0.5} \mathrm{O}_{\mathrm{x}}$ catalysts prepared by $4 \mathrm{~h}$-calcination at $600^{\circ} \mathrm{C}$ in $\mathrm{N}_{2}$, the conversion declined monotonically at a rate of about $0.09 / \mathrm{h}$ and $0.012 / \mathrm{h}$, respectively. However, these two catalysts maintained stable activity in the presence of water vapor after they were further heated for $3 \mathrm{~h}$ at $650^{\circ} \mathrm{C}$ in flowing air.

In conclusion, the transition metal-fluorite oxide composite catalyst exhibits significant enhancement for carbon monoxide oxidation in both catalytic activity and stability in the presence of water vapor, and the enhancement stems from the strong interaction of the two kinds of materials.

\subsubsection{Methane Oxidation}

Screening tests for complete methane oxidation were performed over several transition metal-fluorite oxide catalysts at a contact time of $0.09 \mathrm{~g} \cdot \mathrm{s} / \mathrm{cc}(\mathrm{STP}) . \mathrm{ZrO}_{2}$-based catalysts prepared in this work had much higher packing density than the $\mathrm{CeO}_{2}$-based catalysts. The space velocity for the $\mathrm{ZrO}_{2}$-based catalyst was about $100,000 \mathrm{~h}^{-1}$, while the space velocity 
for the $\mathrm{CeO}_{2}$-based catalysts was typically $42,000 \mathrm{~h}^{-1}$. In Figure 5.12, the $\mathrm{Cu}_{0.2} \mathrm{Zr}_{0.8} \mathrm{O}_{\mathrm{x}}$ catalyst showed high activity for methane oxidation with a light-off temperature $(50 \%$ conversion) of $450^{\circ} \mathrm{C}$. The $\mathrm{Cu}_{0.5} \mathrm{Zr}_{0.5} \mathrm{O}_{\mathrm{x}}$ catalyst had a light-off temperature of $510^{\circ} \mathrm{C}$, which suggests that an excessive amount of copper in the $\mathrm{Cu}-\mathrm{Zr}-\mathrm{O}$ catalyst system may have a negative effect on catalytic activity. Bulk $\mathrm{CeO}_{2}$ had the lowest activity among the catalysts tested. However, the light-off temperature over $\mathrm{CeO}_{2}$ was lowered from 650 to $540^{\circ} \mathrm{C}$ in the presence of 4.5 at. $\% \mathrm{La}$ dopant and further to $490^{\circ} \mathrm{C}$ by the addition of 8 at. $\% \mathrm{Cu}$. The 50 at. \% Cu-containing $\mathrm{Cu}-\mathrm{Ce}(\mathrm{La})-\mathrm{O}$ catalyst showed similar activity to the one containing 8 at. $\% \mathrm{Cu}$.

The 15 at.\% $\mathrm{Cu}$-containing $\mathrm{Cu}-\mathrm{Ce}(\mathrm{D})-\mathrm{O}$ catalysts with different dopant(D) were examined and the results are shown in Figure 5.13. The 1 at.\% $\mathrm{Sc}$-doped $\mathrm{Cu}_{0.15} \mathrm{Ce}_{0.85} \mathrm{O}_{\mathrm{x}}$ catalyst had slightly higher activity than the undoped one, while the 1 at.\% La-doped or 1 at. \% Sr-doped catalyst had significantly higher activity than the undoped. The 4.5 at. $\%$ La-doped catalyst, $\mathrm{Cu}_{0.15}[\mathrm{Ce}(\mathrm{La})]_{0.85} \mathrm{O}_{\mathrm{x}}$, had the highest activity. But, further increasing the La dopant level to 10 at.\% decreased the catalytic activity, which was similar to the case of CO oxidation. $50 \%$ and $95 \%$ methane conversion to carbon dioxide over the $\mathrm{Cu}_{0.15}[\mathrm{Ce}(\mathrm{La})]_{0.85} \mathrm{O}_{\mathrm{x}}$ took place at $450^{\circ} \mathrm{C}$ and $520^{\circ} \mathrm{C}$, respectively. The $\mathrm{Cu}_{0.15}[\mathrm{Ce}(\mathrm{La})]_{0.85} \mathrm{O}_{\mathrm{x}}$ showed comparable activity to the $\mathrm{Cu}_{0.2} \mathrm{Zr}_{0.8} \mathrm{O}_{\mathrm{x}}$ catalyst in Figure 5.12 and higher activity than the $\mathrm{Cu}_{0.08}[\mathrm{Ce}(\mathrm{La})]_{0.92} \mathrm{O}_{\mathrm{x}}$ or $\mathrm{Cu}_{0.5}[\mathrm{Ce}(\mathrm{La})]_{0.5} \mathrm{O}_{\mathrm{x}}$ in Figure 5.12 . The activity of the $\mathrm{Cu}_{0.15}[\mathrm{Ce}(\mathrm{La})]_{0.85} \mathrm{O}_{x}$ catalyst was stable as no conversion decline was observed during a $15 \mathrm{~h}$-run at $600^{\circ} \mathrm{C}$ with $99 \%$ methane conversion. Therefore, the dopant oxide in the $\mathrm{CeO}_{2}$-based catalyst played a more important role in methane oxidation than in $\mathrm{CO}$ oxidation. However, the activity enhancement cannot be explained simply on the basis of oxygen vacancy and energetics. SrO and $\mathrm{La}_{2} \mathrm{O}_{3}$ are more basic oxides than $\mathrm{Sc}_{2} \mathrm{O}_{3}$. It is plausible to assume that the catalyst surface acidic/basic sites are important for methane oxidation. This assumption is illustrated by the following reaction scheme where cat denotes the catalyst; $\mathrm{M}^{\mathrm{n}+}$ is an acidic site, and $\mathrm{O}^{-}$is a basic site.

$$
M_{\text {cat }}^{n+}-\mathrm{CH}_{3}^{\delta-} \cdots \cdots \cdot H^{\delta+}-\mathrm{O}_{\text {cat }}^{-} \stackrel{\text { slow }}{\longrightarrow} M_{\text {cat }}^{n+}-\mathrm{CH}_{3}^{-}+\mathrm{HO}_{\text {cat }}
$$

It is generally agreed that the most difficult step in activating methane is to break the $\mathrm{C}-\mathrm{H}$ bond $(10,40)$. As one hydrogen atom is abstracted from the methane molecule by a surface oxygen(basic site), the negatively charged residual is stabilized by a surface acidic site. The resulting intermediate can become a methyl radical by giving back its electron to the catalyst and the methyl radical may subsequently form the precursors of a variety of chemical products. These intermediate species are easily oxidized into carbon dioxide and water. Both surface basic and acidic sites with suitable strength and geometry are needed to form a transition state and lower the activation energy in the $\mathrm{C}-\mathrm{H}$ bond breakage. The present results indicate that copper-fluorite oxide composites are active catalysts for methane oxidation and more importantly, the activity is tunable by using different dopant oxides in suitable amounts.

It is noted that methane oxidation is much slower than carbon monoxide oxidation, and the light-off curves shown in Figures 5.12 and 5.13 are in the kinetic regime; that is, 
the light-off curve will be shifted to lower temperatures by increasing the contact time. Table 5.5 briefly compares the activity of the $\mathrm{Cu}_{0.15}[\mathrm{Ce}(\mathrm{La})]_{0.85} \mathrm{O}_{\mathrm{x}}$ catalyst with some active perovskite mixed oxide catalysts reported in the literature $(41,42,43)$. Per unit catalyst weight, the $\mathrm{Cu}_{0.15}[\mathrm{Ce}(\mathrm{La})]_{0.85} \mathrm{O}_{\mathrm{x}}$ catalyst had an activity a few times higher than the other catalysts. Per unit surface area, the activity of the $\mathrm{Cu}_{0.15}[\mathrm{Ce}(\mathrm{La})]_{0.85} \mathrm{O}_{\mathrm{x}}$ catalyst was comparable to the $\mathrm{LaCoO}_{3}$ catalyst, an extensively studied perovskite system. Formation of the perovskite compound needs high temperature so that it is difficult to prepare with high surface area. The preparation of the present transition metal-fluorite oxide composite catalyst mostly requires good dispersion of the transition metals in the fluorite matrix and thus, a high catalyst surface area can be obtained by using appropriate low temperature synthesis methods. In conclusion, the present composite oxide catalyst is a promising, new catalyst system showing high activity for the complete oxidation of methane.

\subsubsection{Simultaneous Oxidation of $\mathrm{CO}$ and $\mathrm{CH}_{4}$ over the $\mathrm{Cu}_{0.15}[\mathrm{Ce}(\mathrm{La})]_{0.85} \mathrm{O}_{\mathrm{x}}$ Catalyst}

Figure 5.14 shows the light-off curves of carbon monoxide and methane oxidation over the $\mathrm{Cu}_{0.15}[\mathrm{Ce}(\mathrm{La})]_{0.85} \mathrm{O}_{\mathrm{x}}$ catalyst in two different reacting gas mixtures. The oxidizing gas(II) consisted of $0.228 \% \mathrm{CH}_{4}, 0.1 \% \mathrm{CO}$, and $1.0 \% \mathrm{O}_{2}$. The reducing gas composition(III) consisted of $0.228 \% \mathrm{CH}_{4}, 0.1 \% \mathrm{CO}$, and $0.35 \% \mathrm{O}_{2}$. The light-off curves under the oxidizing and reducing conditions overlapped. Also, the light-off curves of methane oxidation in the presence of $\mathrm{CO}$ were similar to light-off in the absence of $\mathrm{CO}$. $95 \%$ conversion of $\mathrm{CO}$ and methane occurred at about $100^{\circ} \mathrm{C}$ and $550^{\circ} \mathrm{C}$, respectively. The oxidation behavior of the present catalyst is very different from that on precious metal catalysts ( $\mathbf{P d}, \mathbf{P t}, \mathbf{R h})$ reported in the literature (44). On the precious metal catalysts, the light-off curves of both $\mathrm{CO}$ oxidation and $\mathrm{CH}_{4}$ oxidation were strongly affected by the reacting atmosphere. Under reducing conditions, methane oxidation produced substantial amounts of $\mathrm{CO}$ and $\mathrm{H}_{2}$ at high temperatures (44), while no partial oxidation products( $\mathrm{CO}$, $\mathrm{H}_{2}$ ) were observed over the present catalyst. This was confirmed by separate studies under various space velocities. The $\mathrm{CO}$ and $\mathrm{H}_{2}$ oxidation on the metal-fluorite oxide composite catalysts appear to proceed very fast, as previously noted. This is an advantage of the present catalyst over the precious metal catalysts, because $\mathrm{CO}$ is a more harmful pollutant than methane.

\subsection{Summary}

Transition metal-fluorite oxide composite catalysts were studied in this work for the complete oxidation of carbon monoxide and methane. A variety of highly active oxidation catalysts can be prepared from this family of catalysts. The transition metal or metal oxide is usually insoluble in the fluorite oxide, while alkaline earth and rare earth oxides have solubility over a wide concentration range. Therefore, transition metals can be well dispersed in the fluorite oxide matrix without worrying about the adverse effect of solid solution formation, and alkaline and rare earth oxide can be used to tune the physical and chemical properties of the fluorite oxides. The good transition metal dispersion and, more 
importantly, the strong interaction between the transition metal and the fluorite oxide results in high catalyst activity and stability. The transition metal dispersion and display of this "strong interaction" are not sensitive to catalyst preparation process. Some specific conclusions were drawn from this work as follows:

\section{Carbon Monoxide Oxidation}

(1)The $\mathrm{Cu}-\mathrm{Ce}-\mathrm{O}$ composite showed higher $\mathrm{CO}$ oxidation activity than any other of the base metal oxide catalysts reported in the literature. The catalytic activity was not affected by small amounts of alkaline earth and rare earth dopants or impurities(ca. 1 at.\%). Only a small amount of copper(ca. 2 at. \% or $0.7 \mathrm{wt} \%$ ) was needed to promote the catalytic activity of $\mathrm{CeO}_{2}$, while excess copper formed bulk $\mathrm{CuO}$ particles of little contribution to the catalyst activity. These catalysts showed excellent resistance to water vapor poisoning.

(2) $\mathrm{The} \mathrm{Au}_{0.05}[\mathrm{Ce}(\mathrm{La})]_{0.95} \mathrm{O}_{\mathrm{x}}$ is an active and stable catalyst for low temperature $\mathrm{CO}$ oxidation(room temperature).

(3) The activity of the $\mathrm{Cu}-\mathrm{Ce}-\mathrm{O}$ system was superior to $\mathrm{Co}-\mathrm{Ce}-\mathrm{O}$ and $\mathrm{Cu}-\mathrm{Zr}-\mathrm{O}$, but all these catalyst systems showed improved resistance to water vapor poisoning.

\section{Methane Oxidation}

(4) The $\mathrm{Cu}-\mathrm{Ce}-\mathrm{O}$ and $\mathrm{Cu}-\mathrm{Zr}-\mathrm{O}$ composites are active catalysts for the complete methane oxidation. The $\mathrm{Cu}-\mathrm{Ce}-\mathrm{O}$ catalyst activity can be tuned by using alkaline earth and rare earth oxide dopants in suitable amounts. Both $\mathrm{La}$ and $\mathrm{Sr}$ dopants provided significant promotion effect.

(5) No partial oxidation products, such as $\mathrm{CO}, \mathrm{H}_{2}$, etc., were observed during methane oxidation over the $\mathrm{Cu}-\mathrm{Ce}(\mathrm{La})-\mathrm{O}$ and $\mathrm{Cu}-\mathrm{Zr}-\mathrm{O}$ catalysts under reducing conditions.

Further characterization of the $\mathrm{Cu}-\mathrm{Ce}(\mathrm{La})-\mathrm{O}$ catalyst and $\mathrm{CO}$ and methane oxidation kinetics will be presented in Part II of this paper (27). 


\subsection{Literature Cited}

1. Tuller, H.L., and Moon, P.K, Mater. Sci. \& Eng. B1, 171-191 (1988).

2. Hagenmuller, P., and Van Gool, W., Solid Electrolytes, Academic Press, New York, 1978.

3. RienAcker, G., Z. Anorg. Allg. Chem. 59, 280 (1949).

4. RienAcker, G., and Wu, Y., Z.Anorg. Allg. Chem. 315, 121 (1962).

5. RienAcker, G., and Birckenstaedt, M., Z. Anorg. Allg. Chem. 262, 81 (1950).

6. Claudel, B.M., and Brau, G.G., J. Catal. 14, 322 (1969).

7. Breysse, M., Guenin, M., Claudel, B., Latreille, H., and Veron, J., J. Catal. 27, $275-$ 280 (1972).

8. Breysse, M., Guenin, M., Claudel, B., Latreille, H., and Veron, J., J. Catal. 28, 5462 (1972).

9. Sayle, T. X.T., Parker, S.C., and Catlow, C.R.A., J. Chem. Soc., Chem. Commun. 977-978 (1992).

10. Maitra, A.M., Appl. Catal. A: General, 104, 11-59 (1993).

11. Otsuka, K., Komatsu, T., and Shimizu, Y., in Inui, T., (Editor), Successful Design of Catalysts, Elsevier Science Publishers B.V., Amsterdam, pp43-50, 1988.

12. Doshi, R., Alcock, C.B., Gunasekaran, N., and Carberry, J.J., J. Catal. 140, $557-$ 563 (1993).

13. Spivey, J. J., Ind. Eng. Chem. Res. 26, 2165-80 (1987).

14. Satterfield, C. N., Heterogeneous Catalysis in Industrial Practice, 2nd ed., McGrawHill, Inc., 1991.

15. Liu, W., and Flytzani-Stephanopoulos, M., in Armor, J.N., (Editor), Environmental Catalysis(ACS Symposium Series 552), American Chemical Society, Washington, DC, pp373-392, 1994.

16. Liu, W., Sarofim, A. L., and Flytzani-Stephanopoulos, M., 1994, Appl. Catal. B, 4,167-186 (1994).

17. Liu, W., Sarofim, A. L., and Flytzani-Stephanopoulos, M., in Materials and Processes for Environmental Protection, 1994 MRS Spring Meeting, Paper No. I3.9, San Francisco, CA.

18. Yao, H.C., and Yao, Y.F.Y., J. Catal. 86, 254-265 (1984).

19. Crucq, A., (editor), Catalysis and Automotive Pollution Control II, Elsevier Science Publishers B.V., Amsterdam, 1991.

20. Dow, W.P., and Huang, T.J., J. Catal. 147, 322-332 (1994).

21. Frost, J.C., Nature 334, 577-580 (1988).

22. Kim, D.J., J.Am. Ceram. Soc. 72, 1415-1421 (1989).

23. Levine, E.M., Robbins, C.R, and McMurdie, H.F., (Editors), Phase Diagrams for Ceramists, American Ceramic Society Inc. Publisher, 1969.

24. Gerhardt-Anderson, R, and Nowick, A.S., Solid State Ionics 5, 547-550 (1981).

25. Butler, V., Catlow, C.R.A., Fender, B.E.F., and Harding, J.H., Solid Sate Ionics 8, 109-113 (1988).

26. Cullity, B.D., Elements of X-ray Diffraction, Addison-Wesley Pub. Co., Reading, Massachusetts, 1978. 
27. Liu, W., and Flytzani-Stephanopoulos, M., J. Catal. 153(2), May 1995.

28. Zhang, Y.P., Tao, S., Sarofim, A. F., and Flytzani-Stephanopoulos, M., in Agarwal, S.K. Marcelin, G.M., Ozkan, U.S., (editors), NOx Reduction(ACS Symposium Series ---), American Chemical Society, Washington, DC ,1995, in press.

29. Wright, P.A., Natarajan, S., Thomas, J.M., and Gai-Boyes, P.L., Chem.Mater. 4, 1053-1065 (1992).

30. Choi, K.I., and Vannice, M.A., J. Catal. 131, 22-35 (1991).

31. Rajadurai, S., and Carberry, J.J., J. Catal. 147, 594-597 (1994).

32. Bond, G.C., and Namijo, S.N., J. Catal. 118, 507-510 (1989).

33. Haruta, M., Tsubota, S., Kobayashi, T., Kageyma, H., Genet, M. J., and Delmon, B., J. Catal. 144, 175-192 (1993).

34. Stephens, R.E., Hirschler, D.A., Jr., and Lamb, F.W., U.S. Patent No. 3226340 , 1965.

35. Stiles, A.B., U.S.Patent No. 3230 034, 1966.

36. Agudo, A.L., Palacios, J.M., Fierro, J.L.G., Laine, J., and Severio, F., Appl. Catal. A: General 91, 43-55 (1992).

37. Voorhoeve, R.J.H., Remeika, J.P., Freeland, P.E., and Matthias, B.T., Science 177, 353-354 (1972).

38. Schlatter, J.C., Klimisch, R.L., and Taylor, K.C., Science 179, 798-800 (1973).

39. Voorhoeve, R.J.H., Johnson, D.W., Jr., Remeika, J.P., and Gallagher, P.K., Science 195, 827-833 (1977).

40. Zwinkels, M. F.M., Jaras, S. G., and Menon, P. G., Catal. Rev.-Sci. Eng. 35, 319358 (1993).

41. Baiker, A., Marti, P.E., Keusch, P., Fritsch, E., and Reller, A., J. Catal. 146, 268276 (1994).

42. Klvana, D., Vaillancourt, J., Kirchnerova, J., and Chaouki, J., Appl. Catal. A: General 109, 181-193 (1994).

43. Arai, H., Yamada, T., Eguchi, K., and Seiyama, T., Appl. Catal. 26, 265-276 (1986).

44. Oh, S. H., Mitchell, P.J., and Siewert, R.M., J. Catal. 132, 287-301 (1991). 
Table 5.1 Variation of the $\mathrm{Cu}_{0.01}[\mathrm{Ce}(\mathrm{La})]_{0.99} \mathrm{O}_{\mathrm{x}}$ Catalyst Surface Area and Surface Composition With Thermal Treatment in Air.

\begin{tabular}{lllcc}
\hline treatment & \multirow{2}{*}{$\begin{array}{l}\text { Surface Area } \\
\left(\mathrm{m}^{2} / \mathrm{g}\right)\end{array}$} & \multicolumn{3}{c}{ Composition(\%) } \\
\cline { 3 - 6 } & 57.0 & $\mathrm{Cu}$ & $\mathrm{Ce}$ & La \\
\hline fresh $^{\mathrm{a}}$ & 52.4 & 4.97 & 89.0 & 6.02 \\
$+3 \mathrm{~h}$ in flowing air at $650^{\circ} \mathrm{C}$ & 52 & 8.10 & 86.5 & 5.37 \\
$+3 \mathrm{~h}$ in flowing air at $760^{\circ} \mathrm{C}$ & 44.5 & 9.08 & 84.7 & 6.19 \\
$+3 \mathrm{~h}$ in flowing air at $860^{\circ} \mathrm{C}$ & 27.3 & 11.9 & 81.4 & 6.74 \\
\hline
\end{tabular}

a. as prepared by $4-\mathrm{h}$ calcination at $600^{\circ} \mathrm{C}$ in $\mathrm{N}_{2}$.

b. determined by XPS with a standard deviation of $\pm 1 \%$, but not calibrated.

Table 5.2 Particle Size and Surface Composition of $\mathrm{Cu}-\mathrm{Ce}(\mathrm{La})-\mathrm{O}$ Catalysts.

\begin{tabular}{|c|c|c|c|c|c|}
\hline \multirow{2}{*}{$\frac{\text { Catalyst }}{\mathrm{Cu} /(\mathrm{Cu}+\mathrm{Ce}) \times 100 \%}$} & \multicolumn{2}{|c|}{ Particle Size $(\mathrm{nm})^{\mathrm{c}}$} & \multicolumn{3}{|c|}{ Surface Composition $(\%)^{d}$} \\
\hline & $\mathrm{CeO}_{2}$ & $\mathrm{CuO}$ & $\mathrm{La}$ & $\mathrm{Cu}$ & $\mathrm{Ce}$ \\
\hline $2^{a}$ & 10 & - & 5.9 & 11.7 & 82.4 \\
\hline $8(6)^{b}$ & 10 & - & 5.97 & 16.2 & 77.8 \\
\hline $15(10.5)^{b}$ & 7.6 & - & 3.42 & 24.8 & 71.7 \\
\hline $25(8.4)^{b}$ & 13 & 29 & 5.91 & 18.7 & 75.4 \\
\hline $50(8.8)^{b}$ & $14(14)^{b}$ & 29 & $5.8(6.9)^{b}$ & $18.9(11.4)^{b}$ & $75.3(81.7)^{b}$ \\
\hline
\end{tabular}

a. prepared by 4-hour calcination at $650^{\circ} \mathrm{C}$ and $3-\mathrm{h}$ calcination at $860^{\circ} \mathrm{C}$ both in air.

b. the sample was immersed in nitric acid for $14 \mathrm{~h}$ at room temperature, filtered, washed with de-ionized water, and dried for $1 \mathrm{~h}$ at $650^{\circ} \mathrm{C}$.

c. $\mathrm{CeO}_{2}$ and $\mathrm{CuO}$ particle sizes were determined by XRD from the (111) and ( 11$)$ peak widths at half maximum of $\mathrm{CeO}_{2}$ and $\mathrm{CuO}$, respectively.

d. determined by XPS with a standard deviation of $\pm 1 \%$, but not calibrated. 
Table 5.3 Catalyst Activity for CO Oxidation.

\begin{tabular}{|c|c|c|c|}
\hline \multirow{2}{*}{ Catalyst and Reaction Conditions } & \multirow{2}{*}{$\begin{array}{l}\text { Surface Area } \\
\left(\mathrm{m}^{2} / \mathrm{g}\right)\end{array}$} & \multicolumn{2}{|c|}{ Rate } \\
\hline & & $(\mu \mathrm{mol} / \mathrm{gcat} \cdot \mathrm{s})^{\mathrm{d}}$ & $\left(\mu \mathrm{mol} / \mathrm{m}^{2} \cdot \mathrm{s}\right)^{\mathrm{e}}$ \\
\hline \multicolumn{4}{|l|}{ I. $\mathrm{P}_{\mathrm{CO}}=0.01 \mathrm{bar}, 130^{\circ} \mathrm{C}$} \\
\hline $\mathrm{Cu}_{0.15}[\mathrm{Ce}(\mathrm{La})]_{0.85} \mathrm{O}_{\mathrm{x}} \mathbf{a}$ & 30 & 85 & 2.8 \\
\hline amorphous $\mathrm{CuMnO}_{\mathrm{x}}(28)^{\mathrm{b}}$ & 39 & 10 & 0.27 \\
\hline \multicolumn{4}{|l|}{ II. $\mathbf{P}_{\mathrm{CO}}=0.01 \mathrm{bar}, 80^{\circ} \mathrm{C}$} \\
\hline $\mathrm{Cu}_{0.15}[\mathrm{Ce}(\mathrm{La})]_{0.85} \mathrm{O}_{\mathrm{x}} \mathbf{a}$ & 30 & 19 & 0.63 \\
\hline spinel $\mathrm{CoCuMnO}_{4}(28)^{\mathrm{b}}$ & 113 & 9.4 & 0.083 \\
\hline \multicolumn{4}{|l|}{ III. $\mathbf{P}_{\mathrm{CO}}=0.035$ bar, $130^{\circ} \mathrm{C}$} \\
\hline $\mathrm{Cu}_{0.15}[\mathrm{Ce}(\mathrm{La})]_{0.85} \mathrm{O}_{\mathrm{x}} \mathrm{a}^{\mathrm{a}}$ & 30 & 195 & 6.5 \\
\hline 12 wt. $\% \mathrm{Cu} / \delta$-alumina $(30)^{a}$ & 138 & 0.64 & 0.005 \\
\hline \multicolumn{4}{|l|}{ IV. $P_{\mathrm{CO}}=0.01 \mathrm{bar}, 110^{\circ} \mathrm{C}$} \\
\hline $\mathrm{Cu}_{0.15}[\mathrm{Ce}(\mathrm{La})]_{0.85} \mathrm{O}_{\mathrm{x}}{ }^{\mathbf{a}}$ & 30 & 32 & $1.1(4.3)^{f}$ \\
\hline 0.5 wt. $\% \mathrm{Pt} /$ alumina $(31)^{\mathrm{c}}$ & 247 & 25 & $0.10(5.5)^{f}$ \\
\hline $\mathrm{La}_{0.8} \mathrm{Sr}_{0.2} \mathrm{CrO}_{3-\delta}(31)^{\mathrm{c}}$ & 0.33 & 1.8 & 5.5 \\
\hline
\end{tabular}

a. partial pressure of oxygen, $P_{O}$, is 0.17 bar.

b. $P_{\mathrm{O}}=0.2$ bar.

c. $1 \% \mathrm{CO}, 99 \% \mathrm{O}_{2}$, unknown total pressure.

d. specific rate based on unit catalyst weight.

e. specific rate based on unit BET surface area.

f. specific rate based on specific copper or platinum surface area. The specific copper surface area was estimated by BET area $\mathrm{x}$ surface copper fraction $(\mathrm{Cu} /(\mathrm{Cu}+\mathrm{La}+\mathrm{Ce}))$. 
Table 5.4 Gold-Metal Oxide Composite Catalyst Activity for CO Oxidation.

\begin{tabular}{lccc}
\hline Catalyst & $\begin{array}{c}\text { Surface Area } \\
\left(\mathrm{m}^{2} / \mathrm{g}\right)\end{array}$ & $\begin{array}{c}\text { Au particle size } \\
(\mathrm{nm})\end{array}$ & $\begin{array}{c}\text { rate at } 31^{\circ} \mathrm{C} \\
(\mu \mathrm{mol} / \mathrm{gcat} \cdot \mathrm{s})^{\mathrm{a}}\end{array}$ \\
\hline $\mathrm{Au}_{0.05}[\mathrm{Ce}(\mathrm{La})]_{0.95} \mathrm{O}_{\mathrm{x}}$ & 34.2 & 8.0 & 1.2 \\
5 at. $\% \mathrm{Au} / \alpha-\mathrm{Fe}_{2} \mathrm{O}_{3}(33)$ & 72.0 & 4.0 & 1.9 \\
\hline
\end{tabular}

a. rate calculated based on formation of $\mathrm{CO}_{2}$ under the conditions of $1 \% \mathrm{CO}, 1 \% \mathrm{O}_{2}$.

Table 5.5 Catalyst Activity for Methane Oxidation.

\begin{tabular}{|c|c|c|c|}
\hline \multirow{2}{*}{ Catalyst and Reaction Condition } & \multirow{2}{*}{$\begin{array}{l}\text { Surface Area } \\
\left(\mathrm{m}^{2} / \mathrm{g}\right)\end{array}$} & \multicolumn{2}{|c|}{ Rate $^{\mathrm{c}}$} \\
\hline & & $(\mu \mathrm{mol} / \mathrm{gcat} \cdot \mathrm{s})$ & $\left(\mu \mathrm{mol} / \mathrm{m}^{2} \cdot \mathrm{s}\right)$ \\
\hline \multicolumn{4}{|l|}{ I. $\mathbf{P}_{\mathrm{CH} 4}=0.01 \mathrm{bar}, \mathbf{P}_{\mathrm{O}}=0.04 \mathrm{bar}, 557^{\circ} \mathrm{C}$} \\
\hline $\mathrm{Cu}_{0.15}[\mathrm{Ce}(\mathrm{La})]_{0.85} \mathrm{O}_{\mathrm{x}}{ }^{\mathrm{a}}$ & 30 & 11 & 0.36 \\
\hline $\mathrm{LaCoO}_{3}(41)$ & 3.5 & 1.3 & 0.36 \\
\hline \multicolumn{4}{|l|}{ II. $P_{\mathrm{CH} 4}=0.04$ bar, $550^{\circ} \mathrm{C}$} \\
\hline $\mathrm{Cu}_{0.15}[\mathrm{Ce}(\mathrm{La})]_{0.85} \mathrm{O}_{\mathrm{x}}{ }^{\mathbf{a}}$ & 30 & 48 & 1.6 \\
\hline $\mathrm{La}_{0.66} \mathrm{Sr}_{0.34} \mathrm{Ni}_{0.3} \mathrm{Co}_{0.7} \mathrm{O}_{3}(42)^{\mathrm{b}}$ & 19 & 11 & 0.60 \\
\hline $\mathrm{La}_{0.8} \mathrm{Sr}_{0.2} \mathrm{MnO}_{3}(43)^{\mathrm{b}}$ & - & 6.6 & - \\
\hline
\end{tabular}

a. partial pressure of oxygen, $P_{O}$, is 0.12 bar.

b. $P_{\circ}=0.2$ bar.

c. rate calculated based on $\mathrm{CO}_{2}$ formation. 


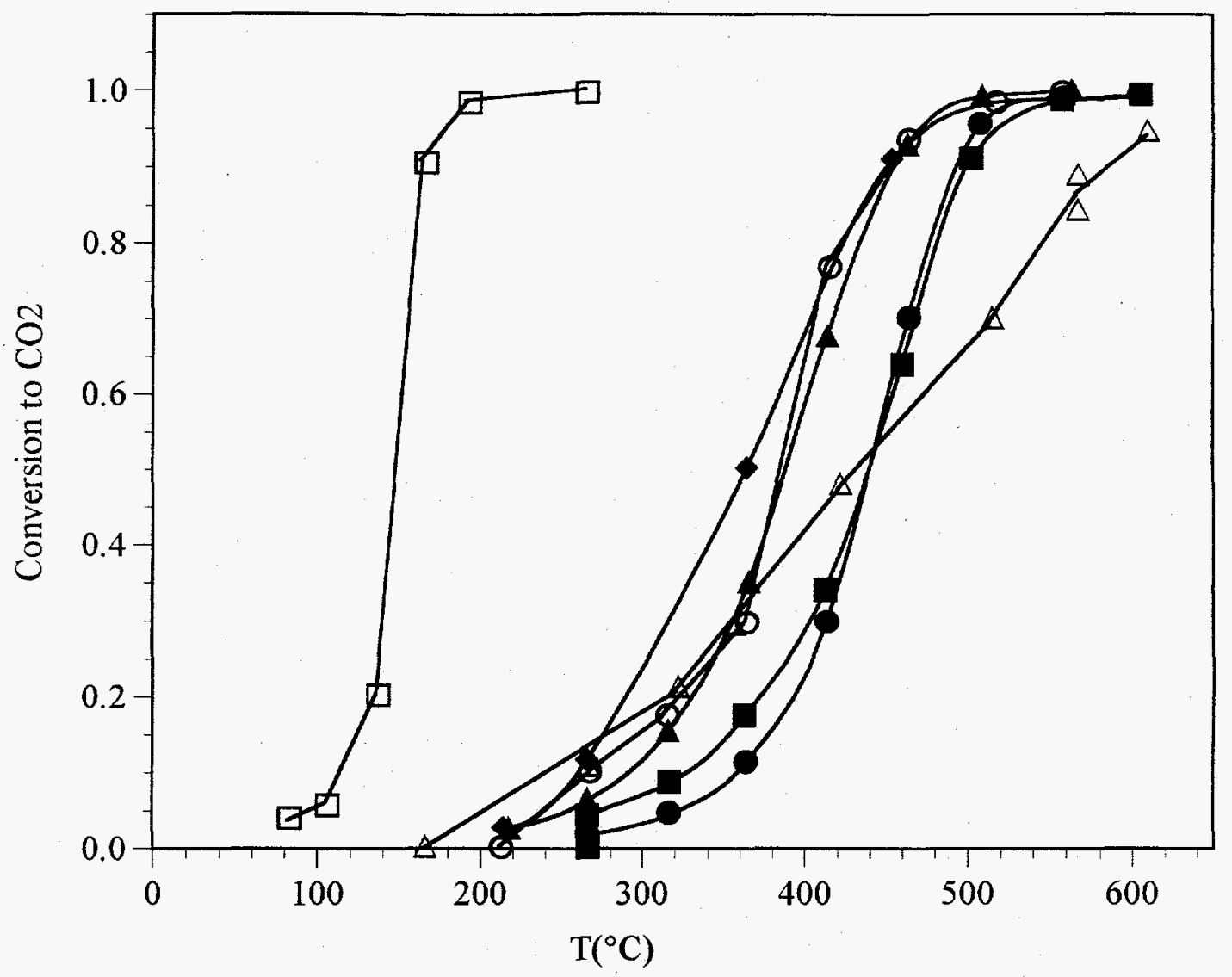

Figure 5.1 Light-off of CO Oxidation over Various 1 at.\% Doped Ceria Catalysts and $\mathrm{Zr}_{0.9} \mathrm{Y}_{0.1} \mathrm{O}_{1.9}$ Catalyst (100 sccm: $2 \% \mathrm{CO}, 16 \% \mathrm{O}_{2}$; surface areas: $\mathrm{Zr}_{0.9} \mathrm{Y}_{0.1} \mathrm{O}_{1.9}=42 \mathrm{~m}^{2} / \mathrm{g}, 1$ at. $\% \mathrm{Cu}=57 \mathrm{~m}^{2} / \mathrm{g}$, others $\left.\cong 28 \mathrm{~m}^{2} / \mathrm{g}\right)$. $\square \mathrm{Cu}-[\mathrm{Ce}(\mathrm{La})] \mathrm{O}_{2}$ prepared by $4-\mathrm{h}$ heating in $\mathrm{N}_{2}$ at $600^{\circ} \mathrm{C}, \bullet \mathrm{La}, \Delta \mathrm{Sr}, \mathrm{O}$ no dopant, $\square \mathrm{Sc}, \bullet \mathrm{Gd}, \Delta \mathrm{Zr}_{0.9} \mathrm{Y}_{0.1} \mathrm{O}_{1.9}$. 


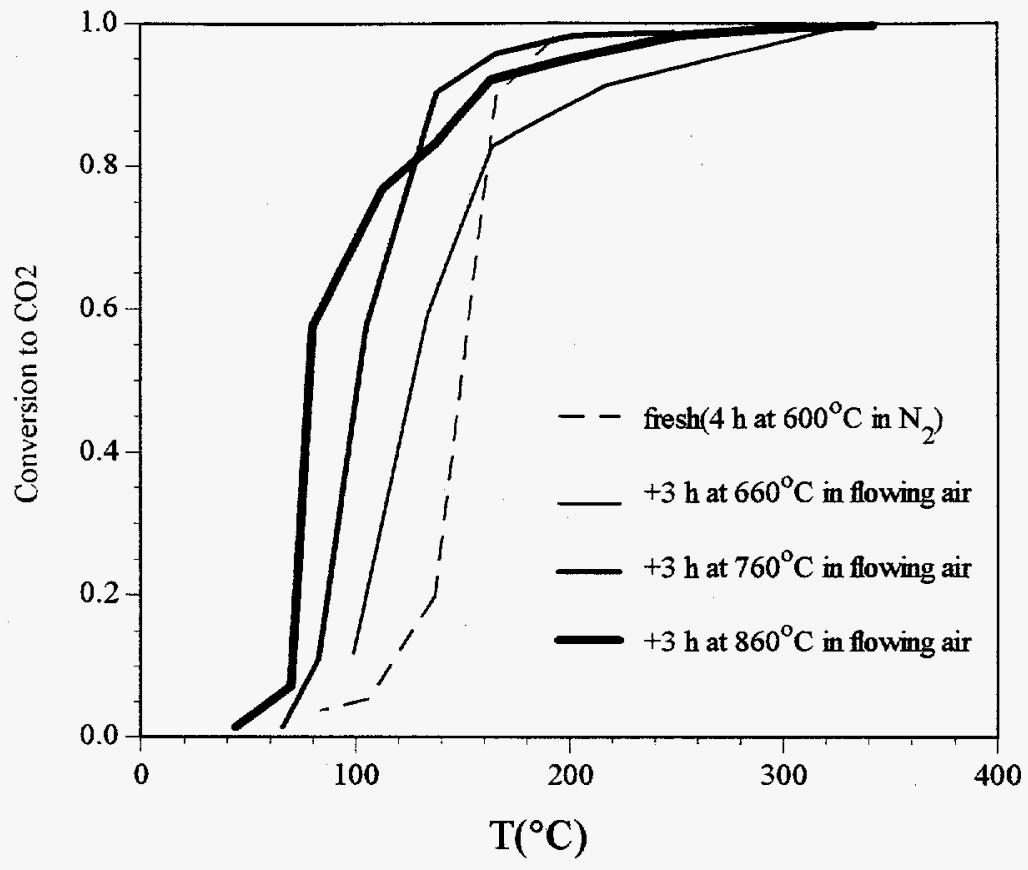

Figure 5.2 Effect of Thermal Treatment on the $\mathrm{Cu}_{0.01}[\mathrm{Ce}(\mathrm{La})]_{0.99} \mathrm{O}_{\mathrm{x}}$ Catalyst Activity for CO Oxidation ( $100 \mathrm{sccm}: 2 \% \mathrm{CO}, 16 \% \mathrm{O}_{2}$ ).

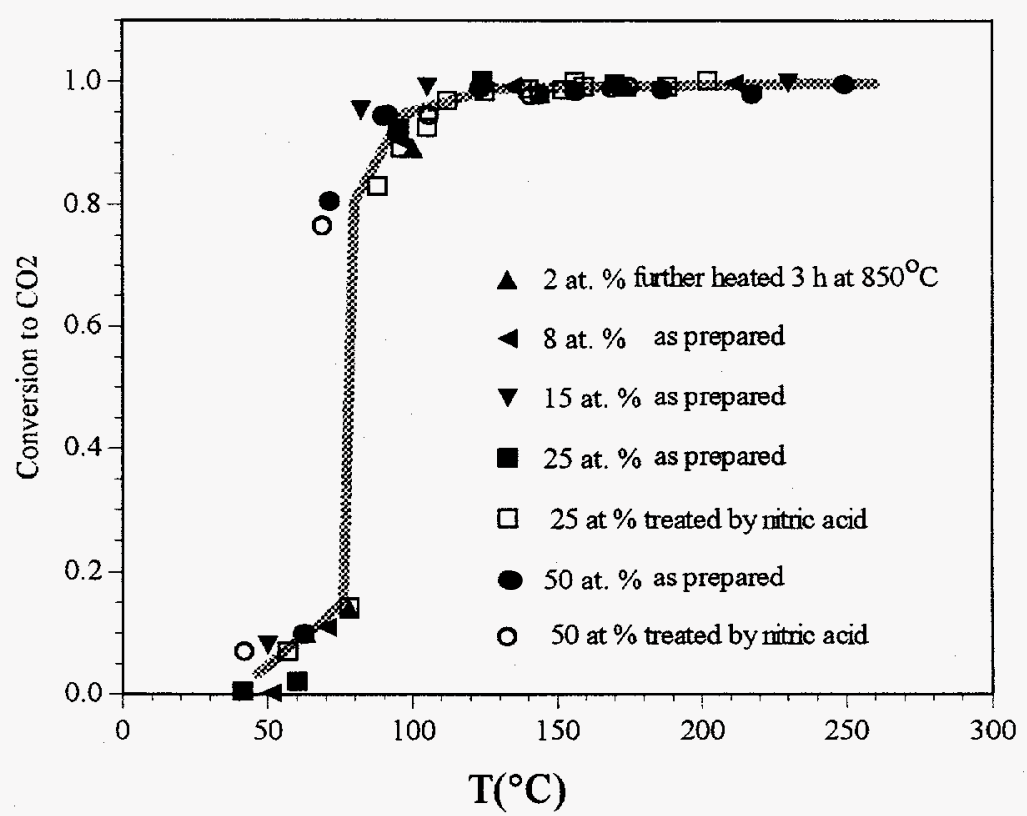

Figure 5.3 Effect of Bulk Copper Content in $\mathrm{Cu}_{\mathrm{x}}[\mathrm{Ce}(\mathrm{La})]_{1 \cdot \mathrm{x}} \mathrm{O}_{2-\mathrm{x}}$ Catalyst on $\mathrm{CO}$ Oxidation Activity (100 sccm: $2 \% \mathrm{CO}, 16 \% \mathrm{O}_{2}$; surface areas $\cong 30 \mathrm{~m}^{2} / \mathrm{g}$ ). 


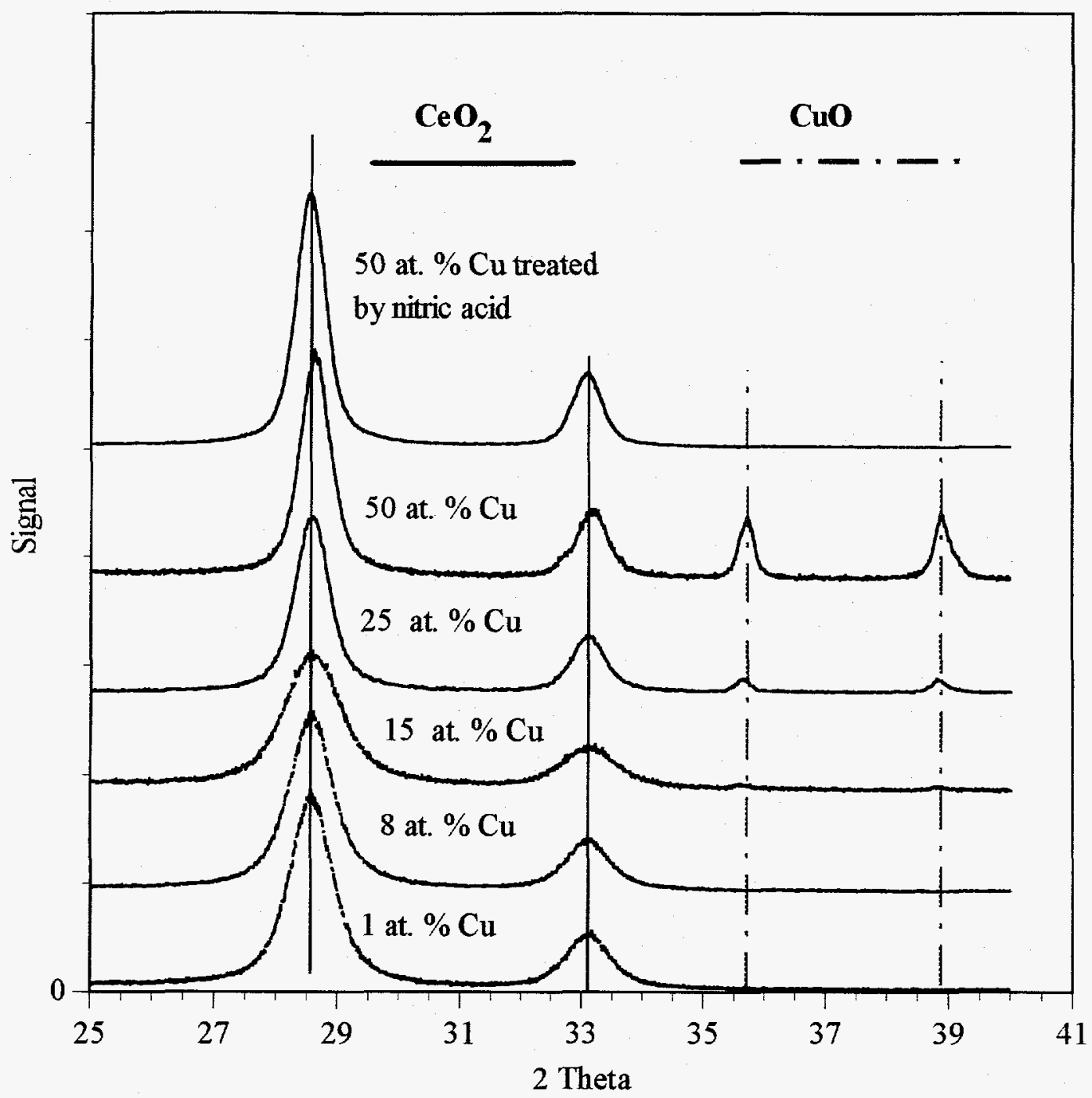

Figure 5.4 XRD Pattern of the $\mathrm{Cu}-\mathrm{Ce}(\mathrm{La})-\mathrm{O}$ Catalysts $(\mathrm{K} \alpha 1$ copper radiation, $50 \mathrm{kV}$, $200 \mathrm{~mA}$, scan rate $1 \% / \mathrm{min}$ ). 


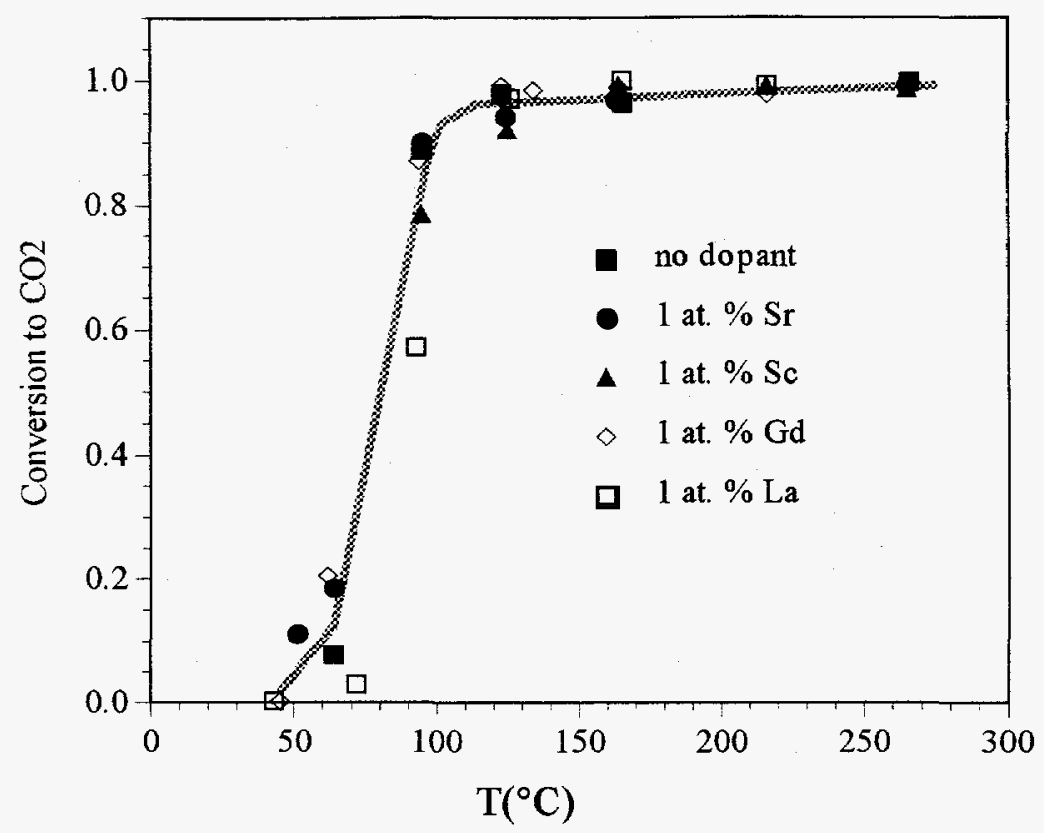

Figure 5.5 Effect of 1 at.\% Dopant on the CO Oxidation Activity of $\mathrm{Cu}_{0.15} \mathrm{Ce}_{0.85} \mathrm{O}_{x}$ Catalyst (100 sccm: $2 \% \mathrm{CO}, 16 \% \mathrm{O}_{2}$; surface areas $\left.\cong 30 \mathrm{~m}^{2} / \mathrm{g}\right)$.

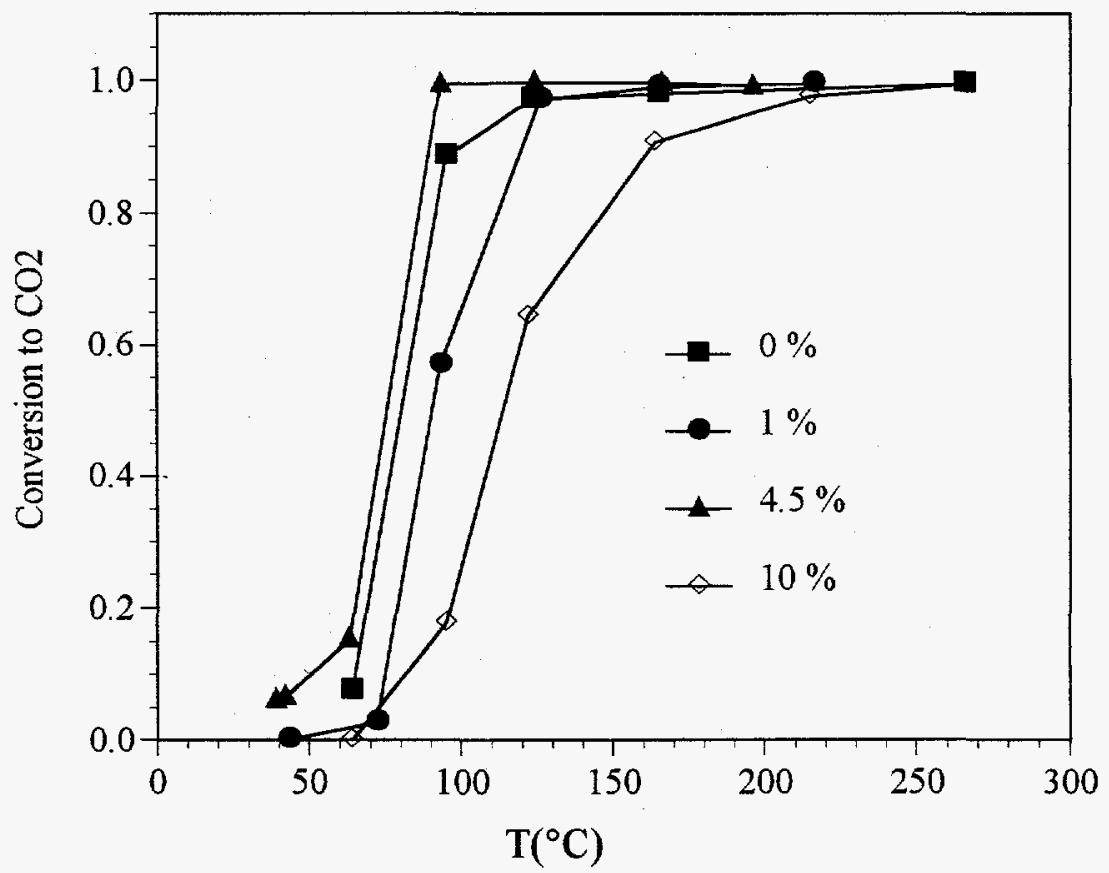

Figure 5.6 Effect of La Dopant Content on the CO Oxidation Activity of $\mathrm{Cu}_{0.15} \mathrm{Ce}_{0.85} \mathrm{O}_{\mathrm{x}}$ Catalyst ( $100 \mathrm{sccm}: 2 \% \mathrm{CO}, 16 \% \mathrm{O}_{2}$; surface areas $\cong 30 \mathrm{~m}^{2} / \mathrm{g}$ ). 


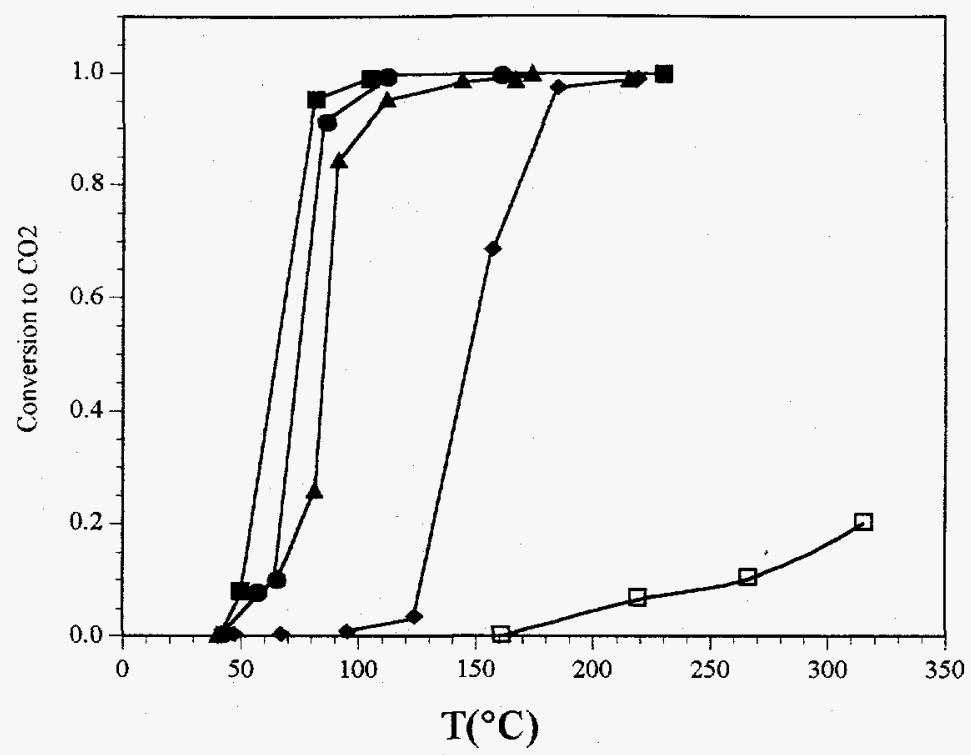

Figure 5.7 Activity Enhancement for $\mathrm{CO}$ Oxidation from Combination of $\mathrm{CeO}_{2}$ and $\mathrm{CuO}$ (100 sccm: $2 \% \mathrm{CO}, 16 \% \mathrm{O}_{2}$ ). $\mathrm{Cu}_{0.15}[\mathrm{Ce}(\mathrm{La})]_{0.85} \mathrm{O}_{\mathrm{x}}, 30 \mathrm{~m}^{2} / \mathrm{g},-15$ at $\%$ $\mathrm{CuO}_{\mathrm{x}} / \mathrm{CeO}_{2}, 22.4 \mathrm{~m}^{2} / \mathrm{g}, \Delta 15$ at. $\% \mathrm{CuO}+\mathrm{CeO}_{2}$ prepared by $1 \mathrm{~h}$ heating in air at $300^{\circ} \mathrm{C}$, $18.6 \mathrm{~m}^{2} / \mathrm{g}, \bullet$ bulk $\mathrm{CuO}, 1.64 \mathrm{~m}^{2} / \mathrm{g}, \square \mathrm{CeO}_{2}, 28 \mathrm{~m}^{2} / \mathrm{g}$.

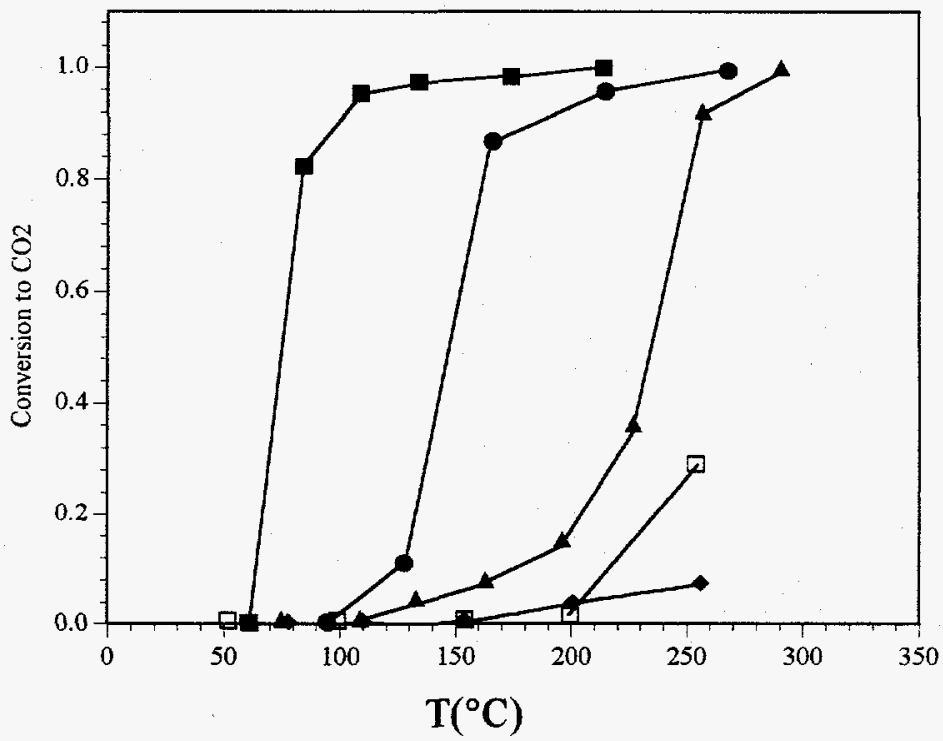

Figure 5.8 Effect of Copper Dispersion on CO Oxidation Activity (100 sccm: $2 \% \mathrm{CO}$, $\left.16 \% \mathrm{O}_{2}\right)$. $\sim \mathrm{Cu}_{0.15}[\mathrm{Ce}(\mathrm{La})]_{0.85} \mathrm{O}_{\mathrm{x}}, 50 \mathrm{mg}, 30 \mathrm{~m}^{2} / \mathrm{g} \bullet \mathrm{CuO}, 1000 \mathrm{mg}, 1.64 \mathrm{~m}^{2} / \mathrm{g} \wedge 14$ at. $\%$ $\mathrm{CuO} / \gamma$-alumina, $150 \mathrm{mg}, 137 \mathrm{~m}^{2} / \mathrm{g} \bullet 3.2$ at. $\%$ Cu-ZSM- $5,150 \mathrm{mg}, 400 \mathrm{~m}^{2} / \mathrm{g}$ 3.1 at. $\%$ $\mathrm{Ce}, 1$ at. $\% \mathrm{Cu}, \mathrm{Ce}-\mathrm{Cu}-\mathrm{ZSM}-5,150 \mathrm{mg}, 400 \mathrm{~m}^{2} / \mathrm{g}$. 


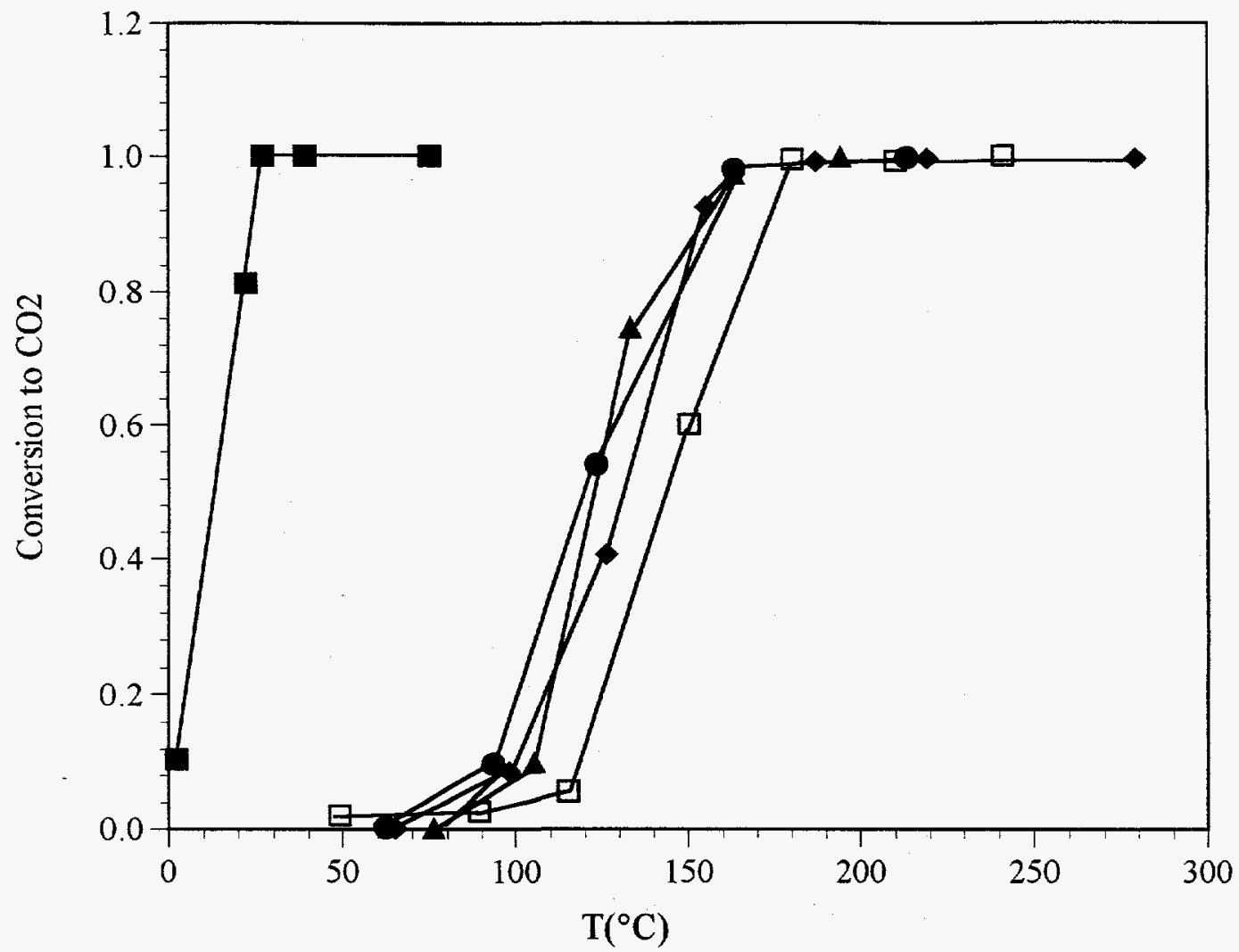

Figure 5.9 CO Oxidation over Various Composite Catalysts(150 mg catalyst loading; 100 sccm: $\left.2 \% \mathrm{CO}, 16 \% \mathrm{O}_{2}\right)$. $\mathrm{Au}_{0.05}[\mathrm{Ce}(\mathrm{La})]_{0.95} \mathrm{O}_{\mathrm{x}}$ prepared by air calcination for $1 \mathrm{~h}$ at $500^{\circ} \mathrm{C}+1 \mathrm{~h}$ at $600^{\circ} \mathrm{C}, 34.2 \mathrm{~m}^{2} / \mathrm{g}, \quad \mathrm{Pt}_{0.03}[\mathrm{Ce}(\mathrm{La})]_{0.97} \mathrm{O}_{\mathrm{x}}, 28.1 \mathrm{~m}^{2} / \mathrm{g} \Delta \mathrm{Cu}_{0.2} \mathrm{Zr}_{0.8} \mathrm{O}_{\mathrm{x}}, 17.8$ $\mathrm{m}^{2} / \mathrm{g}, \bullet \mathrm{Cu}_{0.15}\left[\mathrm{Zr}_{0.9} \mathrm{Y}_{0.1}\right]_{0.85} \mathrm{O}_{\mathrm{x}}, 65 \mathrm{~m}^{2} / \mathrm{g}, \square \mathrm{Co}_{0.2}[\mathrm{Ce}(\mathrm{La})]_{0.8} \mathrm{O}_{\mathrm{x}}, 30 \mathrm{~m}^{2} / \mathrm{g}$. 


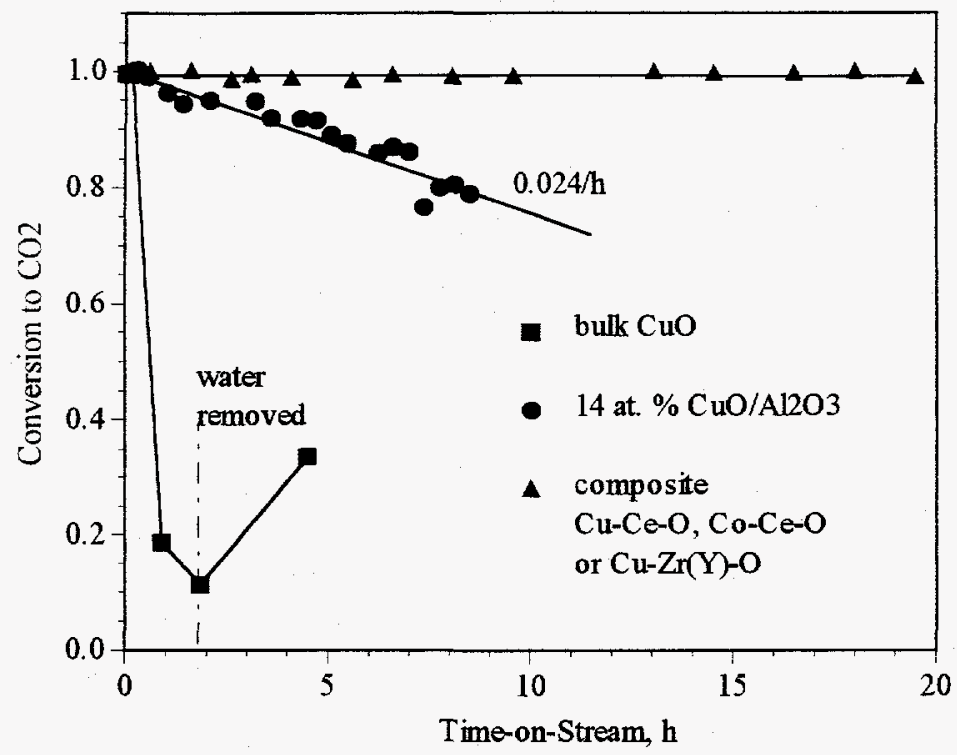

Figure 5.10 Effect of Water Vapor on CO Oxidation Activity over the Catalysts Prepared by $4 \mathrm{~h}$ Calcination at $650^{\circ} \mathrm{C}$ in Air (catalyst loading: $1000 \mathrm{mg}$ for $\mathrm{CuO}$ catalyst, $150 \mathrm{mg}$ for others; $340^{\circ} \mathrm{C}$ reaction temperature; $47 \mathrm{sccm} \mathrm{H}_{2} \mathrm{O}+100 \mathrm{sccm}$ dry gas containing $2 \% \mathrm{CO}$ and $16 \% \mathrm{O}_{2}$ ).

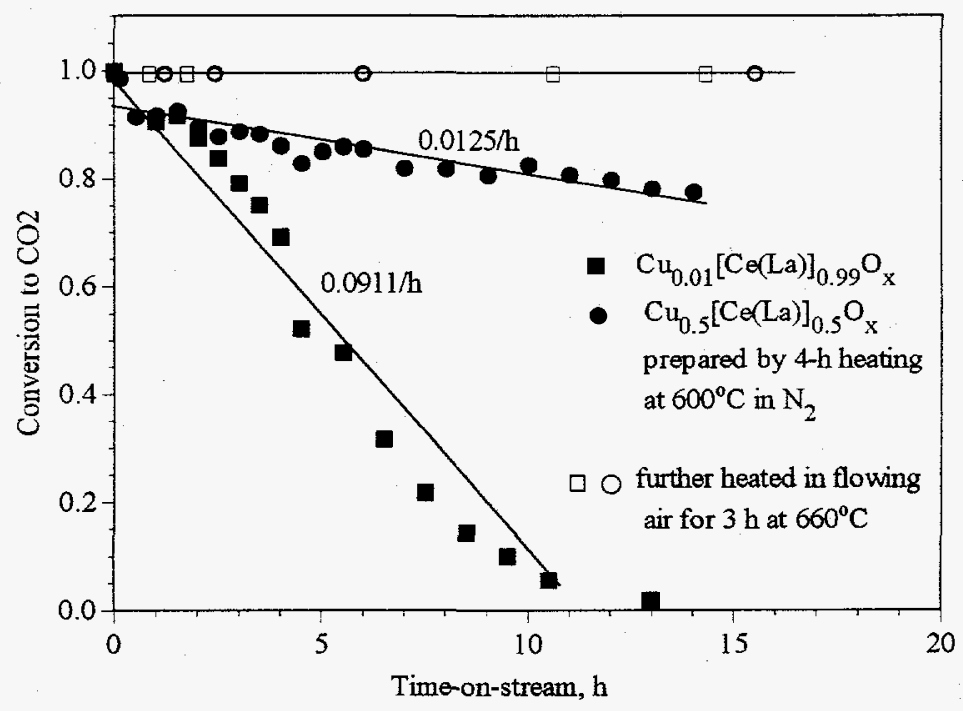

Figure 5.11 Effect of Catalyst Thermal Treatment on the CO Oxidation Activity in the Presence of Water Vapor ( $150 \mathrm{mg}$ catalyst loading; $340^{\circ} \mathrm{C}$ reaction temperature; $47 \mathrm{sccm}$ $\mathrm{H}_{2} \mathrm{O}+100$ scem dry gas containing $2 \% \mathrm{CO}$ and $16 \% \mathrm{O}_{2}$ ). 


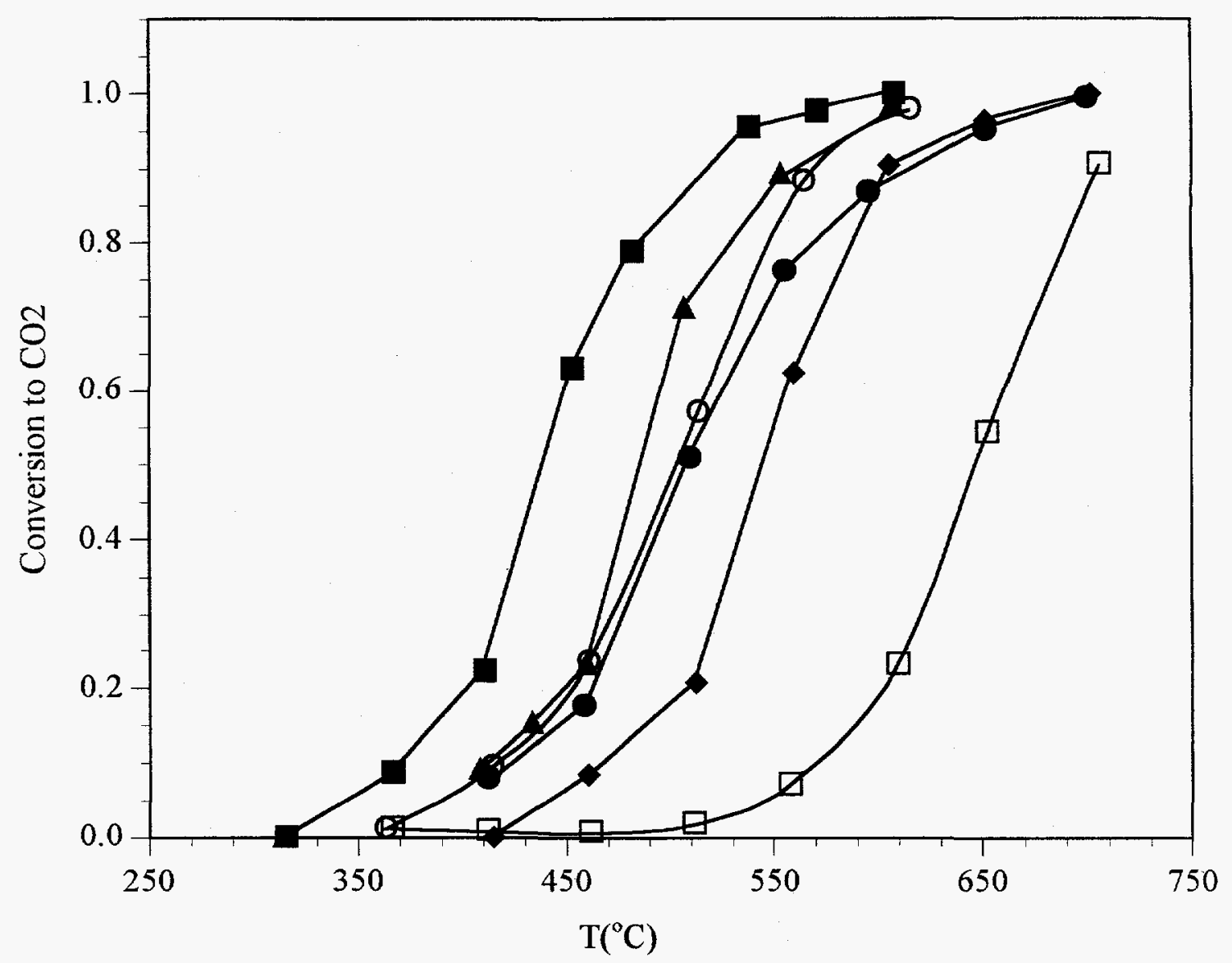

Figure 5.12 Methane Oxidation over Various Composite Catalysts ( $150 \mathrm{mg}$ catalyst loading; 100 sccm: $\left.2 \% \mathrm{CH}_{4}, 16 \% \mathrm{O}_{2}\right)$. $\square \mathrm{Cu}_{0.2} \mathrm{Zr}_{0.8} \mathrm{O}_{\mathrm{x}}, 17.8 \mathrm{~m}^{2} / \mathrm{g} \Delta \mathrm{Cu}_{0.08}[\mathrm{Ce}(\mathrm{La})]_{0.92} \mathrm{O}_{\mathrm{x}}$, $43 \mathrm{~m}^{2} / \mathrm{g}, O \mathrm{Cu}_{0.5}[\mathrm{Ce}(\mathrm{La})]_{0.5} \mathrm{O}_{\mathrm{x}}, 27.8 \mathrm{~m}^{2} / \mathrm{g} \bullet \mathrm{Cu}_{0.5} \mathrm{Zr}_{0.5} \mathrm{O}_{\mathrm{x}}, 50.0 \mathrm{~m}^{2} / \mathrm{g} \bullet[\mathrm{Ce}(\mathrm{La})] \mathrm{O}_{2}, 30$ $\mathrm{m}^{2} / \mathrm{g} \square \mathrm{CeO}_{2}, 28 \mathrm{~m}^{2} / \mathrm{g}$. 


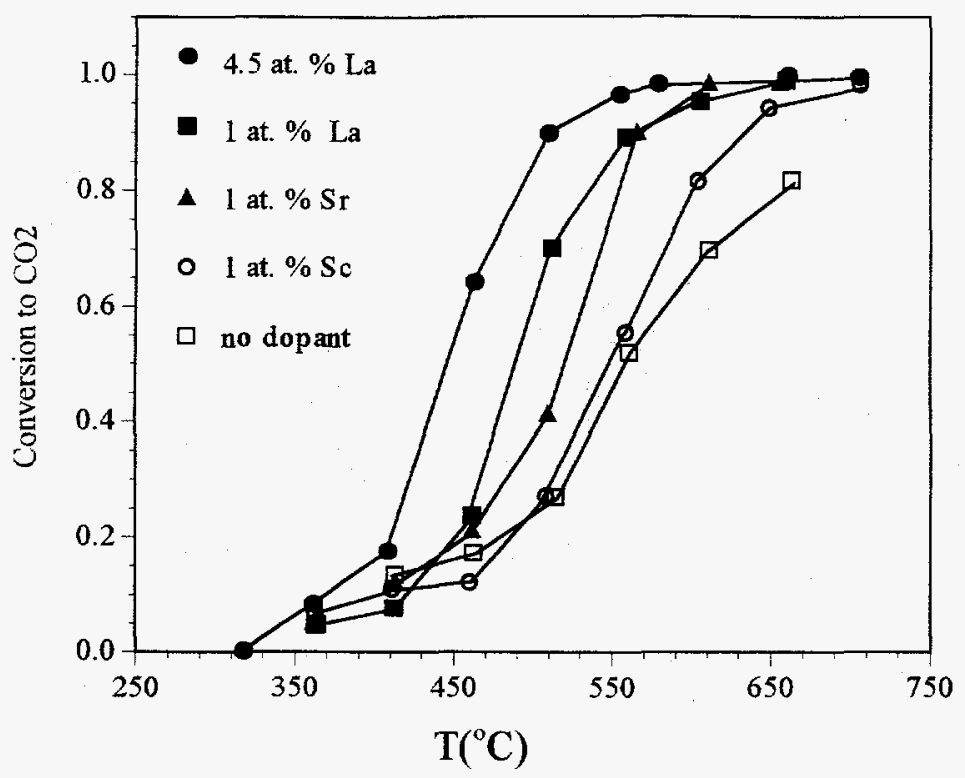

Figure 5.13 Effect of Dopant in the $\mathrm{Cu}_{0.15} \mathrm{Ce}_{0.85} \mathrm{O}_{\mathrm{x}}$ Catalyst on Methane Oxidation Activity $\left(0.09 \mathrm{~s} \cdot \mathrm{g} / \mathrm{cc}, 2 \% \mathrm{CH}_{4}, 16 \% \mathrm{O}_{2} ;\right.$ catalyst surface area $\left.\cong 30 \mathrm{~m}^{2} / \mathrm{g} ;\right)$.

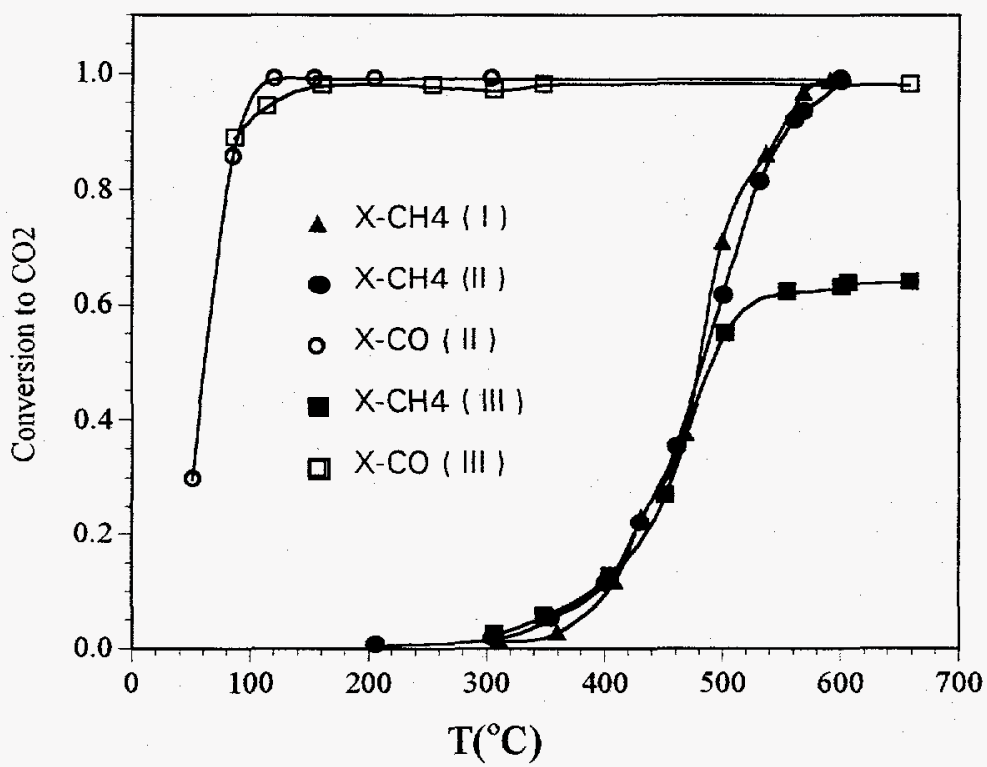

Figure 5.14 Simultaneous Oxidation of Methane and $\mathrm{CO}$ over the $\mathrm{Cu}_{0.15}[\mathrm{Ce}(\mathrm{La})]_{0.85} \mathrm{O}_{\mathrm{x}}$ Catalyst. I: in $0.228 \% \mathrm{CH}_{4}, 1 \% \mathrm{O}_{2}$. $\mathrm{II}$ : in oxidizing gas containing $0.228 \% \mathrm{CH}_{4}, 0.1 \%$ $\mathrm{CO}, 1 \% \mathrm{O}_{2}$. III: in reducing gas containing $0.228 \% \mathrm{CH}_{4}, 0.1 \% \mathrm{CO}, 0.35 \% \mathrm{O}_{2}$. 


\section{Chapter 6}

\section{Complete Oxidation of Carbon Monoxide and Methane over Transition Metal-Fluorite Oxide Composite Catalysts II. Catalyst Characterization and Reaction Kinetics}

\subsection{Introduction}

Transition metal-fluorite oxide composite catalysts were evaluated for the complete oxidation of $\mathrm{CO}$ and methane in the preceding paper (1). The $\mathrm{Cu}-\mathrm{Ce}-\mathrm{O}$ system was identified as one of the most active catalyst systems. The significant enhancement of catalytic activity and resistance to water vapor for $\mathrm{CO}$ oxidation observed with this catalyst cannot be explained on the basis of copper dispersion alone. Thus, a strong interaction between these two kinds of materials was proposed. Strong interaction between a metal particle and its oxide support has long been a fascinating catalysis subject (2-7). Moreover, another concept involving new active sites created at the interface between metal-support has been proposed $(6,7)$.

Although a mechanistic understanding of the correlation between catalyst properties and metal-support interactions is still limited, looking at the oxide support not simply as an inert carrier has given many insights for new catalyst development. For example, Frost (8) predicted the existence and properties of new methanol synthesis catalysts by using the minute Schottky junction theory at the interface between metals and oxides. In studies of $\mathrm{CO}$ hydrogenation, the precious metals- $\mathrm{TiO}_{2}$ strong interaction has been one classic system in this field. "Strong interaction" between precious metals and cerium oxide has been another active area ( 9 ) in environmental catalysis because of the widespread use of cerium oxide in the precious metal-based automotive catalytic converter. The enhanced $\mathrm{CO}$ oxidation activity and stability of precious metal catalysts by yttria-stabilized zirconia(YSZ) support was recently reported and explained in terms of interfacial reactions (10). A reaction mechanism based on the metal-support interface was also proposed for some low temperature $\mathrm{CO}$ oxidation catalysts, such as $\mathrm{Pt} / \mathrm{SnO}_{2}$ (11), $\mathrm{Pd} / \mathrm{SnO}_{2}(12,13), \mathrm{Au} / \alpha-\mathrm{Fe}_{2} \mathrm{O}_{3}$ or $\mathrm{TiO}_{2}(14)$, etc. In a recent study of non-precious metalfluorite oxide system for $\mathrm{CO}$ oxidation, a geometric interfacial interaction in $\mathrm{Cu} / \mathrm{YSZ}$ involving surface oxygen vacancy was proposed (15).

In this work we characterized the $\mathrm{Au}-\mathrm{Ce}-\mathrm{O}$ and $\mathrm{Cu}-\mathrm{Ce}-\mathrm{O}$ catalyst systems by X-ray Photoelectron Spectroscopy (XPS) and Scanning Transmission Electron 
Microscopy(STEM) aided by X-ray microprobe analysis, and measured the reaction kinetics in order to elucidate the "strong interaction" between copper and cerium oxide and its effect on the catalytic activity. The Au-Ce-O catalyst clearly demonstrated a synergistic effect on catalytic activity and best served as a reference.

\subsection{Experimental}

\subsubsection{Catalyst Preparation and Characterization}

Bulk composite catalysts were prepared by coprecipitating the aqueous salt solutions of the metals with ammonium carbonate or sodium carbonate. $\mathrm{CeO}_{2}$ support was prepared by thermal decomposition of cerium acetate hydrate $(99.9 \%$, Aldrich). The supported catalysts were prepared by conventional wet impregnation using the aqueous salt solution of the metal. The mixture of cerium oxide and copper oxide was prepared by mixing the $\mathrm{CuO}$ and $\mathrm{CeO}_{2}$ powder with water and drying it for $1 \mathrm{~h}$ at $300^{\circ} \mathrm{C}$. The details of the preparation procedure were described in the preceding paper (1). The cerium precursor used for coprecipitation was low purity $(99 \%)$ cerium nitrates(from Aldrich) containing 1.5 wt.\% lanthanum. This type of cerium is designated as $\mathrm{Ce}(\mathrm{La})$ in the catalyst formula throughout this paper. The catalyst characterization was performed by nitrogen adsorption/desorption on a Micromeritics ASAP 2000 apparatus for BET surface area and pore size measurement and by X-ray powder diffraction(XRD) on a Rigaku $300 \mathrm{X}$-ray Diffractometer for crystalline identification. The catalyst typically had an average pore size of $20 \mathrm{~nm}$ and a BET surface area from 20 to $57 \mathrm{~m}^{2} / \mathrm{g}$. For the XRD analysis, copper $K \alpha 1$ radiation was used with power setting of $50 \mathrm{kV}$ and $200 \mathrm{~mA}$. The divergence slit, scattering slit, and receiving slit were $1^{\circ}, 1^{\circ}$, and $0.15^{\circ}$, respectively. The data was acquired at a 2 theta interval of $0.02^{\circ}$. The catalyst microstructure analysis was performed on a state-of-the-art Vacuum Generators HB603 Scanning Transmission Electron Microscope(STEM) equipped with a X-ray microprobe of $0.14 \mathrm{~nm}$ optimum resolution. For STEM analysis, the catalyst powder was dispersed on a nickel grid coated by a carbon film and the elemental maps were acquired on a $128 \times 128$ data matrix. The catalyst surface composition was determined by X-ray Photoelectron Spectroscopy(XPS) with a Perkin Elmer 5100 system. For XPS analysis, the catalyst powder was pressed on a tantalum foil and placed into the vacuum chamber without any pre-treatment. $\mathrm{A} \mathrm{Mg}$ electron source was used with power setting of $15 \mathrm{kV}$ and $300 \mathrm{~W}$. The binding energy was adjusted to the C1s peak at $284.6 \mathrm{eV}$ which existed in all measurements. The Auger kinetic energy was calculated by $1253.6-(\mathrm{BE})_{\mathrm{A}}$, where $(\mathrm{BE})_{\mathrm{A}}$ is the measured binding energy of the Auger $\mathrm{L}_{3} \mathrm{VV}$ line.

\subsubsection{Apparatus and Procedure}

The reactor was a $0.6 \mathrm{~cm}$ I.D. $x 50 \mathrm{~cm}$ long quartz tube heated by a Lindberg furnace. The reaction temperature was monitored by a quartz glass-sheathed K-type thermocouple placed at the top of the packed catalyst bed. $\mathrm{CO}$ and $\mathrm{CH}_{4}$ reacting gases were certified calibration gas mixtures balanced by helium(from Matheson). Air and helium(all from AIRCO)were used as oxidizing gas and diluent, respectively. The gas streams were 
measured with mass flow controllers and mixed prior to the reactor inlet. The resulting gas mixture without further purification flowed downward through the packed bed. For kinetic measurements, the reactor was operated in a differential mode with the conversion not exceeding $10 \%$ so that the temperature was nearly uniform in the packed catalyst bed. Separate experimental tests showed that bulk mass transfer and intraparticle mass transfer resistance could be eliminated by using a gas flowrate greater than $200 \mathrm{sccm}$ and catalyst particles size less than $150 \mu \mathrm{m}$. Therefore, total gas flowrate of $400 \mathrm{sccm}$ and average catalyst particle size of $100 \mu \mathrm{m}$ were used for the kinetics study. The reaction conversion was controlled by the catalyst loading, while the catalyst was diluted by silicon carbide to about $10 \mathrm{~mm}$ packed height. The partial pressure of the reacting gas species was varied over the range of 0.001 to 0.09 bar. $\mathrm{CO}$ oxidation over the $\mathrm{Au}-\mathrm{Ce}-\mathrm{O}$ catalyst was measured over the temperature range of 10 to $50^{\circ} \mathrm{C}$. CO oxidation and methane oxidation over the $\mathrm{Cu}-\mathrm{Ce}-\mathrm{O}$ catalysts were conducted at temperatures from 40 to $200^{\circ} \mathrm{C}$ and from 400 to $550^{\circ} \mathrm{C}$, respectively. Before any kinetic measurement, the catalyst was always treated for $1 \mathrm{~h}$ in the reaction gas mixture at $300^{\circ} \mathrm{C}$ for $\mathrm{CO}$ oxidation and $600^{\circ} \mathrm{C}$ for methane oxidation. Carbon dioxide concentration in the product gas stream was analyzed by a HP5880A Gas Chromatograph(GC) with a Thermal Conductivity Detector(TCD). The production of $\mathrm{CO}_{2}$ was used to calculate the reaction rate:

$$
\text { Rate }=N_{t} \cdot X_{\mathrm{CO} 2} / W_{C A T}
$$

where $\mathrm{N}_{\mathrm{t}}$ is the total molar gas flowrate in mol/s, $\mathrm{X}_{\mathrm{CO} 2}$ is the molar fraction of $\mathrm{CO}_{2}$ in the product gas stream, and $\mathrm{W}_{\mathrm{CAT}}$ is the catalyst weight in grams.

\subsection{Results}

\subsubsection{Catalyst Characterization}

\subsubsection{Characterization of $\mathrm{Au}_{0.05}[\mathrm{Ce}(\mathrm{La})]_{0.95} \mathrm{O}_{\mathrm{x}}$ Catalyst}

Only the 5 at.\% Au-containing Au-Ce-O catalyst, $\mathrm{Au}_{0.05}[\mathrm{Ce}(\mathrm{La})]_{0.95} \mathrm{O}_{\mathrm{x}}$, was extensively characterized, because this catalyst showed better activity than the other Au$\mathrm{Ce}-\mathrm{O}$ catalysts of lower or higher gold content. Figures $6.1 \mathrm{a}-\mathrm{c}$ show the XRD pattern, XPS spectra, and STEM elemental maps for the $\mathrm{Au}_{0.05}[\mathrm{Ce}(\mathrm{La})]_{0.95} \mathrm{O}_{x}$ catalyst. The XRD pattern in Figure 6.1a consisted of $\mathrm{CeO}_{2}$ and metallic gold crystal phases. The gold particle size calculated from the peak broadening is about $8 \mathrm{~nm}$. The binding energy of Au4f7/2 in the XPS was close to that of metallic gold given in the literature (16). The gold particles were difficult to be visualized by electron microscopy because of the interference from cerium. However, clear images were obtained by elemental mapping with the STEM $X$-ray microprobe. STEM analysis indicated uniform distribution of small gold particles in the cerium oxide matrix. The gold particle sizes varied from $1 \mathrm{~nm}$ to tens of $\mathrm{nm}$. There was no evidence of epitaxial growth of the gold particles on cerium oxide or spill-over of gold onto cerium oxide. The gold particle image in Figure 6.1c shows that the wellrounded gold particle was in intimate contact with cerium oxide. These results indicate that in the $\mathrm{Au}_{0.05}[\mathrm{Ce}(\mathrm{La})]_{0.95} \mathrm{O}_{\mathrm{x}}$ catalyst small metallic gold particles of an average size of 
$8 \mathrm{~nm}$ were evenly distributed in the cerium oxide matrix and in intimate contact with the cerium oxide.

\subsubsection{XRD and STEM Analyses of Cu-Ce-O Catalyst System}

A few XRD analyses of the $\mathrm{Cu}-\mathrm{Ce}-\mathrm{O}$ catalysts prepared by coprecipitation were reported in the preceding paper (1). For up to 15 at.\% copper content, no $\mathrm{CuO}$ peaks were found by XRD. Figure 6.2 shows the XRD pattern of $\mathrm{Cu}-\mathrm{Ce}-\mathrm{O}$ catalysts containing 15 at. $\%$ or higher copper prepared by coprecipitation, impregnation, and physical mixing methods. The major peaks were due to the $\mathrm{CeO}_{2}$ crystal phase. $\mathrm{CuO}$ appeared in smaller

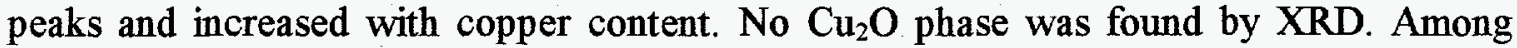
three $\mathrm{Cu}-\mathrm{Ce}-\mathrm{O}$ catalysts containing 15 at. $\% \mathrm{Cu}$, the coprecipitated catalyst showed the lowest $\mathrm{CuO}$ phase intensity and the mixed oxide showed the highest $\mathrm{CuO}$ phase. We tried to correlate the variation of $\mathrm{CeO}_{2}$ lattice space with copper content and catalyst preparation. But, the results were inconclusive. Overall, limited information was obtained from the XRD study.

The microstructure of the $\mathrm{Cu}-\mathrm{Ce}-\mathrm{O}$ system was first analyzed by high resolution transmission electron microscopy (HRTEM). Unlike alumina-supported precious metals, copper in the $\mathrm{Cu}-\mathrm{Ce}-\mathrm{O}$ catalyst could not be distinguished from cerium under electron microscopy because it is lighter than cerium. STEM having both high magnification and elemental analysis functions was found effective for the $\mathrm{Cu}-\mathrm{Ce}-\mathrm{O}$ catalyst characterization. The $\mathrm{Cu}-\mathrm{Ce}-\mathrm{O}$ catalyst was extensively analyzed by STEM. A few typical elemental maps are presented in Figure 6.3. The $\mathrm{Cu}$ map in Figure $6.3 \mathrm{a}$ for the $\mathrm{Cu}_{0.15}[\mathrm{Ce}(\mathrm{La})]_{0.85} \mathrm{O}_{\mathrm{x}}$ catalyst consists of a big $\mathrm{CuO}$ particle $(17 \mathrm{~nm})$ and a number of tiny copper spots distributed in the cerium oxide matrix. These copper domains could not be definitely differentiated from the solid solution as distinguishable fine copper particles due to the lighter copper atomic weight relative to cerium and the instrumental limitation itself. Few fine copper oxide crystals $(\mathrm{nm})$ were found in the $\mathrm{Cu}_{0.15}[\mathrm{Ce}(\mathrm{La})]_{0.85} \mathrm{O}_{\mathrm{x}}$ catalyst by HRTEM. Taking into account the immiscibility of copper oxide in cerium oxide and further characterization evidence from other $\mathrm{Cu}-\mathrm{Ce}-\mathrm{O}$ catalysts as given below, we attribute these tiny copper domains to copper clusters invisible by XRD. Figures $3 b$ and $3 c$ show the elemental maps of the impregnated catalyst, 15 at. $\% \mathrm{CuO}_{\mathrm{s}} / \mathrm{CeO}_{2}$, and the physical mixture, 15 at. $\% \mathrm{CuO}+\mathrm{CeO}_{2}$, respectively. Impregnation did not result in uniform deposition of copper on cerium oxide. But, the physical mixing generated not only mechanical mixture but also spillover of copper onto the cerium oxide. In the $\mathrm{CuO}+\mathrm{CeO}_{2}$ catalyst, a number of bulk copper oxide particles were found, but, copper clusters also existed in the cerium oxide matrix.. Qualitatively, a higher number of bulk copper oxide particles was found with the $\mathrm{CuO}_{\mathrm{x}} / \mathrm{CeO}_{2}$ and $\mathrm{CuO}+\mathrm{CeO}_{2}$ catalysts than the $\mathrm{Cu}_{0.15}[\mathrm{Ce}(\mathrm{La})]_{0.85} \mathrm{O}_{\mathrm{x}}$. In contrast, more clusters were observed with the $\mathrm{Cu}_{0.15}[\mathrm{Ce}(\mathrm{La})]_{0.85} \mathrm{O}_{\mathrm{x}}$ than the other two 15 at.\% copper-containing catalysts. These results are consistent with the smaller $\mathrm{CuO}$ peaks in the XRD pattern of the $\mathrm{Cu}_{0.15}[\mathrm{Ce}(\mathrm{La})]_{0.85} \mathrm{O}_{\mathrm{x}}$. In the preceding paper we reported that only bulk $\mathrm{CuO}$ in the $\mathrm{Cu}-\mathrm{Ce}-\mathrm{O}$ system could be removed by nitric acid. This conclusion is evidenced by the elemental map in Figure $6.3 \mathrm{~d}$ for the $\mathrm{Cu}_{0.15}[\mathrm{Ce}(\mathrm{La})]_{0.85} \mathrm{O}_{\mathrm{x}}$ catalyst after it was immersed in nitric acid for $14 \mathrm{~h}$, filtered, and washed with de-ionized water. Very few 
bulk $\mathrm{CuO}$ particles remained in this nitric acid-treated catalyst, compared to the fresh one. However, the copper clusters remained intact.

Figures $6.3 \mathrm{e}-\mathrm{f}$ show the elemental maps of the $\mathrm{Cu}_{0.5}[\mathrm{Ce}(\mathrm{La})]_{0.5} \mathrm{O}_{\mathrm{x}}$ catalyst. A large number of copper agglomerates were observed with this higher copper-containing material. It is interesting to notice that the bulk $\mathrm{CuO}$ particles were typically covered by smaller cerium oxide particles. This finding is illustrated by Figure $6.3 \mathrm{e}$ in which a big $\mathrm{CuO}$ agglomerate (ca. $300 \mathrm{~nm}$ ) was almost fully covered by smaller cerium oxide particles. But, when we look at a group of cerium oxide particles not associated with bulk $\mathrm{CuO}$, a number of copper clusters are still dispersed in the cerium oxide matrix as shown in Figure 6.3f. Their existence was confirmed by electron-excited X-ray emission spectra in Figure $6.3 \mathrm{~g}$. The spectra also indicates that the amount of these copper clusters relative to cerium is indeed small and they did not appear in Figure $6.3 \mathrm{e}$ because of very low intensity relative to bulk $\mathrm{CuO}$ particles.

Figure 6.3h shows the elemental map of the $\mathrm{Cu}_{0.01}[\mathrm{Ce}(\mathrm{La})]_{0.99} \mathrm{O}_{\mathrm{x}}$ catalyst prepared by coprecipitation and $4 \mathrm{~h}$ calcination at $600^{\circ} \mathrm{C}$ in $\mathrm{N}_{2}$. As expected, copper in this catalyst was well dispersed in the cerium oxide and its distribution pattern exactly matched cerium, which suggests the formation of solid solution. Notice that the high copper dispersion area in Figure $6.3 \mathrm{~h}$ represents uniform copper distribution rather than high copper content. Heating the $\mathrm{Cu}_{0.01}[\mathrm{Ce}(\mathrm{La})]_{0.99} \mathrm{O}_{\mathrm{x}}$ catalyst in flowing air at $860^{\circ} \mathrm{C}$ drove the copper from bulk to surface and copper atoms aggregating into clusters. Resulting elemental maps as illustrated by Figure $6.3 \mathrm{i}$ looked similar to that of the nitric acid-treated $\mathrm{Cu}_{0.15}[\mathrm{Ce}(\mathrm{La})]_{0.85} \mathrm{O}_{\mathrm{x}}$ catalyst but less dense copper cluster population.

Since the coprecipitated catalysts contained lanthanum impurity, the X-probe was also used to check for La distribution. The analyses indicated atomic level mixing of lanthanum with cerium oxide or formation of solid solution. No lanthanum association with copper was found. The overall STEM analysis results are now summarized as: (i) copper in small amounts (a few percent) has strong tendency to associate with cerium oxide irrespective to the catalyst preparation method; (ii) excess copper forms bulk $\mathrm{CuO}$ particles that were covered by smaller $\mathrm{CeO}_{2}$ particles; (iii) heating the catalyst of atomic copper dispersion caused segregation of copper and formation of copper clusters.

\subsubsection{XPS Analyses of Cu-Ce-O Catalyst System}

In the preceding paper (1) we reported the catalyst surface composition as measured by XPS. Here, the detail XP spectra are presented. We found that the XP spectra of the $\mathrm{Cu}-\mathrm{Ce}(\mathrm{La})-\mathrm{O}$ sample were unstable in the high vacuum chamber(ca. $7 \times 10^{-8}$ torr) during the initial period of measurement. Once the sample was introduced into the XPS chamber, the relative intensity of the $\mathrm{Cu} 2 \mathrm{p} 3 / 2$ shake-up peak at $943 \mathrm{eV}$ slightly decreased with onstream measurement time while the $\mathrm{Cu} 2 \mathrm{p} 3 / 2$ peak position shifted toward lower binding energy from $934.0 \mathrm{eV}$. However, the XP spectra became stable after about thirty minutes. The shake-up peak and higher $\mathrm{Cu} 2 \mathrm{p} 3 / 2$ binding energy are two major XPS characteristics of $\mathrm{CuO}$, while the lower $\mathrm{Cu} 2 \mathrm{p} 3 / 2$ binding energy and absence of the shake-up peak are characteristic of reduced copper species (16). It is known that supported-copper oxide can 
be reduced by the X-ray beam during XPS analysis. Although the beam effect could not be eliminated in the present XPS apparatus, further work confirmed that the initial instability of the $\mathrm{Cu}-\mathrm{Ce}(\mathrm{La})-\mathrm{O}$ sample was not suppressed by decreasing the $\mathrm{X}$-ray power and was likely caused by the desorption of weakly-bound surface oxygen under high vacuum. Figures $4 \mathrm{a}-\mathrm{c}$ show the XPS analyses of the 15, 25, and 50 at.\% $\mathrm{Cu}-\mathrm{Ce}(\mathrm{La})-\mathrm{O}$ catalysts prepared by coprecipitation. These data were acquired in the Multiplex mode with about 1-h total acquisition time. Bulk $\mathrm{CuO}$ was prepared by thermal decomposition of copper carbonate and used as reference.

In Figure 6.4a, the bulk $\mathrm{CuO}$ showed a strong shake-up peak, and the shake-up peak intensity of the $\mathrm{Cu}-\mathrm{Ce}(\mathrm{La})-\mathrm{O}$ catalysts increased with the copper content and disappeared after the catalyst was treated by nitric acid using the procedure described previously. The $\mathrm{Cu} 2 \mathrm{p} 3 / 2$ peak of the bulk $\mathrm{CuO}$ centered at $934.0 \mathrm{eV}$, while the same peaks of the $\mathrm{Cu}-$ $\mathrm{Ce}(\mathrm{La})-\mathrm{O}$ catalysts centered at about $933.1 \mathrm{eV}$. The present observations suggest both $\mathrm{CuO}$ and reduced copper species existing in these $\mathrm{Cu}-\mathrm{Ce}(\mathrm{La})-\mathrm{O}$ catalysts. We could deconvolute the $\mathrm{Cu} 2 \mathrm{p} 3 / 2$ peak to find the relative proportion of $\mathrm{CuO}$ in the $\mathrm{Cu}-\mathrm{Ce}(\mathrm{La})-\mathrm{O}$ catalysts. But, this peak did not show an apparent doublet shape, that made it hard to obtain a reliable value from this mathematical process. In addition, the weak shake-up peak did not allow us to use the shake-up peak/peak ratio for a reliable estimation either. Therefore, our discussion of the XPS results will be qualitative.

The two possible reduced copper forms, namely: metallic copper and $\mathrm{Cu}_{2} \mathrm{O}$, have similar binding energies but different Auger parameters (16-20). Figure 6.4b shows the kinetic energy spectra of the Auger $\mathrm{L}_{3} \mathrm{VV}$ electron. The doublet peaks for the $\mathrm{Cu}-\mathrm{Ce}(\mathrm{La})-$ $O$ samples also suggest the presence of two copper species. The $918.4 \mathrm{eV}$ and $915.7 \mathrm{eV}$ peaks in the Auger kinetic spectra correspond to bulk $\mathrm{CuO}$ and $\mathrm{Cu}^{+1}$ species, respectively. In agreement with the literature data we then assign the $\mathrm{Cu} 2 \mathrm{p} 3 / 2$ peak at higher binding energy $(934.0 \mathrm{eV})$ to $\mathrm{CuO}$ and the $\mathrm{Cu} 2 \mathrm{p} 3 / 2$ peak at the lower binding energy $(933.1 \mathrm{eV})$ to the $\mathrm{Cu}^{+1}$ species(Figure 6.4a). Figure 6.4c shows the Ce3d XP spectra for the four catalyst samples under study. The four spectra look basically the same and similar to bulk $\mathrm{CeO}_{2}$ reported in the literature (16). The binding energies for bulk $\mathrm{CeO}_{2}$ and reduced cerium oxide are the same. But, small spikes or peaks are usually found in the reduced cerium oxide at the $\mathrm{D}$ and $\mathrm{D}^{\prime}$ positions $(21,22)$.

Figures 6.5a-b show the $\mathrm{Cu} 2 \mathrm{p}$ XP spectra and $\mathrm{L}_{3} \mathrm{VV}$ kinetic energies of the $\mathrm{Cu}_{0.01}[\mathrm{Ce}(\mathrm{La})]_{0.99} \mathrm{O}_{\mathrm{x}}$ and $\mathrm{Cu}_{0.02}[\mathrm{Ce}(\mathrm{La})]_{0.98} \mathrm{O}_{\mathrm{x}}$ catalysts. No shake-up peak was observed in Figure $6.5 \mathrm{a}$, while the $\mathrm{Cu} 2 \mathrm{p} 3 / 2$ peak was deconvoluted into two components: one at $933.1 \mathrm{eV}$ and another one at $930.0 \mathrm{eV}$. The first one was assigned to $\mathrm{Cu}^{+1}$ species. The second component was difficult to be assigned since no copper species of such a low binding energy has been reported in the literature. We postulate that this component is due to isolated $\mathrm{Cu}^{+2}$ ions in the cerium oxide lattice. The existence of isolated copper ions and ion pairs in the $\mathrm{Cu}-\mathrm{Ce}-\mathrm{O}$ system was reported by Abou Kais, et al. $(23,24)$ and Sorial, et al. (25), both using the electron paramagnetic resonance technique. The fraction of $\mathrm{Cu}^{+1}$ species in Figure 6.5a increased with heating temperature, while the fraction of isolated $\mathrm{Cu}^{+2}$ ions decreased. The STEM analyses indicated that heating the $\mathrm{Cu}_{0.01}[\mathrm{Ce}(\mathrm{La})]_{0.99} \mathrm{O}_{\mathrm{x}}$ catalyst in air drove the isolated copper ions to form copper clusters. Two components 
seem to exist in the kinetic energy spectra of the Auger $\mathrm{L}_{3} \mathrm{VV}$ electron in Figure $6.5 \mathrm{~b}$. It is noted that the isolated copper component at $930.1 \mathrm{eV}$ also appeared in the XP spectra for the nitric acid-treated 50 at.\% copper-containing sample shown in Figure 6.4a. This was probably due to the copper ions remaining on the cerium oxide surface after the sample had been immersed in nitric acid for $14 \mathrm{~h}$.

The XRD, STEM, and XPS analysis results for the $\mathrm{Cu}-\mathrm{Ce}-\mathrm{O}$ catalysts are briefly summarized as follows: (i) copper clusters undetectable by XRD exist in all the $\mathrm{Cu}-\mathrm{Ce}-\mathrm{O}$ catalysts and its relative amount depends on catalyst preparation, composition, and thermal treatment; (ii) the $\mathrm{Cu}^{+1}$ species result from the strong interaction of the copper clusters with cerium oxide.

\subsubsection{Kinetic Results}

\subsubsection{CO Oxidation Kinetics over the $A u_{0.05}[\mathrm{Ce}(\mathrm{La})]_{0.95} \mathrm{O}_{\mathrm{x}}$ Catalyst}

Figure 6.6 shows the variation of $\mathrm{CO}$ oxidation rate on the $\mathrm{Au}_{0.05}[\mathrm{Ce}(\mathrm{La})]_{0.95} \mathrm{O}_{\mathrm{x}}$ catalyst with the partial of pressure of $\mathrm{CO}\left(\mathrm{P}_{\mathrm{CO}}\right)$ and oxygen $\left(\mathrm{P}_{\mathrm{O}}\right)$. The experimental data were best fitted by a power order equation (2), with $\mathrm{m}=0.30$ and $\mathrm{n}=0.18$.

$$
R_{C O}=k P_{C O}^{m} P_{O}^{n}
$$

The $R^{\wedge} 2(R=$ correlation coefficient $)$ values given in Figure 6.6 indicate that the plots of the rate versus $P_{C O}$ under constant $P_{O}$ were generally better fitted than the plots of the rate versus $\mathbf{P}_{\mathrm{O}}$. This is because of the lower reaction order in $\mathbf{P}_{\mathrm{O}}$. Although difficult to regress, this function is not important because of its small contribution to the overall rate process. The Arrhenius plot of the rate constant, $k$, is shown in Figure 6.9. The apparent activation energy was $53.7 \mathrm{~kJ} / \mathrm{mol}$. The reaction orders and activation energy are compared to the literature data for other gold-metal oxide catalysts in Table 6.1. The $\mathrm{Au}_{0.05}[\mathrm{Ce}(\mathrm{La})]_{0.95} \mathrm{O}_{\mathrm{x}}$ catalyst showed similar kinetics to the other gold catalysts but higher activation energy and a stronger dependence on $\mathbf{P}_{\mathrm{CO}}$.

\subsubsection{CO Oxidation Kinetics over the $\mathrm{Cu}-\mathrm{Ce}-\mathrm{O}$ Catalysts}

The $\mathrm{Cu}_{0.15}[\mathrm{Ce}(\mathrm{La})]_{0.85} \mathrm{O}_{\mathrm{x}}$ catalyst and the $\mathrm{Cu}_{0.01}[\mathrm{Ce}(\mathrm{La})]_{0.99} \mathrm{O}_{\mathrm{x}}$ catalyst subjected to different thermal treatment were chosen for the kinetic study to also examine the composition effect. Figures 6.7 and 6.8 show the variation of the $\mathrm{CO}$ oxidation rates on the $\mathrm{Cu}_{0.15}[\mathrm{Ce}(\mathrm{La})]_{0.85} \mathrm{O}_{\mathrm{x}}$ at different reaction temperatures with $\mathrm{P}_{\mathrm{CO}}$ and $\mathrm{P}_{\mathrm{O}}$, respectively. Under constant $\mathbf{P}_{\mathrm{O}}$, the rate increased with $\mathbf{P}_{\mathrm{CO}}$. The reaction order in $\mathbf{P}_{\mathrm{CO}}$ seems to decrease from one to zero as $P_{C O}$ increases. In Figure 6.8 the rate slowly increased with $P_{O}$ under constant $\mathbf{P}_{\mathrm{CO}}$. Various rate equations derived from different reaction mechanism as well as the empirical power order equation (2) were evaluated to regress the experimental data. It was found that the experimental data were best represented by the following equations:

$$
R_{C O}=\frac{k_{C O} K_{C O} P_{C O} P_{O}^{n}}{1+K_{C O} P_{C O}}
$$




$$
\begin{aligned}
& k_{C O}=A \exp (-E a / R T) \\
& K_{C O}=K \exp (Q / R T)
\end{aligned}
$$

The parameters $\mathrm{k}_{\mathrm{CO}}$ and $\mathrm{K}_{\mathrm{CO}}$ in equation (3) can be taken as the surface reaction rate constant and $\mathrm{CO}$ adsorption equilibrium constant, respectively. The Arrhenius plots of $\mathrm{k}_{\mathrm{CO}}$ and $\mathrm{K}_{\mathrm{CO}}$ are shown in Figure 6.9 from which the reaction activation energy and heat of adsorption were obtained.

The experimental data for the $\mathrm{Cu}_{0.01}[\mathrm{Ce}(\mathrm{La})]_{0.99} \mathrm{O}_{x}$ catalysts were also best regressed by equation (3). The Arrhenius plots of the resulting constants are shown in Figure 6.10. The values of those parameters in equations (4) and (5) for all the $\mathrm{Cu}-\mathrm{Ce}(\mathrm{La})-\mathrm{O}$ catalysts are listed in Table 6.2. The reaction orders in $P_{0}, n$, are small numbers close to zero. The activation energy is in the range of 73 to $94 \mathrm{~kJ} / \mathrm{mol}$ while the heat of CO adsorption is in the range of 28 to $61 \mathrm{~kJ} / \mathrm{mol}$. Some interesting results were observed with the $\mathrm{Cu}_{0.01}[\mathrm{Ce}(\mathrm{La})]_{0.99} \mathrm{O}_{\mathrm{x}}$ catalyst. Heating this catalyst at $860^{\circ} \mathrm{C}$ in air changed the negative reaction order of $\mathrm{P}_{O}$ to positive and increased the pre-exponential factor of the reaction constant $\mathbf{k}_{\mathrm{CO}}$ and the heat of adsorption. This increase corresponds to the increase in copper cluster population and $\mathrm{Cu}^{+1}$ fraction as we found from the STEM and XPS analyses. The last column in Table 6.2 shows the apparent activation energy when $\mathrm{K}_{\mathrm{CO}} \mathrm{P}_{\mathrm{CO}}$ $<<1$. Under this condition, the reaction rate becomes first order in $\mathrm{P}_{\mathrm{CO}}$ and the apparent activation energy is Ea-Q. Table 6.2 also includes kinetic data for other copper catalysts from the literature for comparison. The $\mathrm{CuO}-\mathrm{Cr}_{2} \mathrm{O}_{3} / \gamma-\mathrm{Al}_{2} \mathrm{O}_{3}$ catalyst, pre-calcined in air at $500^{\circ} \mathrm{C}$ (26), gave an pre-exponential factor of the constant $\mathrm{k}_{\mathrm{CO}}$ four orders of magnitude lower than those of the $\mathrm{Cu}-\mathrm{Ce}(\mathrm{La})-\mathrm{O}$ catalysts and also low heat of adsorption $(5 \mathrm{~kJ} / \mathrm{mol})$. High heat of adsorption $(30 \mathrm{~kJ} / \mathrm{mol})$ was reported for the $\mathrm{Cu} / \delta-\mathrm{Al}_{2} \mathrm{O}_{3}$ catalyst pre-reduced by $\mathrm{H}_{2}$ at $300^{\circ} \mathrm{C}$ (27). It is noted that we calculated the data in Table 6.2 for the CuO$\mathrm{Cr}_{2} \mathrm{O}_{3} / \gamma-\mathrm{Al}_{2} \mathrm{O}_{3}$ catalyst based on reported rate equation in the literature (26).

Because of the variations in both the pre-exponential factor and activation energy of the rate constant in Table 6.2, it is difficult to evaluate the effect of the copper content on the reaction kinetics. In Figure 6.11 , the rate constant $\mathrm{k}_{\mathrm{CO}}$ normalized by the BET surface area is plotted versus the surface copper content(at.\%) as measured by XPS. One can see that the rate constant $\mathrm{k}_{\mathrm{CO}}$ steeply increases with the surface copper content. The plots for three different reaction temperatures are well regressed by the same power order equation:

$$
k_{C O} / S_{g} \propto S_{C u}^{3.4}
$$

where $\mathrm{Sg}$ is the catalyst surface area, $\mathrm{m}^{2} / \mathrm{g}$, and $\mathrm{S}_{\mathrm{Cu}}$ is the surface copper content. Although we cannot find a mechanistic explanation for such a relationship at the present time, the high nonlinear correlation suggests a complex interaction of copper and cerium oxide. The high catalytic activity did not result from copper dispersion alone. One can extrapolate that $\mathrm{k}_{\mathrm{CO}}$ will increase by an order of magnitude if the surface copper content is further increased from $25 \%$ to $40 \%$. However, we could not achieve a surface copper level higher than ca. 25 at.\% in this work. Figure 6.12 shows that the catalyst surface was enriched in copper for low bulk copper content and reached a plateau for high bulk copper 
content. The 24.8 at. $\%$ for the $\mathrm{Cu}_{0.15}[\mathrm{Ce}(\mathrm{La})]_{0.85} \mathrm{O}_{\mathrm{x}}$ is the largest surface copper content reached by a series of $\mathrm{Cu}-\mathrm{Ce}-\mathrm{O}$ catalysts prepared by $4 \mathrm{~h}$ calcination at $650^{\circ} \mathrm{C}$. The surface copper level of the $\mathrm{Cu}_{0.15}[\mathrm{Ce}(\mathrm{La})]_{0.85} \mathrm{O}_{x}$ was not increased by reduction in $25 \% \mathrm{H}_{2} / \mathrm{He}$ or heating in air. The impregnation method did not increase the copper level either. The main reason, based on the catalyst characterization results, is that excess amount of copper over a certain value favored the agglomeration of copper in bulk $\mathrm{CuO}$ form. Bulk $\mathrm{CuO}$ particles were then covered by fine cerium oxide particles and could not be detected by XPS.

\subsubsection{Methane Oxidation}

Figures 6.13 and 6.14 show the variation of the methane oxidation rate over the $\mathrm{Cu}_{0 .}[\mathrm{Ce}(\mathrm{La})]_{0.85} \mathrm{O}_{\mathrm{x}}$ catalyst with the partial pressure of methane and oxygen, respectively. The action kinetics were similar to the $\mathrm{CO}$ oxidation. Thus, the experimental data were best fitted by equation (7). The Arrhenius plots of the constants $k_{m}$ and $K_{m}$ in this equation are shown in Figure 6.15, from which equations (8) and (9) were derived.

$$
\begin{aligned}
R_{m} & =\frac{k_{m} K_{m} P_{m} P_{O}^{0.18 \pm 0.04}}{1+K_{m} P_{m}} \\
k_{m} & =7.84 \times 10^{1} \exp \left(-93.4 \times 10^{3} / R T\right) \\
K_{m} & =3.46 \exp \left(-14.2 \times 10^{3} / R T\right)
\end{aligned}
$$

The plot of $\mathrm{K}_{\mathrm{m}}$ data versus $1 / \mathrm{T}$ in Figure 6.15 shows an abrupt change between $1.37 \mathrm{x}$ $10^{-3}$ and $1.32 \times 10^{-3}$ in $1 / \mathrm{T}$ axes (corresponding to $455^{\circ} \mathrm{C}$ and $483^{\circ} \mathrm{C}$ ) resulting in a low correlation coefficient. We could have divided the data into two regions to achieve better curve-fitting. Considering, however, the overall small variation in $\mathrm{K}_{\mathrm{m}}$, we preferred to use the single Arrhenius equation as a crude approximation.

\subsubsection{Verification of Kinetic Equations}

Since the above kinetic models for both the $\mathrm{CO}$ and methane oxidation were obtained with experimental data measured in a differential reactor mode, the question whether the rate equations are valid at high conversions was considered next. We calculated the lightoff curves for the simultaneous oxidation of $\mathrm{CO}$ and methane over the $\mathrm{Cu}_{0.15}[\mathrm{Ce}(\mathrm{La})]_{0.85} \mathrm{O}_{\mathrm{x}}$ catalyst for a gas mixture of $0.1 \% \mathrm{CO}, 0.228 \% \mathrm{CH}_{4}$, and $1 \% \mathrm{O}_{2}$ at a contact time of 0.09 $\mathrm{s} \cdot \mathrm{g} / \mathrm{cc}$. We did not detect any axial temperature gradient under these reaction conditions because of the small reactor diameter and shallow packed catalyst bed. Therefore, $\mathrm{CO}$ conversion at each temperature was calculated by integrating the following equation:

$$
\begin{aligned}
& \frac{N_{t} \cdot d P_{C O 2}}{P \cdot d W_{C a t}}=\frac{k_{C O} K_{C O} P_{C O} P_{o}^{0.08}}{1+K_{C O} P_{C O}} \\
& P_{C O 2}=\left(P_{C O}\right)_{\text {inlet }}-P_{C O}
\end{aligned}
$$

Where $N_{t}$ is the total gas flowrate; $P$ is the total pressure and is assumed to be constant when a dilute reacting gas is used; $W_{\text {cat }}$ is the catalyst weight. Methane conversion was calculated in exactly the same manner. The calculated light-off curves in Figure 6.16 are in 
excellent agreement with experimental data. It is noteworthy that kinetic model was developed based on individual reaction data while the experimental data were for the simultaneous oxidation of $\mathrm{CO}$ and methane. This indicates that oxidation of $\mathrm{CO}$ and methane are independent reactions.

\subsection{Discussion}

\subsubsection{CO Oxidation over the $\mathrm{Au}_{0.05}[\mathrm{Ce}(\mathrm{La})]_{0.95} \mathrm{O}_{\mathrm{x}}$ Catalyst}

The $\mathrm{Au}_{0.05}[\mathrm{Ce}(\mathrm{La})]_{0.95} \mathrm{O}_{\mathrm{x}}$ catalyst characterization revealed that gold was distributed in the cerium oxide matrix as distinct metallic particles. There was no evidence of "strong interaction" between the gold particles and cerium oxide. It is known that neither cerium oxide nor gold alone is an active $\mathrm{CO}$ oxidation catalyst. The enhanced activity was solely due to the synergistic effect of the two kinds of materials. Extensive studies of the gold/oxide catalysts were reported by Haruta et al. (14). The Au-Ce-O is a new catalyst system, but we propose a reaction mechanism similar to that for other gold/oxide catalysts (14) as illustrated by the following Figure.

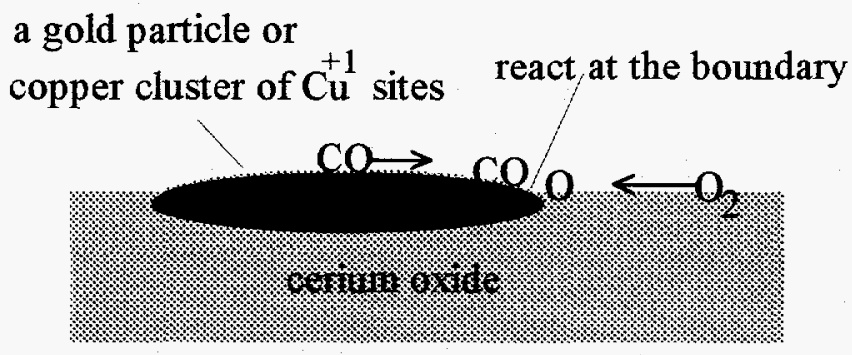

Figure 6.17 Synergistic Reaction Model for CO Oxidation over the Au-Ce-O and Cu-Ce-O Catalysts.

In this model, CO molecules adsorb on the gold particle surface, while oxygen molecules adsorb on the metal oxide surface. Then, the two adsorbed species react at the boundary of the gold and metal oxide. The highly active sites created at the boundary provides quick turnover of reacting species and high reaction activity. The adsorbed $\mathrm{CO}$ on the gold particle and the surface oxygen on the metal oxide may move to the boundary area by surface diffusion. Apparently, decreasing gold particle size will increase the boundary area and thus, the catalytic activity. The kinetic results in Table 6.1 show that the rate on the $\mathrm{Au}_{0.05}[\mathrm{Ce}(\mathrm{La})]_{0.95} \mathrm{O}_{\mathrm{x}}$ catalyst had stronger dependence on the partial pressure of the reacting species and higher activation energy than those on the other gold/oxide catalysts (14). The present catalyst, prepared by air calcination for $1 \mathrm{~h}$ at $500^{\circ} \mathrm{C}+1 \mathrm{~h}$ at $650^{\circ} \mathrm{C}$, comprised bigger gold particles $(8 \mathrm{~nm})$. The bigger gold particles resulted in lower interface and slower diffusion of the reacting species on the surface.

The high activity of the $\mathrm{Au}_{0.05}[\mathrm{Ce}(\mathrm{La})]_{0.95} \mathrm{O}_{\mathrm{x}}$ catalyst clearly demonstrated the synergistic effect of dual function materials in the $\mathrm{CO}$ oxidation. It is known that water vapor inhibits $\mathrm{CO}$ adsorption on cerium oxide. $\mathrm{CO}$ oxidation on the $\mathrm{Au}_{0.05}[\mathrm{Ce}(\mathrm{La})]_{0.95} \mathrm{O}_{\mathrm{x}}$ catalyst was not affected by water vapor further suggests the role which gold plays in 
providing $\mathrm{CO}$ adsorption sites. The role of cerium oxide in supplying oxygen will be discussed next together with the $\mathrm{CO}$ oxidation on the $\mathrm{Cu}-\mathrm{Ce}-\mathrm{O}$ catalyst.

\subsubsection{CO Oxidation over the $\mathrm{Cu}-\mathrm{Ce}(\mathrm{La})-\mathrm{O}$ Catalyst}

On base metal oxide catalysts (26-28), the CO oxidation rate generally has a weak dependence on $\mathrm{P}_{O}$ and has a positive order from 0 to 1 in $\mathrm{P}_{C O}$. The kinetic behavior of the $\mathrm{Cu}-\mathrm{Ce}(\mathrm{La})-\mathrm{O}$ catalyst is overall similar to that of the base metal oxide catalysts. Both the Eley-Rideal and Langmuir-Hinshelwood models have been proposed for $\mathrm{CO}$ oxidation on the copper-based catalysts. Dekker et al. (26) developed a comprehensive kinetic model for $\mathrm{CO}$ oxidation over the $\mathrm{CuO}-\mathrm{Cr}_{2} \mathrm{O}_{3} / \gamma-\mathrm{Al}_{2} \mathrm{O}_{3}$ catalyst based on a Eley-Rideal model consisting of several elementary steps. With in situ IR measurements of $\mathrm{CO}$ oxidation on the $\mathrm{Cu} / \delta-\mathrm{Al}_{2} \mathrm{O}_{3}$ catalyst, Choi and Vannice (27) revealed a clear first-order dependence of the reaction on chemisorbed $\mathrm{CO}$ and the absence of activity when no adsorbed $\mathrm{CO}$ was detected. The different conclusion was underlined by the difference in catalyst pretreatment and reaction conditions. Copper was in a partially oxidized state in the $\mathrm{Cu} / \delta$ $\mathrm{Al}_{2} \mathrm{O}_{3}$ catalyst but likely in fully oxidized state in the $\mathrm{CuO}-\mathrm{Cr}_{2} \mathrm{O}_{3} / \gamma-\mathrm{Al}_{2} \mathrm{O}_{3}$. Jernigan and Somorjai (18) recently compared the $\mathrm{CO}$ oxidation over three different oxidation states of copper: $\mathrm{Cu}, \mathrm{Cu}_{2} \mathrm{O}$, and $\mathrm{CuO}$, and found that the apparent activation energy increases with increasing copper oxidation state $\left(\mathrm{Cu}(37.6)<\mathrm{Cu}_{2} \mathrm{O}(58.5)<\mathrm{CuO}(71.1)\right)$. The apparent activation energy listed in Table 6.2 for the $\mathrm{Cu}-\mathrm{Ce}(\mathrm{La})-\mathrm{O}$ catalysts is in the range of 26 to $50 \mathrm{~kJ} / \mathrm{mol}$, similar to the reduced copper oxide.

The unique information conveyed by Table 6.2 is the high heat of $\mathrm{CO}$ adsorption over the $\mathrm{Cu}-\mathrm{Ce}(\mathrm{La})-\mathrm{O}$ derived from the kinetic measurements, which is comparable to that of $\mathrm{CO}$ adsorption on metallic copper, 30 to $68 \mathrm{~kJ} / \mathrm{mol}$ as reported in the literature $(29,30)$. Notice that heat of $\mathrm{CO}$ adsorption over the pre-calcined $\mathrm{CuO}-\mathrm{Cr}_{2} \mathrm{O}_{3} / \gamma-\mathrm{Al}_{2} \mathrm{O}_{3}$ catalyst is indeed a small number. This may be the reason that $\mathrm{CO}$ has been assumed not to adsorb on the $\mathrm{CuO}$ surface. Recall that the $\mathrm{Cu}^{+1}$ species for the $\mathrm{Cu}-\mathrm{Ce}(\mathrm{La})-\mathrm{O}$ catalyst was observed by XPS. We believe that the $\mathrm{Cu}^{+1}$ surface species provide strong $\mathrm{CO}$ adsorption sites and $\mathrm{CO}$ oxidation over the $\mathrm{Cu}-\mathrm{Ce}(\mathrm{La})-\mathrm{O}$ catalyst proceeds via the LangmuirHinshelwood mechanism.

\subsubsection{Strong Interaction of Copper with Cerium Oxide and Synergism}

Given the fact that the present $\mathrm{Cu}-\mathrm{Ce}(\mathrm{La})-\mathrm{O}$ catalyst was typically prepared by a few hour-long calcination at temperatures of or over $650^{\circ} \mathrm{C}$ in air and used for kinetic studies without any pre-reduction treatment, how are the $\mathrm{Cu}^{+1}$ species stabilized? We propose that the copper ions at the interfacial area of a copper cluster and cerium oxide can penetrate into the cerium oxide lattice by occupying the vacant sites of cerium ions as illustrated by Figure 6.18. The copper ionic size found in the literature varies among different sources. However, it is agreed that $\mathrm{Cu}^{+1}$ ion size is bigger than the $\mathrm{Cu}^{+2}$. The $\mathrm{Cu}^{+1}$ species is more compatible in cerium oxide lattice in terms of the size. Thus, $\mathrm{Cu}^{+1}$ is stabilized by the cerium oxide lattice and transferred to the outer surface by a copper oxide chain, $\mathrm{Cu}^{+1}-\mathrm{O}$ $\mathrm{Cu}-\bullet \bullet-\mathrm{O}-\mathrm{Cu}^{+1}$. The reducibility of $\mathrm{Ce}^{+4}$ to $\mathrm{Ce}^{+3}$ enhances the flexibility for a copper ion 
to adapt to different oxidation state by maintaining the electronic neutrality of the lattice. The existence of isolated $\mathrm{Cu}^{+2}$ ions and ion pairs in the cerium oxide lattice was studied with the electron paramagnetic resonance technique (23-25), but this technique cannot detect the $\mathrm{Cu}^{+1}$ species. The formation of chemical bonding between the copper clusters and cerium oxide explains the strong association of copper with cerium oxide as found in catalyst preparation and activity tests.

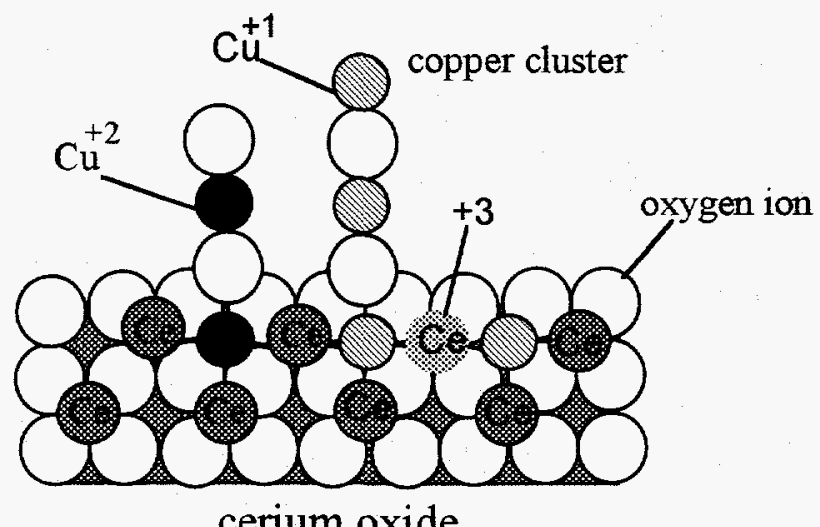

Figure 6.18 Interaction Model of Copper with Cerium Oxide(cross section of ceria showing a [001] plane of oxygen ions and adjacent cerium cations).

In addition to the strong $\mathrm{CO}$ adsorption, the reaction rate on the $\mathrm{Cu}-\mathrm{Ce}(\mathrm{La})-\mathrm{O}$ catalysts was several orders of magnitude higher than that either on the oxidized $\mathrm{CuO}$ $\mathrm{Cr}_{2} \mathrm{O}_{3} / \gamma-\mathrm{Al}_{2} \mathrm{O}_{3}$ or the reduced $\mathrm{Cu} / \delta-\mathrm{Al}_{2} \mathrm{O}_{3}$ catalyst. We propose a reaction model for $\mathrm{CO}$ oxidation over the $\mathrm{Cu}-\mathrm{Ce}(\mathrm{La})-\mathrm{O}$ catalyst similar to the $\mathrm{Au} /$ metal oxide system with the $\mathrm{Cu}^{+1}$ species of the copper cluster replacing gold particles and providing surface sites for $\mathrm{CO}$ adsorption. Given the catalyst configuration in Figure 6.17, a minute Schottky junction can form at the interface between metals and oxides and affect the electronic properties of metal oxides (3l). However, it has always been difficult to relate the catalyst electronic property to catalytic activity. We rather attribute the enhanced catalytic activity to the concerted effect of $\mathrm{CO}$ adsorption and oxygen activation. Cerium oxide can provide various active surface oxygen species for oxidation reactions. The surface oxygen species on cerium oxide were studied by TPR (32), FT-IR $(33,34)$, and EPR (35). The possible oxygen species are shown in equation (12). Generally, increasing the catalyst treatment temperature shifts the equilibrium to the right, that is, the lattice oxygen will be a major component if heated at high temperatures.

$$
\mathrm{O}_{2} \stackrel{e}{\longleftrightarrow} \mathrm{O}_{2}^{-} \stackrel{e}{\longleftrightarrow} \mathrm{O}_{2}^{2-} \longleftrightarrow \mathrm{O}^{-} \stackrel{e}{\longleftrightarrow} \mathrm{O}_{\text {lattice }}^{2-}
$$

Superoxide species $\left(\mathrm{O}_{2}{ }^{-}\right)$forms from the adsorption of an oxygen molecule on a single unsaturated surface cerium ion $\left(\mathrm{Ce}^{+4} \cdots \mathrm{O}_{2}^{-}\right)$. Formation of peroxide species $\left(\mathrm{O}_{2}^{-2}\right)$ increases with the reduction extent of the cerium oxide surface. The peroxide species is probably associated with a pair of reduced cerium ions or one oxygen vacancy. The superoxide species has very quick exchange rate with gaseous oxygen at low temperatures (below $100^{\circ} \mathrm{C}$ ) according to $\mathrm{Li}$ et al. $(34,36)$. It is labile on cerium oxide surface and its surface 
diffusion is much faster than on $\mathrm{SiO}_{2}$ or $\mathrm{Al}_{2} \mathrm{O}_{3}$ (37). Therefore, we propose the superoxide species as the active surface oxygen species in $\mathrm{CO}$ oxidation over both the $\mathrm{Au}-\mathrm{Ce}(\mathrm{La})-\mathrm{O}$ and $\mathrm{Cu}-\mathrm{Ce}(\mathrm{La})-\mathrm{O}$ catalysts according to the reaction model in Figure 6.17. In fact, oxygen spill-over and reaction with $\mathrm{CO}$ at the interface were demonstrated by Metcalfe and Sundaresan with the Pt/YSZ catalyst (10). Tarasov et al. (38) proposed that the junction effect between the precious metals and cerium oxide facilitates the formation of superoxide species. This argument is applicable to the $\mathrm{Au}-\mathrm{Ce}(\mathrm{La})-\mathrm{O}$ catalyst where distinctive metallic gold particles were identified. In the $\mathrm{Cu}-\mathrm{Ce}-\mathrm{O}$ system, however, we do not regard the copper cluster as distinct fine metallic copper or $\mathrm{Cu}_{2} \mathrm{O}$ particles but rather as a group of copper atoms. We postulate that the presence of copper ions in the $\mathrm{Cu}$ $\mathrm{Ce}(\mathrm{La})-\mathrm{O}$ systems may increase the concentration of unsaturated cerium ion $\left(\mathrm{Ce}^{+3}\right)$ and the concentration of superoxide species.

Most of experimental observations in this work can be explained with this reaction model. First of all, based on the model, only a small amount of copper or gold is needed to form an active catalyst. Bulk $\mathrm{CuO}$ oxide does not contribute to the observed $\mathrm{CO}$ oxidation activity. Isolated copper ions as found in the $\mathrm{Cu}_{0.01}[\mathrm{Ce}(\mathrm{La})]_{0.99} \mathrm{O}_{\mathrm{x}}$ catalyst prepared by calcination in nitrogen are not active because they can be capped by oxygen and water molecules so that $\mathrm{CO}$ adsorption sites are greatly suppressed. In the $\mathrm{Cu}-\mathrm{Zr}-\mathrm{O}$ system, copper clusters may be stabilized by zirconia through the interstitial interaction model in Figure 6.18. But, the high stability of $\mathrm{Zr}^{+4}$ ion would not favor the formation of superoxide species $\left(\mathrm{O}_{2}^{-}\right)$and the $\mathrm{Cu}^{+1}$ species. This may be the reason why the $\mathrm{Cu}-\mathrm{Zr}-\mathrm{O}$ catalyst showed greatly improved resistance to water vapor poisoning but only a small enhancement in catalytic activity compared to bulk $\mathrm{CuO}$ catalyst as reported in the preceding paper (1).

\subsubsection{Methane Oxidation Kinetics}

A variety of kinetic models for methane combustion on metal oxides have been reported $(39,40)$. The activation energy for methane oxidation over the $\mathrm{Cu}_{0.15}[\mathrm{Ce}(\mathrm{La})]_{0.85} \mathrm{O}_{\mathrm{x}}$ catalyst is comparable to the literature data. In general, the rates on base metal oxides such as perovskite-type mixed oxides are first order in methane, while the order in oxygen may vary from zero to approximately 0.5 . A non-competitive Langmuir-Hinshelwood kinetic model was proposed by Otsuka et al. (41) for oxidative coupling of methane over a $\mathrm{Ba}$-doped $\mathrm{CeO}_{2}$ catalyst. However, all previous kinetic studies used a narrower window of partial pressure of methane $\left(P_{m}\right)$ than the present work. The Langmuir adsorption type dependence on $\mathrm{P}_{\mathrm{m}}$ in the kinetic expression (Equation 6 ) for methane oxidation over the $\mathrm{Cu}_{0.15}[\mathrm{Ce}(\mathrm{La})]_{0.85} \mathrm{O}_{\mathrm{x}}$ catalyst suggests that the rate-determining step involves the adsorbed methane. The power order dependence on the partial pressure of oxygen $\left(\mathrm{P}_{\mathrm{O}}\right)$ suggests complex oxygen sources for the reaction. The following reaction mechanism is proposed based on the present kinetic results.

$$
\begin{gathered}
\mathrm{CH}_{4, c a t}+\mathrm{O}_{\text {cat }}^{-} \stackrel{\text { slow }}{\longrightarrow} \mathrm{CH}_{3, c a t}^{-}+\mathrm{HO}_{\text {cat }} \\
\mathrm{CH}_{3, \text { cat }}^{-}+\mathrm{O}_{\text {cat }} \stackrel{\text { fast }}{\longrightarrow} \mathrm{O}_{\text {cat }}^{-}+\mathrm{CH}_{3, \text { cat }} \stackrel{\mathrm{o}}{\longrightarrow} \mathrm{CO}_{2}+\mathrm{H}_{2} \mathrm{O}
\end{gathered}
$$


In the above equations, cat denotes catalyst surface. Gas phase oxygen can quickly reach equilibrium with the various surface oxygen species as described by equation (2). The rate-limiting step involves the reaction of adsorbed methane with the surface basic groups(oxygen ions). The negative charge on the resulting methyl group can transfer to the surface oxygen through the electronic band or a metal ion intermediate(e.g., $\left.\mathrm{M}^{+n}+\mathrm{e} \rightarrow \mathrm{M}^{+(\mathrm{n}-1)}+\mathrm{O}_{\text {cat }} \rightarrow \mathrm{M}^{+n}+\mathrm{O}_{\text {cat }}^{-}\right)$. The methyl radical is rapidly and completely oxidized into carbon dioxide and water over the present catalyst. This mechanism is overall similar to the ones proposed in the literature for methane oxidation over base metal oxide catalysts. But, some of previous kinetic studies of methane combustion suggested the direct reaction of gaseous methane with the catalyst surface. Here, we would like to emphasize that methane adsorption on the catalyst surface is necessary to activate the methane at low temperatures, because the hydrogen abstraction process is a complex step as we stated in the preceding paper (I).

Although it has a similar rate expression to $\mathrm{CO}$ oxidation, the methane oxidation process may be intrinsically different from $\mathrm{CO}$ oxidation. The pre-exponential factor of the methane oxidation rate constant in equation (8) is about five orders of magnitude smaller than that of the $\mathrm{CO}$ oxidation rate constant in Table 6.2. The heat of methane adsorption on the $\mathrm{Cu}_{0.15}[\mathrm{Ce}(\mathrm{La})]_{0.85} \mathrm{O}_{\mathrm{x}}$ catalyst is only about $14.2 \mathrm{~kJ} / \mathrm{mol}$. The $\mathrm{Cu}^{+1}$ species provide sites for strong $\mathrm{CO}$ adsorption but not for methane. Van Kooten et al. (42) found no measurable interaction of methane with metallic and oxidized copper over the temperature range of 300 to $750 \mathrm{~K}$. At the present time, we do not know what are the specific surface sites for methane adsorption on the $\mathrm{Cu}-\mathrm{Ce}(\mathrm{La})-\mathrm{O}$ catalyst. Regarding the oxygen source, $\mathrm{Li}$ et al. (43) observed that methane oxidation on cerium oxide occurred in the absence of gaseous oxygen and superoxide species, which were considered to be active for $\mathrm{CO}$ oxidation. Our fixed-bed, steady-state measurements of $\mathrm{CO}$ and methane oxidation found that the two reactions were virtually independent of each other. Methane oxidation over the $\mathrm{Cu}-\mathrm{Ce}(\mathrm{La})-\mathrm{O}$ catalyst occurred at higher temperatures $\left(>300^{\circ} \mathrm{C}\right)$. Although such temperatures may not be high enough to cause significant bulk oxygen mobility, the participation of surface capping $\left(\mathrm{O}_{2}^{-2}, \mathrm{O}^{-}\right.$or $\left.\mathrm{O}^{-2}\right)$ and lattice oxygen is very likely since surface species on the $\mathrm{CeO}_{2}$ surface are more active than the bulk $(33,44)$. In conclusion, methane oxidation is a more complicated process than $\mathrm{CO}$ oxidation and a detailed adsorption/desorption study is necessary to elucidate the reaction mechanism.

\subsection{Summary}

Gold in the $\mathrm{Au}_{0.05} \mathrm{Ce}(\mathrm{La}){ }_{0.95} \mathrm{O}_{\mathrm{X}}$ catalyst exists in fine metallic particles in contact with the cerium oxide. The $\mathrm{CO}$ oxidation kinetics over the $\mathrm{Au}_{0.05} \mathrm{Ce}(\mathrm{La})_{0.95} \mathrm{O}_{\mathrm{X}}$ catalyst were described by a rate equation such as $\mathrm{kP}_{\mathrm{CO}}^{0.30} \mathrm{P}_{\mathrm{o}}^{0.18}$.

Copper in small amounts showed strong tendency to attach to cerium oxide surface irrespective of catalyst preparation. Copper in the $\mathrm{Cu}-\mathrm{Ce}-\mathrm{O}$ composite existed in the form of isolated ions, clusters, and bulk $\mathrm{CuO}$ particles. Isolated ions aggregated into clusters after heating at high temperatures $\left(\geq 650^{\circ} \mathrm{C}\right)$ in air. When the cerium oxide surface was saturated by copper clusters, excess copper formed bulk $\mathrm{CuO}$ particles which were 
typically covered by the fine cerium oxide particles. $\mathrm{Cu}^{+1}$ species was observed with all the $\mathrm{Cu}-\mathrm{Ce}-\mathrm{O}$ catalysts in the XPS studies and its formation is considered to originate from the interaction of copper clusters with cerium oxide.

The oxidation rates of $\mathrm{CO}$ and methane over the $\mathrm{Cu}-\mathrm{Ce}(\mathrm{La})-\mathrm{O}$ catalysts were expressed as $k K_{R} P_{R} P_{O}^{n} /\left(1+K_{R} P_{R}\right)$, where $P_{R}$ denotes the partial pressure of $C O$ or methane and $P_{O}$ is the partial pressure of oxygen. The activation energies of the surface reactions were $78-94 \mathrm{~kJ} / \mathrm{mol}$ for $\mathrm{CO}$ oxidation and $79 \mathrm{~kJ} / \mathrm{mol}$ for methane oxidation, respectively. The heat of adsorption on the $\mathrm{Cu}-\mathrm{Ce}-\mathrm{O}$ catalyst was in the range of 28 to $62 \mathrm{~kJ} / \mathrm{mol}$ for $\mathrm{CO}$ adsorption and $14 \mathrm{~kJ} / \mathrm{mol}$ for methane adsorption, respectively.

The Langmuir-Hinshelwood mechanism and synergistic reaction model was proposed for $\mathrm{CO}$ oxidation over the $\mathrm{Cu}-\mathrm{Ce}-\mathrm{O}$ and $\mathrm{Au}-\mathrm{Ce}-\mathrm{O}$ catalysts. In this model, the $\mathrm{Cu}^{+1}$ species of a copper cluster or fine gold particles provide sites for $\mathrm{CO}$ adsorption, cerium oxide provides the oxygen source, and the reaction proceeds at the boundary of the two kinds of materials. The Langmuir-Hinshelwood mechanism was also proposed for methane oxidation over the $\mathrm{Cu}-\mathrm{Ce}-\mathrm{O}$ catalyst.

\subsection{Notation}

$\mathrm{Ea}=$ activation energy, $\mathrm{kJ} / \mathrm{mol}$.

$E_{\text {app }}=$ apparent activation energy, $\mathrm{kJ} / \mathrm{mol}$.

$\mathrm{k}=$ reaction constant, $\mathrm{mol} /\left(\mathrm{g} \cdot \mathrm{s} \cdot \mathrm{bar}^{\mathrm{m}+\mathrm{n}}\right)$

$\mathrm{k}_{\mathrm{CO}}=$ reaction constant of $\mathrm{CO}$ oxidation, $\mathrm{mol} /\left(\mathrm{g} \cdot \mathrm{s} \cdot \mathrm{bar}{ }^{\mathrm{n}}\right)$.

$\mathrm{k}_{\mathrm{m}}$ = reaction constant of methane oxidation, $\mathrm{mol} /\left(\mathrm{g} \cdot \mathrm{s} \cdot \mathrm{bar} \mathrm{r}^{\mathrm{n}}\right)$.

$\mathrm{K}_{\mathrm{CO}}=\mathrm{CO}$ adsorption equilibrium constant, 1/bar.

$\mathrm{K}_{\mathrm{m}}=$ methane adsorption equilibrium constant, 1/bar.

$\mathrm{K}_{\mathrm{O}}=$ adsorption equilibrium constant of reacting species, $1 / \mathrm{bar}$.

$\mathrm{m}, \mathbf{n}=$ reaction orders.

$\mathrm{N}_{\mathrm{t}}=$ total gas flow rate, $\mathrm{mol} / \mathrm{s}$.

$\mathbf{P}=$ total pressure of reacting gases mixture, bar.

$\mathbf{P}_{\mathrm{CO}}=$ partial pressure of $\mathrm{CO}$, bar.

$\mathrm{P}_{\mathrm{CO} 2}=$ partial pressure of $\mathrm{CO}_{2}$, bar.

$P_{m}=$ partial pressure of methane, bar.

$P_{\mathrm{O}}=$ partial pressure of oxygen, bar.

$\mathrm{P}_{\mathrm{R}}=$ partial pressure of reacting species, bar

$\mathrm{Q}=$ heat of adsorption, $\mathrm{kJ} / \mathrm{mol}$.

$\mathbf{R}=$ gas constant, $\mathrm{J} / \mathrm{mol} \cdot \mathrm{K}$.

$\mathbf{R}_{\mathrm{CO}}=$ reaction rate of $\mathrm{CO}$ oxidation, $\mathrm{mol} / \mathrm{g} \cdot \mathrm{s}$.

$\mathbf{R}_{\mathrm{m}}=$ reaction rate of methane oxidation, $\mathrm{mol} / \mathrm{g} \cdot \mathrm{S}$.

$T=$ reaction temperature, $K$.

$\mathrm{W}_{\text {Cat }}=$ weight of catalyst loading, $\mathrm{g}$.

$\mathrm{X}_{\mathrm{CO} 2}=$ conversion to $\mathrm{CO}_{2}$. 


\subsection{Literature Cited}

1. Liu, W., and Flytzani-Stephanopoulos, M., J. Catal.,Vol. 153, No. 2, May 1995.

2. Tauster, S.J., Fung, S.C., Baker, R.T.K., and Horsley, J.A.Science 211, 1121-1125 (1981).

3. Baker, R.T.K., Tauster, S.J., and Dumesic, J.A., (Editors), "Strong Support Interactions", American Chemical Society, Washington, DC, 1986.

4. Stevenson, S.A., Dumesic, J.A., Baker, R.T.K, and Ruckenstein, E., (Editors), "Metal-Support Interactions in Catalysis, Sintering, and Redispersion", Van Nostrand Reinhold Company Inc., 1987.

5. Narayanan, S., J. of Sci. and Ind. Res. 44, 580-587 (1985).

6. Burch, B., and Flambard, A.R., J. Catal. 78, 389-405 (1982).

7. Bell, A.T., in Hegedus, L.L., et al. (Editors), "Catalyst Design, Process and Perspectives", Wiley, New York, p 103, 1987.

8. Frost, J.C, Nature 334, 577-580 (1988).

9. Crucq, A., (editor), "Catalysis and Automotive Pollution Control II", Elsevier Science Publishers B.V., Amsterdam, 1991.

10. Metcalfe, I.S., and Sundaresan, S., AIChE J. 34, 195-208 (1988).

11. Schryer, D.R, Upchurch, B.T., Sidney, B.D., Hoflund, G.B., and Herz, RK, J. Catal. 130, 314 (1991).

12. Boulahouache, A., Kous, G., Lintz, H.-G., and Schulz, P., Appl. Catal. A: General 9, $115-123$ (1990).

13. Sheintuch, M., Schmidt, J., Lecthman, Y., and Yahav, G., Appl. Catal. 49, 55 (1989).

14. Haruta, M., Tsubota, S., Kobayashi, T., Kageyma, H., Genet, M.J., and Delmon, B., J. Catal. 144, 175-192 (1993).

15. Dow, W.P., and Huang, T.J., J. Catal. 147, 322-332 (1994).

16. Wagner, C.D., Riggs, W.M., Davis, L.E., Moulder, J.F., and Muilenberg, G.E., (Editors), "Handbook of X-ray Photoelectron Spectroscopy", Perkin-Elmer Corporation, 1978.

17. Agudo, A.L., Palacios, J.M., Fierro, J.L.G., Laine, J., Severio, F., Appl. Catal. A: General 91, 43-55 (1992).

18. Jernigan, G.G., and Somorjai, G.A., J. Catal. 147, 567-577 (1994).

19. Siriwardane, R.V., and Poston, J.A., Appl. Surf. Sci. 68, $65-80$ (1993).

20. Shpiro, E.S., Grunert, W., Joyner, R.W., and Baeva, G.N., Catal. Lett. 24, 159-169 (1994).

21. Jin, T., Zhou, Y., Mains, G.J., and White, H.M., J. Phys.Chem. 91, 5931-5937 (1987).

22. Arai, T., Maruya, K., Domen, K., and Onishi, T., J. Catal. 141, 533-539 (1993).

23. Abou kais, A., Bennani, A., Aissi, C.F., Guelton, M., and Vedrine, J., Chem. Mater. 4, 977-979 (1992).

24. Abou kais, A., Bennani, A., Aissi, C.F., Wrobel, G., and Guelton, M., J. Chem. Soc. Faraday Trans. 89(9), 1321-1325 (1992). 
25. Soria, J., Conesa, J.C., Martinez-Arias, A., and Coronado, J.M., Bechara, Solid State Ionics 63-65, 755-761 (1993).

26. Dekker, N.J.J., Hoorn, J.A.A., Stegenga, S., Kapteijn, F., and Moulijn, J.A., AIChE $J .38,385-396$ (1992).

27. Choi, K.I., and Vannice, M.A., J. Catal. 131, 22-35 (1991).

28. Klimisch, R.L., and Taylor, K.C., Science 179, 798-799 (1973).

29. Clarke, D.B., Suzuki, I., and Bell, A.T., J. Catal. 142, 27-36 (1993).

30. Sandval, M.J., and Bell, A.T., J. Catal. 144, 227-237 (1993).

31. Sze, S.M., Physics of Semiconductor Devices, 2nd edition, Wiley, New York, 1981.

32. Yao, H.C., and Yao, Y.F.Y., J. Catal. 86, 254-265 (1984).

33. Li, C., Domen, K., Maruya, K.I., and Onishi, T., J. Am. Chem. Soc. 111, 7683-7687 (1989).

34. Li, C., Domen, K., Maruya, K.I., and Onishi, T., J. Catal. 123, 436-442 (1990).

35. Zhang, X., and Klabunde, K.J., Inorg. Chem. 31, 1706-1709 (1992).

36. Li, C., Chen, Y., Li, W., and Xin, Q., in Inui, T., et al. (Editors), New Aspects of Spillover in Catalysis, Elsevier Science Publishers B.V., pp217-220, 1993.

37. Martin, D., and Duprez, D., in Inui, T., et al. (Editors), New Aspects of Spillover in Catalysis, Elsevier Science Publishers B.V., pp201-206, 1993.

38. Tarasov, A.L., Przheval'skaya, L. K., Shvets, V.A., and Kazanskii, V.B., Kinet. $i$ Katal. 29, 1181-1188 (1988).

39. Seiyama, T., Catal. Rev.-Sci. Eng. 34, 281-300 (1992).

40. Zwinkels, M.F.M., Jaras, S. G., and Menon, P. G., Catal. Rev.-Sci. Eng. 35, 319358 (1993).

41. Otsuka, K., Komatsu, T., and Shimizu, Y., in Inui, T., (Editor), Successful Design of Catalysts, Elsevier Science Publishers B.V., Amsterdam, PP43-50, 1988.

42. van Kooten, W.E.J., Kragten, D.D., Gijzeman, O.L.J., and Geus, J.W., Surf. Sci. 290, 302-308 (1993).

43. Li, C., Xin, Q., Guo, X., and Onishi, T., in Guczi, L., et al.(Editors), New Frontiers in Catalysis, Proceedings of the 10th International Conference on Catalysis, 19-24 July, Budapest, Hungary, 1993 Elsevier Science Publishers B.V., pp1955-1958M, 1992.

44. Sayle, T. X.T., Parker, S.C., and Catlow, C.R.A., J. Chem. Soc., Chem. Commun. 977-978 (1992). 
Table 6.1 CO Oxidation Kinetics over the Au-Oxide Catalysts.

\begin{tabular}{lcccc}
\hline Catalysts & $\mathrm{Au}$ size $(\mathrm{nm})$ & $\mathrm{m}$ & $\mathrm{n}$ & $\mathrm{E}_{\text {app }}(\mathrm{kJ} / \mathrm{mol})$ \\
\hline $\mathrm{Au}_{0.05}[\mathrm{Ce}(\mathrm{La})]_{0.95} \mathrm{O}_{\mathrm{x}}{ }^{*}$ & 8.0 & 0.30 & 0.18 & 53.7 \\
$\mathrm{Au}-\mathrm{Fe}_{2} \mathrm{O}_{3}(14)$ & 4.0 & 0.00 & 0.05 & 35.0 \\
$\mathrm{Au}-\mathrm{TiO}_{2}(14)$ & 2.0 & 0.05 & 0.24 & 34.2 \\
\hline
\end{tabular}

*catalyst was prepared by air calcination: $1 \mathrm{~h}$ at $500^{\circ} \mathrm{C}+1 \mathrm{~h}$ at $600^{\circ} \mathrm{C}$. 
Table 6.2 CO Oxidation Kinetics over the $\mathrm{Cu}-\mathrm{Ce}(\mathrm{La})-\mathrm{O}$ and Other Copper Catalysts.

\begin{tabular}{|c|c|c|c|c|c|c|}
\hline \multirow{2}{*}{ Catalyst } & \multirow{2}{*}{$\mathrm{n}$} & A & $\mathrm{E}$ & $\mathrm{K}$ & Q & \multirow{2}{*}{$\begin{array}{c}\mathrm{E}_{\mathrm{app}}^{\mathrm{d}} \\
(\mathrm{kJ} / \mathrm{mol})\end{array}$} \\
\hline & & $\left.(\mathrm{mol} / \mathrm{g} \cdot \mathrm{s} \cdot \mathrm{bar})^{\mathrm{n}}\right)$ & $(\mathrm{kJ} / \mathrm{mol})$ & (1/bar) & $(\mathrm{kJ} / \mathrm{mol})$ & \\
\hline $\mathrm{Cu}_{0.15}[\mathrm{Ce}(\mathrm{La})]_{0.85} \mathrm{O}_{\mathrm{x}}{ }^{\mathrm{a}}$ & $0.08 \pm 0.03$ & $5.91 \times 10^{6}$ & 78.0 & $6.47 \times 10^{-3}$ & 27.9 & 50.1 \\
\hline \multicolumn{7}{|l|}{$\mathrm{Cu}_{0.01}[\mathrm{Ce}(\mathrm{La})]_{0.99} \mathrm{O}_{\mathrm{x}}$} \\
\hline fresh $^{b}$ & $-0.09 \pm 0.02$ & $9.82 \times 10^{3}$ & 72.7 & $6.82 \times 10^{-4}$ & 36.8 & 35.9 \\
\hline$+3 \mathrm{~h}$ in air at $660^{\circ} \mathrm{C}^{\mathrm{c}}$ & $0.0 \pm 0.07$ & $3.23 \times 10^{7}$ & 93.9 & $2.49 \times 10^{-5}$ & 45.6 & 48.3 \\
\hline$+3 \mathrm{~h}$ in air at $860^{\circ} \mathrm{C}^{\mathrm{c}}$ & $0.12 \pm 0.02$ & $1.78 \times 10^{7}$ & 87.3 & $2.50 \times 10^{-7}$ & 61.2 & 26.1 \\
\hline $\mathrm{CuO}-\mathrm{Cr}_{2} \mathrm{O}_{3} / \gamma-\mathrm{Al}_{2} \mathrm{O}_{3}(26)$ & 0.0 & $2.96 \times 10^{2}$ & 91.0 & $7.4 \times 10^{-2}$ & 5.0 & 86 \\
\hline \multicolumn{7}{|l|}{$(\mathrm{Cu}: \mathrm{Cr}=1: 1) 10 \mathrm{wt} . \%$} \\
\hline 12 wt. $\% \mathrm{Cu} / \delta-\mathrm{Al}_{2} \mathrm{O}_{3}(27)$ & - & - & $90-110$ & - & $\sim 30.1$ & - \\
\hline
\end{tabular}

a. calcined in air for $4 \mathrm{~h}$ at $650^{\circ} \mathrm{C}$.

b. calcined in $\mathrm{N}_{2}$ for $4 \mathrm{~h}$ at $600^{\circ} \mathrm{C}$.

c. calcined in flowing air.

d. $\quad \mathbf{E}_{\mathrm{app}}=\mathrm{Ea}-\mathrm{Q}$, corresponding to the kinetic equation $\mathrm{kK}_{\mathrm{CO}} \mathbf{P}_{\mathrm{CO}} \mathbf{P}_{\mathrm{O}}{ }^{\mathbf{n}}$ when $\mathrm{K}_{\mathrm{CO}} \mathbf{P}_{\mathrm{CO}} \ll<1$. 


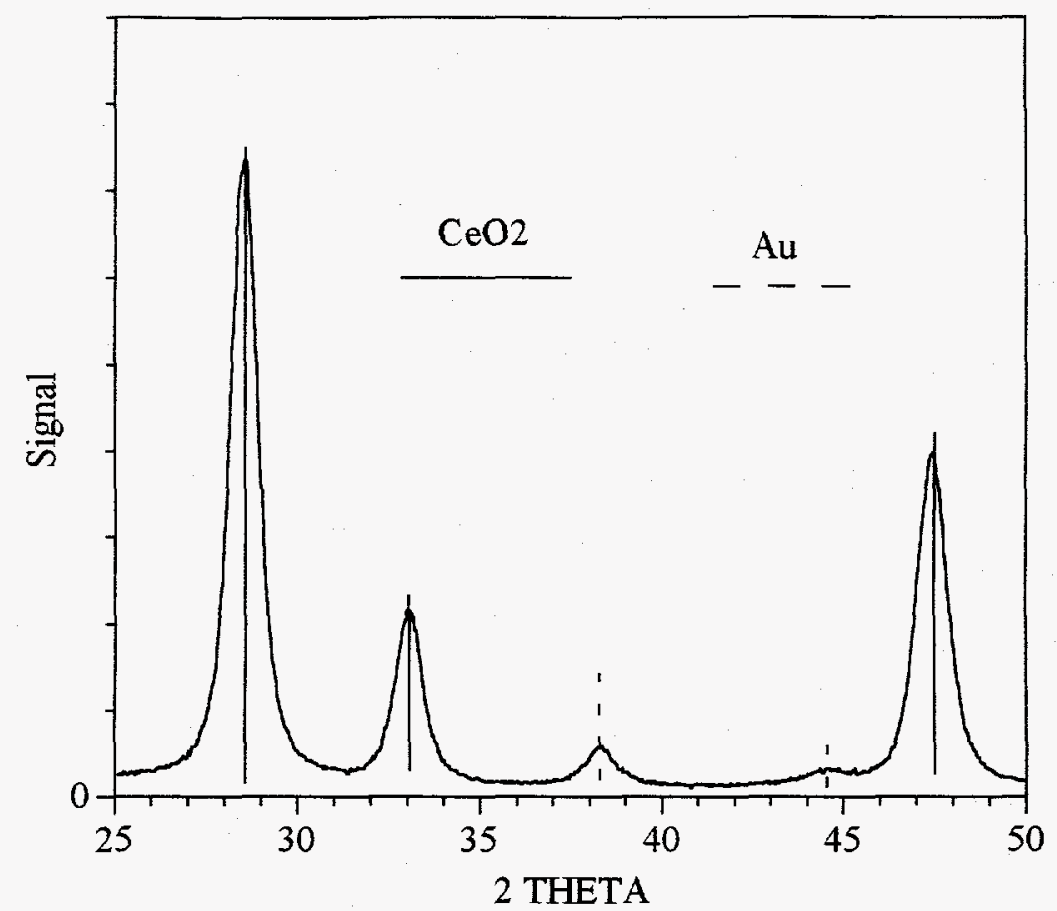

Figure 6.1a XRD Pattern of the $\mathrm{Au}_{0.05}[\mathrm{Ce}(\mathrm{La})]_{0.95} \mathrm{O}_{\mathrm{x}}$ Catalyst.

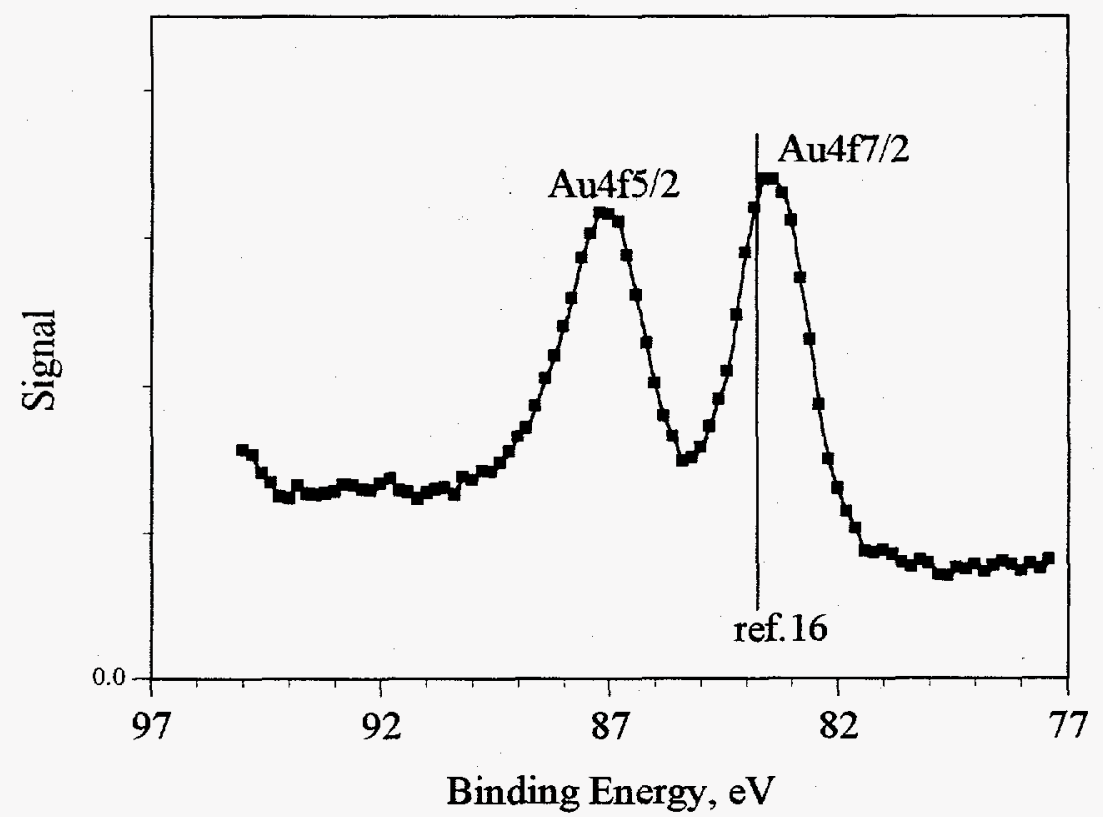

Figure 6.1b XP Spectra of $\mathrm{Au} 4 \mathrm{f}$ in the $\mathrm{Au}_{0.05}[\mathrm{Ce}(\mathrm{La})]_{0.95} \mathrm{O}_{\mathrm{x}}$ Catalyst. 


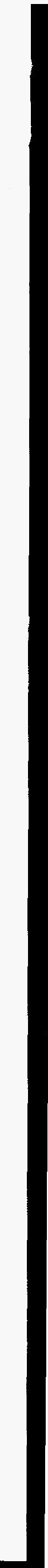



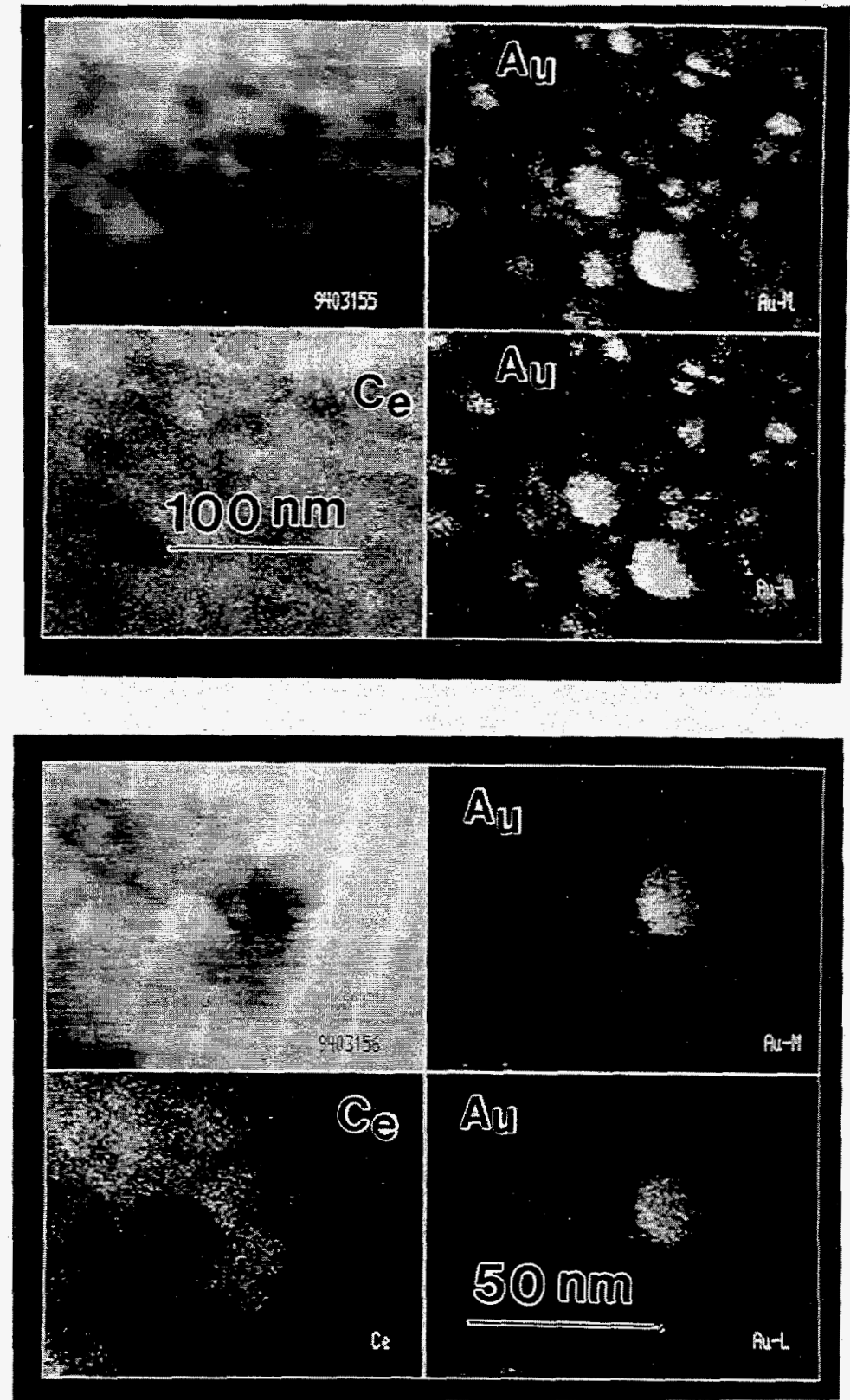

Figure 6.1c STEM/EDX Elemental Maps of the $\mathrm{Au}_{0.05}[\mathrm{Ce}(\mathrm{La})]_{0.95} \mathrm{O}_{\mathrm{x}}$ Catalyst. 


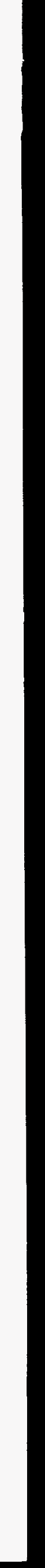




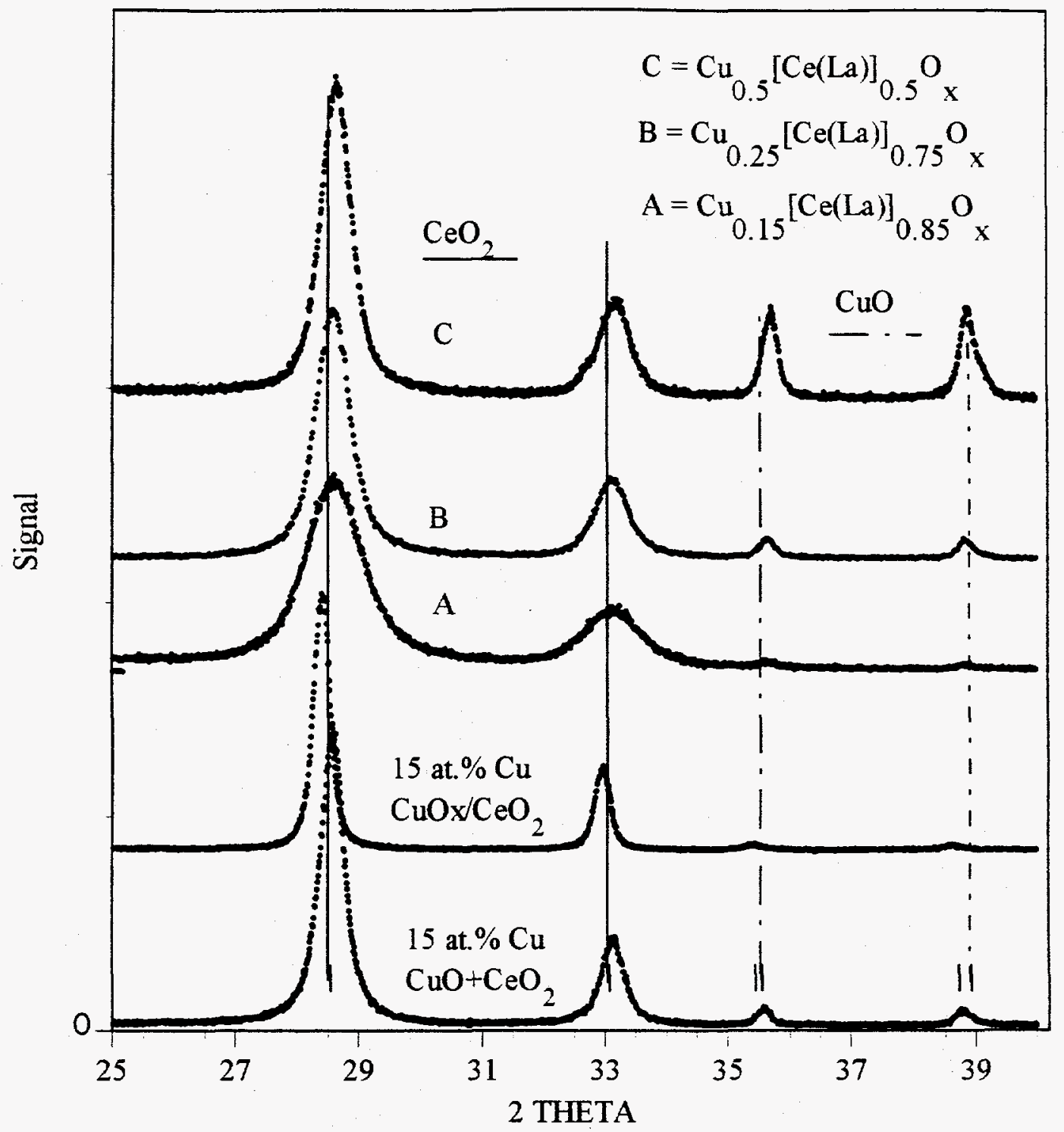

Figure 6.2 XRD Pattems of Various $\mathrm{Cu}-\mathrm{Ce}-\mathrm{O}$ Catalysts (wet mixture of $\mathrm{CuO}+\mathrm{CeO} 2$ was dried for $1 \mathrm{~h}$ at $300^{\circ} \mathrm{C}$ and all the others were prepared by $4-\mathrm{h}$ calcination at $650^{\circ} \mathrm{C}$ in air). 



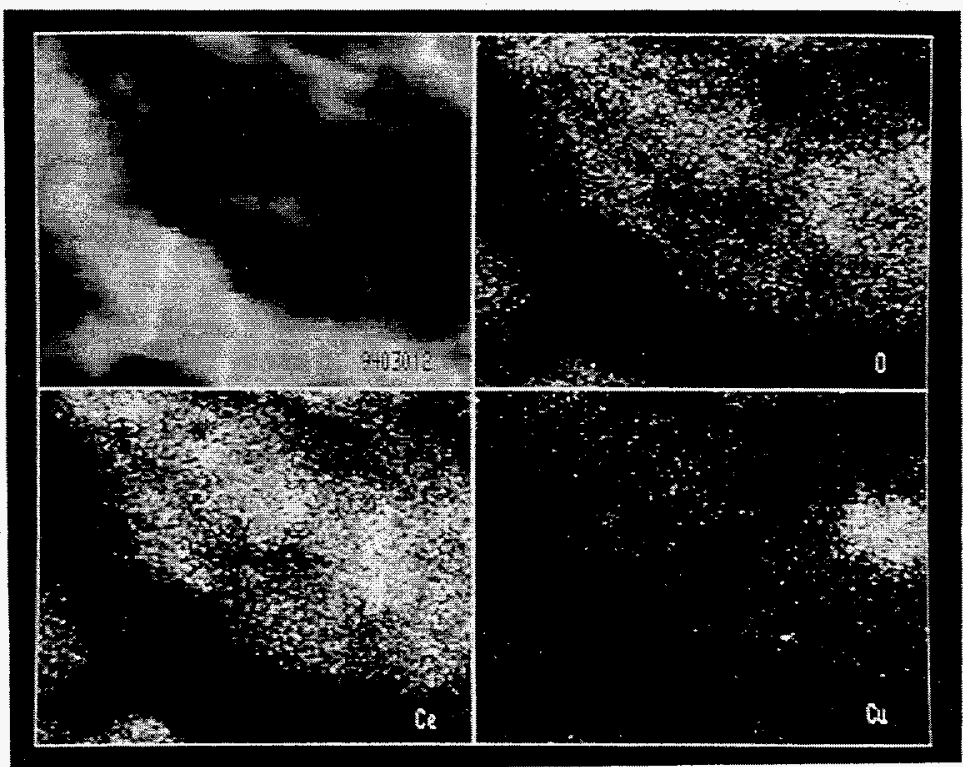

(a) $\quad \mathrm{Cu}_{0.15}[\mathrm{Ce}(\mathrm{La})]_{0.85} \mathrm{O}_{\mathrm{x}}$

$40 \mathrm{~nm}$

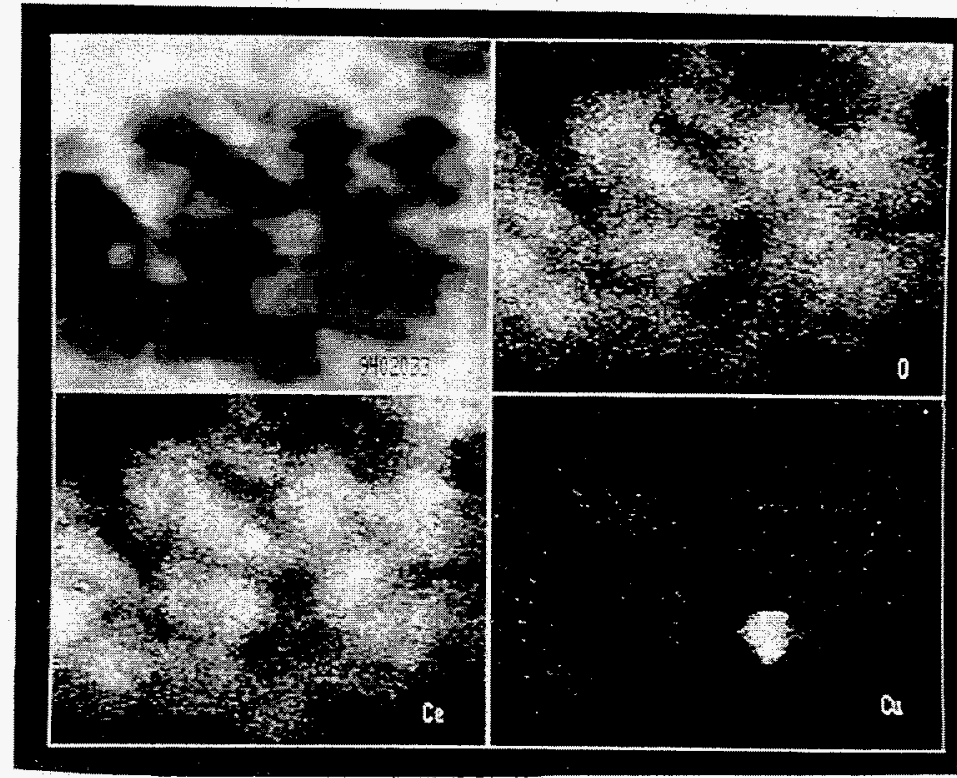

(b) 15 at. $\% \mathrm{CuOx} / \mathrm{CeO}_{2}$

$40 \mathrm{~nm}$

Figure 6.3 Elemental Mapps of $\mathrm{Cu}-\mathrm{Ce}-\mathrm{O}$ Catalysts by STEM/EDX. 


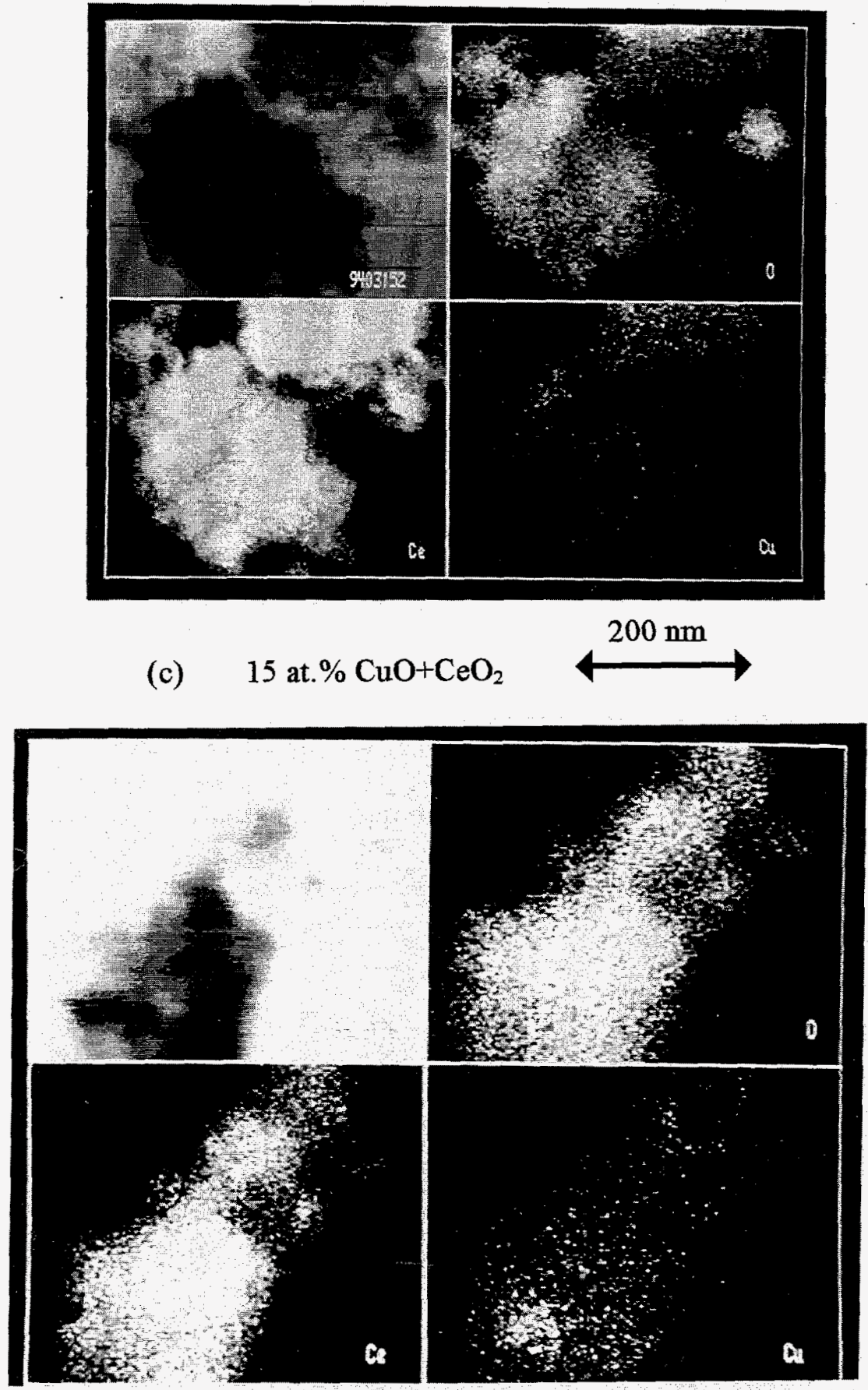

(d) $\mathrm{Cu}_{0.15}[\mathrm{Ce}(\mathrm{La})]_{0.85} \mathrm{O}_{\mathrm{x}}$ leached by nitric acid

$40 \mathrm{~nm}$

Figure $6.3-$ contd. 


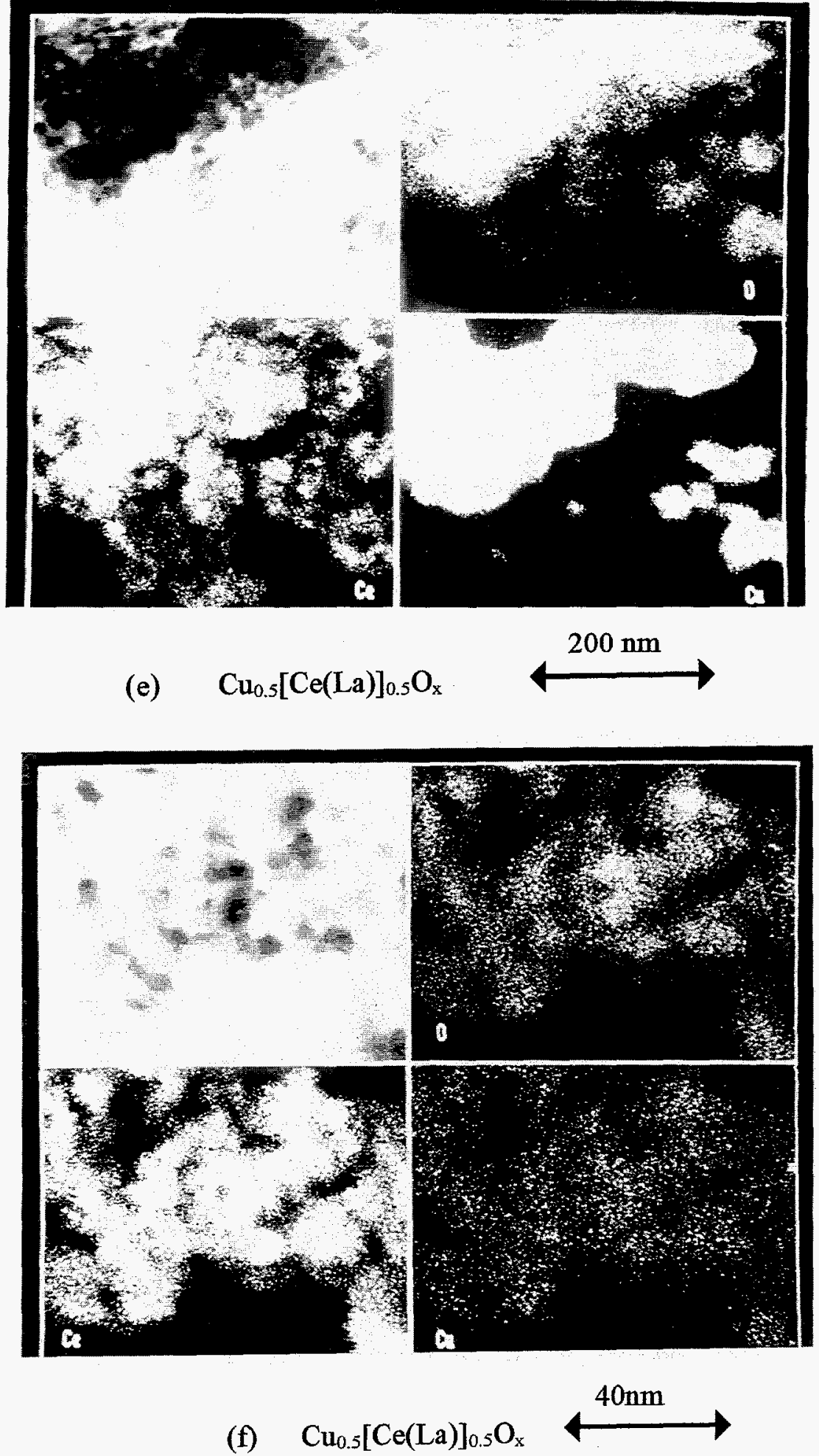

Figure 6.3-contd. 


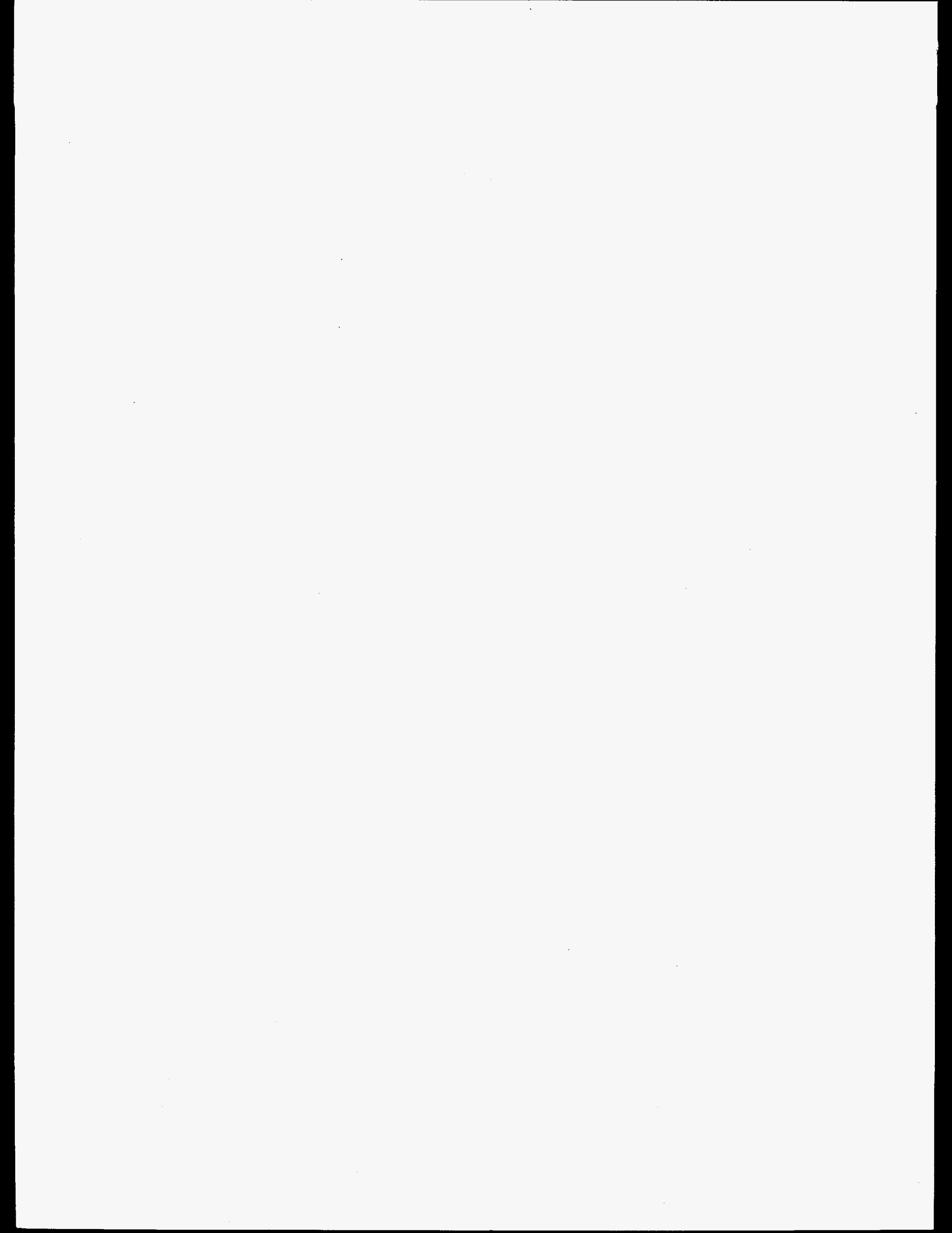




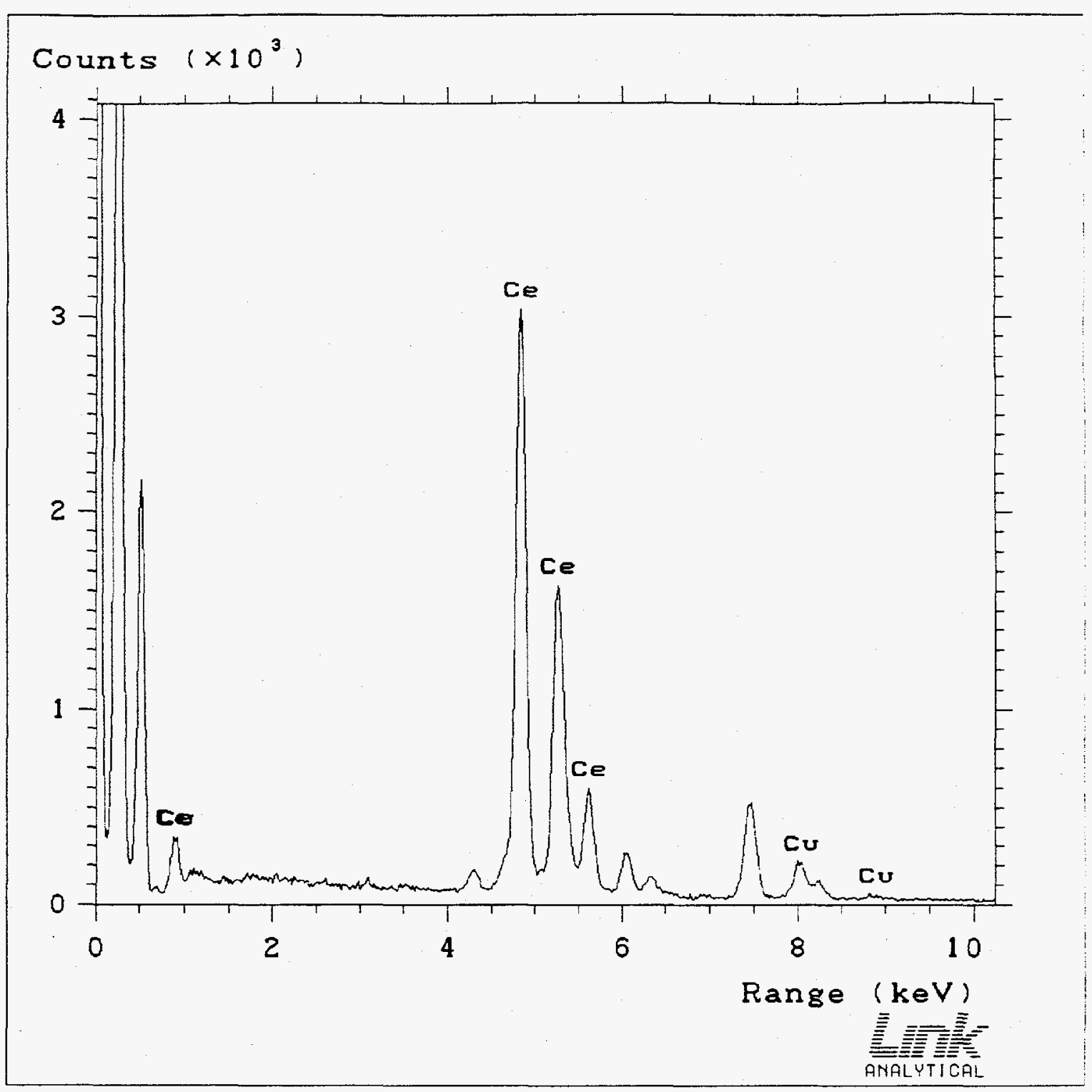

(g) X-ray Energy Dispersive Spectra of An Area Shown in Figure 7.3f.

Figure 6.3-contd. 



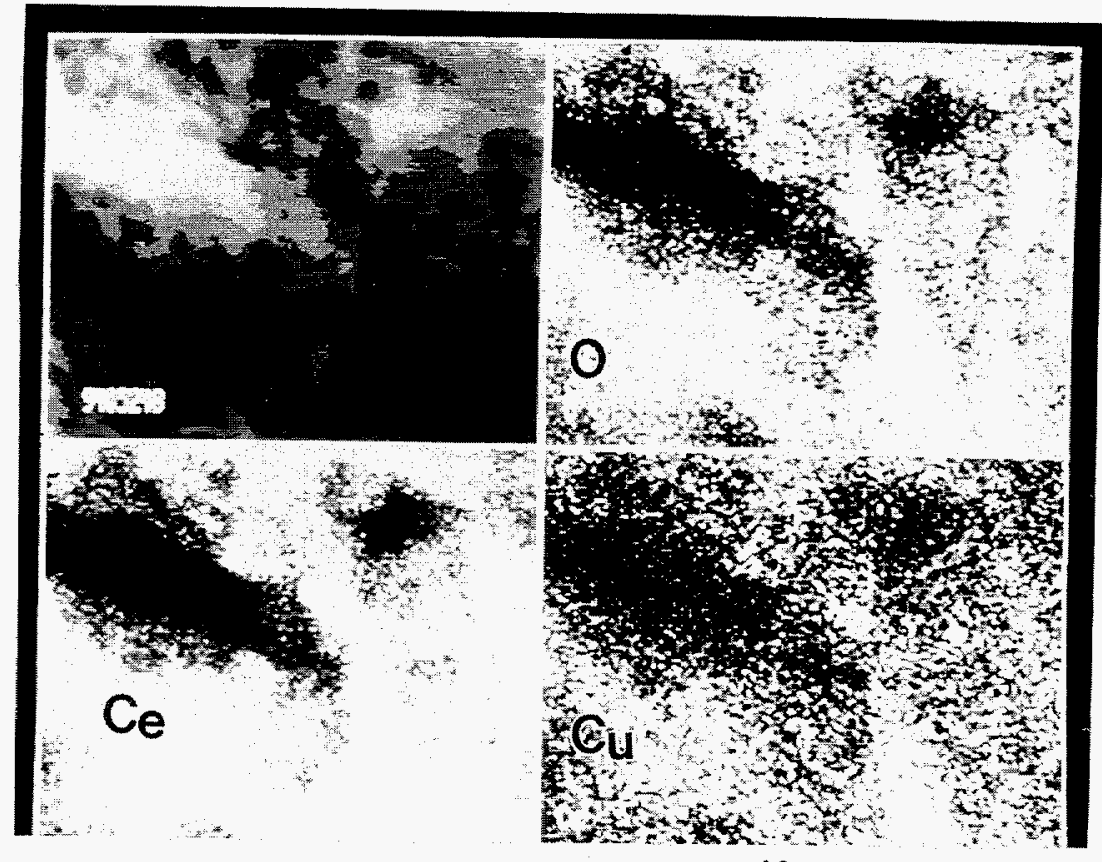

(h) $\quad \mathrm{Cu}_{0.01}[\mathrm{Ce}(\mathrm{La})]_{0.99} \mathrm{O}_{\mathrm{x}}$
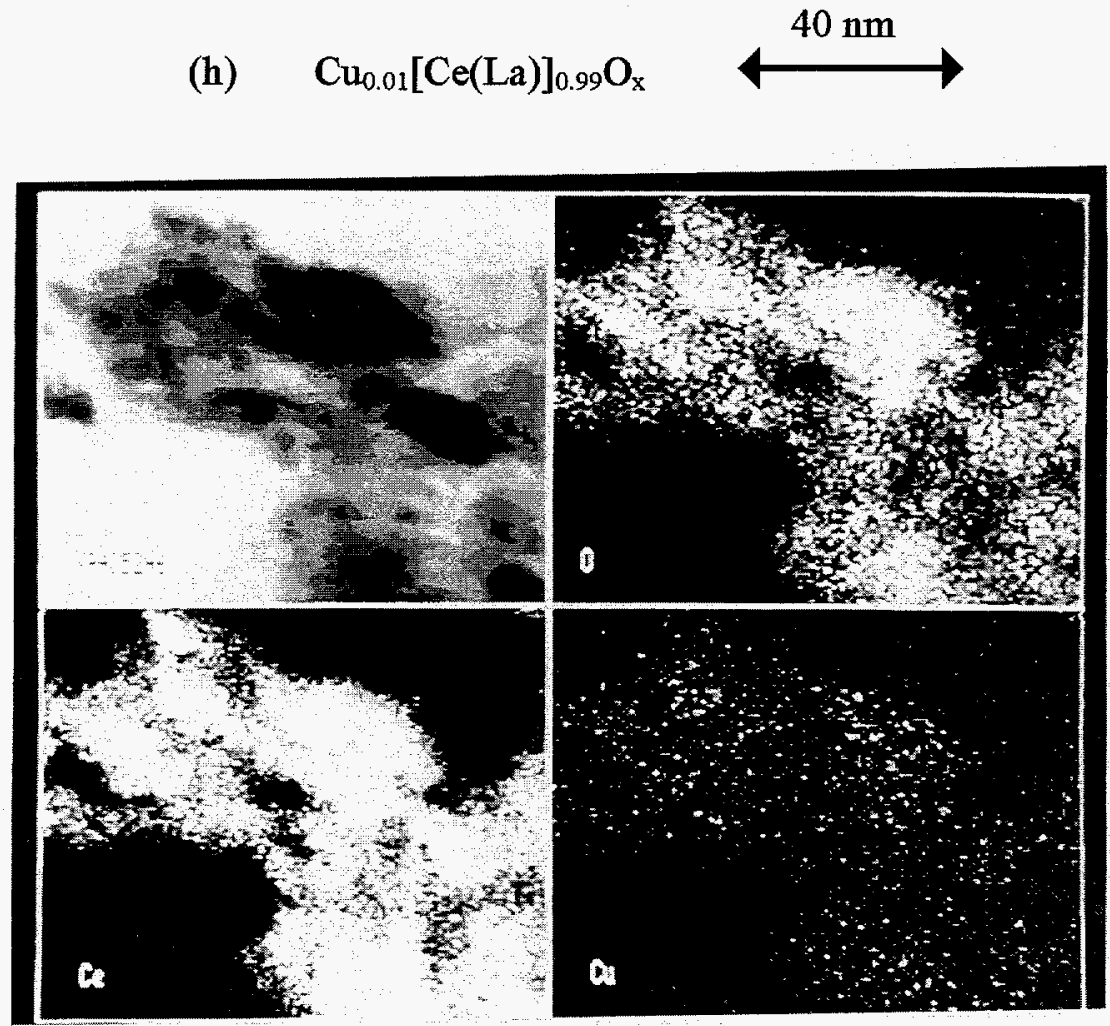

(i) $\mathrm{Cu}_{0.01}[\mathrm{Ce}(\mathrm{La})]_{0.99} \mathrm{O}_{\mathrm{x}}+3 \mathrm{~h}$ in air at $860^{\circ} \mathrm{C}$

$40 \mathrm{~nm}$

Figure 6.3-contd. 


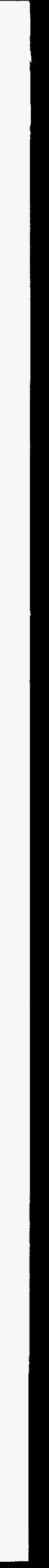




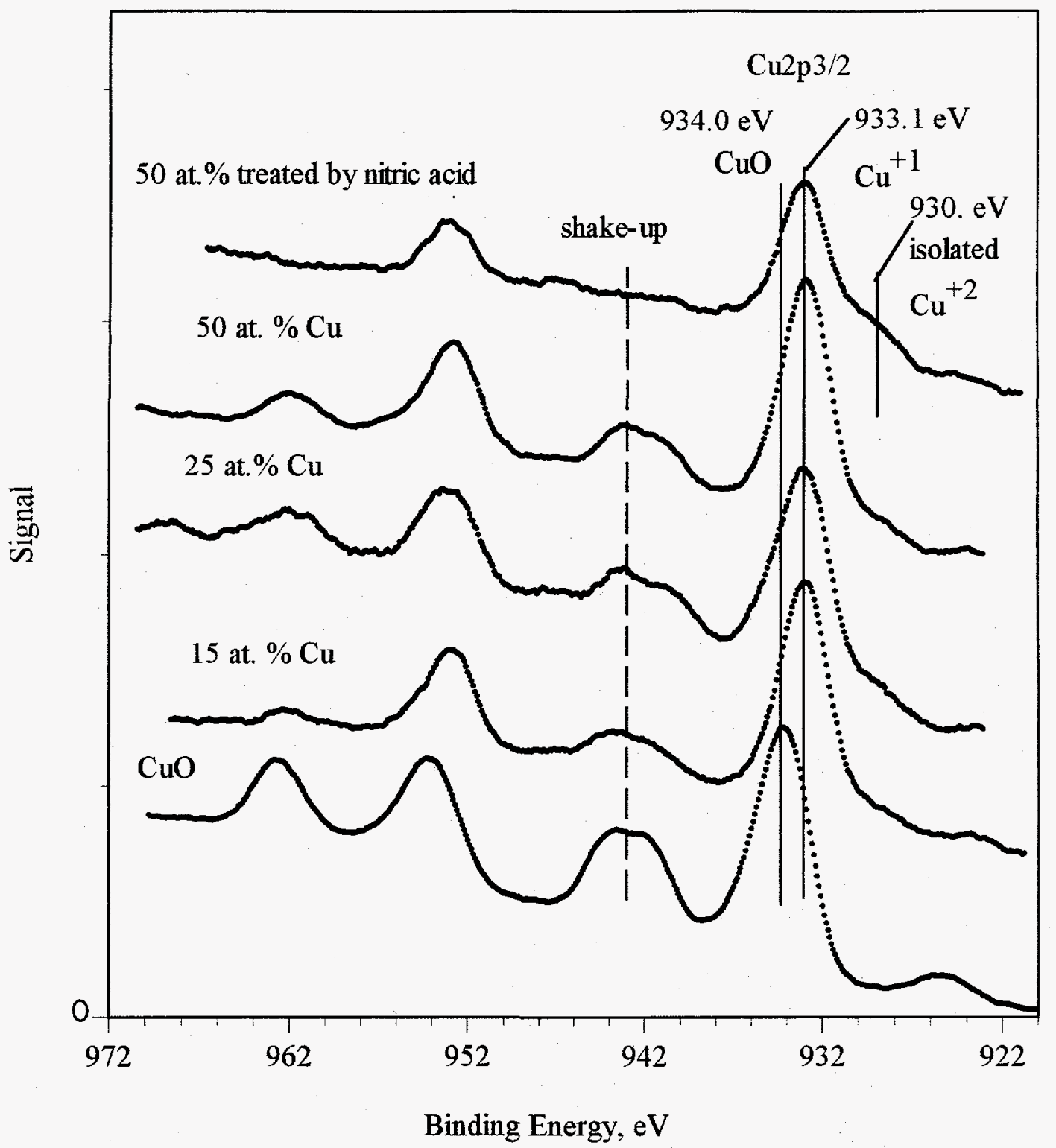

Figure 6.4a $\mathrm{Cu} 2 \mathrm{p} \mathrm{XP} \mathrm{Spectra} \mathrm{of} \mathrm{Cu}-\mathrm{Ce}(\mathrm{La})-\mathrm{O}$ Catalysts of High Copper Content (prepared by coprecipitation). 


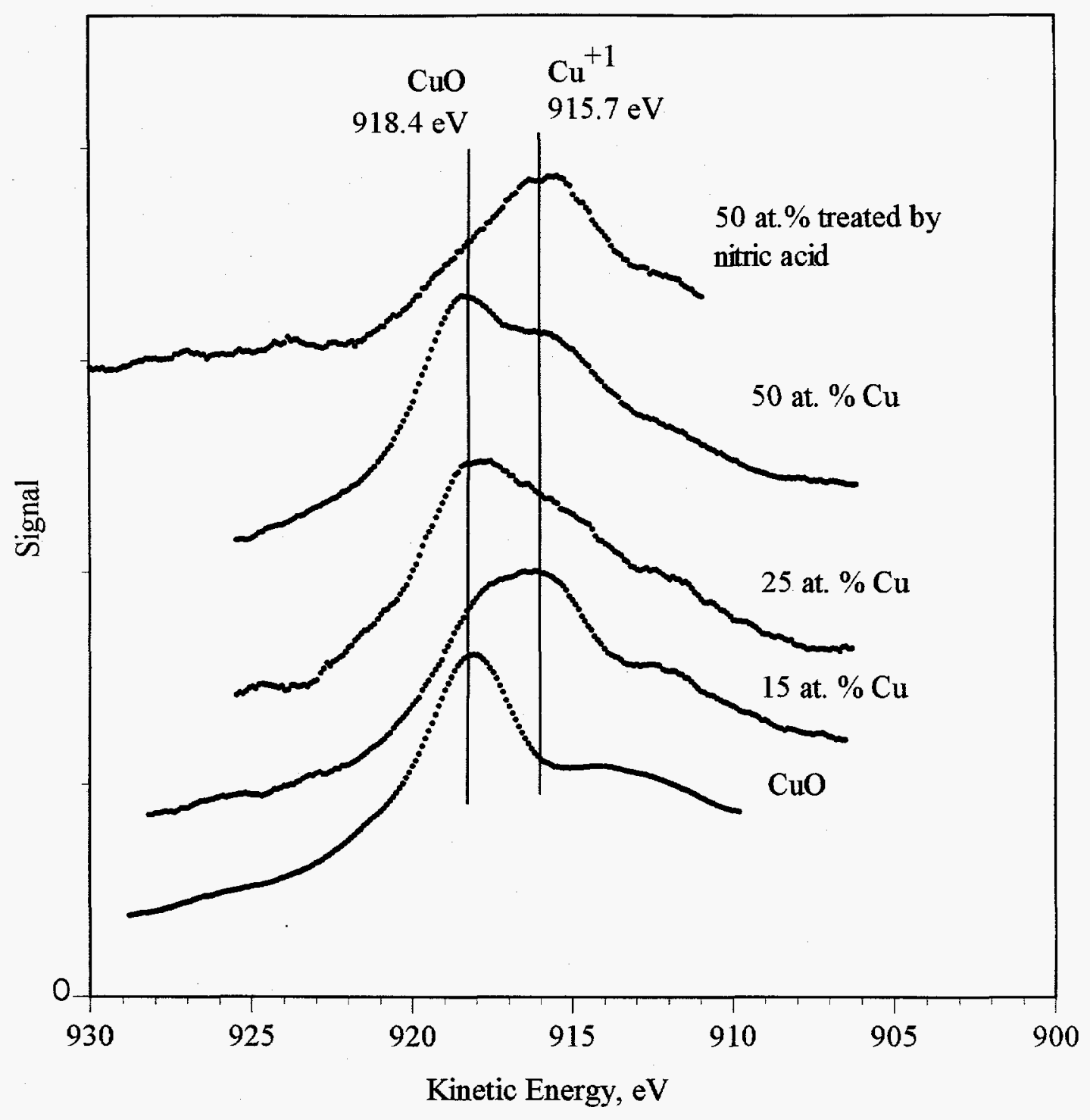

Figure 6.4b Kinetic Energy Spectra of the Auger $\mathrm{L}_{3} \mathrm{VV}$ Electron of the $\mathrm{Cu}-\mathrm{Ce}(\mathrm{La})-\mathrm{O}$ Catalysts. 


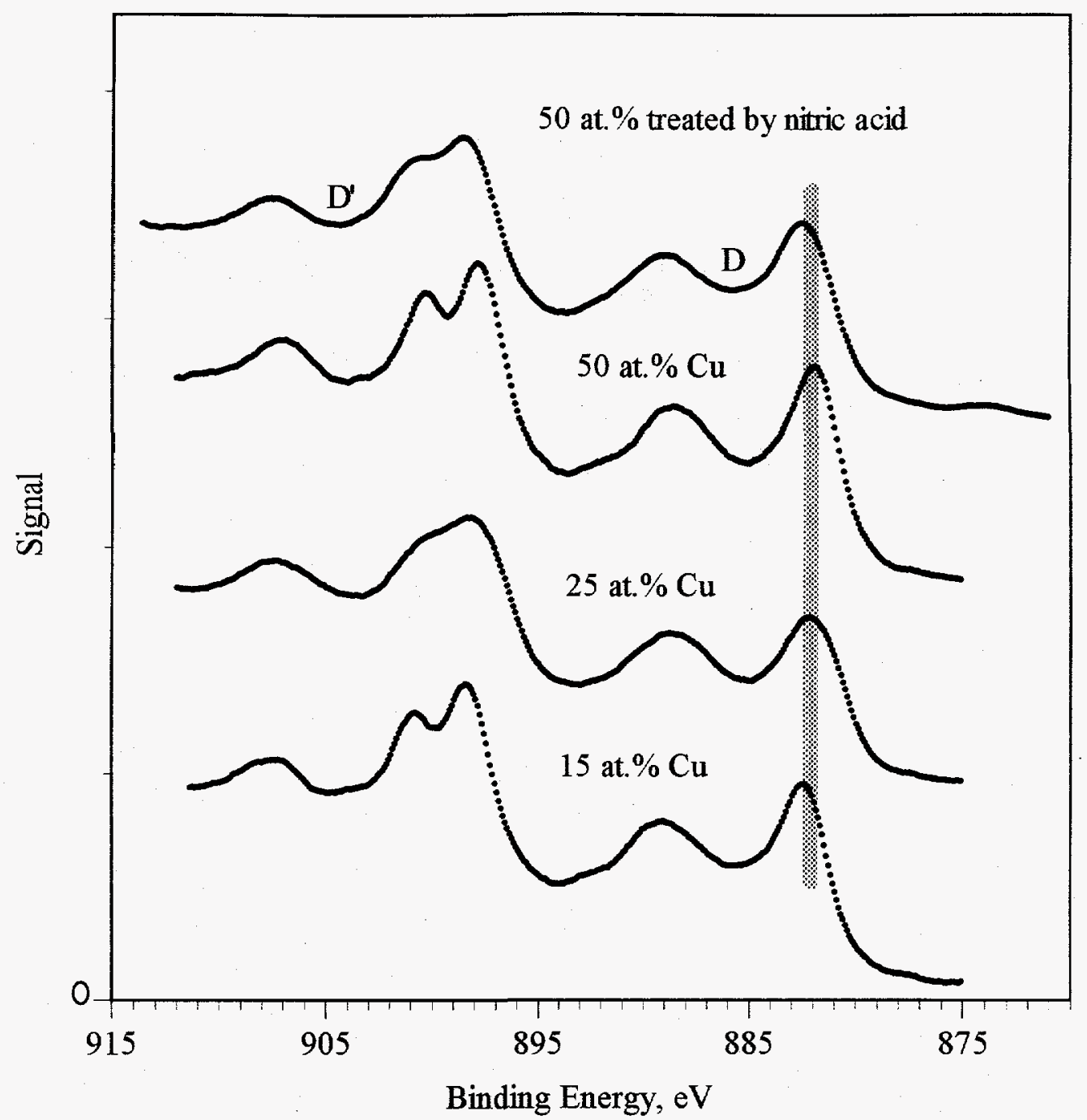

Figure 6.4c Ce3d XP Spectra of the $\mathrm{Cu}-\mathrm{Ce}(\mathrm{La})-\mathrm{O}$ Catalysts. 


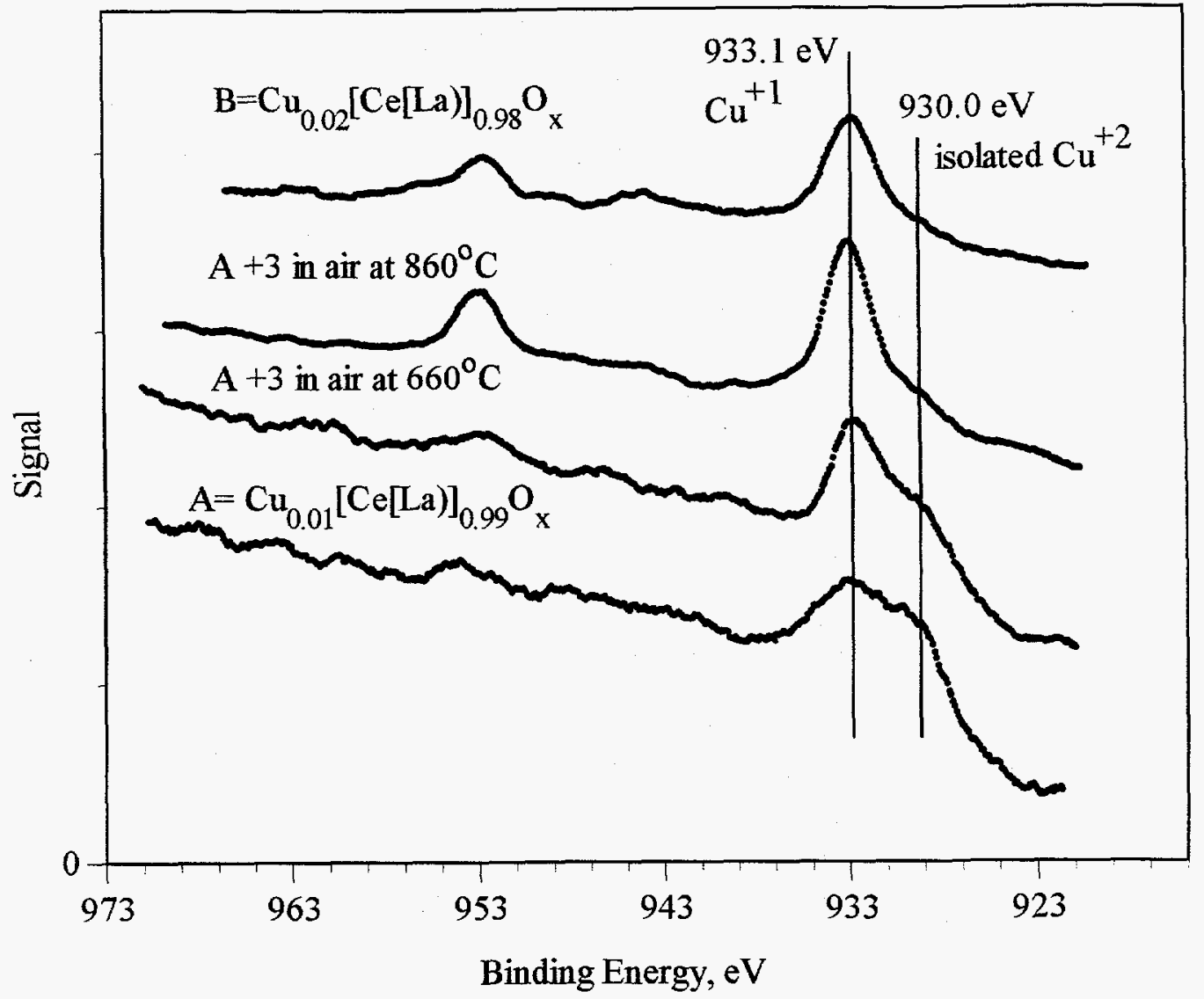

Figure 6.5a $\mathrm{Cu} 2 \mathrm{p}$ XP Spectra of $\mathrm{Cu}_{0.01}[\mathrm{Ce}(\mathrm{La})]_{0.99} \mathrm{O}_{\mathrm{x}}$ and $\mathrm{Cu}_{0.02}[\mathrm{Ce}(\mathrm{La})]_{0.98} \mathrm{O}_{\mathrm{x}}$ Catalysts $\left(\mathrm{Cu}_{0.01}[\mathrm{Ce}(\mathrm{La})]_{0.99} \mathrm{O}_{x}\right.$ prepared by $4 \mathrm{~h}$ calcination in $\mathrm{N}_{2}$ at $600^{\circ} \mathrm{C} ; \mathrm{Cu}_{0.02}[\mathrm{Ce}(\mathrm{La})]_{0.98} \mathrm{O}_{\mathrm{x}}$ prepared by $4-\mathrm{h}$ calcination at $650^{\circ} \mathrm{C}$ and $3-\mathrm{h}$ calcination at $860^{\circ} \mathrm{C}$ both in air). 


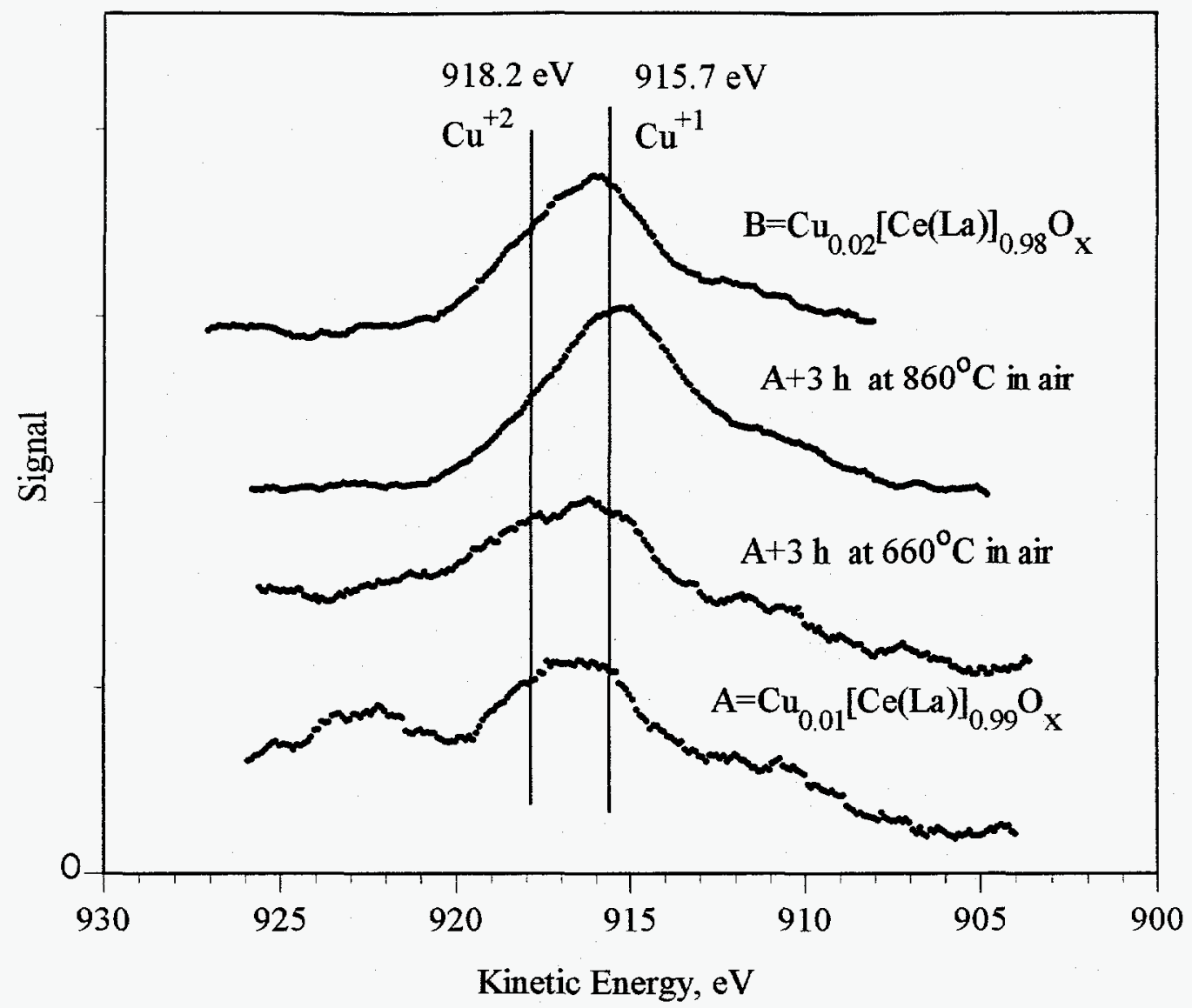

Figure 6.5b Kinetic Energy Spectra of the Auger $\mathrm{L}_{3} \mathrm{VV}$ Electron of the $\mathrm{Cu}_{0.01}[\mathrm{Ce}(\mathrm{La})]_{0.99} \mathrm{O}_{\mathrm{x}} \mathrm{Cu}_{0.02}[\mathrm{Ce}(\mathrm{La})]_{0.98} \mathrm{O}_{\mathrm{x}}$ Catalysts. 


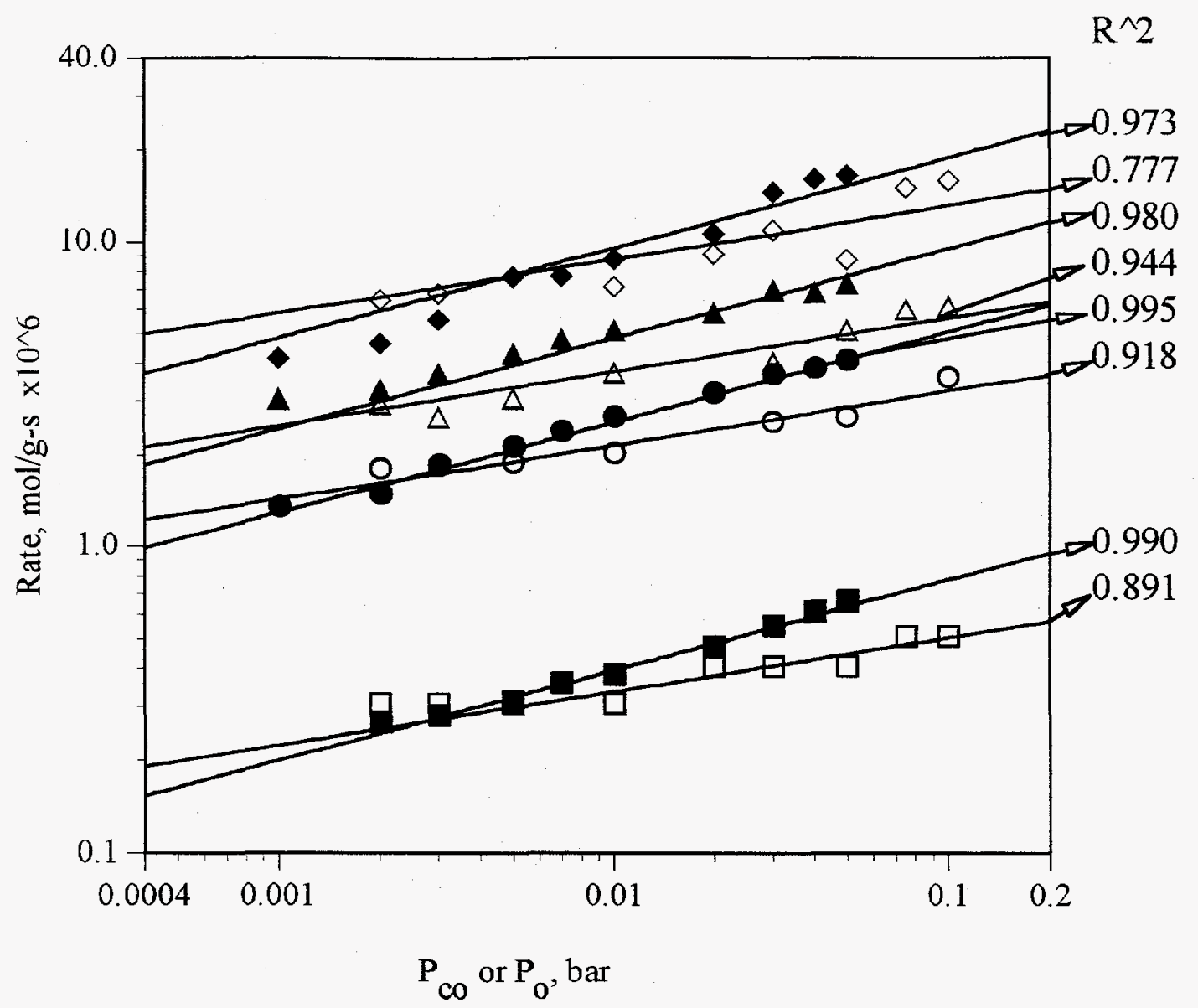

Figure 6.6 Variation of $\mathrm{CO}$ Oxidation Rate over the $\mathrm{Au}_{0.05}[\mathrm{Ce}(\mathrm{La})]_{0.95} \mathrm{O}_{\mathrm{x}}$ Catalyst with Partial Pressure of Oxygen and CO. Filled symbols for $P_{C O}$ under $P_{O}=0.05$ and the open ones for $\mathrm{P}_{\mathrm{O}}$ under $\mathrm{P}_{\mathrm{CO}}=0.01$. $10^{\circ} \mathrm{C} \odot 25^{\circ} \mathrm{C} \Delta 43^{\circ} \mathrm{C} \bullet 54^{\circ} \mathrm{C}$. 


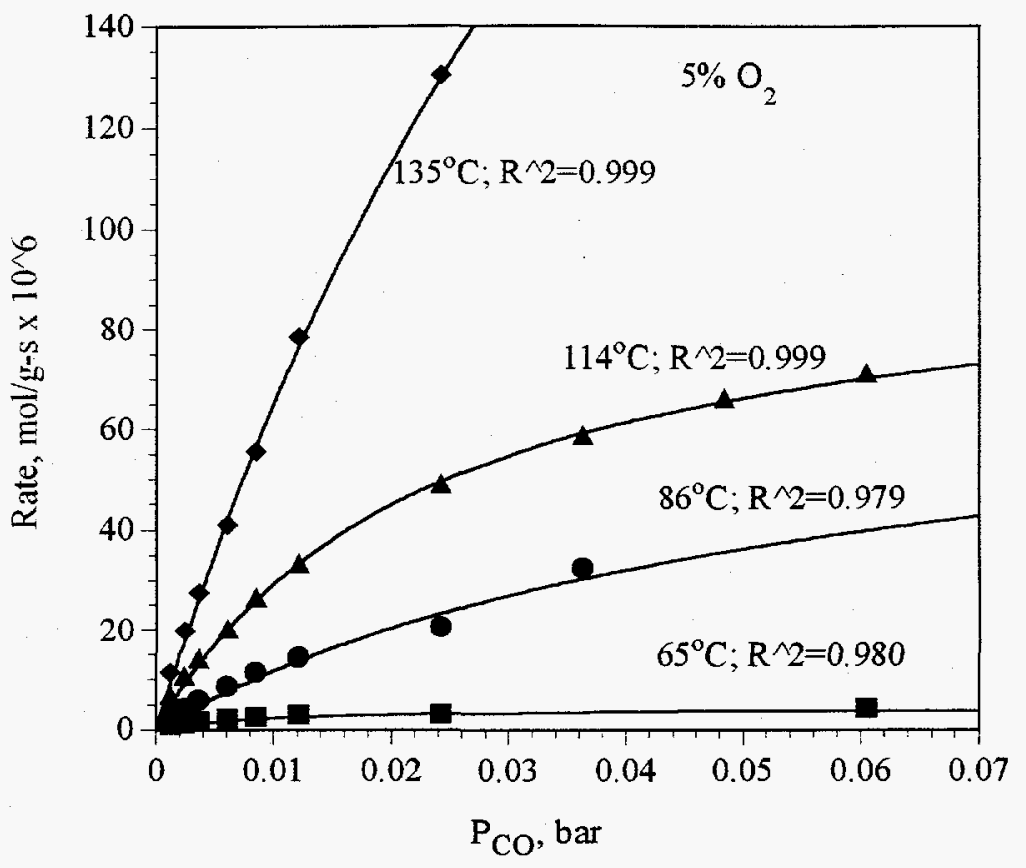

Figure 6.7 Variation of CO Oxidation Rate over the $\mathrm{Cu}_{0.15}[\mathrm{Ce}(\mathrm{La})]_{0.85} \mathrm{O}_{\mathrm{x}}$ Catalyst with Partial Pressure of $\mathrm{CO}$ under Constant $\mathrm{P}_{\mathrm{O}}$.

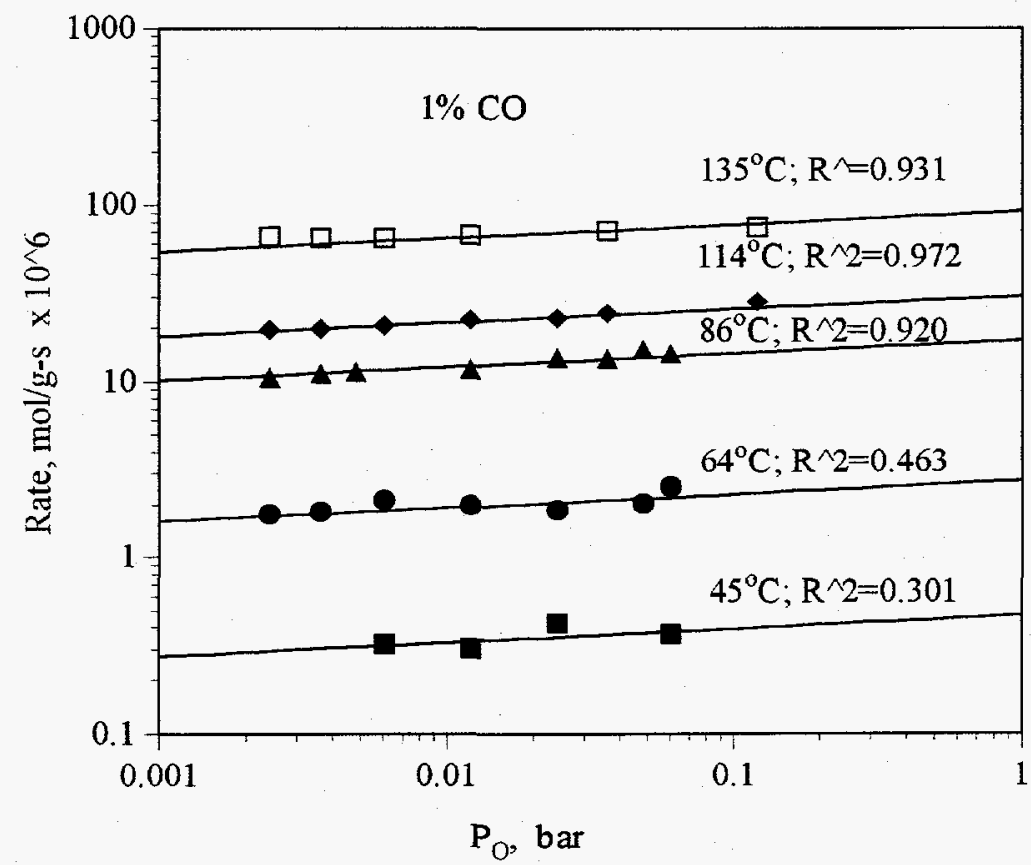

Figure 6.8 Variation of CO Oxidation Rate over the $\mathrm{Cu}_{0.15}[\mathrm{Ce}(\mathrm{La})]_{0.85} \mathrm{O}_{\mathrm{x}}$ Catalyst with Partial Pressure of Oxygen under Constant $\mathbf{P}_{\mathrm{CO}}$. 


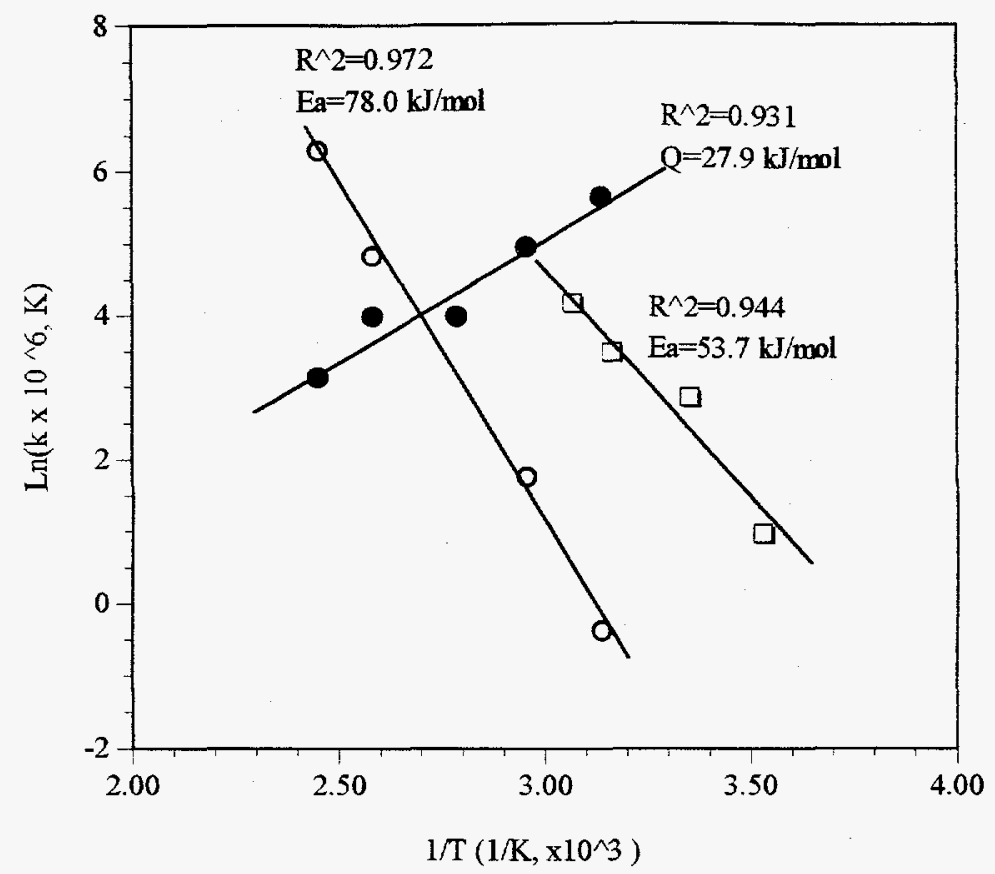

Figure 6.9 Arrhenius Plots of Constants $\mathrm{k}$ and $\mathrm{K}$ for $\mathrm{CO}$ Oxidation over $\mathrm{Au}_{0.05}[\mathrm{Ce}(\mathrm{La})]_{0.95} \mathrm{O}_{\mathrm{x}}$ and $\mathrm{Cu}_{0.15}[\mathrm{Ce}(\mathrm{La})]_{0.85} \mathrm{O}_{\mathrm{x}}$ Catalysts. $\square \mathrm{k}$ for $\mathrm{Au}_{0.05}[\mathrm{Ce}(\mathrm{La})]_{0.95} \mathrm{O}_{\mathrm{x}}, \mathrm{O}$ $\mathrm{k}_{\mathrm{CO}}$ for $\mathrm{Cu}_{0.15}[\mathrm{Ce}(\mathrm{La})]_{0.85} \mathrm{O}_{\mathrm{x}}, \bullet \mathrm{K}_{\mathrm{CO}}$ for $\mathrm{Cu}_{0.15}[\mathrm{Ce}(\mathrm{La})]_{0.85} \mathrm{O}_{\mathrm{x}}$.

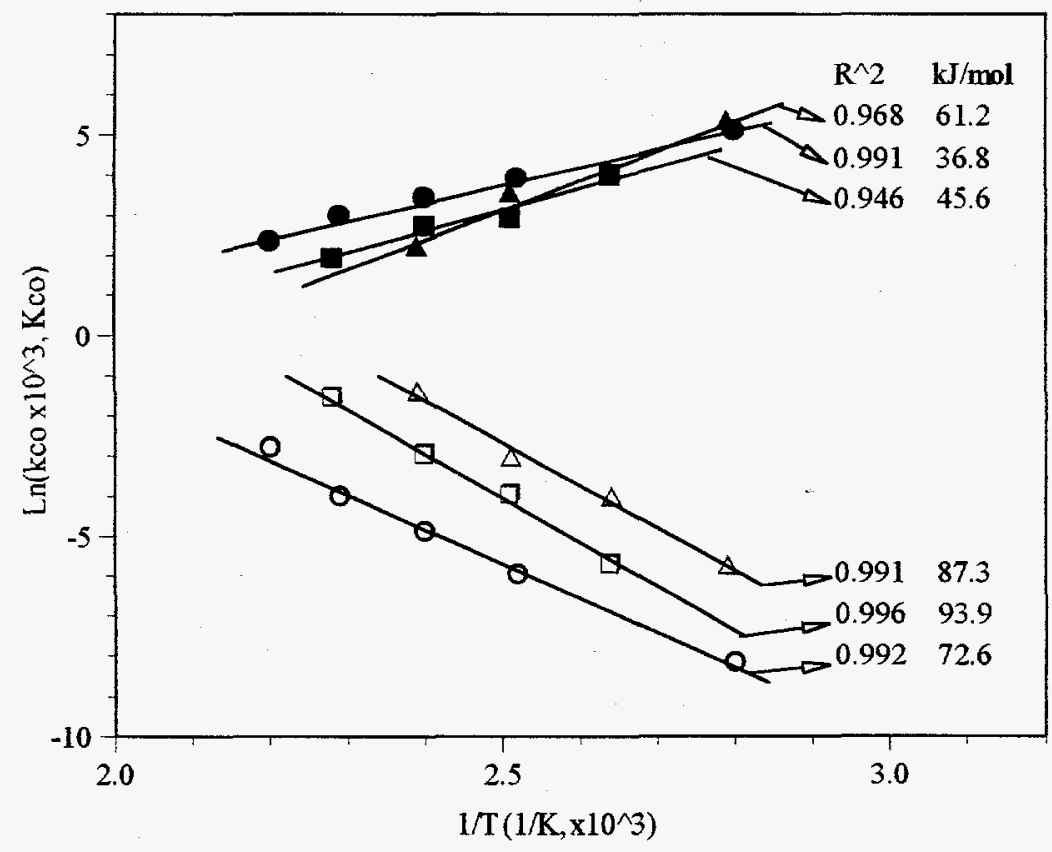

Figure 6.10 Arrhenius Plots of Constants $\mathrm{k}_{\mathrm{CO}}$ and $\mathrm{K}_{\mathrm{CO}}$ for CO Oxidation over $\mathrm{Cu}_{0.01}[\mathrm{Ce}(\mathrm{La})]_{0.99} \mathrm{O}_{\mathrm{x}}$ Catalysts. Open symbols for $\mathrm{k}_{\mathrm{CO}}$ and the filled ones for $\mathrm{K}_{\mathrm{CO}}$ : $\mathrm{O}$ fresh $\square+3 \mathrm{~h}$ at $650^{\circ} \mathrm{C}, \triangle+3 \mathrm{~h}$ at $860^{\circ} \mathrm{C}$. 


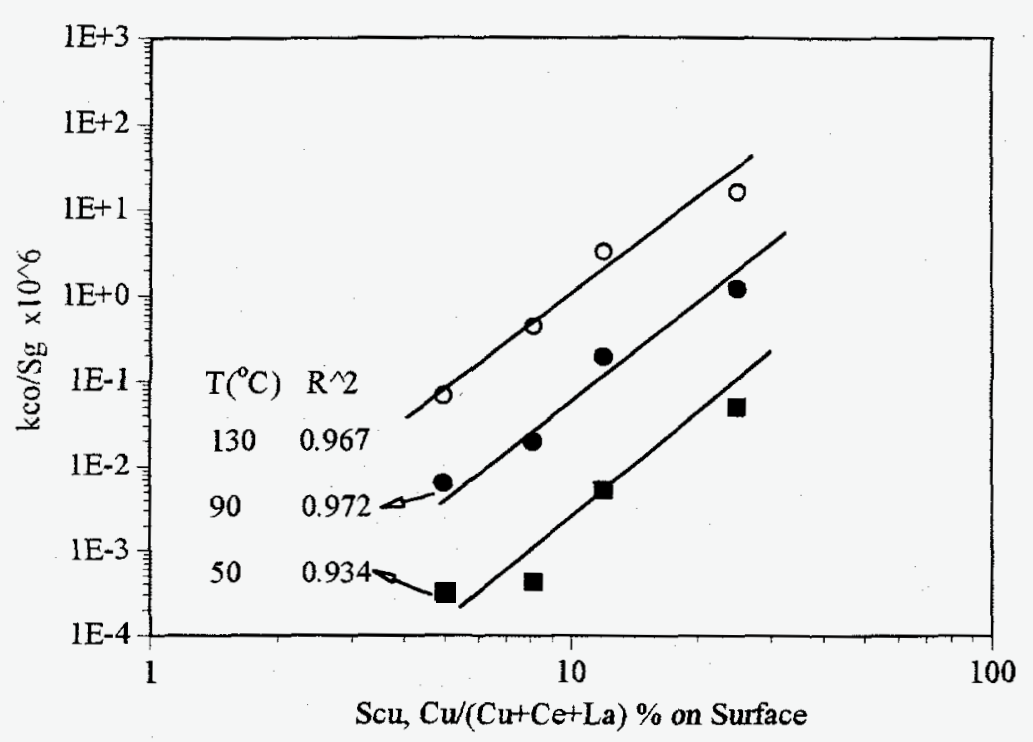

Figure 6.11 Variation of Normalized Reaction Rate Constant $\left(\mathrm{k}_{\mathrm{co}} / \mathrm{Sg}\right)$ for $\mathrm{CO}$ Oxidation over the $\mathrm{Cu}-\mathrm{Ce}(\mathrm{La})-\mathrm{O}$ Catalysts with the Surface Copper Fraction.

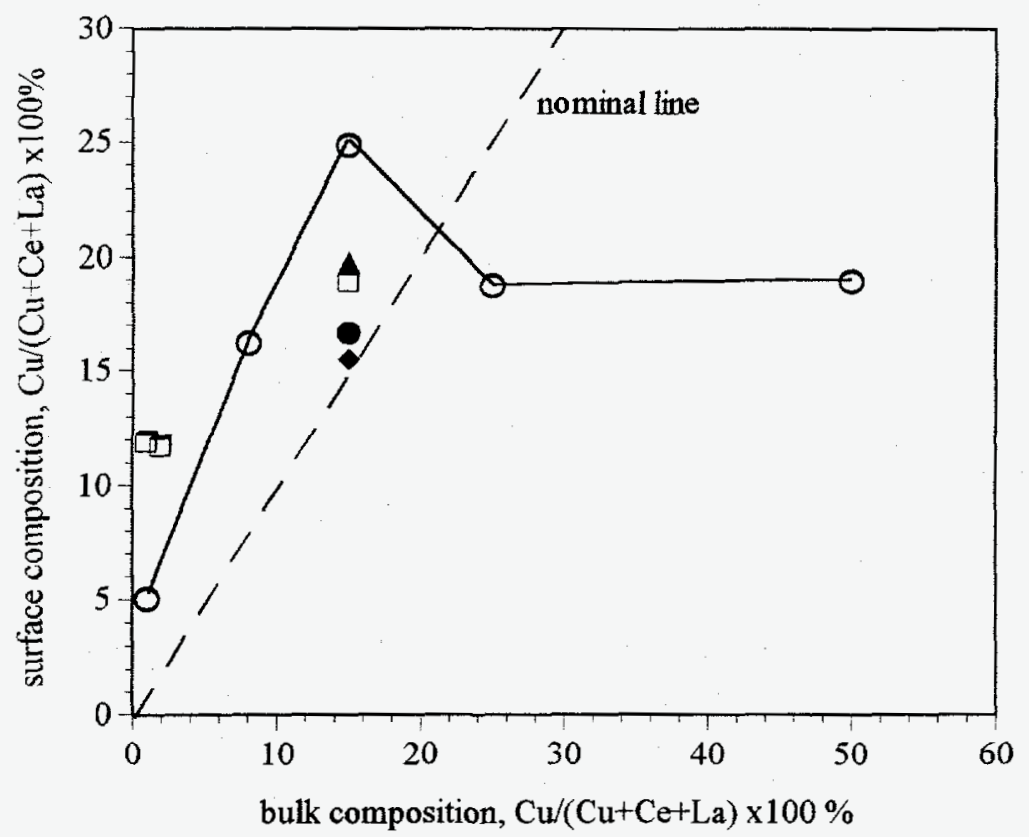

Figure 6.12 Variation of the Surface Copper Fraction of the $\mathrm{Cu}-\mathrm{Ce}(\mathrm{La})-\mathrm{O}$ Catalyst with Bulk Composition and Thermal Treatment. $O$ as prepared by $4-h$ calcination at $650^{\circ} \mathrm{C}$ in air, $\square$ further heated for $3 \mathrm{~h}$ in flowing air at $860^{\circ} \mathrm{C}$, $\Delta$ reduced by $25 \% \mathrm{H}_{2} / \mathrm{He}$ for $2 \mathrm{~h}$ at $300^{\circ} \mathrm{C}$, reduced by $25 \% \mathrm{H}_{2} / \mathrm{He}$ for $1 \mathrm{~h}$ at $600^{\circ} \mathrm{C}$, prepared by impregnation. 


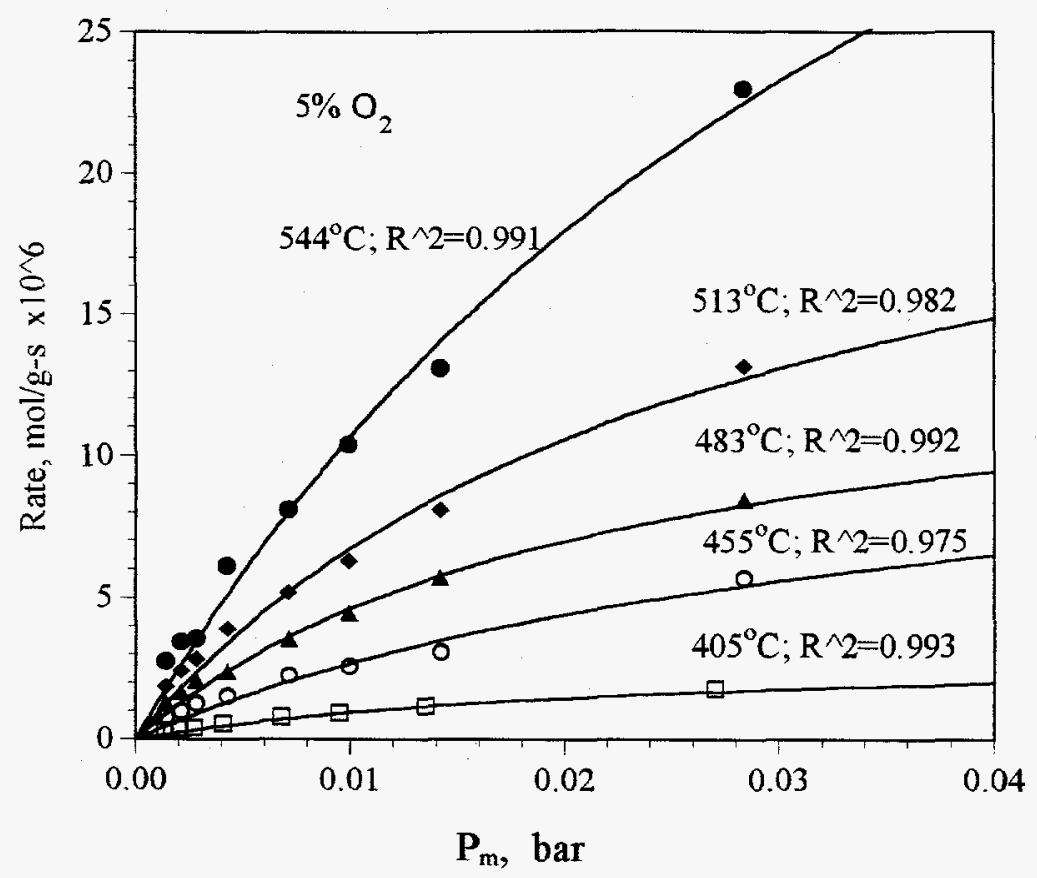

Figure 6.13 Variation of Methane Oxidation Rate over the $\mathrm{Cu}_{0.15}[\mathrm{Ce}(\mathrm{La})]_{0.85} \mathrm{O}_{\mathrm{x}}$ Catalyst with Partial Pressure of Methane under Constant $P_{O}$.

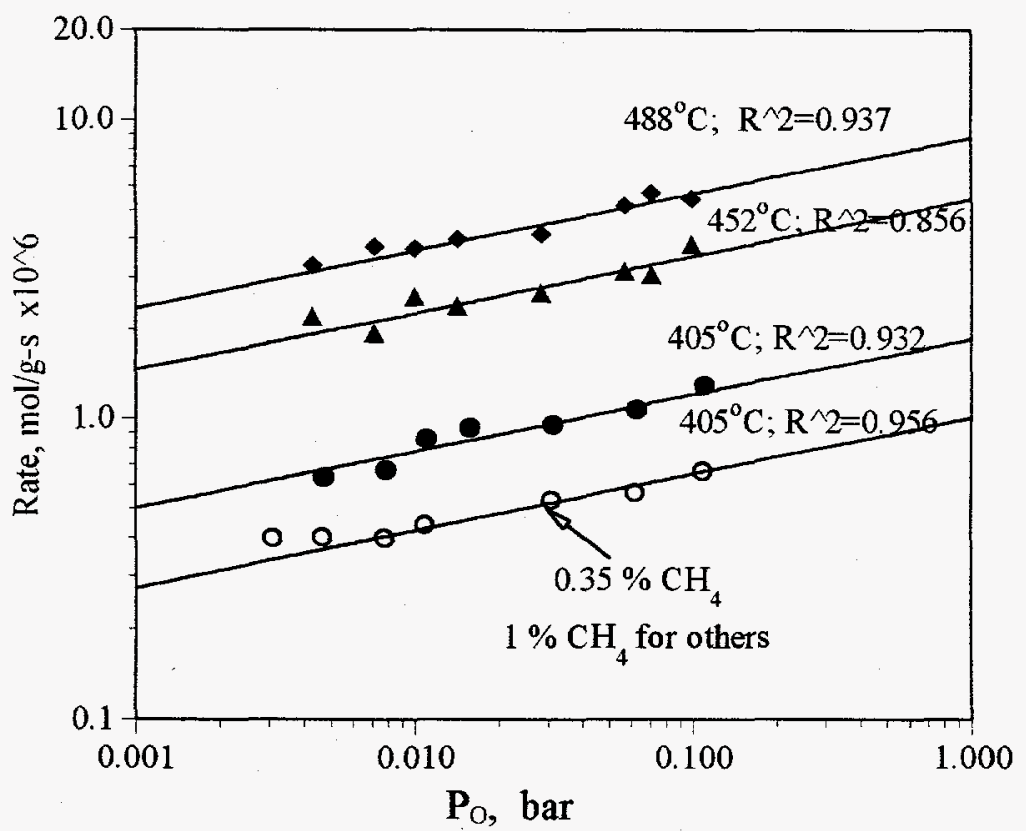

Figure 6.14 Variation of Methane Oxidation Rate over the $\mathrm{Cu}_{0.15}[\mathrm{Ce}(\mathrm{La})]_{0.85} \mathrm{O}_{\mathrm{x}}$ Catalyst with Partial Pressure of Oxygen under Constant $\mathbf{P}_{m}$ 


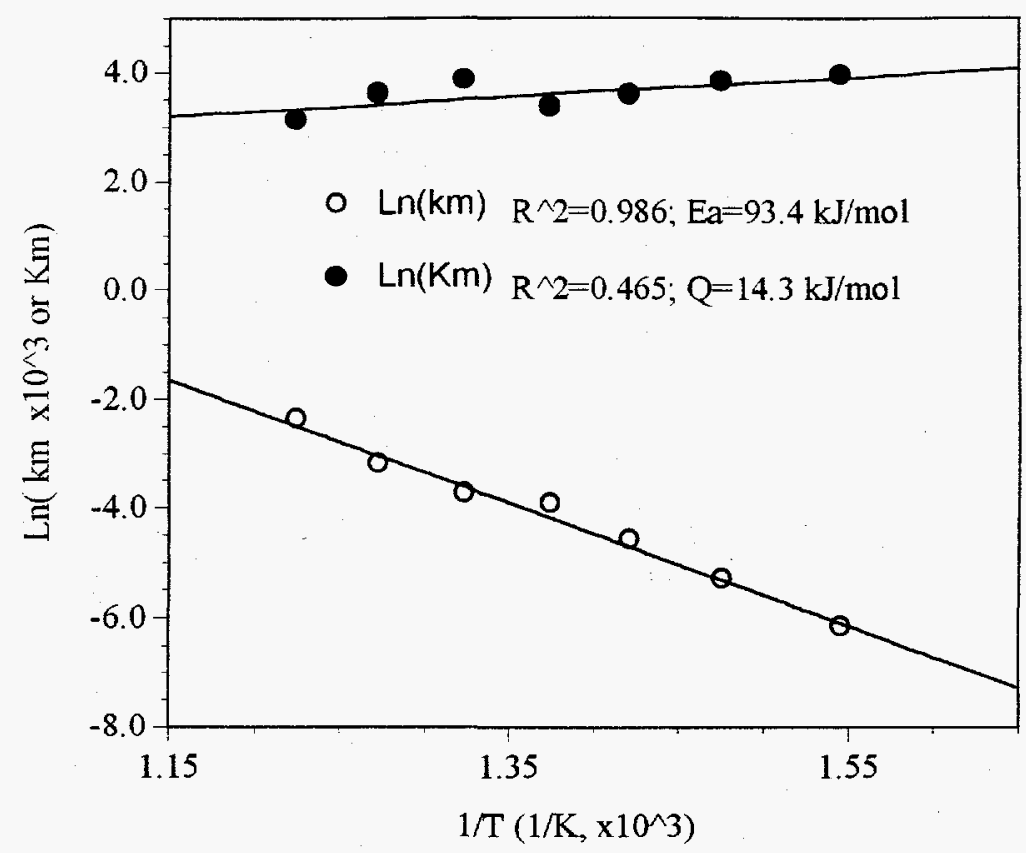

Figure 6.15 Arrhenius Plots of Constants $\mathrm{k}_{\mathrm{m}}$ and $\mathrm{K}_{\mathrm{m}}$ for Methane Oxidation over $\mathrm{Cu}_{0.15}[\mathrm{Ce}(\mathrm{La})]_{0.85} \mathrm{O}_{\mathrm{x}}$ Catalyst.

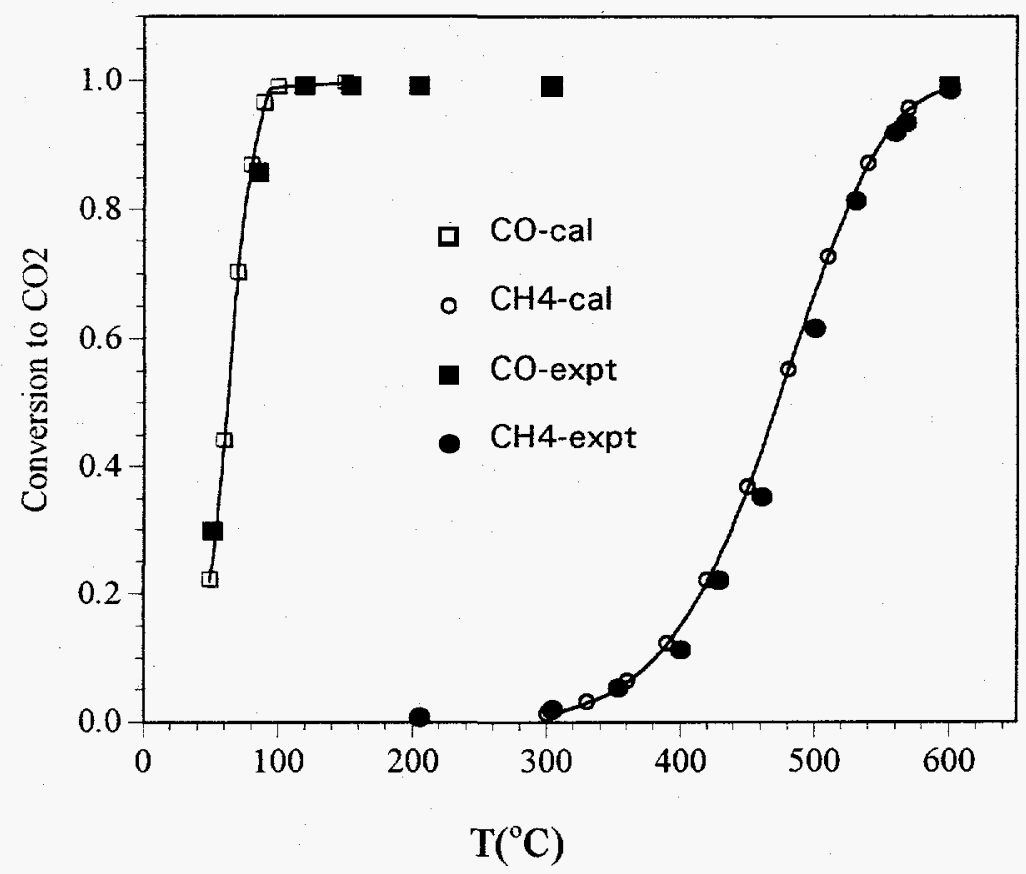

Figure 6.16 Comparison of Calculated Light-off Curves with Experimental Data $\left(\mathrm{Cu}_{0.15}[\mathrm{Ce}(\mathrm{La})]_{0.85} \mathrm{O}_{\mathrm{x}}\right.$ catalyst; $\left.0.09 \mathrm{~g} \cdot \mathrm{s} / \mathrm{cc} ; 0.228 \% \mathrm{CH}_{4}, 0.1 \% \mathrm{CO}, 1 \% \mathrm{O}_{2}\right)$. 


\section{Chapter 7}

\section{Conclusions and Recommendations}

\subsection{Reduction of $\mathrm{SO}_{2}$ by $\mathrm{CO}$ to Elemental Sulfur}

Fluorite oxides, $\mathrm{CeO}_{2}$ and $\mathrm{ZrO}_{2}$, and rare earth zirconates such as $\mathrm{Gd}_{2} \mathrm{Zr}_{2} \mathrm{O}_{7}$ are active catalysts for reduction of $\mathrm{SO}_{2}$ by $\mathrm{CO}$. More than $95 \%$ sulfur yield was achieved at reaction temperatures about $500^{\circ} \mathrm{C}$ or higher with the feed gas of stoichiometric composition. These catalysts were stable and did not lose their structure after the reaction. Detailed studies of $\mathrm{CeO}_{2}$ catalyst found that the catalytic activity can be enhanced by rare earth dopants ( $\mathrm{La}, \mathrm{Gd}$, etc). Fluorite oxides and rare earth zirconates are known oxygen ion conducting materials of high oxygen mobility and/or vacancy concentration. Reaction of $\mathrm{SO}_{2}$ and $\mathrm{CO}$ over these catalysts demonstrated a strong correlation of catalytic activity with the catalyst oxygen mobility.

However, the above catalysts showed strong hysteresis effect and propensity to $\mathrm{H}_{2} \mathrm{O}$ and $\mathrm{CO}_{2}$ poisoning. These catalysts need to be activated either by pre-reduction with $\mathrm{CO}$ or by starting the reaction at high temperatures. With the stoichiometric feed gas, the fluorite oxide catalysts lighted off at temperatures above $600^{\circ} \mathrm{C}$, while the zirconates lighted off above $650^{\circ} \mathrm{C}$. To avoid $\mathrm{H}_{2} \mathrm{O}$ and $\mathrm{CO}_{2}$ poisoning, reaction temperatures higher than $550^{\circ} \mathrm{C}$ were required for these catalysts. Addition of active transition metals, such as $\mathrm{Cu}, \mathrm{Ni}, \mathrm{Co}$, etc., to the fluorite oxide lowered the light-off temperature to about $500^{\circ} \mathrm{C}$ and significantly enhanced the catalyst resistance toward $\mathrm{H}_{2} \mathrm{O}$ and $\mathrm{CO}_{2}$ poisoning. Among various composite catalysts the $\mathrm{Cu}-\mathrm{Ce}-\mathrm{O}$ system was chosen for extensive studies.

An active $\mathrm{Cu}-\mathrm{Ce}-\mathrm{O}$ catalyst can be prepared by either coprecipitation or impregnation. XRD, XPS, and STEM analyses of the used $\mathrm{Cu}-\mathrm{Ce}-\mathrm{O}$ catalyst found that the fluorite crystal structure of ceria was stable at the present reaction conditions, a small amount of copper was dispersed and stabilized on the ceria matrix, and excess copper oxide particles formed copper sulfide crystals of little contribution to catalytic activity. Kinetic studies were carried out with the $\mathrm{Cu}_{0.02}[\mathrm{Ce}(\mathrm{La})]_{0.98} \mathrm{O}_{\mathrm{x}}$ and $\mathrm{Cu}_{0.15}[\mathrm{Ce}(\mathrm{La})]_{0.85} \mathrm{O}_{\mathrm{x}}$ catalysts. The conversion-contact time profiles were approximately represented by the following first order equation:

$$
-\frac{\mathrm{dP}_{\mathrm{SO} 2}}{\mathrm{~d} \tau}=\mathrm{k} \cdot \mathrm{P}_{\mathrm{SO} 2}
$$

The reaction mechanism was discussed within the following redox framework:

Initiation step:

Follow-up step:

$$
\begin{aligned}
& \mathrm{CO}_{a d s}+\mathrm{O}_{c a t} \rightarrow \mathrm{CO}_{2, \mathrm{gas}}+V_{O, c a t} \\
& \mathrm{SO}_{2}+2 \mathrm{~V}_{O, c a t} \rightarrow S_{c a t}+2 O_{c a t}
\end{aligned}
$$


$\mathrm{SO}_{2}$ inhibition effect: $\quad \mathrm{SO}_{2}+2 \mathrm{O}_{\text {cat }} \stackrel{\text { fast }}{\longrightarrow} \mathrm{SO}_{4, \text { cat }}+2 \mathrm{CO} \stackrel{\text { slow }}{\longrightarrow} \mathrm{SO}_{2}+2 \mathrm{CO}_{2}+2 \mathrm{~V}_{\text {O.cat }}$

Surface capping oxygen has to be scavenged by $\mathrm{CO}$ to create oxygen vacancies. $\mathrm{SO}_{2}$ molecule then fills the vacancy. But, $\mathrm{SO}_{2}$ can also react with the surface oxygen to form strongly-bonded sulfate species. Thus, a working catalyst consisted of partially sulfated cerium oxide surface and partially sulfided copper. Copper and cerium oxide in the composite catalyst play different roles: copper provides $\mathrm{CO}$ adsorption sites and cerium oxide provides oxygen vacancy sites. Thus, a synergism is realized. In the presence of water vapor, $\mathrm{H}_{2} \mathrm{O}$ molecule competes with $\mathrm{SO}_{2}$ to donate oxygen to the vacancy site that the water-gas-shift(WGS) reaction proceeds. Hydrogen produced from the WGS reaction promoted $\mathrm{H}_{2} \mathrm{~S}$ production. The sulfur yield in the presence of water vapor could not be optimized by changing the reactor operation conditions. However, the strong redox property of the $\mathrm{Cu}-\mathrm{Ce}-\mathrm{O}$ catalyst always made complete conversion of $\mathrm{CO}$.

\subsection{Total Oxidation of $\mathrm{CO}$ and Methane}

Transition metal-fluorite oxide composite catalysts were studied in this work for the complete oxidation of carbon monoxide and methane. A variety of highly active oxidation catalysts can be prepared from this family of catalysts. The $\mathrm{Cu}-\mathrm{Ce}-\mathrm{O}$ composite showed higher $\mathrm{CO}$ oxidation activity than any other base metal oxide catalysts reported in the literature. The catalytic activity was not affected by small amounts of alkaline earth and rare earth dopants or impurities(ca. 1 at.\%). Only a small amount of copper(ca. 2 at.\% or $0.7 \mathrm{wt} . \%$ ) was needed to promote the catalytic activity of $\mathrm{CeO}_{2}$, while excess copper formed bulk $\mathrm{CuO}$ particles of little contribution to the catalyst activity. These catalysts showed excellent resistance to water vapor poisoning. The $\mathrm{Au}-\mathrm{Ce}-\mathrm{O}$ was identified as an active and stable catalyst for low temperature $\mathrm{CO}$ oxidation. Complete $\mathrm{CO}$ conversion at room temperature over $\mathrm{Au}_{0.05}[\mathrm{Ce}(\mathrm{La})]_{0.95} \mathrm{O}_{\mathrm{x}}$ catalyst was achieved at a space velocity of $45,000 \mathrm{v} / \mathrm{v} / \mathrm{h}$. This catalyst also exhibited remarkable resistance to water vapor poisoning and thermal sintering. The activity of the $\mathrm{Cu}-\mathrm{Ce}-\mathrm{O}$ system was superior to $\mathrm{Co}-\mathrm{Ce}-\mathrm{O}$ and $\mathrm{Cu}-\mathrm{Zr}-\mathrm{O}$, but all these catalyst systems showed significantly improved resistance to water vapor poisoning.

The $\mathrm{Cu}-\mathrm{Ce}-\mathrm{O}$ and $\mathrm{Cu}-\mathrm{Zr}-\mathrm{O}$ composites are also active catalysts for complete oxidation of methane. The $\mathrm{Cu}-\mathrm{Ce}-\mathrm{O}$ catalyst activity can be tuned by using alkaline earth and rare earth oxide dopants in suitable amounts. Both $\mathrm{La}$ and $\mathrm{Sr}$ dopants provided significant promotion effect. No partial oxidation products, such as $\mathrm{CO}, \mathrm{H}_{2}$, etc., were observed during methane oxidation over the $\mathrm{Cu}-\mathrm{Ce}(\mathrm{La})-\mathrm{O}$ and $\mathrm{Cu}-\mathrm{Zr}-\mathrm{O}$ catalysts, even under reducing reaction conditions.

$\mathrm{Au}$ in the $\mathrm{Au}_{0.05} \mathrm{Ce}(\mathrm{La})_{0.95} \mathrm{O}_{\mathrm{X}}$ catalyst exists as fine metallic particles in intimate contact with the cerium oxide. This is a model catalyst system demonstrating synergism in $\mathrm{CO}$ oxidation. Copper in the $\mathrm{Cu}-\mathrm{Ce}-\mathrm{O}$ composite existed in the forms of isolated ions, clusters, and bulk $\mathrm{CuO}$ particles. Isolated ions and clusters were strongly bonded to cerium oxide matrix, while bulk $\mathrm{CuO}$ particles were segregated and physically covered by the fine cerium oxide particles. $\mathrm{Cu}^{+1}$ species was observed with all the $\mathrm{Cu}-\mathrm{Ce}-\mathrm{O}$ catalysts in the XPS studies and its formation is considered to originate from the interaction of 
copper clusters with cerium oxide. The oxidation rates of $\mathrm{CO}$ and methane over the $\mathrm{Cu}-$ $\mathrm{Ce}(\mathrm{La})-\mathrm{O}$ catalysts were expressed by the following equation:

$$
\frac{d P_{C O 2}}{d t}=\frac{k K_{R} P_{R} P_{O}^{n}}{1+K_{R} P_{R}}
$$

where $P_{R}$ denotes the partial pressure of $C O$ or methane and $P_{O}$ is the partial pressure of oxygen, and $n$ is a small number close to zero. The activation energies of the surface reactions were $78-94 \mathrm{~kJ} / \mathrm{mol}$ for $\mathrm{CO}$ oxidation and $79 \mathrm{~kJ} / \mathrm{mol}$ for methane oxidation, respectively. The heat of adsorption derived from the kinetics is in the range of 28 to 62 $\mathrm{kJ} / \mathrm{mol}$ for $\mathrm{CO}$ and $14 \mathrm{~kJ} / \mathrm{mol}$ for methane, respectively. The Langmuir-Hinshelwood mechanism and synergistic reaction model were proposed for $\mathrm{CO}$ oxidation over the $\mathrm{Cu}$ $\mathrm{Ce}-\mathrm{O}$ and Au-Ce-O catalysts. In this model, copper clusters of $\mathrm{Cu}^{+1}$ species or fine gold particles provide sites for $\mathrm{CO}$ adsorption, cerium oxide provides the oxygen source, and the reaction proceeds at the interface of the two kinds of materials. The LangmuirHinshelwood mechanism was also proposed for methane oxidation over the $\mathrm{Cu}-\mathrm{Ce}-\mathrm{O}$ catalyst.

Effect of thermal treatment on the $\mathrm{Cu}-\mathrm{Ce}-\mathrm{O}$ catalyst activity was studied with $\mathrm{CO}$ oxidation as a model reaction. Heating the $\mathrm{Cu}-\mathrm{Ce}-\mathrm{O}$ catalyst induced the following processes: copper diffusion from bulk to surface, clustering of isolated copper ions, aggregation of copper clusters, strengthening interaction of copper and cerium oxide, crystal growth of cerium oxide, and decreasing active oxygen species on cerium oxide. The catalytic activity is determined by the sum of these effects. Formation of copper clusters and strong interaction of copper with cerium oxide are desirable to obtain high activity. One salient conclusion drawn from this study is that a small amount of copper (e.g. $<2$ at. \%) is preferred for a catalyst to have good resistance to thermal sintering, while excess amount of copper has detrimental effect on catalytic activity.

\subsection{Oxidation Activity of Non-stoichiometric Cerium Oxide}

For $\mathrm{SO}_{2}$ reduction by $\mathrm{CO}$ over non-stoichiometric cerium oxide, the light-off temperature was decreased by about $100^{\circ} \mathrm{C}$ and hysteresis effect was almost eliminated. This result confirmed the proposed redox reaction mechanism in which the active catalyst comprises a partially reduced surface. Also, light-off temperatures of $\mathrm{CO}$ oxidation and methane oxidation over the non-stoichiometric cerium oxide were decreased by ca. $175^{\circ} \mathrm{C}$ and $60^{\circ} \mathrm{C}$, respectively. Pronounced activity enhancement with the non-stoichiometric cerium oxide catalyst for the above three reactions suggests that structural defects of metal oxide are important for oxidation reactions.

\subsection{Recommendations}

Direct reduction of $\mathrm{SO}_{2}$ to elemental sulfur is a promising technology for the treatment of $\mathrm{SO}_{2}$-containing industrial streams. To make this process scheme more viable for practical applications, other reducing gases in addition to $\mathrm{CO}$ may need to be considered. 
Chapter 7

Consequently, the composite catalysts need to be optimized in basic and acidic properties, as opposed to the redox property.

$\mathrm{Cu}-\mathrm{Ce}(\mathrm{D})-\mathrm{O}(\mathrm{D}=$ dopant) appears to be a strong oxidation catalyst. Application to catalytic combustion of volatile organic compounds merits to be explored. $\mathrm{Cu}-\mathrm{Ce}(\mathrm{La})-\mathrm{O}$ catalysts may be used in the fluid catalytic cracking unit as a $\mathrm{CO}$ oxidation promoter replacing the Pt/alumina catalyst and/or $\mathrm{SO}_{2}$ transfer agent, and also for the lowtemperature light-off application in the automobile catalytic converter. Life time test and parametric studies of $\mathrm{Au}-\mathrm{CeO}_{2}$ catalyst need to be further studied for its application as low temperature $\mathrm{CO}$ oxidation catalyst for indoor air filter, sensors, etc. The $\mathrm{Au}-\mathrm{CeO}_{2}$ catalyst has intrinsic superiority to the other Au-based and (Pt, Pd)-based low temperature CO oxidation catalyst.

In this project, only alkaline earth and rare earth elements were considered as dopants to the composite catalysts. Ceria can be made electronically conductive by doping with pentavalent or hexavalent cations. From a fundamental point of view, it is worthwhile to try such dopants as $\mathrm{Nb}, \mathrm{Ta}, \mathrm{W}$, etc.

149 
